\title{
High-entropy ceramics: Present status, challenges, and a look forward
}

\author{
Huimin XIANG ${ }^{a}$, Yan $\mathrm{XING}^{b}$, Fu-zhi DAI ${ }^{a}$, Hongjie $\mathrm{WANG}^{c}$, Lei $\mathrm{SU}^{c}$, \\ Lei MIAO ${ }^{d}$, Guojun $Z_{\text {HANG }}$, Yiguang $\mathrm{WANG}^{f}$, Xiwei $^{g}{ }^{g}$, Lei YAO ${ }^{h}$, \\ Hailong $\mathrm{WANG}^{i}$, Biao ZHAO ${ }^{j}$, Jianqiang $\mathrm{LI}^{k}$, Yanchun $\mathrm{ZHOU}^{a,{ }^{*}}$ \\ ${ }^{a}$ Science and Technology on Advanced Functional Composite Laboratory, Aerospace Research \\ Institute of Materials \& Processing Technology, Beijing 100076, China \\ ${ }^{b}$ New Energy Technology Engineering Laboratory of Jiangsu Province, Nanjing University of \\ Posts and Telecommunications, Nanjing 210023, China
}

${ }^{c}$ State Key Laboratory for Mechanical Behavior of Materials, Xi' an Jiaotong University, Xi' an 710049, China

${ }^{d}$ Guangxi Key Laboratory of Information Materials, Guangxi Collaborative Innovation Center of Structure and

Property for New Energy and Material, School of Material Science and Engineering,

Guilin University of Electronic Technology, Guilin 541004, China

${ }^{e}$ Institute of Functional Material, College of Material Science and Engineering, Donghua University, Shanghai 201620, China

${ }^{f}$ Institute of Advanced Structure Technology, Beijing Institute of Technology, Beijing 100081, China

${ }^{g}$ College of Metallurgy and Energy, North China University of Science and Technology, Tangshan 063210, China

${ }^{h}$ College of Material Science and Engineering, Shenzhen University, Shenzhen 518060, China

${ }^{i}$ School of Materials Science and Engineering, Zhengzhou University, Zhengzhou 450001, China

${ }^{j}$ Henan Key Laboratory of Aeronautical Materials and Application Technology, School of Material Science and

Engineering, Zhengzhou University of Aeronautics, Zhengzhou 450046, China

${ }^{k}$ National Engineering Laboratory for Hydrometallurgical Cleaner Production Technology,

CAS Key Laboratory of Green Process and Engineering, Institute of Process Engineering,

Chinese Academy of Sciences, Beijing 100190, China

Received: January 31, 2021; Revised: March 20, 2021; Accepted: March 22, 2021

(c) The Author(s) 2021.

\begin{abstract}
High-entropy ceramics (HECs) are solid solutions of inorganic compounds with one or more Wyckoff sites shared by equal or near-equal atomic ratios of multi-principal elements. Although in the infant stage, the emerging of this new family of materials has brought new opportunities for material design and property tailoring. Distinct from metals, the diversity in crystal structure and electronic structure of ceramics provides huge space for properties tuning through band structure engineering and phonon engineering. Aside from strengthening, hardening, and low thermal conductivity that have already been found in high-entropy alloys, new properties like colossal dielectric constant, super ionic conductivity, severe anisotropic thermal expansion coefficient, strong electromagnetic wave absorption, etc., have been discovered in HECs. As a response to the rapid development in this nascent field, this article gives a comprehensive review on the structure features,
\end{abstract}

* Corresponding author.

E-mail: yczhou@alum.imr.ac.cn 
theoretical methods for stability and property prediction, processing routes, novel properties, and prospective applications of HECs. The challenges on processing, characterization, and property predictions are also emphasized. Finally, future directions for new material exploration, novel processing, fundamental understanding, in-depth characterization, and database assessments are given.

Keywords: high-entropy ceramics (HECs); processing; structure; properties; applications

\section{Introduction}

High-entropy ceramics (HECs) are solid solutions of inorganic compounds with one or more Wyckoff sites shared by equal or near-equal atomic ratios of multiprincipal elements.

This concept is inherited from that of high-entropy alloys (HEAs), which are multi-principal element alloys (MPEAs) with equal or near-equal atomic fraction of constituting elements $[1,2]$. For HEAs, two definitions have been proposed based on the composition and configuration entropy [3]. In light of composition, HEAs are defined as alloys comprising more than five principal elements mixed in an equiatomic or nearequiatomic fraction. In light of entropy, HEAs are defined as alloys having configuration entropies larger than $1.5 R$ (herein $R$ is the gas constant) when random solid solutions are formed. The difference between HEAs and traditional alloys lies in not only properties but also design strategy. In the traditional alloy design paradigm, one base element such as $\mathrm{Fe}, \mathrm{Ni}$, and $\mathrm{Ti}$ is used as a principal element and some minor alloy elements are added to enhance properties (the so-called base element concept) [4]. In the HEA design strategy, five or more multi-principal elements are mixed into a single lattice to form a solid solution [5]. In the phase diagrams, the compositions of traditional alloys are generally located at the corners which have limited compositional design space, while those of HEAs are located in the central region; thus the design space has significantly been opened through the combination of multi-principal elements as well as microstructures [6]. The significantly different design philosophy has brought about four core effects for HEAs, as summarized by Yeh [7]: i.e., (1) high-entropy effect, which expands the solution limits between elements and offers the stability for the formation of random solid solutions; (2) sluggish diffusion effect, which retards the growth of second phase nanoparticles; (3) severe lattice distortion, which contributes to strengthening and hardening; (4) cocktail effect, which provides unexpected properties after mixing many elements [8]. The unique combination of these characteristics has led to a great number of new materials with appealing properties such as superb specific strength [9], high strength at elevated temperatures [10], high cryogenic temperature fracture toughness $[11,12]$, good wear and corrosion resistance [13], enhanced magnetocaloric effect [14], superconductivity [15], high hydrogen storage capacity [16], etc.

Inspired by the breakthrough in metal community, the high-entropy concept has been extended to ceramics (HECs), polymers (HEPs), and composites (HECOMPs) [17]. Similar to HEAs, all high-entropy materials (HEMs) are long-range structurally ordered but compositionally disordered. Compare to HEAs, the advent of high-entropy ceramics (HECs) provides more opportunities for tuning properties and overcoming the bottleneck for material applications. On one hand, the crystal structures of ceramics are more diverse in contrast to the simple FCC, BCC, and HCP structures for metals [18]. On the other hand, the diversity of band structure and chemical bonding opens up new avenues for material design and property tuning through band structure engineering and phonon engineering. Due to the countless possibilities in composition design and property tuning paradigms, HECs have been found to exhibit better stability, enhanced mechanical properties, amorphous-like thermal conductivity [19], colossal dielectric constant [20], super ionic conductivity [21], and are promising in structural and functional applications covered from ultrahigh temperature thermal protection and thermal insulation in hypersonic vehicles, thermal/ environmental barrier protection of engine materials, high-speed and dry cutting to Li-ion batteries, thermoelectrics, catalysts, electromagnetic wave absorption, and electromagnetic interference shielding [22,23]. Despite of the rapid development, the field of HECs is still in the infant stage for both academic research and practical applications. In addition, the novel design 
concept and the unknown mechanism that underpin the unusual phenomena pose great challenges both theoretically and experimentally. As a timely response to this emerging field, this review aims to provide the ceramic community a comprehensive overview of current status in compositional design, processing, properties, and potential applications of HECs. The theoretical and experimental challenges posed by this new material design paradigm will also be introduced. And future directions will be given to guide the academic studies and technical breakthrough in this emerging field.

It is worth mentioning that there are several review papers that have already been published concerning HECs [24-26]. To make a difference from these early papers, this review is organized as follows. Section 2 discusses the electronic and crystal structure features, existing material systems, and methods for stability prediction. In Section 3, synthesis and densification methods are summarized. In Section 4, properties of HECs are overviewed and methods for tuning properties are proposed. In Section 5, present and prospective applications are introduced. In Section 6, future directions are suggested, and finally conclusions are given in Section 7.

\section{Structure features and material systems}

\section{1 Crystal structure features}

\subsubsection{Crystal structure}

For HEAs and HECs, the crystal structures are generally determined by the crystal structures of individual constituents. In HEAs, since most elements prefer a BCC or FCC structure, it is not surprising that most HEAs are in simple BCC or FCC structure [4]. Several criteria have been proposed to predict the structure of HEAs, such as valence electron concentration (VEC) [27] and atomic-level strain energy [28]. The situations in HECs are quite different, since the crystal structures of HECs are diverse instead of the simple BCC and FCC structures. Rost et al. [29] have proposed a rationale for the selection of individual constituents, i.e., no uniform crystal structure exhibited in the ensemble of binary compound, electronegativity or cation coordination, and existence of pairs that do not exhibit extensive solubility. Based on these criteria, series of novel HECs with diversity and complex structures emerged [30-33]. Besides, HECs with constituents disobeying the rationale proposed by Rost et al. have also been reported [34-38], which has expanded the library of entropy-stabilized ceramics. Up to now, no matured conclusions have been drawn on the relationship between the structure of HECs and single-component systems yet. However, the diversity in crystal structures of HECs has provided an orthogonal strategy to discover new crystalline matters and untapped opportunities for property engineering [29].

\subsubsection{Atomic distribution}

Down to the atomic arrangement, a major difference between HEAs and HECs is the existence of an ordered anion/cation sub-lattice and more uniform distribution of elements in HECs. For ideal HEAs, all elements distribute randomly in the structure. While in real HEAs, regulated by entropy and diffusion barriers, local vibrations in chemical composition or short-range order (SRO) exist, as shown in Fig. 2.1 [39]. The so-called incipient concentration waves decrease the configuration entropy but provide new deformation mechanisms and mechanical properties for HEAs. In HECs, as demonstrated by Rost et al. [29], with the existence of an ordered sub-lattice, the differentiation between every cation lattice site is small since each has the same immediate surroundings. A large number of quasi-equivalent sites in a crystal with an intermediate sub-lattice will increase the distribution homogeneousness and configurational entropy of cations and favor the formation of single-phase solid solution. The homogeneous atomic arrangement of HECs has been observed experimentally by scanning electron microscopy with energy dispersive X-ray spectroscopic system (SEM-EDS) for various HECs, and this technique is now considered as a standard tool to probe distribution homogeneity $[33,35,37]$. Delicate techniques to determine element distribution, such as scanning transmission electron microscopy (STEM) and atomic probe tomography (APT), have also been employed, and the atomic scale homogeneous distribution has been reported and no significant aggregation has been found in high-entropy oxides, carbides, borides, etc. [22,40-44]. Nevertheless, segregation of elements at the grain boundary of triple point of high-entropy perovskite has been observed [45], which may significantly influence the mechanical properties of HECs. Thus, more delicate works are needed to probe the element distribution, especially 

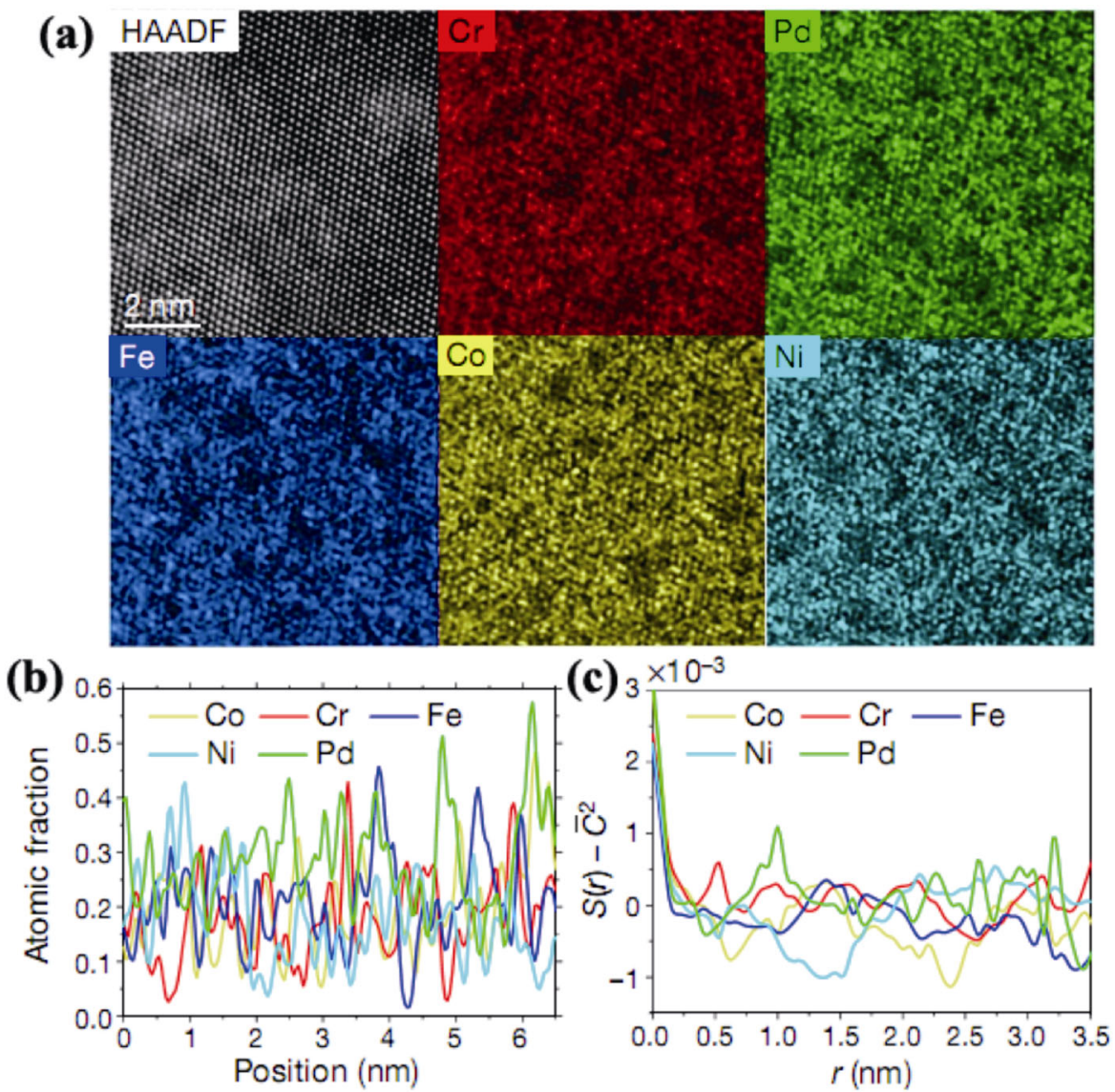

Fig. 2.1 Aberration-corrected TEM imaging and mapping of element distributions in the CrFeCoNiPd alloy. (a) HAADF image of atomic structure and corresponding EDS maps for individual elements, exhibiting strong inhomogeneous fluctuations with local aggregations. (b) Line profiles of atomic fraction of individual elements taken from respective EDS maps in (a). (c) Plots of pair correlation function $S(r)$ of individual elements against concentration wavelength $r$. Reproduced with permission from Ref. [39], (c) Springer Nature 2019.

around the imperfections.

\subsubsection{Lattice distortion}

Ideally, all atoms locate perfectly in their own atomic sites in solids. However, affected by atomic size, electronegativity, and neighboring atoms, fluctuation from perfect site is observed in HEMs, leading to severe lattice distortion, which is one of the core effects in HEMs [4]. Using fitted extended X-ray absorption fine structure (EXAFS) data, Rost et al. $[29,46]$ quantified the local atomic structure of $\left(\mathrm{Mg}_{0.2} \mathrm{Ni}_{0.2} \mathrm{Co}_{0.2} \mathrm{Cu}_{0.2} \mathrm{Zn}_{0.2}\right) \mathrm{O}$ on an element-by-element basis. The local bond lengths between metal and oxygen were found to vary around each cation, while the interatomic distances of second nearest neighbor (i.e., the cation-cation pair) were uniform. Model fitted experimental data and density functional theory (DFT) calculations demonstrated that the anion sublattice with oxygen ions displaced from ideal locations to accommodate the distortions, while metal atoms distributed randomly on an FCC sublattice with minimal positional disorder. Berardan et al. [47] measured the electron paramagnetic resonance (EPR) signal of copper ion in $(\mathrm{MgCoNiZn})_{0.74} \mathrm{Cu}_{0.26} \mathrm{O}$ lattices, and a distorted signal was yielded, indicating deviation of lattice from ideal rock salt structure. DFT and molecular dynamics calculations on the structure of $(\mathrm{MgCoCuNiZn}) \mathrm{O}$ system verified that the lattice distortion was derived from the effect of a combination of both Jahn-Teller and/or simple size arguments [48,49]. Dai et al. [50] employed a deep learning potential to predict the structure of high-entropy $\left(\mathrm{Zr}_{0.2} \mathrm{Hf}_{0.2} \mathrm{Ti}_{0.2} \mathrm{Nb}_{0.2} \mathrm{Ta}_{0.2}\right) \mathrm{C}$ ceramic and found that the carbon atoms deviated more significantly from the ideal positions in comparison with transition metal atoms, which was also verified by $\mathrm{Ye}$ et al. [41,51] using DFT calculations, as illustrated in Fig. 2.2. Similar result on lattice distortion of high-entropy diborides 

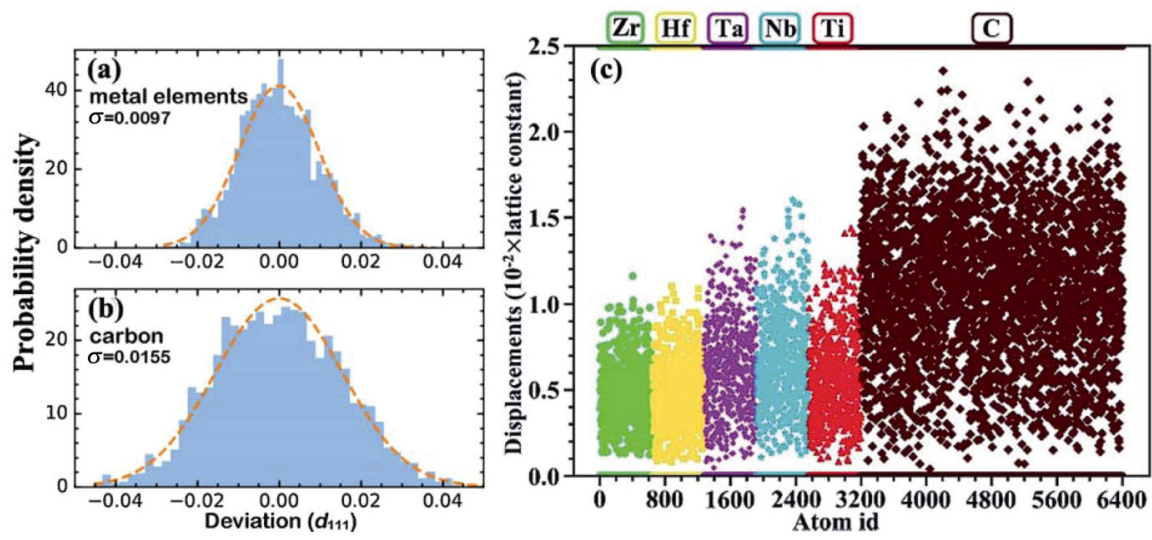

Fig. 2.2 Lattice distortion in high-entropy carbide (TiZrHfNbTa)C. $(\mathrm{a}, \mathrm{b})$ the atomic deviations from their ideal position estimated by deep learning potentials, illustrating more significant deviation of carbon from its ideal position. (c) Atomic displacements of the different elements expressed as the fraction of the lattice constant after relaxation, and large displacement of carbon is observed. Reproduced with permission from Ref. [50] for (a, b), (C) Elsevier 2020; Ref. [51] for (c), (C) The American Ceramic Society 2018.

was also reported by Dai et al. [52]. In short, lattice distortion is one of the main structure features in highentropy materials, and it shapes the unique combination of mechanical and thermal properties of HECs, such as low thermal conductivity and hardening.

\section{2 Electronic structure and band gap engineering}

The electronic structure of a material is decisive to the stability, transport, and optical properties. For HECs, the mixing of more than five principal elements provides huge chemical space for tuning the electronic structure and tailoring the related properties. With the development of calculation techniques, it is more convenient to obtain the electronic structure from theoretical calculations than experiments. Among the available predictive techniques, DFT method is probably the most desirable technique to tackle the electronic structure problem of HECs, since the only required input into the DFT calculations to yield electronic properties is the crystal structure. For HEMs, modeling of the structure is challenging since completely disordered structure requires a supercell that is large enough to include the effect of lattice distortion and eliminate the periodicity errors. Such calculations are computationally very demanding. Therefore, few works on the calculation of electronic structure of HE carbides, borides, and oxides have been conducted. Rák et al. [53] carried out extensive DFT calculations on three high-entropy oxides (HEOs), (MgCoCuNiZn)O, ( $\mathrm{MgCoCuNiZnLi}) \mathrm{O}$, and (MgCoCuNiZnSc)O [53]. To model the random structure, a 480 atoms rock-salt supercell with a size of $3 \times 4 \times 5$ unit cells was constructed.
Analysis on the Bader charges and density of states indicated that the addition of $\mathrm{Sc}$ to $(\mathrm{MgCoCuNiZn}) \mathrm{O}$ resulted in the reduction of a majority of $\mathrm{Cu}$ cations, and these $\mathrm{Cu}$ cations deviated from their ideal lattice sites largely. While addition of $\mathrm{Li}$ to (MgCoCuNiZn)O resulted in oxidation of $\mathrm{Co}, \mathrm{Ni}$, and $\mathrm{Cu}$ atoms with no substantial displacement from their ideal lattice sites. Using the same model, they calculated the density of states of $(\mathrm{MgCoCuNiZn}) \mathrm{O}$, and found that the $\mathrm{CuO}_{6}$ octahedra were in both elongated and compressed geometry [48]. The projected DOS of $\mathrm{Cu}$ atoms illustrated a splitting of $\mathrm{Cu}$ d-states near Fermi level, and the elongated and compressed $\mathrm{Cu}$-centers adopt different electronic ground states with half-filled $\mathrm{d}_{x 2-y 2}$ or $\mathrm{d}_{z 2}$ orbitals, respectively. The displacement of $\mathrm{O}$ atoms was responsible for the experimentally observed Jahn-Teller distortion in (MgCoCuNiZn)O.

To reduce the scale and overcome the difficulty of calculations, special quasi-random structures (SQS) are introduced to construct the disordered structure of high-entropy ceramics. The concept of SQS $[54,55]$ is to build a special periodic structure with a small number of atoms per unit cell whose correlation functions for the first few nearest-neighbor shells are as close to those of a target random alloy as possible such that the periodicity errors only exist between more distant neighbors. Using this technique, Ye et al. [41] and Jiang et al. [56] constructed the $2 \times 2 \times 2$ SQS supercell of high-entropy carbide (TiZrHfNbTa)C with 64 atoms. The predicted DOS indicated that the metallic conductivity of carbides was preserved, and the presence of a pseudogap at the Fermi level suggested 
strong covalent bonding between metal atoms and carbon. Similar results were also reported by Wang et al. [57] in the calculation of electronic structure of (TiZrHfNbTa)B ${ }_{2}$ using SQS supercell. Liu et al. [58] constructed an SQS supercell containing 100 atoms for $\mathrm{Zn}_{0.1} \mathrm{Ca}_{0.1} \mathrm{Sr}_{0.4} \mathrm{Ba}_{0.4} \mathrm{ZrO}_{3}$. They found that the lattice distortion resulted from high-entropy effect induced chemical bond inhomogeneity, which was reflected by the different binding energy ranges of $A-\mathrm{O}(A=\mathrm{Zn}, \mathrm{Ca}$, $\mathrm{Sr}, \mathrm{Ba})$ and $\mathrm{Zr}-\mathrm{O}$ bonds. $\mathrm{Zn}-\mathrm{O}$ and $\mathrm{Ca}-\mathrm{O}$ bonds are weaker than $\mathrm{Sr}-\mathrm{O}$ and $\mathrm{Ba}-\mathrm{O}$ bonds, which is responsible for the lower stiffness and mechanical properties of high-entropy ceramic than their single-component counterparts. Although SQS is efficient in constructing the quasi-random structure and easing the calculation burden, usage of this method should be proceeded with caution. Since in SQS, the interactions between distant neighbors are considered to contribute much less to the system, which may not be the case for ionic crystals where long range interactions may still be important under a given unit cell size constraint. Moreover, the energy of the SQS of some systems might be sensitive to the atomic configurations and the uncertainty in the energy of those systems is too high, especially for anisotropic lattices [59].

Besides theoretical exploration on the electronic structure of HECs, experimental efforts have also been devoted in tuning the band structure by controlling the compositions to tailor the properties of high-entropy oxides. Sarkar et al. [60] prepared high-entropy rare earth oxides (HE-REOs) containing 3-7 rare earth cations (Ce, Gd, La, Nd, Pr, Sm, Y) in equiatomic amounts by nebulized spray pyrolysis. The structure of HE-REOs was identified as fluorite-type structure and transformed to a bixbyite-type structure upon calcination. Band gap measurement with ultraviolet-visible (UVVis) absorption spectra revealed narrowing of the gap compared with $\mathrm{CeO}_{2}$. They speculated that multivalent element $\mathrm{Pr}$ was responsible to the band gap narrowing, and thus, enabled HE-REOs to absorb light over the entire visible spectral range. To verify the hypothesis, they further obtained element resolved charge state and electronic structure of (CeLaPrSmY)O ${ }_{2-\delta}$ by X-ray absorption spectroscopy (XAS) and electron energy loss spectroscopy (EELS) [61], and the ability of Pr in tuning the bandgap energy of HE-REO by redox reaction was confirmed, as demonstrated in Fig. 2.3.

Bérardan et al. [20] synthesized high-entropy oxide $(\mathrm{MgNiCoCuZn}) \mathrm{O}$ and colossal dielectric permittivity

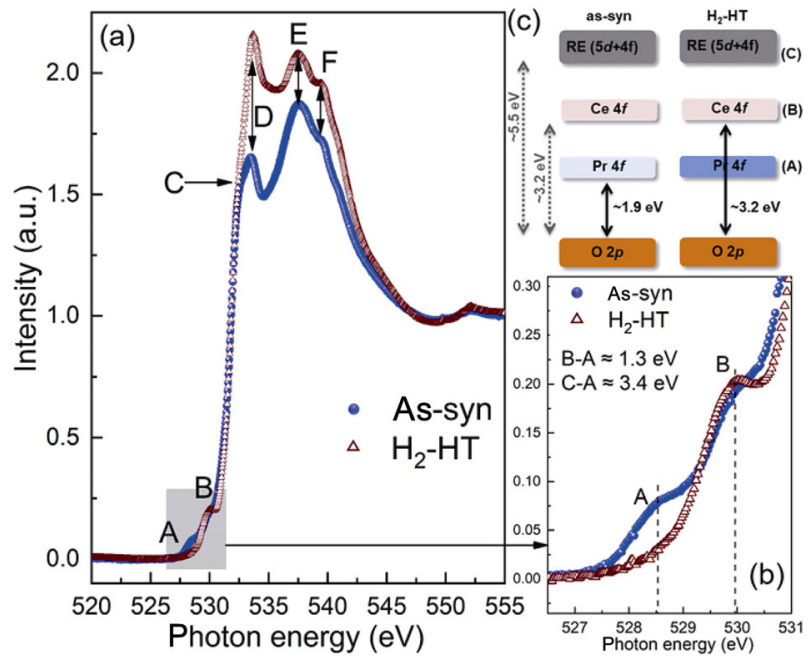

Fig. 2.3 (a) $\mathrm{O} K$ edge $\mathrm{X}$-ray absorption spectra of as-synthesized and reduced by $\mathrm{H}_{2}$-heat treatment high-entropy oxide $\left(\mathrm{Ce}_{0.2} \mathrm{La}_{0.2} \mathrm{Pr}_{0.2} \mathrm{Sm}_{0.2} \mathrm{Y}_{0.2}\right) \mathrm{O}_{2-\delta}$ and (b) magnification of the pre-edge region. (c) Schematic of the electronic band diagram to illustrate electron transition from occupied to unoccupied state before and after the reduction. Reproduced with permission from Ref. [61], (C) The Author(s) 2020.

was found. With the alkaline metal Li introduced, the colossal dielectric constant of HEOs was preserved while the band gap reduced from 1 to $0.6 \mathrm{eV}$. The lithium content has a large impact on the observed dielectric constants. The less lithium the sample contains, the higher its intrinsic resistance and also the higher its maximum permittivity. These pioneering works have demonstrated the vast potential for the application of HECs as catalyst, energy storage, electric and optical materials by tuning the electronic structure and band gap of HECs, which is achievable simply by choosing suitable additional elements due to their huge chemical and structural space.

In HEAs, the selection of constituents is constrained in metallic elements and the structures are limited to BCC, FCC, and HCP [4]. While for HECs, selection of constituents and crystal structure types is abundant and new types of HECs are still emerging. The crystal structures of two representatives of HECs, i.e., highentropy carbide and diboride [50,52], are shown in Fig. 2.4. In the recently published reviews, a comprehensive list of the material systems in HECs can be found [24-26,62]. Inspired by the pioneering work of Rost et al. [29], most of the researches focus on the synthesis and property exploring of entropy stabilized oxides. Shortly, oxides with rock salt $[21,29$, 63-67], fluorite [38,60,68-71], pyrochlore [36,37, 
72-75], and spinel [80-83] structures were explored and fascinating properties brought by high-entropy effects have been reported. Gild et al. [34] extended the material systems to ultrahigh temperature ceramics (UHTCs) by fabricating high-entropy borides with $\mathrm{AlB}_{2}$ structure. And soon after, carbides and nitrides in UHTCs category were also synthesized $[35,84]$. These materials often possess enhanced hardness, ultralow thermal conductivity compared to their binary constituents, which make them suitable for extreme environment

(a)

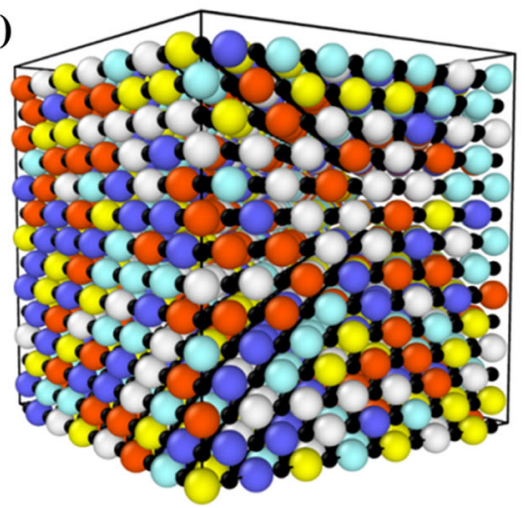

applications. Other than materials with simple structures, high-entropy materials with relatively complex and lowsymmetry structure are also fabricated recently, such as monosilicates [43,85,86], disilicates [87-89], aluminates [23,90,91], phosphates [92,93], magnetoplumbites [94], monoborides [95-97], hexaborides [98,99], tetraborides [100], silicide carbides [101], and silicides [33,102], which have enriched our knowledge on the HECs, as shown in Table 1.

In ideal HECs, the elements are incorporated into

(b)

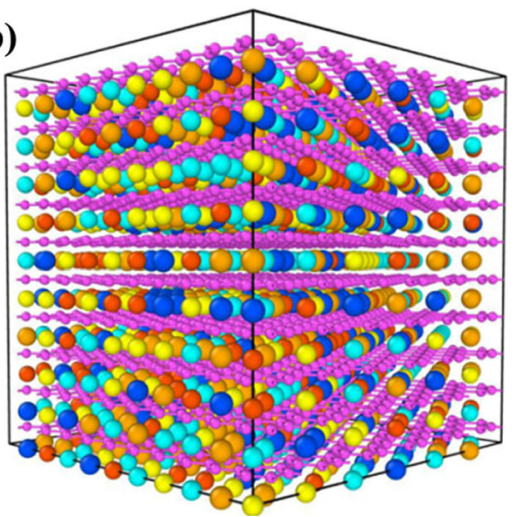

Fig. 2.4 Crystal structure of high-entropy (a) carbide and (b) diboride. Small balls are carbon and boron atoms, and colored big atoms are metal atoms. Reproduced with permission from Ref. [50] for (a), (C) Elsevier 2020; Ref. [52] for (b), (C) Elsevier 2021.

Table 1 High-entropy material systems

\begin{tabular}{|c|c|c|}
\hline Structure type & Material system & Ref. \\
\hline \multirow{4}{*}{ Rock salt } & $(\mathrm{MgCoNiCuZn})_{1-x y} \mathrm{Ga}_{y} \mathrm{~A}_{x} \mathrm{O}(\mathrm{A}=\mathrm{Li}, \mathrm{Na}, \mathrm{K})$ & [21] \\
\hline & $(\mathrm{MgCoNiCuZn}) \mathrm{O}$ & {$[26,63-66]$} \\
\hline & $\begin{array}{l}\mathrm{Li}_{1.3} \mathrm{Mn}_{0.2} \mathrm{Mn}_{0.2} \mathrm{Ti}_{0.1} \mathrm{Nb}_{0.2} \mathrm{O}_{1.7} \mathrm{~F}_{0.3} \\
\mathrm{Li}_{1.3} \mathrm{Mn}_{0.1} \mathrm{Co}_{0.1} \mathrm{Mn}_{0.1} \mathrm{Cr}_{0.1} \mathrm{Ti}_{0.1} \mathrm{Nb}_{0.2} \mathrm{O}_{1.7} \mathrm{~F}_{0.3}\end{array}$ & [67] \\
\hline & $\left(\mathrm{Hf}_{0.2} \mathrm{Zr}_{0.2} \mathrm{Ta}_{0.2} \mathrm{Nb}_{0.2} \mathrm{Ti}_{0.2}\right) \mathrm{C}$ & [35] \\
\hline \multirow{6}{*}{ Fluorite } & $\begin{array}{l}\left(\mathrm{Hf}_{0.25} \mathrm{Zr}_{0.25} \mathrm{Ce}_{0.25} \mathrm{Y}_{0.25}\right) \mathrm{O}_{2-\delta} \\
\left(\mathrm{Hf}_{0.25} \mathrm{Zr}_{0.25} \mathrm{Ce}_{0.25}\right)\left(\mathrm{Y}_{0.125} \mathrm{M}_{0.125}\right) \mathrm{O}_{2-\delta}(\mathrm{M}=\mathrm{Yb}, \mathrm{Ca}, \mathrm{Gd}) \\
\left(\mathrm{Hf}_{0.2} \mathrm{Zr}_{0.2} \mathrm{Ce}_{0.2}\right)\left(\mathrm{Y}_{0.2} \mathrm{M}_{0.2}\right) \mathrm{O}_{2-\delta}(\mathrm{M}=\mathrm{Yb}, \mathrm{Gd}) \\
\left(\mathrm{Hf}_{0.25} \mathrm{Zr}_{0.25} \mathrm{Ce}_{0.25}\right)\left(\mathrm{Yb}_{0.125} \mathrm{Gd}_{0.125}\right) \mathrm{O}_{2-\delta} \\
\left(\mathrm{Hf}_{0.2} \mathrm{Zr}_{0.2} \mathrm{Ce}_{0.2}\right)\left(\mathrm{Yb}_{0.2} \mathrm{Gd}_{0.2}\right) \mathrm{O}_{2-\delta}\end{array}$ & [38] \\
\hline & $\mathrm{REO}_{2-\delta}(\mathrm{RE}=\mathrm{Ce}, \mathrm{Gd}, \mathrm{La}, \mathrm{Nd}, \mathrm{Pr}, \mathrm{Sm}, \mathrm{Y})$ & {$[60]$} \\
\hline & $\left(\mathrm{Ce}_{0.2} \mathrm{Zr}_{0.2} \mathrm{Hf}_{0.2} \mathrm{Sn}_{0.2} \mathrm{Ti}_{0.2}\right) \mathrm{O}_{2}$ & [68] \\
\hline & $\begin{array}{l}\left(\mathrm{Ce}, \mathrm{Gd}, \mathrm{Nd}, \mathrm{Sm}, \mathrm{Pr}, \mathrm{Mo}_{x}\right) \mathrm{O}_{2-\delta}(x=0-0.5) \\
\left(\mathrm{Ce}, \mathrm{Gd}, \mathrm{La}, \mathrm{Sm}, \mathrm{Pr}, \mathrm{Mo}_{x}\right) \mathrm{O}_{2-\delta}(x=0-0.5)\end{array}$ & [69] \\
\hline & $(\mathrm{CeNdCaSrBa}) \mathrm{F}_{12}$ & [70] \\
\hline & $\begin{array}{l}\left(\mathrm{Y}_{1 / 3} \mathrm{Yb}_{1 / 3} \mathrm{Er}_{1 / 3}\right)_{3} \mathrm{TaO}_{7},\left(\mathrm{Y}_{1 / 3} \mathrm{Yb}_{1 / 3} \mathrm{Er}_{1 / 3}\right)_{3} \mathrm{NbO}_{7} \\
\left(\mathrm{Sm}_{1 / 6} \mathrm{Eu}_{1 / 6} \mathrm{Y}_{1 / 6} \mathrm{Yb}_{1 / 6} \mathrm{Lu}_{1 / 6} \mathrm{Er}_{1 / 6}\right)_{3}\left(\mathrm{Nb}_{1 / 2} \mathrm{Ta}_{1 / 2}\right) \mathrm{O}_{7}\end{array}$ & [71] \\
\hline \multirow{5}{*}{ Pyrochlore } & $\begin{array}{l}\left(\mathrm{Sm}_{1 / 3} \mathrm{Eu}_{1 / 3} \mathrm{Dy}_{1 / 3}\right)_{2} \mathrm{Zr}_{2} \mathrm{O}_{7} \\
\left(\mathrm{Sm}_{0.2} \mathrm{Eu}_{0.2} \mathrm{~Tb}_{0.2} \mathrm{Dy}_{0.2} \mathrm{Lu}_{0.2}\right)_{2} \mathrm{Zr}_{2} \mathrm{O}_{7}\end{array}$ & {$[36]$} \\
\hline & $\left(\mathrm{La}_{0.2} \mathrm{Ce}_{0.2} \mathrm{Nd}_{0.2} \mathrm{Sm}_{0.2} \mathrm{Eu}_{0.2}\right)_{2} \mathrm{Zr}_{2} \mathrm{O}_{7}$ & [37] \\
\hline & $\left(\mathrm{Gd}_{1 / 7} \mathrm{Eu}_{1 / 7} \mathrm{Sm}_{1 / 7} \mathrm{Nd}_{1 / 7} \mathrm{La}_{1 / 7} \mathrm{Dy}_{1 / 7} \mathrm{Ho}_{1 / 7}\right)_{2} \mathrm{Zr}_{2} \mathrm{O}_{7}$ & [72] \\
\hline & $\begin{array}{l}\left(\mathrm{Sm}_{1 / 4} \mathrm{Eu}_{1 / 4} \mathrm{Gd}_{1 / 4} \mathrm{Yb}_{1 / 4}\right)_{2}\left(\mathrm{Ti}_{1 / 4} \mathrm{Sn}_{1 / 4} \mathrm{Hf}_{1 / 4} \mathrm{Zr}_{1 / 4}\right)_{2} \mathrm{O}_{7} \\
\left(\mathrm{La}_{1 / 7} \mathrm{Ce}_{1 / 7} \mathrm{Pr}_{1 / 7} \mathrm{Nd}_{1 / 7} \mathrm{Sm}_{1 / 7} \mathrm{Eu}_{1 / 7} \mathrm{Gd}_{1 / 7}\right)_{2}\left(\mathrm{Sn}_{1 / 3} \mathrm{Hf}_{1 / 3} \mathrm{Zr}_{1 / 3}\right)_{2} \mathrm{O}_{7}\end{array}$ & [73] \\
\hline & $\left(5 \mathrm{RE}_{1 / 5}\right)_{2} \mathrm{Zr}_{2} \mathrm{O}_{7}(\mathrm{RE}=\mathrm{La}, \mathrm{Nd}, \mathrm{Sm}, \mathrm{Eu}, \mathrm{Gd}, \mathrm{Y})$ & {$[74,75]$} \\
\hline
\end{tabular}




\begin{tabular}{|c|c|c|}
\hline & & (Continued) \\
\hline \multirow{6}{*}{ Perovskite } & $\left(\mathrm{Gd}_{0.2} \mathrm{La}_{0.2} \mathrm{Nd}_{0.2} \mathrm{Sm}_{0.2} \mathrm{Y}_{0.2}\right)\left(\mathrm{Co}_{0.2} \mathrm{Cr}_{0.2} \mathrm{Fe}_{0.2} \mathrm{Mn}_{0.2} \mathrm{Ni}_{0.2}\right) \mathrm{O}_{3}$ & [31] \\
\hline & $\mathrm{Zn}_{0.1} \mathrm{Ca}_{0.1} \mathrm{Sr}_{0.4} \mathrm{Ba}_{0.4} \mathrm{ZrO}_{3}$ & [58] \\
\hline & $\operatorname{Sr}\left(\mathrm{Zr}_{0.2} \mathrm{Sn}_{0.2} \mathrm{Ti}_{0.2} \mathrm{Hf}_{0.2} \mathrm{M}_{0.2}\right) \mathrm{O}_{3}(\mathrm{M}=\mathrm{Mn}, \mathrm{Ce}, \mathrm{Y}, \mathrm{Ge}, \mathrm{Nb})$ & \\
\hline & $\mathrm{Ba}\left(\mathrm{Zr}_{0.2} \mathrm{Sn}_{0.2} \mathrm{Ti}_{0.2} \mathrm{Hf}_{0.2} \mathrm{M}_{0.2}\right) \mathrm{O}_{3}(\mathrm{M}=\mathrm{Mn}, \mathrm{Ce}, \mathrm{Y}, \mathrm{Ge}, \mathrm{Nb})$ & [76] \\
\hline & $\left(\mathrm{Sr}_{0.5} \mathrm{Ba}_{0.5}\right)\left(\mathrm{Zr}_{0.2} \mathrm{Sn}_{0.2} \mathrm{Ti}_{0.2} \mathrm{Hf}_{0.2} \mathrm{Nb}_{0.2}\right) \mathrm{O}_{3}$ & \\
\hline & $\mathrm{Ba}\left(\mathrm{Zr}_{0.2} \mathrm{Ti}_{0.2} \mathrm{Sn}_{0.2} \mathrm{Hf}_{0.2} \mathrm{Me}_{0.2}\right) \mathrm{O}_{3}(\mathrm{Me}=\mathrm{Y}, \mathrm{Nb}, \mathrm{Ta}, \mathrm{V}, \mathrm{Mo}, \mathrm{W})$ & {$[77,79]$} \\
\hline \multirow{5}{*}{ Spinel } & $(\mathrm{Co}, \mathrm{Cr}, \mathrm{Fe}, \mathrm{Mn}, \mathrm{Ni})_{3} \mathrm{O}_{4}$ & {$[80,81]$} \\
\hline & $\left(\mathrm{Cr}_{0.2} \mathrm{Fe}_{0.2} \mathrm{Mn}_{0.2} \mathrm{Ni}_{0.2} \mathrm{Zn}_{0.2}\right)_{3} \mathrm{O}_{4},\left(\mathrm{Cr}_{0.2} \mathrm{Fe}_{0.2} \mathrm{Mn}_{0.2} \mathrm{Co}_{0.2} \mathrm{Zn}_{0.2}\right)_{3} \mathrm{O}_{4}$ & [82] \\
\hline & $\mathrm{NiFe}_{1.9}\left(\mathrm{Dy}_{0.02} \mathrm{Er}_{0.02} \mathrm{Gd}_{0.02} \mathrm{Ho}_{0.02} \mathrm{~Tb}_{0.02}\right) \mathrm{O}_{4}$ & \\
\hline & $\left(\mathrm{Co}_{0.2} \mathrm{Cr}_{0.2} \mathrm{Fe}_{0.2} \mathrm{Mn}_{0.2} \mathrm{Ni}_{0.2}\right) \mathrm{Fe}_{2} \mathrm{O}_{4}$ & [83] \\
\hline & $\left(\mathrm{Co}_{0.2} \mathrm{Cr}_{0.2} \mathrm{Fe}_{0.2} \mathrm{Mn}_{0.2} \mathrm{Ni}_{0.2}\right) \mathrm{Fe}_{1.9}\left(\mathrm{Dy}_{0.02} \mathrm{Er}_{0.02} \mathrm{Gd}_{0.02} \mathrm{Ho}_{0.02} \mathrm{~Tb}_{0.02}\right) \mathrm{O}_{4}$ & \\
\hline $\mathrm{AlB}_{2}$ structure & $\left(5 \mathrm{TM}_{0.2}\right) \mathrm{B}_{2}(\mathrm{TM}=\mathrm{Ti}, \mathrm{Zr}, \mathrm{Hf}, \mathrm{Cr}, \mathrm{Nb}, \mathrm{Ta}, \mathrm{Mo})$ & [34] \\
\hline \multirow{3}{*}{ Monosilicates } & $\left(\mathrm{Y}_{1 / 4} \mathrm{Ho}_{1 / 4} \mathrm{Er}_{1 / 4} \mathrm{Yb}_{1 / 4}\right)_{2} \mathrm{SiO}_{5}$ & [43] \\
\hline & $\left(\mathrm{Yb}_{0.25} \mathrm{Y}_{0.25} \mathrm{Lu}_{0.25} \mathrm{Er}_{0.25}\right)_{2} \mathrm{SiO}_{5}$ & [85] \\
\hline & $(\mathrm{Sc}, \mathrm{Y}, \mathrm{Dy}, \mathrm{Er}, \mathrm{Yb})_{2} \mathrm{SiO}_{5}$ & [86] \\
\hline \multirow{3}{*}{ Disilicates } & $\left(\mathrm{Yb}_{0.2} \mathrm{Y}_{0.2} \mathrm{Lu}_{0.2} \mathrm{Sc}_{0.2} \mathrm{Gd}_{0.2}\right)_{2} \mathrm{Si}_{2} \mathrm{O}_{7}$ & [87] \\
\hline & $\left(\mathrm{Gd}_{1 / 6} \mathrm{~Tb}_{1 / 6} \mathrm{Dy}_{1 / 6} \mathrm{Tm}_{1 / 6} \mathrm{Yb}_{1 / 6} \mathrm{Lu}_{1 / 6}\right)_{2} \mathrm{Si}_{2} \mathrm{O}_{7}$ & [88] \\
\hline & $\left(\mathrm{Er}_{0.25} \mathrm{Tm}_{0.25} \mathrm{Yb}_{0.25} \mathrm{Lu}_{0.25}\right)_{2} \mathrm{Si}_{2} \mathrm{O}_{7}$ & [89] \\
\hline \multirow{3}{*}{ Aluminates } & $\left(\mathrm{Y}_{0.2} \mathrm{Nd}_{0.2} \mathrm{Sm}_{0.2} \mathrm{Eu}_{0.2} \mathrm{Er}_{0.2}\right) \mathrm{AlO}_{3}$ & [23] \\
\hline & $\left(\mathrm{Y}_{0.2} \mathrm{Yb}_{0.2} \mathrm{Lu}_{0.2} \mathrm{Eu}_{0.2} \mathrm{Er}_{0.2}\right)_{3} \mathrm{Al}_{5} \mathrm{O}_{12}$ & {$[90]$} \\
\hline & $\left(\mathrm{Nd}_{0.2} \mathrm{Sm}_{0.2} \mathrm{Eu}_{0.2} \mathrm{Y}_{0.2} \mathrm{Yb}_{0.2}\right)_{4} \mathrm{Al}_{2} \mathrm{O}_{9}$ & [91] \\
\hline \multirow{2}{*}{ Phosphates } & (TiZrHf) $\mathrm{P}_{2} \mathrm{O}_{7}$ & [92] \\
\hline & $\left(\mathrm{La}_{0.2} \mathrm{Ce}_{0.2} \mathrm{Nd}_{0.2} \mathrm{Sm}_{0.2} \mathrm{Eu}_{0.2}\right) \mathrm{PO}_{4}$ & [93] \\
\hline Magnetoplumbites & $\mathrm{Ba}\left(\mathrm{Fe}_{6} \mathrm{Ti}_{1.2} \mathrm{Co}_{1.2} \mathrm{In}_{1,2} \mathrm{Ga}_{1,2} \mathrm{Cr}_{1.2}\right) \mathrm{O}_{19}$ & [94] \\
\hline \multirow{5}{*}{ Monoborides } & $\left(\mathrm{Mo}_{0.2} \mathrm{Ta}_{0.2} \mathrm{Ni}_{0.2} \mathrm{Cr}_{0.2} \mathrm{~W}_{0.2}\right) \mathrm{B}$ & [95] \\
\hline & $\left(\mathrm{Cr}_{0.2} \mathrm{Mn}_{0.2} \mathrm{Fe}_{0.2} \mathrm{Co}_{0.2} \mathrm{Mo}_{0.2}\right) \mathrm{B}$ & [96] \\
\hline & $\left(\mathrm{V}_{0.2} \mathrm{Cr}_{0.2} \mathrm{Nb}_{0.2} \mathrm{Mo}_{0.2} \mathrm{Ta}_{0.2}\right) \mathrm{B}$ & \\
\hline & $\left(\mathrm{V}_{0.2} \mathrm{Cr}_{0.2} \mathrm{Nb}_{0.2} \mathrm{Mo}_{0.2} \mathrm{~W}_{0.2}\right) \mathrm{B}$ & [97] \\
\hline & $\left(\mathrm{V}_{0.2} \mathrm{Cr}_{0.2} \mathrm{Nb}_{0.2} \mathrm{Ta}_{0.2} \mathrm{~W}_{0.2}\right) \mathrm{B}$ & \\
\hline \multirow[b]{2}{*}{ Hexaborides } & $\left(\mathrm{Y}_{0.2} \mathrm{Yb}_{0.2} \mathrm{Sm}_{0.2} \mathrm{Nd}_{0.2} \mathrm{Eu}_{0.2}\right) \mathrm{B}_{6}$ & {$[98]$} \\
\hline & $\begin{array}{l}\left(\mathrm{Ce}_{0.2} \mathrm{Y}_{0.2} \mathrm{Sm}_{0.2} \mathrm{Er}_{0.2} \mathrm{Yb}_{0.2}\right) \mathrm{B}_{6} \\
\left(\mathrm{Ce}_{0.2} \mathrm{Eu}_{0.2} \mathrm{Sm}_{0.2} \mathrm{Er}_{0.2} \mathrm{Yb}_{0.2}\right) \mathrm{B}_{6} \\
\left(\mathrm{Ce}_{0.2} \mathrm{Y}_{0.2} \mathrm{Eu}_{0.2} \mathrm{Er}_{0.2} \mathrm{Yb}_{0.2}\right) \mathrm{B}_{6} \\
\left(\mathrm{Ce}_{0.2} \mathrm{Y}_{0.2} \mathrm{Sm}_{0.2} \mathrm{Eu}_{0.2} \mathrm{Yb}_{0.2}\right) \mathrm{B}_{6} \\
\left(\mathrm{Nd}_{0.2} \mathrm{Y}_{0.2} \mathrm{Sm}_{0.2} \mathrm{Eu}_{0.2} \mathrm{Yb}_{0.2}\right) \mathrm{B}_{6}\end{array}$ & [99] \\
\hline Tetraborides & $\left(\mathrm{Y}_{0.2} \mathrm{Nd}_{0.2} \mathrm{Sm}_{0.2} \mathrm{Gd}_{0.2} \mathrm{~Tb}_{0.2}\right) \mathrm{B}_{4}$ & {$[100]$} \\
\hline \multirow{3}{*}{ Silicide carbides } & $\left(\mathrm{Tm}_{0.2} \mathrm{Y}_{0.2} \mathrm{Dy}_{0.2} \mathrm{Gd}_{0.2} \mathrm{~Tb}_{0.2}\right)_{3} \mathrm{Si}_{2} \mathrm{C}_{2}$ & \\
\hline & $\left(\mathrm{Tm}_{0.2} \mathrm{Y}_{0.2} \mathrm{Pr}_{0.2} \mathrm{Gd}_{0.2} \mathrm{Dy}_{0.2}\right)_{3} \mathrm{Si}_{2} \mathrm{C}_{2}$ & {$[101]$} \\
\hline & $\left(\mathrm{Tm}_{0.2} \mathrm{Y}_{0.2} \mathrm{Pr}_{0.2} \mathrm{Gd}_{0.2} \mathrm{~Tb}_{0.2}\right)_{3} \mathrm{Si}_{2} \mathrm{C}_{2}$ & \\
\hline \multirow{2}{*}{ Silicides } & $\left(\mathrm{Ti}_{0.2} \mathrm{Zr}_{0.2} \mathrm{Nb}_{0.2} \mathrm{Mo}_{0.2} \mathrm{~W}_{0.2}\right) \mathrm{Si}_{2}$ & {$[33]$} \\
\hline & $\left(\mathrm{Mo}_{0.2} \mathrm{Nb}_{0.2} \mathrm{Ta}_{0.2} \mathrm{Ti}_{0.2} \mathrm{~W}_{0.2}\right) \mathrm{Si}_{2}$ & {$[102]$} \\
\hline
\end{tabular}

one sublattice in equiatomic ratio. Recently, Wright et al. [103] proposed to extend HECs to compositionally complex ceramics (CCCs) to include medium-entropy and non-equiatomic compositions. In CCCs, the mixing configurational entropy is in the range of $(1-1.5) k_{\mathrm{B}}$ per cation. Materials with one cation sublattice include 3-4 equimolar cations or non-equimolar cations (3-4 principal plus a few minor cations) can be classified as mediumentropy ceramics (MECs). These CCCs are found to prevail against their high-entropy counterparts in lowing thermal conductivity [73]. Moreover, broadening of HECs to CCCs increases compositional space and provides more degrees of freedom to tune properties [26].

\section{3 Theoretical methods for stability prediction}

Searching for more unknown stable members with unexpected properties is one of the main subjects in the field of HEMs, and this process can be accelerated by theoretical prediction on the stability of possible candidates. Up to now, different simulation techniques 
have been used to identify stable HECs. DFT is the most common method in the establishment of different descriptors that help to predict single-phase formation in HECs. As we have stated above, due to the difficulty and scale of the calculation, auxiliary methods are needed in structure construction. Ye et al. [51] used DFT to calculate the mixing enthalpy and configurational entropy of SQS supercells of (TiZrHfNbTa)C. Using the thermodynamical data, they determined the stable temperature of (TiZrHfNbTa)C when the mixing Gibbs free energy was negative, which guided the synthesis of this high-entropy carbide. Sarker et al. [104] used DFT calculations to validate their descriptor, i.e., entropy forming ability (EFA), on the synthesizability of 56 five-metal high-entropy carbides. The calculations on the mixed-phase enthalpy, formation enthalpies of competing binary and ternary ordered structures, and energy spectrum were conducted within the Automatic FLOW framework [105]. Pitike et al. [106] presented a generic method to evaluate the relative feasibility of formation of 56 single-phase multi-component compounds. They adopted a nearest neighbor model (NNM), whose parameters could be easily obtained from twocomponent oxides, to reduce the computational costs of DFT calculations. They established descriptors related to the enthalpy and configurational entropy obtained from the mixing enthalpies of two-component oxides and used these descriptors to evaluate the stability of candidate HEOs.

Other than DFT, molecular dynamics (MD) and CALPHAD can also be used to explore the stability of HECs. The advantage of MD calculations is the ability to deal with at least thousands of atoms; however, the accuracy of this method depends on the interatomic potentials. Anand et al. [49] explored the stability of $(\mathrm{MgCoNiCuZn}) \mathrm{O}$ and its derivatives and the competition between enthalpy and entropy of these materials. The Buckingham interatomic potential was used to depict ionic interaction. Nevertheless, usage of MD is still limited due to the lack of high accurate interatomic potentials to capture the chemical complexity for different material systems. Recently, a new paradigm emerges with the development of machine learning and artificial intelligence. In this new paradigm, machine learning methods are adopted to fit interatomic potentials from data sets by DFT calculations. The fitted potentials are called machine learning potentials [50,52]. These potentials show high accuracy comparable to DFT calculations. To the authors' knowledge, the application of machine learning potentials to the stability of HECs has not been reported yet. CALPHAD describes the Gibbs free energy of a system using a large amount of thermodynamic data, which is obtained from experiments or DFT calculations [107].

In perovskite $\mathrm{LaMnO}_{3 \pm \delta}$ system [108], combining with defect chemistry, CALPHAD was used to investigate the effects of oxygen partial pressure on the thermochemical properties and the correlation between thermochemical properties and defect mixing behavior. Using this approach, mixed ionic-electronic conductive HECs in co-doped systems could be designed.

\section{Synthesis and densification methods}

\section{1 Synthesis methods}

Besides theoretical impact, the advent of HECs also poses challenges on the synthesis and densification of this new family of materials. In order to obtain random distribution of constituting elements in HECs, various methods including solid state reaction $[32,58,85,99$, 101,109-111], wet chemical route [37,60,63-65,91,93], solidification [112-114], field assisted synthesis $[115,116]$, and epitaxial growth [117] have been used.

Solid state reaction synthesis is the most commonly used method for the preparation of HECs, which is suitable to not only oxides but also silicates, borides, carbides, silicide carbides, and sulfides [32,58,67, $80,85,88,95,96,99,101,109-111]$. For example, Chen et al. [90] synthesized phase-pure high-entropy $\left(\mathrm{Y}_{0.2} \mathrm{Yb}_{0.2} \mathrm{Lu}_{0.2} \mathrm{Eu}_{0.2} \mathrm{Er}_{0.2}\right)_{3} \mathrm{Al}_{5} \mathrm{O}_{12}$ with uniform distribution of constituting elements using $\mathrm{Y}_{2} \mathrm{O}_{3}, \mathrm{Yb}_{2} \mathrm{O}_{3}, \mathrm{Lu}_{2} \mathrm{O}_{3}$, $\mathrm{Eu}_{2} \mathrm{O}_{3}, \mathrm{Er}_{2} \mathrm{O}_{3}$, and $\mathrm{Al}_{2} \mathrm{O}_{3}$ as starting materials. The whole process is schematically shown in Fig. 3.1(a). The solid-state reaction at $1600{ }^{\circ} \mathrm{C}$ can be described in Eq. (3.1).

$$
\begin{aligned}
& 3 \mathrm{Y}_{2} \mathrm{O}_{3}+3 \mathrm{Yb}_{2} \mathrm{O}_{3}+3 \mathrm{Lu}_{2} \mathrm{O}_{3} \\
& +3 \mathrm{Eu}_{2} \mathrm{O}_{3}+3 \mathrm{Er}_{2} \mathrm{O}_{3}+25 \mathrm{Al}_{2} \mathrm{O}_{3} \\
= & 10\left(\mathrm{Y}_{0.2} \mathrm{Yb}_{0.2} \mathrm{Lu}_{0.2} \mathrm{Eu}_{0.2} \mathrm{Er}_{0.2}\right)_{3} \mathrm{Al}_{5} \mathrm{O}_{12}
\end{aligned}
$$

During the heating process, $\left(\mathrm{Y}_{0.2} \mathrm{Yb}_{0.2} \mathrm{Lu}_{0.2} \mathrm{Eu}_{0.2} \mathrm{Er}_{0.2}\right)_{3} \mathrm{AlO}_{3}$ was identified as an intermediate phase so that the possible stepwise reactions for the synthesis of high-entropy $\left(\mathrm{Y}_{0.2} \mathrm{Yb}_{0.2} \mathrm{Lu}_{0.2} \mathrm{Eu}_{0.2} \mathrm{Er}_{0.2}\right)_{3} \mathrm{Al}_{5} \mathrm{O}_{12}$ can be described following Eq. (3.2) and Eq. (3.3):

$$
\begin{aligned}
\mathrm{Y}_{2} \mathrm{O}_{3} & +\mathrm{Yb}_{2} \mathrm{O}_{3}+\mathrm{Lu}_{2} \mathrm{O}_{3}+\mathrm{Eu}_{2} \mathrm{O}_{3}+\mathrm{Er}_{2} \mathrm{O}_{3}+5 \mathrm{Al}_{2} \mathrm{O}_{3} \\
& =10\left(\mathrm{Y}_{0.2} \mathrm{Yb}_{0.2} \mathrm{Lu}_{0.2} \mathrm{Eu}_{0.2} \mathrm{Er}_{0.2}\right) \mathrm{AlO}_{3}
\end{aligned}
$$



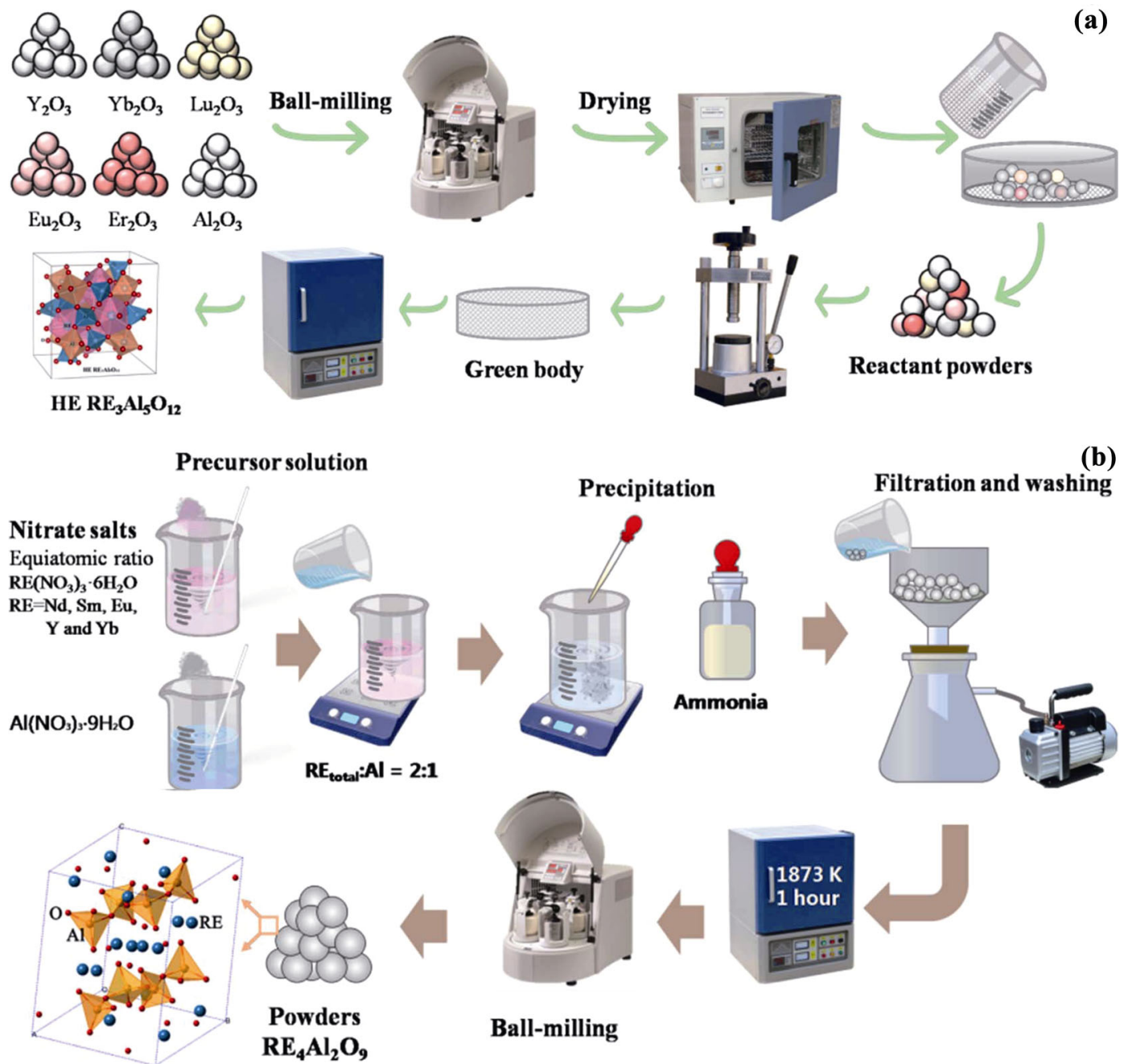

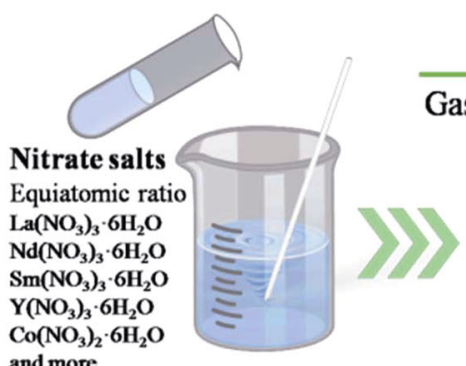

Precursor

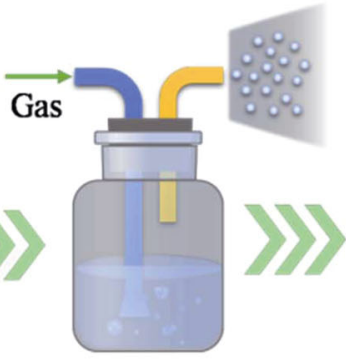

Nebuliser

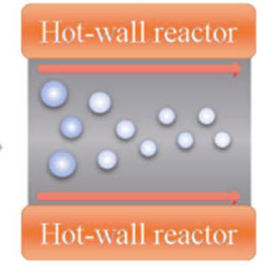

Thermal treatment (c)

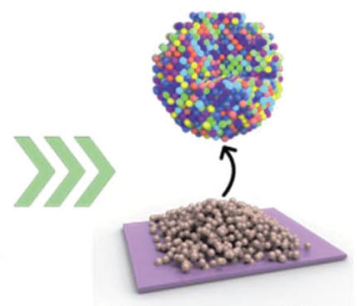

HE nanoparticles

Fig. 3.1 Schematic illustration of (a) solid state reaction process for the synthesis of $\left(\mathrm{Y}_{0.2} \mathrm{Yb}_{0.2} \mathrm{Lu}_{0.2} \mathrm{Eu}_{0.2} \mathrm{Er}_{0.2}\right)_{3} \mathrm{Al}_{5} \mathrm{O}_{12}$ [90], (b) co-precipitation process for the synthesis of $\left(\mathrm{Nd}_{0.2} \mathrm{Sm}_{0.2} \mathrm{Eu}_{0.2} \mathrm{Y}_{0.2} \mathrm{Yb}_{0.2}\right)_{4} \mathrm{Al}_{2} \mathrm{O}_{9}$ [91], and (c) nebulised spray pyrolysis for the synthesis of rare earth and transition metal based high-entropy perovskite oxides [31].

$$
\begin{gathered}
3\left(\mathrm{Y}_{0.2} \mathrm{Yb}_{0.2} \mathrm{Lu}_{0.2} \mathrm{Eu}_{0.2} \mathrm{Er}_{0.2}\right) \mathrm{AlO}_{3}+\mathrm{Al}_{2} \mathrm{O}_{3} \\
\quad=\left(\mathrm{Y}_{0.2} \mathrm{Yb}_{0.2} \mathrm{Lu}_{0.2} \mathrm{Eu}_{0.2} \mathrm{Er}_{0.2}\right)_{3} \mathrm{Al}_{5} \mathrm{O}_{12}
\end{gathered}
$$

Intriguingly, high-entropy $\left(\mathrm{Y}_{0.2} \mathrm{Yb}_{0.2} \mathrm{Lu}_{0.2} \mathrm{Eu}_{0.2} \mathrm{Er}_{0.2}\right)_{3} \mathrm{Al}_{5} \mathrm{O}_{12}$ exhibits a low thermal conductivity of $3.81 \mathrm{~W} \cdot \mathrm{m}^{-1} \cdot \mathrm{K}^{-1}$ at $300 \mathrm{~K}$, a close thermal expansion coefficient $((8.54 \pm$ $0.29) \times 10^{-6} \mathrm{~K}^{-1}$ at $673-1273 \mathrm{~K}$ ) to that of $\mathrm{Al}_{2} \mathrm{O}_{3}$, a slow grain growth rate when annealed at high temperatures.
Most importantly, there is no reaction between highentropy $\left(\mathrm{Y}_{0.2} \mathrm{Yb}_{0.2} \mathrm{Lu}_{0.2} \mathrm{Eu}_{0.2} \mathrm{Er}_{0.2}\right)_{3} \mathrm{Al}_{5} \mathrm{O}_{12}$ and thermally grown (TG) $\mathrm{Al}_{2} \mathrm{O}_{3}$, indicating the potential for the application of this high-entropy complex oxide as thermal barrier coatings on top of $\mathrm{TG}-\mathrm{Al}_{2} \mathrm{O}_{3}$. Using $\mathrm{Y}_{2} \mathrm{O}_{3}, \mathrm{Yb}_{2} \mathrm{O}_{3}, \mathrm{Lu}_{2} \mathrm{O}_{3}, \mathrm{Er}_{2} \mathrm{O}_{3}$, and $\mathrm{SiO}_{2}$ powders as starting materials, Chen et al. [85] also synthesized high-entropy $\left(\mathrm{Y}_{0.25} \mathrm{Yb}_{0.25} \mathrm{Lu}_{0.25} \mathrm{Er}_{0.25}\right)_{2} \mathrm{SiO}_{5}$. Upon heating, 
solid state reaction was completed before $1484{ }^{\circ} \mathrm{C}$ according to Eq. (3.4).

$$
\begin{gathered}
\mathrm{Y}_{2} \mathrm{O}_{3}+\mathrm{Yb}_{2} \mathrm{O}_{3}+\mathrm{Lu}_{2} \mathrm{O}_{3}+\mathrm{Er}_{2} \mathrm{O}_{3}+4 \mathrm{SiO}_{2} \\
=4\left(\mathrm{Y}_{0.25} \mathrm{Yb}_{0.25} \mathrm{Lu}_{0.25} \mathrm{Er}_{0.25}\right)_{2} \mathrm{SiO}_{5}
\end{gathered}
$$

Further heating to $1600{ }^{\circ} \mathrm{C}$, a bulk $\left(\mathrm{Y}_{0.25} \mathrm{Yb}_{0.25} \mathrm{Lu}_{0.25} \mathrm{Er}_{0.25}\right)_{2} \mathrm{SiO}_{5}$ of about $88 \%$ was obtained. This monosilicate $\left(\mathrm{Y}_{0.25} \mathrm{Yb}_{0.25} \mathrm{Lu}_{0.25} \mathrm{Er}_{0.25}\right)_{2} \mathrm{SiO}_{5}$ has strong anisotropic thermal expansion coefficient and is promising as a thermal barrier coating or environmental barrier coating material if the preferred orientation can be controlled. Recently, Sun et al. [88] synthesized $\gamma$-type $\left(\mathrm{Gd}_{1 / 6} \mathrm{~Tb}_{1 / 6} \mathrm{Dy}_{1 / 6} \mathrm{Tm}_{1 / 6} \mathrm{Yb}_{1 / 6} \mathrm{Lu}_{1 / 6}\right)_{2} \mathrm{Si}_{2} \mathrm{O}_{7}$ through the solid state reaction using $\mathrm{RE}_{2} \mathrm{O}_{3}(\mathrm{RE}=\mathrm{Gd}$, Dy, $\mathrm{Tm}, \mathrm{Yb}$, and $\mathrm{Lu}$ ), $\mathrm{Tb}_{4} \mathrm{O}_{7}$, and $\mathrm{SiO}_{2}$ as starting materials. This new high-entropy disilicate has outstanding phase stability without polymorph transition from room temperature to the melting point (over $1900{ }^{\circ} \mathrm{C}$ ).

High-entropy borides and carbides can also be synthesized using the solid state reaction method. For example, Tallarita et al. [118] synthesized high-entropy $\left(\mathrm{Hf}_{0.2} \mathrm{Mo}_{0.2} \mathrm{Ta}_{0.2} \mathrm{Nb}_{0.2} \mathrm{Ti}_{0.2}\right) \mathrm{B}_{2}$ powders using elemental $\mathrm{Hf}, \mathrm{Mo}, \mathrm{Ta}, \mathrm{Nb}, \mathrm{Ti}$, and $\mathrm{B}$ powders as raw materials. The reaction process can described as

$$
\begin{aligned}
0.2 \mathrm{Hf} & +0.2 \mathrm{Mo}+0.2 \mathrm{Ta}+0.2 \mathrm{Nb}+0.2 \mathrm{Ti}+(2+x) \mathrm{B} \\
& \rightarrow\left(\mathrm{Hf}_{0.2} \mathrm{Mo}_{0.2} \mathrm{Ta}_{0.2} \mathrm{Nb}_{0.2} \mathrm{Ti}_{0.2}\right) \mathrm{B}_{2}
\end{aligned}
$$

The reaction was conducted by self-propagating high-temperature synthesis and the use of excess of B $(x=0.2)$ was helpful for the removal of oxide impurities in the raw powders. X-ray diffraction analysis indicated that besides high-entropy $\left(\mathrm{Hf}_{0.2} \mathrm{Mo}_{0.2} \mathrm{Ta}_{0.2} \mathrm{Nb}_{0.2} \mathrm{Ti}_{0.2}\right) \mathrm{B}_{2}$, impurities such as $\mathrm{HfO}_{2}$, $\mathrm{HfB}_{2},\left(\mathrm{Ta}_{0.5} \mathrm{Ti}_{0.5}\right) \mathrm{B}_{2}$, and $\left(\mathrm{Hf}_{0.5} \mathrm{Ti}_{0.5}\right) \mathrm{B}_{2}$ could also be detected. High-entropy $\left(\mathrm{Mo}_{0.2} \mathrm{Ta}_{0.2} \mathrm{Ni}_{0.2} \mathrm{Cr}_{0.2} \mathrm{~W}_{0.2}\right) \mathrm{B}$ [95] and $\left(\mathrm{Cr}_{0.2} \mathrm{Mn}_{0.2} \mathrm{Fe}_{0.2} \mathrm{Co}_{0.2} \mathrm{Mo}_{0.2}\right) \mathrm{B}$ [96] bulk ceramics were also prepared by direct reaction of transition metal powders with $\mathrm{B}$ powders through reactive hot-pressing (HP).

Wet chemical routes including co-precipitation, sol-gel, nebulized spray pyrolysis, and flame spray pyrolysis have the advantage of homogeneous mixing of constituting elements at a molecular level in the solutions and thus synthesis of HECs can be conducted at lower temperatures $[37,60,63,64,66,91,93,119]$. For example, Zhao et al. [91] used a co-precipitation method to synthesize high-entropy $\left(\mathrm{Nd}_{0.2} \mathrm{Sm}_{0.2} \mathrm{Eu}_{0.2} \mathrm{Y}_{0.2} \mathrm{Yb}_{0.2}\right)_{4} \mathrm{Al}_{2} \mathrm{O}_{9}$ powders. As shown in Fig. 3.1(b), nitrate salts of $\mathrm{RE}\left(\mathrm{NO}_{3}\right)_{3} \cdot 6 \mathrm{H}_{2} \mathrm{O}(\mathrm{RE}=\mathrm{Nd}, \mathrm{Sm}, \mathrm{Eu}, \mathrm{Y}$, and $\mathrm{Yb})$ in equal molar ratio were mixed and dissolved in distilled water to form a clear solution. Then $\mathrm{Al}\left(\mathrm{NO}_{3}\right)_{3}$ solution was added into the mixed $\mathrm{RE}\left(\mathrm{NO}_{3}\right)_{3}$ solution with stirring. After thoroughly mixing, excess aqueous ammonia was added slowly into the mixed solution with vigorous stirring to obtain gel-like precipitants. The precipitants were then filtered, washed, and finally calcined at $1873 \mathrm{~K}$ for $1 \mathrm{~h}$ to obtain high-entropy $\left(\mathrm{Nd}_{0.2} \mathrm{Sm}_{0.2} \mathrm{Eu}_{0.2} \mathrm{Y}_{0.2} \mathrm{Yb}_{0.2}\right)_{4} \mathrm{Al}_{2} \mathrm{O}_{9}$ powders.

Nebulized spray pyrolysis (NSP) is an aerosol based synthesis technique in which the decompositions of the precursor solution at elevated temperature lead to the formation of the either intermediate or desired phase [120]. This method has been used by Sarkar et al. [31,60] and Witte et al. [78] to the synthesis of rare earth and transition metal based entropy stabilized perovskite-type oxides as well as fluorite structured rare earth oxides. As illustrated in Fig. 3.1(c), to synthesize perovskite type oxides [31], water based solution containing nitrate salts of $\mathrm{Gd}, \mathrm{La}, \mathrm{Nd}, \mathrm{Sm}, \mathrm{Y}$, $\mathrm{Co}, \mathrm{Fe}, \mathrm{Mn}$, and $\mathrm{Ni}$ were delivered into the nebulizer, and then the generated mist containing fine droplets of the solution was transported by flowing oxygen into the hot-wall reactor where the particles were formed at $1050{ }^{\circ} \mathrm{C}$ and a pressure of 900 mbar. Further solid solution treatment was conducted by calcining at $1200{ }^{\circ} \mathrm{C}$ for $2 \mathrm{~h}$ in air, which resulted in the formation of high-entropy $\mathrm{RECoO}_{3}, \mathrm{RECrO}_{3}, \mathrm{REFeO}_{3}, \mathrm{REMnO}_{3}$, $\mathrm{RENiO}_{3}, \mathrm{GdTMO}_{3}, \mathrm{LaTMO}_{3}, \mathrm{NdTMO}_{3}, \mathrm{SmTMO}_{3}$, $\mathrm{YTMO}_{3}$, and $\mathrm{RETMO}_{3}(\mathrm{RE}=\mathrm{Gd}, \mathrm{La}, \mathrm{Nd}, \mathrm{Sm}, \mathrm{Y}$, $\mathrm{TM}=\mathrm{Co}, \mathrm{Cr}, \mathrm{Fe}, \mathrm{Mn}, \mathrm{Ni})$. Sarkar et al. [119] also compared the phase composition and microstructure of nebulized spray pyrolysis (NSP), flame spray pyrolysis (FSP), and reverse co-precipitation (RCP) synthesized (CoMgNiZn)O and (CoCuMgNiZn)O. They found that rock-salt structured high-entropy oxides could directly form after NSP, but for the FSP and RCP produced powders, high-temperature annealing was needed.

The wet chemical route can also be used to synthesize high-entropy carbide and boride ceramics. For example, $\mathrm{Du}$ et al. [121] synthesized $\left(\mathrm{Hf}_{0.25} \mathrm{Nb}_{0.25} \mathrm{Zr}_{0.25} \mathrm{Ti}_{0.25}\right) \mathrm{C}$ powders by mixing $\mathrm{HfCl}_{4}$, $\mathrm{ZrCl}_{4}, \quad \mathrm{NbCl}_{5}, \quad \mathrm{TiCl}_{4}$, and $\mathrm{C}_{5} \mathrm{H}_{8} \mathrm{O}_{2}$ in butanol $\left(\mathrm{CH}_{3}\left(\mathrm{CH}_{2}\right)_{3} \mathrm{OH}\right)$ with stirring followed by polymerization at $200{ }^{\circ} \mathrm{C}$ for $20 \mathrm{~h}$ to obtain a polymer precursor. After pyrolyzing at $2200{ }^{\circ} \mathrm{C}$, rock-salt structured $\left(\mathrm{Hf}_{0.25} \mathrm{Nb}_{0.25} \mathrm{Zr}_{0.25} \mathrm{Ti}_{0.25}\right) \mathrm{C}$ powders were obtained. Aside from carbides and borides, high- 
entropy metal nitride composed of $\mathrm{V}, \mathrm{Cr}, \mathrm{Nb}, \mathrm{Mo}, \mathrm{Zr}$, and $\mathrm{N}$ was synthesized using a soft urea strategy [122].

Different from the conventional methods, applying an electric field during the solid-state reaction process can significantly reduce the reaction time and allow the synthesis and sintering conducted at low furnace temperature. This flash sintering approach also enables the production of high-density ceramics in a single step by combining a solid state synthesis with densification [123]. Using the reactive flash sintering methods, high-entropy $\left(\mathrm{Mg}_{0.2} \mathrm{Ni}_{0.2} \mathrm{Co}_{0.2} \mathrm{Cu}_{0.2} \mathrm{Zn}_{0.2}\right) \mathrm{O}$ has been successfully prepared even at room temperature [124, 125]. Recently, Wang et al. [126] synthesized highentropy $\operatorname{Sr}\left(\mathrm{Ti}_{0.2} \mathrm{Y}_{0.2} \mathrm{Zr}_{0.2} \mathrm{Sn}_{0.2} \mathrm{Hf}_{0.2}\right) \mathrm{O}_{3-x}$ using a reactive flash sintering method. Using $\mathrm{Y}_{2} \mathrm{O}_{3}, \mathrm{SnO}_{2}, \mathrm{SrO}, \mathrm{HfO}_{2}$, $\mathrm{SrTiO}_{3}, \mathrm{SrZrO}_{3}$ powders as starting materials, singlephase perovskite-structured $\mathrm{Sr}\left(\mathrm{Ti}_{0.2} \mathrm{Y}_{0.2} \mathrm{Zr}_{0.2} \mathrm{Sn}_{0.2} \mathrm{Hf}_{0.2}\right) \mathrm{O}_{3-x}$ was formed at $1000{ }^{\circ} \mathrm{C}$ in $1 \mathrm{~min}$, demonstrating the prospective of this ultrafast synthesis and sintering method.

Carbothermal shock (CTS) method provides a novel route to synthesize a diverse array of high-entropy nanoparticles with narrow size distribution and uniformly dispersion. Moreover, the easily tunable processing parameters, rapid and energy-efficient synthetic procedure make CTS promising technology for high-rate and high-volume production of high quality HE nanoparticles. To put it simply, the CTS method employs a rapid heating process in milliseconds through an electrical pulse and a controllable cooling process of metal precursors on oxygenated carbon support. A serial of HEA nanoparticles containing up to ten elements were fabricated using this method. In addition, three strategies (temperature, oxidation, and entropy-driven mixing) were proposed for the efficient synthesis of different HEA and oxide nanoparticles $[127,128]$.

Solidification process is also a promising strategy to synthesize HECs, which involves melting the raw materials, forming homogeneous melt, and cooling. This process has widely been used in the preparation of metallic materials and has been proven to be simple, quick, and cost-effective. Using this method, Zhang et $a l$. [113] successfully synthesized high-entropy amorphous oxide spheres through melting $10 \mathrm{La}_{2} \mathrm{O}_{3}-20 \mathrm{TiO}_{2}-$ $10 \mathrm{Nb}_{2} \mathrm{O}_{5}-20 \mathrm{WO}_{3}-20 \mathrm{ZrO}_{2}$ mixture by aerodynamic levitation. Very recently, Guo and Li [114] prepared high-entropy (RETiZrYAl)O ( $\mathrm{RE}=\mathrm{La}, \mathrm{Sm}, \mathrm{Gd})$ glass with ultra-high hardness and Young's modulus.

\section{2 Synthesis methods for different forms of HECs}

\subsubsection{Powders}

High-quality HEC powders are starting materials for sintering of bulk materials, thermal/environmental barrier coatings, and also final products for anodes of Li-ion batteries, catalysts, electromagnetic wave absorbers, etc. Depending on the application targets and material systems, a variety of methods including solid-state synthesis, sol-gel or co-precipitation followed by high-temperature calcination, reactive high-energy ball milling, molten salt synthesis, carbothermal reduction, borothermal reduction, boron/carbothermal reduction, etc., can be used. The following are typical examples that have been utilized to synthesize HEC powders. The first example is a room temperature sonochemical-based method for one-pot synthesis of perovskite-structured nanoparticles [115]. Taking the advantage of the acoustic cavitation phenomenon in the ultrasonication process, single-phase $\mathrm{BaSr}(\mathrm{ZrHfTi}) \mathrm{O}_{3}$, $\mathrm{BaSrBi}(\mathrm{ZrHfTiFe}) \mathrm{O}_{3}$, and $\mathrm{Ru} / \mathrm{BaSrBi}(\mathrm{ZrHfTiFe}) \mathrm{O}_{3}$ nanoparticles with an average crystallite size of approximately $5.9 \mathrm{~nm}$ were crystallized through ultrasonication exposure without calcinations [115]. In the second example, Dong et al. [87] synthesized $\left(\mathrm{Yb}_{0.2} \mathrm{Y}_{0.2} \mathrm{Lu}_{0.2} \mathrm{Sc}_{0.2} \mathrm{Gd}_{0.2}\right)_{2} \mathrm{Si}_{2} \mathrm{O}_{7}$ powders using a sol-gel method. In this process, tetraethoxysilane (TEOS) was first dissolved in distilled water and ethanol with molar ratio of 1:4:1. Then, the $\mathrm{RE}\left(\mathrm{NO}_{3}\right)_{3}$ solution was added into the TEOS solution with stirring until the TEOS was fully hydrolyzed. Subsequently, the solution was heated at $70{ }^{\circ} \mathrm{C}$ for $24 \mathrm{~h}$ and $120{ }^{\circ} \mathrm{C}$ for $24 \mathrm{~h}$ to obtain the dry gel. After calcining at $800{ }^{\circ} \mathrm{C}$ for $2 \mathrm{~h}$ and $1500{ }^{\circ} \mathrm{C}$ for $2 \mathrm{~h}$ in air, $\beta$-type $\left(\mathrm{Yb}_{0.2} \mathrm{Y}_{0.2} \mathrm{Lu}_{0.2} \mathrm{Sc}_{0.2} \mathrm{Gd}_{0.2}\right)_{2} \mathrm{Si}_{2} \mathrm{O}_{7}$ powders were obtained.

Solid state synthesis has widely been used for preparing HEC powders. For example, Dabrowa et al. [32] prepared spinel-structured $(\mathrm{CoCrFeMnNi})_{3} \mathrm{O}_{4}$ by vibrational milling the $\mathrm{Co}_{3} \mathrm{O}_{4}, \mathrm{Cr}_{2} \mathrm{O}_{3}, \mathrm{Fe}_{2} \mathrm{O}_{3}, \mathrm{MnO}$, $\mathrm{NiO}$ powders and then calcining the powder mixture at $1050{ }^{\circ} \mathrm{C}$ for $20 \mathrm{~h}$. $\mathrm{Pu}$ et al. [129] prepared $\left(\mathrm{Na}_{0.2} \mathrm{Bi}_{0.2} \mathrm{Ba}_{0.2} \mathrm{Sr}_{0.2} \mathrm{Ca}_{0.2}\right) \mathrm{TiO}_{3}$ by calcining the $\mathrm{Na}_{2} \mathrm{CO}_{3}$, $\mathrm{Bi}_{2} \mathrm{O}_{3}, \mathrm{BaCO}_{3}, \mathrm{SrCO}_{3}, \mathrm{CaCO}_{3}$, and $\mathrm{TiO}_{2}$ powder mixture at $1050{ }^{\circ} \mathrm{C}$. Chen et al. [101] synthesized high-entropy rare earth silicide carbides $\left(\mathrm{Tm}_{0.2} \mathrm{Y}_{0.2} \mathrm{Pr}_{0.2} \mathrm{Gd}_{0.2} \mathrm{Dy}_{0.2}\right)_{3} \mathrm{Si}_{2} \mathrm{C}_{2}$ and $\left(\mathrm{Tm}_{0.2} \mathrm{Y}_{0.2} \mathrm{Pr}_{0.2} \mathrm{Gd}_{0.2} \mathrm{~Tb}_{0.2}\right)_{3} \mathrm{Si}_{2} \mathrm{C}_{2}$ powders at $1600{ }^{\circ} \mathrm{C}$ with dwell time of $1 \mathrm{~h}$ in Ar using rare earth elements and $\mathrm{SiC}$ powders as starting materials. 
Since the densification of high-entropy ultrahigh temperature ceramics (UHTCs) including transition metal carbides and borides ceramics usually requires higher temperatures, reducing the particle size of the starting powders with higher surface energies is beneficial, which provides a higher driving force for densification. To achieve such a goal, various methods have been used to synthesize ultrafine high-entropy carbide and boride powders. Moskovskikh et al. [130] synthesized high-entropy $\mathrm{Hf}_{0.2} \mathrm{Ta}_{0.2} \mathrm{Ti}_{0.2} \mathrm{Nb}_{0.2} \mathrm{Zr}_{0.2} \mathrm{C}$ and $\mathrm{Hf}_{0.2} \mathrm{Ta}_{0.2} \mathrm{Ti}_{0.2} \mathrm{Nb}_{0.2} \mathrm{Mo}_{0.2} \mathrm{C}$ powders through reactive high-energy ball milling (R-HEBM) of elemental transition metal powders and graphite particles. X-ray diffraction analysis indicated that rock-salt structured high-entropy carbides could be formed after ball milling for $60 \mathrm{~min}$. Another example is that Guan et al. [131] synthesized high-entropy metal boron carbonitride $\left(\mathrm{Ta}_{0.2} \mathrm{Nb}_{0.2} \mathrm{Zr}_{0.2} \mathrm{Hf}_{0.2} \mathrm{~W}_{0.2}\right) \mathrm{BCN}$, $\left(\mathrm{Ta}_{0.2} \mathrm{Nb}_{0.2} \mathrm{Zr}_{0.2} \mathrm{Hf}_{0.2} \mathrm{Ti}_{0.2}\right) \mathrm{BCN}$, and $\left(\mathrm{Ta}_{0.2} \mathrm{Nb}_{0.2} \mathrm{Zr}_{0.2} \mathrm{Ti}_{0.2} \mathrm{~W}_{0.2}\right) \mathrm{BCN}$ powders via mechanical alloying at room temperature. Molten salt method was also used to prepare nanometer sized $\left(\mathrm{Ta}_{0.25} \mathrm{Nb}_{0.25} \mathrm{Ti}_{0.25} \mathrm{~V}_{0.25}\right) \mathrm{C}$ powders. Using $\mathrm{Ta}, \mathrm{Nb}, \mathrm{Ti}$, and $\mathrm{V}$ powders as starting materials and $\mathrm{KCl}$ as the molten salt medium, high-entropy $\left(\mathrm{Ta}_{0.25} \mathrm{Nb}_{0.25} \mathrm{Ti}_{0.25} \mathrm{~V}_{0.25}\right) \mathrm{C}$ with particle sizes of 50-100 nm was synthesized at $1300{ }^{\circ} \mathrm{C}$ by Ning et al. [132]. Aside from the foregoing low temperature processes, carbothermal reduction, borothermal reduction, and boro/carbothermal reaction are also beneficial for the synthesis of fine-grained high quality powders. For example, Feng et al. [133] synthesized $\left(\mathrm{Hf}_{0.2} \mathrm{Zr}_{0.2} \mathrm{Ti}_{0.2} \mathrm{Ta}_{0.2} \mathrm{Nb}_{0.2}\right) \mathrm{C}$ powders with an average particle size of about $550 \mathrm{~nm}$ at $2000{ }^{\circ} \mathrm{C}$ using transition-metal oxides and carbon powders as starting materials. Liu et al. [134] synthesized $\left(\mathrm{Hf}_{0.2} \mathrm{Zr}_{0.2} \mathrm{Ta}_{0.2} \mathrm{Nb}_{0.2} \mathrm{Ti}_{0.2}\right) \mathrm{B}_{2}$ with an average particle size of $\sim 310 \mathrm{~nm}$ at $1700{ }^{\circ} \mathrm{C}$ using a facile borothermal reduction method. Zhang et al. [135] prepared $\left(\mathrm{Hf}_{0.2} \mathrm{Zr}_{0.2} \mathrm{Ta}_{0.2} \mathrm{Nb}_{0.2} \mathrm{Ti}_{0.2}\right) \mathrm{B}_{2}, \quad\left(\mathrm{Hf}_{0.2} \mathrm{Zr}_{0.2} \mathrm{Mo}_{0.2} \mathrm{Nb}_{0.2} \mathrm{Ti}_{0.2}\right) \mathrm{B}_{2}$, and $\left(\mathrm{Hf}_{0.2} \mathrm{Mo}_{0.2} \mathrm{Ta}_{0.2} \mathrm{Nb}_{0.2} \mathrm{Ti}_{0.2}\right) \mathrm{B}_{2}$ powders through boro/ carbothermal reduction of transition metal oxides at $1600{ }^{\circ} \mathrm{C}$ using $\mathrm{B}_{4} \mathrm{C}$ and graphite powders as reducing agents. Utilizing the ultrafine high-entropy carbides and borides as initial materials, near fully dense bulk carbide and boride HECs with improved mechanical properties have been prepared [130,135-137].

\subsubsection{Dense and porous bulks}

Although the initial work of Gild et al. [34] implies that densification of high-entropy boride ceramics is difficult and pressure assisted methods such as spark plasma sintering (SPS) and HP are needed for borides and carbides, densification of bulk HECs in other system including oxides, silicates, and sulfides can be achieved using pressureless sintering or a single step process combining synthesis and densification. Generally, for ultrahigh temperature HECs including borides and carbides with strong covalent bonding [138] and low self-diffusion coefficient, SPS, HP, or oscillatory hot pressing (OHP) methods are needed to achieve nearly full density at temperatures over $2000{ }^{\circ} \mathrm{C}$. For example, Gild et al. [34] prepared bulk $\left(\mathrm{Hf}_{0.2} \mathrm{Zr}_{0.2} \mathrm{Ta}_{0.2} \mathrm{Nb}_{0.2} \mathrm{Ti}_{0.2}\right) \mathrm{B}_{2}, \quad\left(\mathrm{Hf}_{0.2} \mathrm{Zr}_{0.2} \mathrm{Ta}_{0.2} \mathrm{Mo}_{0.2} \mathrm{Ti}_{0.2}\right) \mathrm{B}_{2}$, $\left(\mathrm{Hf}_{0.2} \mathrm{Zr}_{0.2} \mathrm{Mo}_{0.2} \mathrm{Nb}_{0.2} \mathrm{Ti}_{0.2}\right) \mathrm{B}_{2},\left(\mathrm{Hf}_{0.2} \mathrm{Mo}_{0.2} \mathrm{Ta}_{0.2} \mathrm{Nb}_{0.2} \mathrm{Ti}_{0.2}\right) \mathrm{B}_{2}$, and $\left(\mathrm{Mo}_{0.2} \mathrm{Zr}_{0.2} \mathrm{Ta}_{0.2} \mathrm{Nb}_{0.2} \mathrm{Ti}_{0.2}\right) \mathrm{B}_{2}$ by SPS at $2000{ }^{\circ} \mathrm{C}$ and $30 \mathrm{MPa}$ using high-energy ball milled constituting boride mixtures as starting materials. Zhang et al. [139] prepared $\left(\mathrm{Hf}_{0.2} \mathrm{Zr}_{0.2} \mathrm{Ta}_{0.2} \mathrm{Cr}_{0.2} \mathrm{Ti}_{0.2}\right) \mathrm{B}_{2},\left(\mathrm{Hf}_{0.2} \mathrm{Mo}_{0.2} \mathrm{Zr}_{0.2} \mathrm{Nb}_{0.2} \mathrm{Ti}_{0.2}\right) \mathrm{B}_{2}$, and $\left(\mathrm{Hf}_{0.2} \mathrm{Mo}_{0.2} \mathrm{Ta}_{0.2} \mathrm{Nb}_{0.2} \mathrm{Ti}_{0.2}\right)_{2}$ by SPS at $2000{ }^{\circ} \mathrm{C}$ and $30 \mathrm{MPa}$ using the high-entropy powders synthesized by borothermal reduction method as initial materials. Gu et al. [140] fabricated $\left(\mathrm{Ti}_{0.2} \mathrm{Hf}_{0.2} \mathrm{Zr}_{0.2} \mathrm{Nb}_{0.2} \mathrm{Ta}_{0.2}\right) \mathrm{B}_{2}$ by SPS at $2000-2050{ }^{\circ} \mathrm{C}$ and $50 \mathrm{MPa}$ of boro/carbothermal reduction produced powders. Feng et al. [141] prepared dense $\left(\mathrm{Hf}_{0.2} \mathrm{Zr}_{0.2} \mathrm{Ti}_{0.2} \mathrm{Ta}_{0.2} \mathrm{Nb}_{0.2}\right) \mathrm{B}_{2}$ using a two-step SPS process. In the first step, the boro/carbothermal reduction produced powder compact was heated to $1650{ }^{\circ} \mathrm{C}$ under mild vacuum $(\sim 2 \mathrm{~Pa})$ at $15 \mathrm{MPa}$ load; and in the second step, densification was conducted at 2000-2200 ${ }^{\circ} \mathrm{C}$ under $50 \mathrm{MPa}$. Monteverde et al. [142] fabricated $\left(\mathrm{Hf}_{0.2} \mathrm{Nb}_{0.2} \mathrm{Ta}_{0.2} \mathrm{Ti}_{0.2} \mathrm{Zr}_{0.2}\right) \mathrm{B}_{2}$ by hot-pressing carbo/boro-thermal reduction produced powders at $1927{ }^{\circ} \mathrm{C}$ and $50 \mathrm{MPa}$. It is worth mentioning that the final microstructure and mechanical properties strongly depend on the particle size and impurity content of the raw materials and densification temperature. Small grain size and high purity of raw materials and low sintering temperatures generally result in fine grain size and enhanced mechanical properties [34,135, 137,139-141]. For high-entropy carbides, Castle et al. [143] prepared $\left(\mathrm{Hf}_{0.25} \mathrm{Ta}_{0.25} \mathrm{Zr}_{0.25} \mathrm{Ti}_{0.25}\right) \mathrm{C}$ and $\left(\mathrm{Hf}_{0.25} \mathrm{Ta}_{0.25} \mathrm{Zr}_{0.25} \mathrm{Nb}_{0.25}\right) \mathrm{C}$ with a relative density of $\sim 99 \%$ by SPS at $2300{ }^{\circ} \mathrm{C}$ and 16-40 MPa. Yan et al. [35] prepared $\left(\mathrm{Hf}_{0.2} \mathrm{Zr}_{0.2} \mathrm{Ti}_{0.2} \mathrm{Ta}_{0.2} \mathrm{Nb}_{0.2}\right) \mathrm{C}$ with a relative density of $\sim 93 \%$ by SPS at $2000{ }^{\circ} \mathrm{C}$ in a vacuum of $2 \times 10^{-2}$ Torr under a pressure of $30 \mathrm{MPa}$. Sarker et al. [104] produced (Hf,Zr,Ti,Ta,Nb)C ceramics with a relative density of $\sim 99 \%$ by SPS at $2200{ }^{\circ} \mathrm{C}$. Intriguingly, a combination of in situ synthesis and 
pulsed current processing (PCP) resulted in the formation of a new hexagonal phase $\mathrm{B}_{4}\left(\mathrm{HfMo}_{2} \mathrm{TaTi}\right) \mathrm{C}$ from a mixture of $\mathrm{HfC}, \mathrm{Mo}_{2} \mathrm{C}, \mathrm{TaC}, \mathrm{TiC}$, and $\mathrm{B}_{4} \mathrm{C}$ [144].

For HECs in other systems, although SPS has also frequently been used in many works, near fully dense bulks have been prepared by pressureless sintering $[45,110]$. In addition, other methods such as solidification [113,114] and reactive flash sintering have been utilized to prepare bulk HECs [124,125]. For examples, bulk $\left(\mathrm{Mg}_{0.2} \mathrm{Ni}_{0.2} \mathrm{Co}_{0.2} \mathrm{Cu}_{0.2} \mathrm{Zn}_{0.2}\right) \mathrm{O}$ [125] and $\left(\mathrm{La}_{0.2} \mathrm{Nd}_{0.2} \mathrm{Sm}_{0.2} \mathrm{Eu}_{0.2} \mathrm{Gd}_{0.2}\right)_{2} \mathrm{Zr}_{2} \mathrm{O}_{7}$ [145] have been fabricated by reactive flash sintering at low furnace temperatures, which combines the solid-state reaction and densification in one step. A good example of pressureless sintering is the fabrication of transparent $\left(\mathrm{Lu}_{0.2} \mathrm{Y}_{0.395} \mathrm{Gd}_{0.2} \mathrm{Yb}_{0.2} \mathrm{Tm}_{0.005}\right)_{2} \mathrm{O}_{3}$ [110], which was conducted through vacuum sintering at $1800{ }^{\circ} \mathrm{C}$ for $20 \mathrm{~h}$ followed by annealing in air at $1000{ }^{\circ} \mathrm{C}$ for $13 \mathrm{~h}$, using $\mathrm{La}_{2} \mathrm{O}_{3}$ and $\mathrm{ZrO}_{2}$ as sintering additives. Another example is that bulk ( $\mathrm{Ca}, \mathrm{Sr}, \mathrm{Ba}) \mathrm{ZrO}_{3}$ with a relative density of $97.8 \%$ was prepared by pressureless sintering of $\mathrm{CaZrO}_{3}, \mathrm{SrZrO}_{3}$, and $\mathrm{BaZrO}_{3}$ mixed powder compact at $1550{ }^{\circ} \mathrm{C}$ [45]. Although not widely used, the results of these pioneer works are appealing since they demonstrate the potential to fabricate HECs in a simple presureless sintering method, which is useful in scaling up the sample size and beneficial for manufacturing complex and large size bulk HECs for the practical applications.

Porous ultrahigh temperature ceramics play a pivotal role in ultrahigh temperature insulation. They also find applications in molten metal and corrosive gas filtration, catalyst supports, and electromagnetic wave absorption. However, high thermal conductivity is the main obstacle for ultrahigh temperature insulating application. In order to reduce the thermal conductivity, low thermal conductivity high-entropy carbides and borides were selected as backbone materials and a novel in-situ reaction/partial sintering method was developed to fabricate highly porous bulk materials [146-148]. This process is based on the fact that highentropy carbides and borides can be synthesized through carbothermal reduction, borothermal reduction, and boro/carbothermal reduction. The reaction released gases can not only increase the porosity but also block

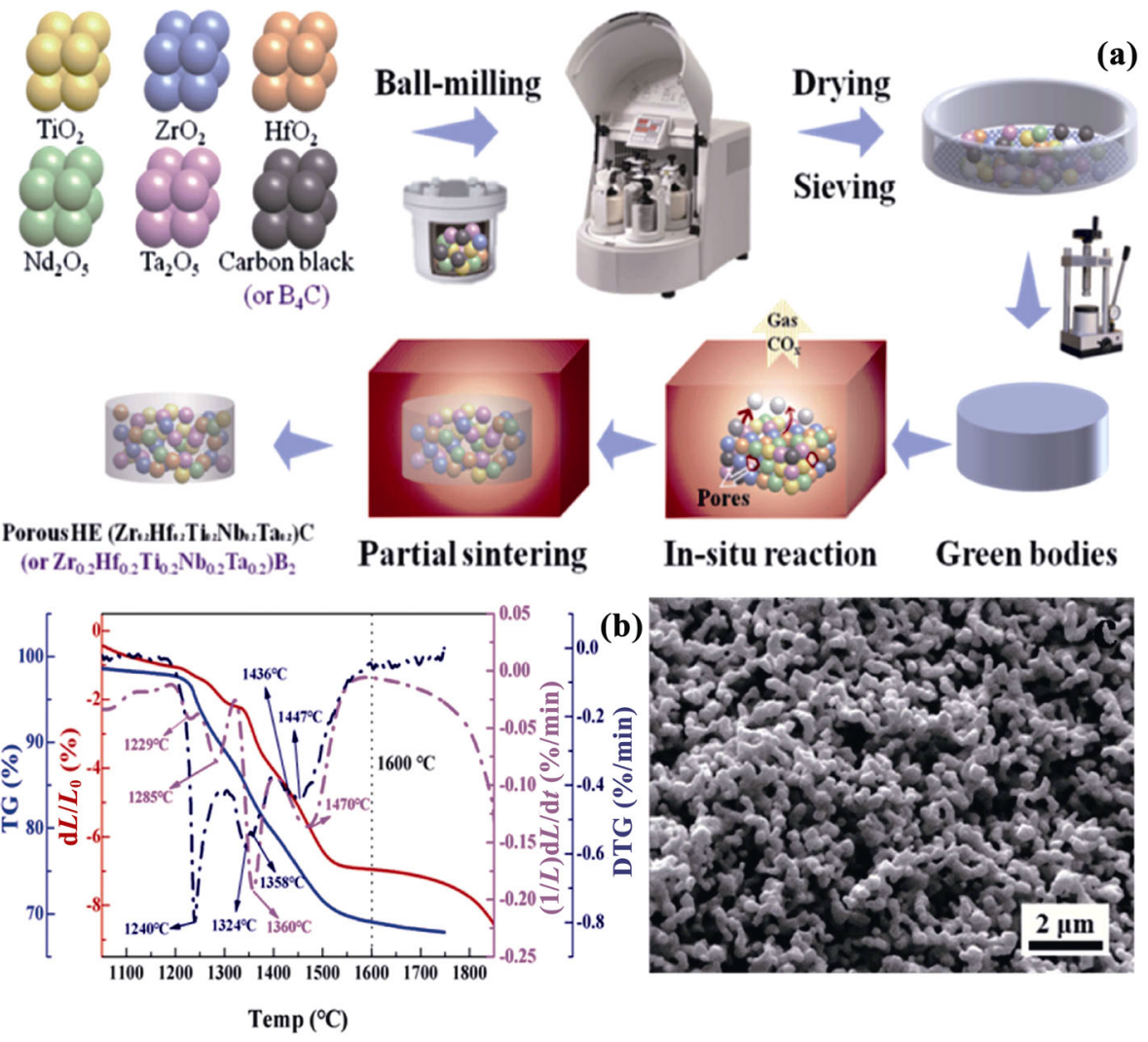

Fig. 3.2 (a) Schematic illustration of in situ synthesis/partial sintering for fabricating porous $\left(\mathrm{Zr}_{0.2} \mathrm{Hf}_{0.2} \mathrm{Ti}_{0.2} \mathrm{Nb}_{0.2} \mathrm{Ta}_{0.2}\right) \mathrm{C}$; (b) $\mathrm{d} L / L_{0},\left(1 / L_{0}\right) \mathrm{d} L / \mathrm{d} t$, TG, and DTG curves recorded during the heating of the $\mathrm{ZrO}_{2} / \mathrm{HfO}_{2} / \mathrm{TiO}_{2} / \mathrm{Nb}_{2} \mathrm{O}_{5} / \mathrm{Ta}_{2} \mathrm{O}_{5} / \mathrm{C}$ powder compact; (c) SEM micrograph of porous $\left(\mathrm{Zr}_{0.2} \mathrm{Hf}_{0.2} \mathrm{Ti}_{0.2} \mathrm{Nb}_{0.2} \mathrm{Ta}_{0.2}\right)$ C. Reproduced with permission from Ref. [22], C Elsevier 2019. 
the large shrinkage, e.g., the volume shrinkage during carbothermal reduction of $\mathrm{ZrO}_{2}$ is about $60 \%$. Thus no pore forming agent is needed and the synthesis/partial sintering of the porous high-entropy carbide and boride ceramics can be finished in a single step. Using this novel method, high porosity $\left(\mathrm{Zr}_{0.2} \mathrm{Hf}_{0.2} \mathrm{Ti}_{0.2} \mathrm{Nb}_{0.2} \mathrm{Ta}_{0.2}\right) \mathrm{C}$ [22], $\quad\left(\mathrm{Zr}_{0.2} \mathrm{Hf}_{0.2} \mathrm{Ti}_{0.2} \mathrm{Nb}_{0.2} \mathrm{Ta}_{0.2}\right) \mathrm{B}_{2} \quad$ [40], and $\left(\mathrm{Y}_{0.2} \mathrm{Yb}_{0.2} \mathrm{Sm}_{0.2} \mathrm{Nd}_{0.2} \mathrm{Eu}_{0.2}\right) \mathrm{B}_{6}$ [98] have been prepared. Figure 3.2(a) illustrates the in situ synthesis/partial sintering process for the fabricating of high porosity $\left(\mathrm{Zr}_{0.2} \mathrm{Hf}_{0.2} \mathrm{Ti}_{0.2} \mathrm{Nb}_{0.2} \mathrm{Ta}_{0.2}\right) \mathrm{C}$ [22]. The total reaction for the formation of high-entropy $\left(\mathrm{Zr}_{0.2} \mathrm{Hf}_{0.2} \mathrm{Ti}_{0.2} \mathrm{Nb}_{0.2} \mathrm{Ta}_{0.2}\right) \mathrm{C}$ can be described in Eqs. (3.6)-(3.12):

$$
\begin{aligned}
& 2 \mathrm{ZrO}_{2}(\mathrm{~s})+2 \mathrm{HfO}_{2}(\mathrm{~s})+2 \mathrm{TiO}_{2}(\mathrm{~s}) \\
& +\mathrm{Nb}_{2} \mathrm{O}_{5}(\mathrm{~s})+\mathrm{Ta}_{2} \mathrm{O}_{5}(\mathrm{~s})+32 \mathrm{C}(\mathrm{s}) \\
& =10\left(\mathrm{Zr}_{0.2} \mathrm{Hf}_{0.2} \mathrm{Ti}_{0.2} \mathrm{Nb}_{0.2} \mathrm{Ta}_{0.2}\right) \mathrm{C}(\mathrm{s})+22 \mathrm{CO}(\mathrm{g}) \\
& \mathrm{ZrO}_{2}(\mathrm{~s})+3 \mathrm{C}=\mathrm{ZrC}+2 \mathrm{CO}(\mathrm{g}) \\
& \mathrm{HfO}_{2}(\mathrm{~s})+3 \mathrm{C}=\mathrm{HfC}+2 \mathrm{CO}(\mathrm{g}) \\
& \mathrm{TiO}_{2}(\mathrm{~s})+3 \mathrm{C}=\mathrm{TiC}+2 \mathrm{CO}(\mathrm{g}) \\
& \mathrm{Nb}_{2} \mathrm{O}_{5}(\mathrm{~s})+7 \mathrm{C}=2 \mathrm{NbC}(\mathrm{s})+5 \mathrm{CO}(\mathrm{g}) \\
& \mathrm{Ta}_{2} \mathrm{O}_{5}(\mathrm{~s})+7 \mathrm{C}=2 \mathrm{TaC}(\mathrm{s})+5 \mathrm{CO}(\mathrm{g}) \\
& \mathrm{ZrC}(\mathrm{s})+\mathrm{HfC}(\mathrm{s})+\mathrm{TiC}(\mathrm{s})+\mathrm{NbC}(\mathrm{s})+\mathrm{TaC}(\mathrm{s}) \\
& =5\left(\mathrm{Zr}_{0.2} \mathrm{Hf}_{0.2} \mathrm{Ti}_{0.2} \mathrm{Nb}_{0.2} \mathrm{Ta}_{0.2}\right) \mathrm{C}(\mathrm{s})
\end{aligned}
$$

To obtain porous samples with excellent shape stability, the in-situ synthesis/shrinkage process must be precisely controlled such that cracking and collapse can be avoided. Based on the linear shrinkage $\left(\mathrm{d} L / L_{0}\right.$, with $L_{0}$ being the height of columnar shaped green bodies at room temperature) and linear shrinkage rate $\left(\left(1 / L_{0}\right) \mathrm{d} L / \mathrm{d} t\right)$ curves together with the corresponding thermogravimetric (TG) and differential thermogravimetric (DTG) curves shown in Fig. 3.2(b), porous
$\left(\mathrm{Zr}_{0.2} \mathrm{Hf}_{0.2} \mathrm{Ti}_{0.2} \mathrm{Nb}_{0.2} \mathrm{Ta}_{0.2}\right) \mathrm{C}$ with homogeneous microstructure (Fig. 3.2(c)) was prepared through carbothermal reduction at $1500{ }^{\circ} \mathrm{C}$ with carefully controlled slow heat rate and partial sintering at $1850{ }^{\circ} \mathrm{C}$. The grain size is $100-500 \mathrm{~nm}$ and the pore size is in the range of $0.2-1 \mu \mathrm{m}$. The porosity is $80.99 \%$ with a compressive strength of $3.45 \mathrm{MPa}$ and low room temperature thermal conductivity of $0.39 \mathrm{~W} \cdot \mathrm{m}^{-1} \cdot \mathrm{K}^{-1}$.

Using a similar method, porous $\left(\mathrm{Zr}_{0.2} \mathrm{Hf}_{0.2} \mathrm{Ti}_{0.2} \mathrm{Nb}_{0.2} \mathrm{Ta}_{0.2}\right) \mathrm{B}_{2}$ with a porosity of $75.7 \%$, grain size of $400-800 \mathrm{~nm}$, pore size of $0.3-1.2 \mu \mathrm{m}$ (Fig. 3.3(a)), compressive strength of $3.93 \mathrm{MPa}$, and room temperature thermal conductivity of $0.51 \mathrm{~W} \cdot \mathrm{m}^{-1} \cdot \mathrm{K}^{-1}$ was prepared following reaction (3.13) [40]:

$$
\begin{aligned}
& 14 \mathrm{ZrO}_{2}(\mathrm{~s})+14 \mathrm{HfO}_{2}(\mathrm{~s})+14 \mathrm{TiO}_{2}(\mathrm{~s}) \\
& +7 \mathrm{Nb}_{2} \mathrm{O}_{5}(\mathrm{~s})+7 \mathrm{Ta}_{2} \mathrm{O}_{5}(\mathrm{~s})+52 \mathrm{~B}_{4} \mathrm{C}(\mathrm{s}) \\
= & 70\left(\mathrm{Zr}_{0.2} \mathrm{Hf}_{0.2} \mathrm{Ti}_{0.2} \mathrm{Nb}_{0.2} \mathrm{Ta}_{0.2}\right) \mathrm{B}_{2}(\mathrm{~s}) \\
& +34 \mathrm{~B}_{2} \mathrm{O}_{3}+52 \mathrm{CO}(\mathrm{g})
\end{aligned}
$$

Porous $\left(\mathrm{Y}_{0.2} \mathrm{Yb}_{0.2} \mathrm{Sm}_{0.2} \mathrm{Nd}_{0.2} \mathrm{Eu}_{0.2}\right) \mathrm{B}_{6}$ [98] was also prepared by the in-situ synthesis and simultaneous partial sintering method (reaction (3.14) or (3.15)). It is interesting to note that the microstructure of the porous materials depends on the reaction route, e.g., porous $\left(\mathrm{Y}_{0.2} \mathrm{Yb}_{0.2} \mathrm{Sm}_{0.2} \mathrm{Nd}_{0.2} \mathrm{Eu}_{0.2}\right) \mathrm{B}_{6}$ produced by borothermal reduction (reaction (3.14)) has larger pore size, as shown in Fig. 3.3(b):

$$
\begin{gathered}
\mathrm{Y}_{2} \mathrm{O}_{3}(\mathrm{~s})+\mathrm{Yb}_{2} \mathrm{O}_{3}(\mathrm{~s})+\mathrm{Sm}_{2} \mathrm{O}_{3}(\mathrm{~s}) \\
+\mathrm{Nd}_{2} \mathrm{O}_{3}(\mathrm{~s})+\mathrm{Eu}_{2} \mathrm{O}_{3}(\mathrm{~s})+70 \mathrm{~B} \\
=10\left(\mathrm{Y}_{0.2} \mathrm{Yb}_{0.2} \mathrm{Sm}_{0.2} \mathrm{Nd}_{0.2} \mathrm{Eu}_{0.2}\right) \mathrm{B}_{6}(\mathrm{~s}) \\
+5 \mathrm{~B}_{2} \mathrm{O}_{3}(\mathrm{~g}) \\
\mathrm{Y}_{2} \mathrm{O}_{3}(\mathrm{~s})+\mathrm{Yb}_{2} \mathrm{O}_{3}(\mathrm{~s})+\mathrm{Sm}_{2} \mathrm{O}_{3}(\mathrm{~s}) \\
+\mathrm{Nd}_{2} \mathrm{O}_{3}(\mathrm{~s})+\mathrm{Eu}_{2} \mathrm{O}_{3}(\mathrm{~s})+15 \mathrm{~B}_{4} \mathrm{C} \\
=10\left(\mathrm{Y}_{0.2} \mathrm{Yb}_{0.2} \mathrm{Sm}_{0.2} \mathrm{Nd}_{0.2} \mathrm{Eu}_{0.2}\right) \mathrm{B}_{6}(\mathrm{~s})+15 \mathrm{CO}(\mathrm{g})
\end{gathered}
$$
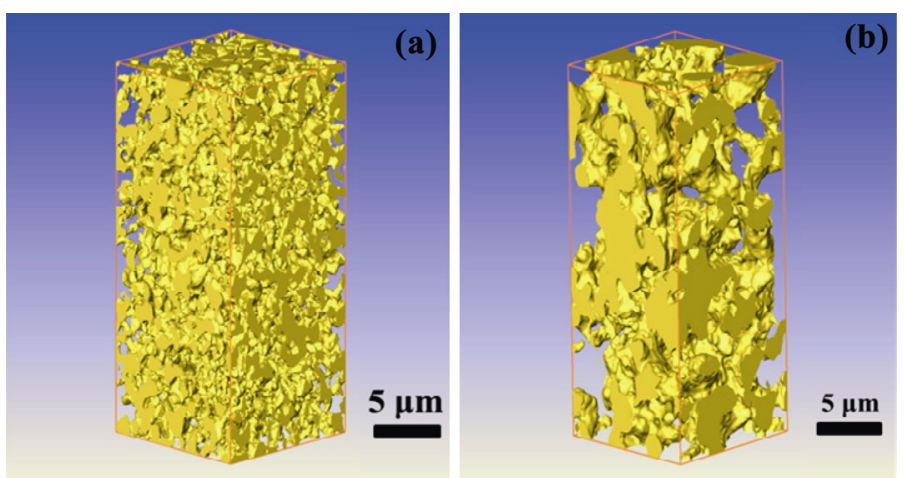

Fig. 3.3 XRT images of porous (a) $\left(\mathrm{Zr}_{0.2} \mathrm{Hf}_{0.2} \mathrm{Nb}_{0.2} \mathrm{Ta}_{0.2} \mathrm{Ti}_{0.2}\right) \mathrm{B}_{2}$ and (b) $\left(\mathrm{Y}_{0.2} \mathrm{Yb}_{0.2} \mathrm{Sm}_{0.2} \mathrm{Nd}_{0.2} \mathrm{Eu}_{0.2}\right) \mathrm{B}_{6}$. Reproduced with permission from Ref. [98], (c) Elsevier 2020. 


\subsubsection{Thin films and thick coatings}

Taking the advantages of tunable thermal expansion coefficient, high hardness, slow grain growth rate, and better stability, HEC thin films and coatings show great potential in the field of thermal/environmental barrier coatings (TBC/EBCs) [23,37,71,85,87-90,93,149], hard coatings, oxidation and corrosion resistant coatings [150-157]. TBC/EBCs can be deposited by atmospheric plasma spraying [149], while nitride, carbide, and oxide thin films can be prepared by reactive RF magnetron sputtering or DC sputtering of high-entropy alloys or co-sputtering of pure metal targets [150-157].

Atmospheric plasma spraying (APS) is a conventional technique to prepare thermal barrier coatings (TBC) on superalloy substrates, adapting to yttria stabilized zirconia (YSZ), rare earth zirconate, rare earth phosphate, and other material systems. Recently, Zhou et al. [149] found that APS is also suitable for preparing thermal barrier HEC coating. They deposited a $\left(\mathrm{La}_{0.2} \mathrm{Nd}_{0.2} \mathrm{Sm}_{0.2} \mathrm{Eu}_{0.2} \mathrm{Gd}_{0.2}\right)_{2} \mathrm{Zr}_{2} \mathrm{O}_{7} / \mathrm{YSZ}$ double-ceramic-layer (DCL) coating on Ni-based superalloy by APS, which exhibited enhanced thermal stability. Thermal cycling tests demonstrated that the $\left(\mathrm{La}_{0.2} \mathrm{Nd}_{0.2} \mathrm{Sm}_{0.2} \mathrm{Eu}_{0.2} \mathrm{Gd}_{0.2}\right)_{2} \mathrm{Zr}_{2} \mathrm{O}_{7} / \mathrm{YSZ}$ DCL coating exhibited improved thermal stability due to the good sintering resistance and close thermal expansion coefficient of $\left(\mathrm{La}_{0.2} \mathrm{Nd}_{0.2} \mathrm{Sm}_{0.2} \mathrm{Eu}_{0.2} \mathrm{Gd}_{0.2}\right)_{2} \mathrm{Zr}_{2} \mathrm{O}_{7}$ to $\mathrm{YSZ}$. Besides APS, Dong et al. [87] fabricated a $\left(\mathrm{Yb}_{0.2} \mathrm{Y}_{0.2} \mathrm{Lu}_{0.2} \mathrm{Sc}_{0.2} \mathrm{Gd}_{0.2}\right)_{2} \mathrm{Si}_{2} \mathrm{O}_{7}$ environmental barrier coating (EBC) on carbon fiber-reinforced silicon carbide composites $\left(\mathrm{C}_{\mathrm{f}} / \mathrm{SiC}\right)$ by a slurry paste process, in which liquid polysilazane was dissolved in ethanol and mixed with $\left(\mathrm{Yb}_{0.2} \mathrm{Y}_{0.2} \mathrm{Lu}_{0.2} \mathrm{Sc}_{0.2} \mathrm{Gd}_{0.2}\right)_{2} \mathrm{Si}_{2} \mathrm{O}_{7}$ powders and then $\mathrm{Ba}_{0.5} \mathrm{Sr}_{0.5} \mathrm{Al}_{2} \mathrm{Si}_{2} \mathrm{O}_{7}$ was added as a sintering aid to lower the sintering temperature. After $1250{ }^{\circ} \mathrm{C}$ and up to $300 \mathrm{~h}$ test in $50 \% \mathrm{H}_{2} \mathrm{O}-50 \% \mathrm{O}_{2}$ environment, the $\left(\mathrm{Yb}_{0.2} \mathrm{Y}_{0.2} \mathrm{Lu}_{0.2} \mathrm{Sc}_{0.2} \mathrm{Gd}_{0.2}\right)_{2} \mathrm{Si}_{2} \mathrm{O}_{7}$ coated $\mathrm{C}_{\mathrm{f}} / \mathrm{SiC}$ exhibited significantly reduced weight loss and high residual strength compared to the uncoated $\mathrm{C}_{\mathrm{f}} / \mathrm{SiC}$ composite.

Sputtering, including reactive RF magnetron sputtering, DC sputtering, and multi-metal co-sputtering, can be used to make hard and corrosion resistant HE nitride, carbide and oxide films. For example, Chen et al. [150] deposited $\mathrm{HE}$ nitride films using $\mathrm{Fe}-\mathrm{Co}-\mathrm{Ni}-\mathrm{Cr}-\mathrm{Cu}-$ $\mathrm{Al}-\mathrm{Mn}$ and $\mathrm{Fe}-\mathrm{Co}-\mathrm{Ni}-\mathrm{Cr}-\mathrm{Cu}-\mathrm{Al}_{0.5}$ alloys as target materials through reactive sputtering and found that the measured hardness of nitride films (11 GPa) was significantly higher than that of alloy films (4 GPa). In addition, (AlCrTaTiZr)N [151,152], (AlCrTaTiZr) $-\mathrm{Si}_{x}-\mathrm{N}$ [153], $\left(\mathrm{Al}_{23.1} \mathrm{Cr}_{30.8} \mathrm{Nb}_{7.7} \mathrm{Si}_{7.7} 7 \mathrm{Ti}_{30.7}\right) \mathrm{N}_{50},\left(\mathrm{Al}_{29.1} \mathrm{Cr}_{30.8} \mathrm{Nb}_{11.2} \mathrm{Si}_{7.7} \mathrm{Ti}_{21.2}\right) \mathrm{N}_{50}$ [154], (TiAlCrSiV) ${ }_{x} \mathrm{~N}_{y}$ [155], (CuSiTiYZr)C [158], $(\mathrm{CrNbSiTiZr}) \mathrm{C}_{x}[159], \mathrm{Al}_{x} \mathrm{CoCrCuFeNi}(x=0.5,1,2)$ oxide [160], and $\mathrm{AlCoCrCu}{ }_{0.5} \mathrm{NiFe}$ oxide [116] films were also prepared by reactive RF sputtering. The influence of atmosphere components and their ratio, substrate bias voltage and gas flux rate on the microstructure, mechanical and tribological properties of the HE coatings has been investigated to find optimized processing conditions for harder and more corrosion-resistant HE coatings. For example, the highest hardness $(29.5 \mathrm{GPa})$, lowest friction coefficient $(\sim 0.15)$, and best wear-corrosion resistance were reached for the (CuSiTiYZr)C coating with carbon/metal ratio of about 1.3 and $\mathrm{CH}_{4} /\left(\mathrm{CH}_{4}\right.$ and $\left.\mathrm{Ar}\right)$ flow rate as 0.50 [158].

Other methods have also been employed to prepare HE thin films. (TiZrHfVNbTa)C coatings [162] with hardness of 43-48 $\mathrm{GPa}$ and friction coefficient of $0.14-0.16$ at the loads $2.2-5.2 \mathrm{~N}$ were produced by ion scattering of a TiZrHfVNbTa alloy target in plasma of compressed vacuum-arc discharge. Thin (CrNbTaTiW)C (30-40 at \% C) films with different metal contents were deposited using non-reactive DC magnetron sputtering [163] and corrosion studies revealed that the (CrNbTaTiW)C (30-40 at\% C) films exhibited excellent corrosion resistance in $1.0 \mathrm{M} \mathrm{HCl}$, superior to that of a reference hyper-duplex stainless steel. Besides nitrides and carbides, $\mathrm{HE}$ boride $\left(\mathrm{Zr}_{0.23} \mathrm{Ti}_{0.20} \mathrm{Hf}_{0.19} \mathrm{~V}_{0.14} \mathrm{Ta}_{0.24}\right) \mathrm{B}_{2}$ thin film with improved hardness (47 GPa) was prepared by physical vapor deposition (PVD) method [164].

\section{Properties and tailoring methods}

\section{1 Phase stability}

Thermodynamically, the phase stability of HECs is determined by the Gibbs free energy, which can be defined as

$$
\Delta G_{\text {mix }}=\Delta H_{\text {mix }}-T \Delta S_{\text {mix }}
$$

where $H_{\text {mix }}$ is the mixing enthalpy, $S_{\text {mix }}$ is the mixing entropy, which can be expressed as

$$
\Delta S_{\text {conf }}=-R \sum_{x_{i}}\left(x_{i} \sum_{n} c_{j} \ln c_{j}\right)
$$

where $R, x_{i}, n$, and $c_{j}$ are the gas constant, fraction of 
the sublattice $i$, number of components, and atomic fraction of components $j$, respectively. Larger entropy favors lower Gibbs free energy and hence phase stability. Rost et al. [29] initially pointed out the critical role of configurational entropy in stabilizing $(\mathrm{MgCoCuNiZn}) \mathrm{O}$, in spite of an enthalpic penalty associated with the structure transition of $\mathrm{CuO}$ and $\mathrm{ZnO}$ from tenorite and wurtzite to rock-salt. This effect is confirmed by the endothermic reaction of (MgCoCuNiZn)O and MD simulation [165], and thus utilized to predict and explain the stability of other high entropy systems, such as oxides, carbides, and borides [38,58,96,98]. Sarker et al. [104] developed an entropy related descriptor called entropy forming ability (EFA) to address the synthesizability of HECs from first-principles calculations, which is defined as

$$
E F A=\left(\sqrt{\frac{\sum_{i=1}^{n} g_{i}\left(H_{i}-H_{\text {mix }}\right)^{2}}{\left(\sum_{i=1}^{n} g_{i}\right)-1}}\right)^{-1}
$$

where $n$ is the total number of sampled geometrical configurations and $g_{i}$ are their degeneracies. $H_{\text {mix }}$ is the mixed-phase enthalpy approximated by averaging the enthalpies $H_{i}$ of the sampled configurations:

$$
H_{\text {mix }}=\sum_{i=1}^{n} g_{i} H_{i} / \sum_{i=1}^{n} g_{i}
$$

Large EFA corresponds to large entropy for a given composition. A total of 56 five-metal carbides were generated in their simulations and nine of them were synthesized, while six out of nine were single-phase high-entropy carbides. Combining simulations and experiments, they proposed a potential threshold for 5-metal carbides that could form single phase: EFA larger than $50(\mathrm{eV} / \text { atom })^{-1}$. In addition, by utilizing large configurational entropy, it is possible to stabilize the unstable phase to ambient conditions and improve the phase stability at high temperatures, as demonstrated in silicides, silicates, phosphates, niobates, and tantalates $[33,71,88,92]$.

Besides configurational entropy, the phase stability of HECs could be affected by the size and charge of the constituent elements. Djenadic et al. [30] found the important role of $\mathrm{Ce}$ in the formation of fluoritestructured high-entropy rare earth oxides. The systems without $\mathrm{Ce}$ could not form single-phase fluorite. They suggested that the oxidation state $(+4)$ and size ratio of
Ce to oxygen atom are the main factors in the stabilization of fluorite structure. Transformation from bixbyite $(I a \overline{3})$ structure to fluorite structure is found in $\mathrm{Ce}-\mathrm{Gd}-\mathrm{Nd}-\mathrm{Pr}-\mathrm{Sm}-\mathrm{O}$ and $\mathrm{Ce}-\mathrm{Gd}-\mathrm{La}-\mathrm{Nd}-\mathrm{Pr}-\mathrm{O}$ systems with the addition of Mo [69]. High oxidation state of Mo $(+6)$ seems to be responsible. Intriguingly, the atomic size difference $(\delta)$ is one of the main factors that influence the formation of single phases in HEAs, where the threshold is $6.5 \%$ [29]. Nevertheless, in HECs, single phases are still observed in the systems with $\delta$ larger than $6.5 \%$ [71,76,88]. Jiang et al. [76] proposed that the Goldschmidt tolerance factor $(t)$ was a useful parameter in predicting the stability of high-entropy perovskites. They found that the systems with unity tolerance factor tended to form single phase in spite of large size difference. It is also suggested that having unity tolerance factor is a necessary, but not sufficient, condition for forming single phases [76].

Some more interesting phenomena regarding phase stability of HECs are observed. Jiang et al. [76] found precipitation in the high temperature treated $\mathrm{Sr}$ - and Ba-based high-entropy perovskites. The dissolution of high-entropy ceramics is opposite to the concept of entropy-stabilization. In a very recent work, Qiu et al. [45] synthesized an entropy stabilized $(\mathrm{Ca}, \mathrm{Sr}, \mathrm{Ba}) \mathrm{ZrO}_{3}$ with tetragonal perovskite structure from orthogonal perovskite structural $\mathrm{CaZrO}_{3}, \quad \mathrm{SrZrO}_{3}$, and cubic perovskite structural $\mathrm{BaZrO}_{3}$. The structure of final product is different from those of all raw materials. These intriguing results demonstrate the complexity of phase stability of HECs due to their vast and complex chemical and structure space, which warrants investigations theoretically and experimentally.

\section{2 Hardness and strength}

For HEAs, Yeh et al. [1,3,7] attributed the excess strength to severe lattice distortion, which is one of the four core effects of HEAs. The severe lattice distortion results in pining of dislocations which provides excess strength. Lattice strain arises from the atomic radius difference and elastic modulus mismatch between the constituent elements. According to the model of TodaCaraballo and Rivera-Díaz-del-castillo [166], solidsolution strengthening effect can be expressed by

$$
\Delta_{\mathrm{SS}, \mathrm{HEA}}=\left(\sum_{i} B_{i, \mathrm{~L}}^{3 / 2} x_{i}\right)^{3 / 2}
$$

where $x_{i}$ is the atomic fraction, $B_{i}$ is a hardening 
parameter depending upon atomic radius difference, shear modulus, and Young's modulus misfit. From Eq. (4.5), a pronounced strengthening and hardening are anticipated [167]. Similar to HEAs, strengthening and hardening have been widely observed in HECs. Csanádi et al. [168] investigated the strength and slip behavior of grains of a high-entropy carbide (Hf-Ta-Zr-Nb)C during micropillar compression. Significantly enhanced yield and failure strength were observed. Intriguingly, this high-entropy ( $\mathrm{Hf}-\mathrm{Ta}-\mathrm{Zr}-\mathrm{Nb}) \mathrm{C}$ exhibits a hardness of $36 \mathrm{GPa}$ [143], being much higher than the constituting components. Actually, for most current investigated HECs, the measured hardness values are well beyond the values estimated from the rule of mixture. Very recently, superhard high-entropy transition metal monoborides were reported [95,97]. TEM images of $\left(\mathrm{Mo}_{0.2} \mathrm{Ta}_{0.2} \mathrm{Ni}_{0.2} \mathrm{Cr}_{0.2} \mathrm{~W}_{0.2}\right) \mathrm{B}$, which has Vickers of $48.51 \pm 4.07 \mathrm{GPa}$ measured at $0.49 \mathrm{~N}$, show a high density of dislocations pinned within the $\left(\mathrm{Mo}_{0.2} \mathrm{Ta}_{0.2} \mathrm{Ni}_{0.2} \mathrm{Cr}_{0.2} \mathrm{~W}_{0.2}\right) \mathrm{B}$ grains [95], indicating the severe lattice distortion. This hardening mechanism is supported by the work of Wang et al. [169], who investigated the irradiation damage in $\left(\mathrm{Zr}_{0.25} \mathrm{Ta}_{0.25} \mathrm{Nb}_{0.25} \mathrm{Ti}_{0.25}\right)$ C. They observed irradiationinduced hardness increase, which was possibly caused by dislocation loops and lattice strain. One of the main important reasons for the severe lattice distortion in $\left(\mathrm{Mo}_{0.2} \mathrm{Ta}_{0.2} \mathrm{Ni}_{0.2} \mathrm{Cr}_{0.2} \mathrm{~W}_{0.2}\right) \mathrm{B}$ is that the constituting components have not only atomic radius mismatch but also different type of crystal structures. The significance of this work is that it opens new windows for designing new superhard materials through the formation of solid solutions from constituting components with big atomic mismatch and different crystal structures.

In addition to room temperature strengthening, the flexural strength can be maintained up to $1800{ }^{\circ} \mathrm{C}$ for high-entropy carbide (HfZrTiTaNb)C and $1600{ }^{\circ} \mathrm{C}$ for medium-entropy carbide (TaZrNb)C [170,171], demonstrating significant high-temperature strengthening. High-temperature strengthening was also demonstrated by recent investigation on the creep behavior of (TaHfZrNb)C [172]. As reported by Han et al. [172], due to the lattice distortion and the good thermodynamic stability of high-entropy (TaHfZrNb)C at elevated temperatures, the measured steady-state creep rates are approximately 10 times lower than those of the corresponding monocarbides. These results are appealing for their application in ultrahigh temperature environment.
In contrast to HEAs, high fracture toughness or low temperature ductility was not observed in HECs. The exceptional ductility and fracture toughness of HEAs are attributed to the extremely low stacking fault energy (SFE) and easy twinning $[1,10,173]$. Such mechanism may not work for ceramic materials. The available data revealed that the room temperature mechanical properties of HECs are comparable to their constituting components. For example, the four-point flexural strength $(421 \pm 27 \mathrm{MPa})$, fracture toughness $\left(3.5 \pm 0.3 \mathrm{MPa} \cdot \mathrm{m}^{1 / 2}\right)$, and Young's modulus $(450 \mathrm{GPa})$ but Vickers hardness $(25.0 \pm 1.0 \mathrm{GPa}$ at a load of $4.9 \mathrm{~N})$ are close to those of single components [170]. Brittleness index [174] $B=H / K_{\mathrm{IC}}$ and damage tolerance index $D_{\mathrm{t}}=K_{\mathrm{IC}} \cdot E / \sigma_{\mathrm{b}} \cdot H \quad[175]$ are quantitative measure of brittleness and damage tolerance of ceramics, where $H, K_{\mathrm{IC}}, E$, and $\sigma_{\mathrm{b}}$ are Vickers hardness, fracture toughness, Young's modulus, and flexural strength. High brittleness index or low damage tolerant index is an indication of brittleness. The higher hardness and strength but comparable fracture toughness and Young's modulus imply that the high-entropy carbide [170] has become more brittle. The very recent work by Sun et al. [176] clearly indicated that high-entropy bixbyite structured oxides $\mathrm{RE}_{2} \mathrm{O}_{3}(\mathrm{RE}=\mathrm{Sm}, \mathrm{Eu}, \mathrm{Er}, \mathrm{Lu}, \mathrm{Y}$, and $\mathrm{Yb})$ had higher brittleness and lower damage tolerance values, implying that they are more brittle than the single component like $\mathrm{Y}_{2} \mathrm{O}_{3}$. Needless to say, more works are needed to confirm the brittleness of HECs.

\section{3 Thermal conductivity}

Lattice distortion and mass disorder are the main features of high-entropy ceramics. Controlled by the scattering process of phonons and electrons, the reduction of thermal conductivity $(\kappa)$ for these materials is a natural deduction, since these structure features are efficient scattering sources for phonons and electrons. We have summarized the thermal conductivity of several high-entropy material systems [19,35-40, $43,44,58,68,71,73,74,79,86-88,90-93,95,102,130,177-$ 181] and presented the results in Fig. 4.1. For all high-entropy material systems, the diminishment in thermal conductivity is reported. However, few researches have investigated this phenomenon in depth to reveal the mechanism behind the deterioration. Braun et al. [19] investigated the thermal conductivity of $(\mathrm{MgCoNiCuZn}) \mathrm{O}$ and found that with the addition of sixth cation ( $\mathrm{Sc}, \mathrm{Sb}, \mathrm{Sn}, \mathrm{Cr}$, or $\mathrm{Ge}$ ), $50 \%$ reduction 


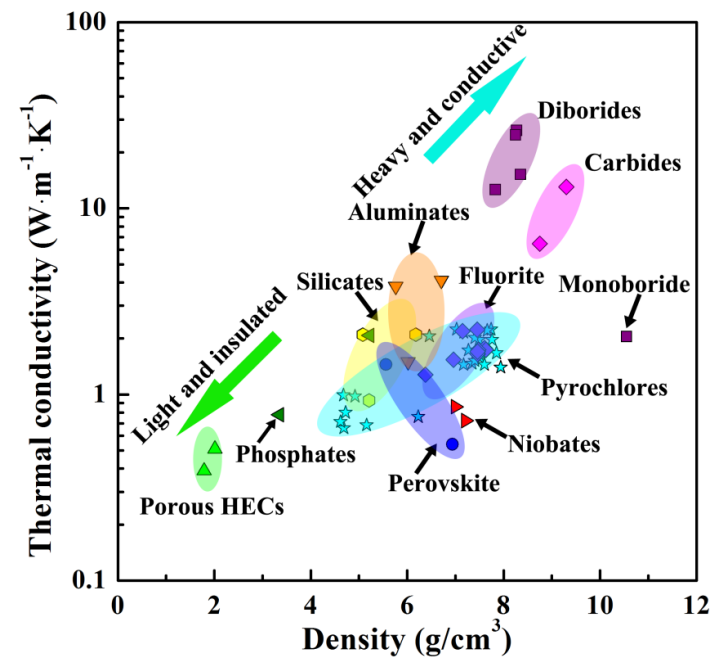

Fig. 4.1 Summarized thermal conductivity of some typical high-entropy oxides, carbides, and borides.

in thermal conductivity could be achieved. Using a virtual crystal approximation (VCA) model, they attributed the amorphous or glass-like thermal conductivity to disorder in interatomic force constants (IFC) rather than mass and size disorder, which was verified by EXAFS analysis and molecular dynamics simulation. Their results also demonstrated that it was possible to achieve ultralow thermal conductivity without the expense of a crystal's stiffness by local ionic charge disorder. Wright et al. [73] investigated a series of 22 single-phase pyrochlores, including 18 compositionally-complex (i.e., medium- and highentropy) pyrochlore oxides (CCPOs) and four additional "low-entropy" benchmark compositions. They tried to establish the relationship between thermal conductivity of these oxides and structure parameters, such as mass disorder, size disorder, density, and mixing configurational entropies. They found that size disorder parameter was a more effective descriptor to forecast reduced thermal conductivity than the ideal mixing configurational entropy, and severe lattice distortion was significant in reducing the thermal conductivity. Guided by this concept, they broadened HECs to compositionally-complex ceramics to achieve lower thermal conductivity in ceramics with severe size disorder but medium configurational entropy [103]. They found that in their YSZ-like fluorite oxides, the nominal oxygen vacancy concentration resulted in the amorphous-like thermal behavior. The presence of disordered vacancies increased the distortion on the anion sublattice and would likely lead to clustering and potentially ordering of the oxygen vacancies that suppressed the point defect scattering.

Besides HEOs, investigation on the thermal conductivity of metallic carbides and borides are also conducted. Due to the contribution from electrons, the thermal conductivity of these metallic HEMs are considerable large than oxides, as shown in Fig. 4.1. Wen et al. [180] separated the thermal conductivity of phonons and electrons for three HEMs, $\left(\mathrm{Hf}_{0.2} \mathrm{Zr}_{0.2} \mathrm{Ta}_{0.2} \mathrm{Nb}_{0.2} \mathrm{Ti}_{0.2}\right) \mathrm{C},\left(\mathrm{Hf}_{0.2} \mathrm{Zr}_{0.2} \mathrm{Ta}_{0.2} \mathrm{Nb}_{0.2} \mathrm{Ti}_{0.2}\right) \mathrm{N}$, and $\left(\mathrm{Hf}_{0.2} \mathrm{Zr}_{0.2} \mathrm{Ta}_{0.2} \mathrm{Nb}_{0.2} \mathrm{Ti}_{0.2}\right)\left(\mathrm{N}_{0.5} \mathrm{C}_{0.5}\right)$, using a simple empirical relationship. They found that the contributions of electrons for three materials were nearly the same, while the phonon thermal conductivity of nitride and carbonitide was much lower than that of carbide. Rost et al. [182] investigated the electron and phonon thermal conductivity in high-entropy carbides with variable carbon contents. Their measurements of $\kappa_{\text {total }}$ and resulting calculations of $\kappa_{\mathrm{e}}$ and $\kappa_{\mathrm{p}}$ showed a cross-over from electron-dominated thermal conductivity to phonon-dominated thermal conductivity as the primary bonding character in the HEC films transitioned from metallic to covalent with increasing of methane content. In carbon-rich HECs, $\kappa_{\mathrm{e}}$ kept constant, while $\kappa_{\mathrm{p}}$ was affected by a combination of changes in microstructure, defect concentration and secondary phase formation, and stiffness. Although the thermal conductivity of $\mathrm{HE}$ carbides and borides is significantly lower than their monolithic constituents $[177,180]$, it is still too high for thermal insulating. To decrease the thermal conductivity of $\mathrm{HE}$ carbides and borides further, Chen et al. [22,40] employed a gas-released in situ reaction followed by high-temperature sintering to fabricate porous $\mathrm{HE}\left(\mathrm{Zr}_{0.2} \mathrm{Hf}_{0.2} \mathrm{Ti}_{0.2} \mathrm{Nb}_{0.2} \mathrm{Ta}_{0.2}\right) \mathrm{C}$ and $\left(\mathrm{Zr}_{0.2} \mathrm{Hf}_{0.2} \mathrm{Nb}_{0.2} \mathrm{Ta}_{0.2} \mathrm{Ti}_{0.2}\right) \mathrm{B}_{2}$. The grain and pore size distribution was uniform and the thermal conductivity of these porous ceramics was only $c a 1 / 20$ of the dense high entropy ones, as shown in Fig. 4.1.

Theoretically predicting the lattice thermal conductivity for HECs is appealing due to the ability of modeling to reveal the micro-mechanism of transportation, screen material systems, and tune the thermal property. Lim et al. [183] constructed a cell containing a total of 30,720 atoms and calculated the thermal conductivity of $\mathrm{J} 14 \quad\left(\mathrm{Mg}_{0.2} \mathrm{Co}_{0.2} \mathrm{Ni}_{0.2} \mathrm{Cu}_{0.2} \mathrm{Zn}_{0.2}\right) \mathrm{O}$ as well as J14 plus Sc, Sn, Cr, or Ge in equal-molar cation proportions by MD. The thermal conductivity was calculated using the Green-Kubo method, and the interatomic potential was modeled using a pair sum of an exponential-6 function and long-range Coulomb 
interactions. They controlled the atomic mass and charge in the interatomic potential to identify the main factor that determines the thermal behavior of these HEOs. They found that phonon scattering from charge disorder was responsible for the lowering of thermal conductivity with the addition of a sixth cation. It is worth noting that the interatomic potentials in classical MD are oversimplied, and the accuracy is not guaranteed. To tackle this problem, Dai et al. [50,52] employed a deep leaning potential to investigate lattice thermal conductivity of $\mathrm{HE}\left(\mathrm{Zr}_{0.2} \mathrm{Hf}_{0.2} \mathrm{Ti}_{0.2} \mathrm{Nb}_{0.2} \mathrm{Ta}_{0.2}\right) \mathrm{C}$ and $\left(\mathrm{Zr}_{0.2} \mathrm{Hf}_{0.2} \mathrm{Nb}_{0.2} \mathrm{Ta}_{0.2} \mathrm{Ti}_{0.2}\right) \mathrm{B}_{2}$. They found that the predicted lattice thermal conductivity of these two HECs was rather low, which is consistent with experiments.

\section{4 Thermal expansion}

For the applications of HECs that involve high temperature, thermal expansion is a critical but less investigated property. Intrinsic thermal expansion of a material is related to the lattice energy which is determined by its composition, structure, and bonding. Generally, materials with higher lattice energy exhibit lower thermal expansion coefficients (TECs). The complex composition, distorted lattice, and various bonding in HECs compared with single component systems lead to unexpected behavior of TECs. Experimentally, the average TEC can be probed by a high temperature push-rod dilatometer or an optical dilatometer [71,91,93], while the anisotropic TEC can be obtained from high-temperature powder XRD or high temperature push-rod dilatometer using single crystals [23,85,86,90,91]. Yan et al. [35] measured the thermal expansion of (TiZrHfNbTa)C at $25-300{ }^{\circ} \mathrm{C}$, and the TEC of HE carbides did not show significant deviation from the binary carbides. Zhao et al. [71,93, 181] systematically investigated TECs of several high entropy oxides, such as $\left(\mathrm{La}_{0.2} \mathrm{Ce}_{0.2} \mathrm{Nd}_{0.2} \mathrm{Sm}_{0.2} \mathrm{Eu}_{0.2}\right) \mathrm{PO}_{4}$, $\left(\mathrm{Sm}_{1 / 6} \mathrm{Eu}_{1 / 6} \mathrm{Y}_{1 / 6} \mathrm{Yb}_{1 / 6} \mathrm{Lu}_{1 / 6} \mathrm{Er}_{1 / 6}\right)_{3}\left(\mathrm{Nb}_{1 / 2} \mathrm{Ta}_{1 / 2}\right) \mathrm{O}_{7}$, $\left(\mathrm{Y}_{0.2} \mathrm{Yb}_{0.2} \mathrm{Er}_{0.2} \mathrm{Lu}_{0.2}\right)_{2}\left(\mathrm{Zr}_{0.5} \mathrm{Hf}_{0.5}\right)_{2} \mathrm{O}_{7}$. They observed an obvious decrease in thermal expansion of HEOs compared to their single component counterparts and proposed that the high entropy effect hindered the oscillation amplitude of constituting atoms by severe lattice distortion and decreased the thermal expansion [71]. Meanwhile, increase in TECs of $\left(\mathrm{Y}_{0.2} \mathrm{Nd}_{0.2} \mathrm{Sm}_{0.2} \mathrm{Eu}_{0.2} \mathrm{Er}_{0.2}\right) \mathrm{AlO}_{3},\left(\mathrm{Yb}_{0.25} \mathrm{Y}_{0.25} \mathrm{Lu}_{0.25} \mathrm{Er}_{0.25}\right)_{2} \mathrm{SiO}_{5}$, $\left(\mathrm{Y}_{0.2} \mathrm{Yb}_{0.2} \mathrm{Lu}_{0.2} \mathrm{Eu}_{0.2} \mathrm{Er}_{0.2}\right)_{3} \mathrm{Al}_{5} \mathrm{O}_{12},\left(\mathrm{Nd}_{0.2} \mathrm{Sm}_{0.2} \mathrm{Eu}_{0.2} \mathrm{Y}_{0.2} \mathrm{Yb}_{0.2}\right)_{4} \mathrm{Al}_{2} \mathrm{O}_{9}$ had also been reported $[23,85,90,91]$. To illustrate the anisotropy in thermal expansion, Zhao et al. $[23,91]$ and Chen et al. [85] used high-temperature powder XRD to explore the structure change of HECs with temperature. Interestingly, the anisotropy of thermal expansion is dependent on the material systems. For $\left(\mathrm{Nd}_{0.2} \mathrm{Sm}_{0.2} \mathrm{Eu}_{0.2} \mathrm{Y}_{0.2} \mathrm{Yb}_{0.2}\right)_{4} \mathrm{Al}_{2} \mathrm{O}_{9}$ and $\left(\mathrm{Yb}_{0.25} \mathrm{Y}_{0.25} \mathrm{Lu}_{0.25} \mathrm{Er}_{0.25}\right)_{2} \mathrm{SiO}_{5}$, the anisotropy in TECs increased, while for $\left(\mathrm{Y}_{0.2} \mathrm{Nd}_{0.2} \mathrm{Sm}_{0.2} \mathrm{Eu}_{0.2} \mathrm{Er}_{0.2}\right) \mathrm{AlO}_{3}$, the TECs were more isotropic. In the investigation on anisotropy of TEC for $\left(\mathrm{Nd}_{0.2} \mathrm{Sm}_{0.2} \mathrm{Eu}_{0.2} \mathrm{Y}_{0.2} \mathrm{Yb}_{0.2}\right)_{4} \mathrm{Al}_{2} \mathrm{O}_{9}$, Zhao et al. [91] employed a simple theory called chemical bonding theory (CBT) to describe their observation quantitatively. They found that bond energies of $\mathrm{Al}-\mathrm{O}$ bonds were significantly higher than those of RE-O, indicating that the chemical environments around RE atoms determined the expansion behavior of HEOs. The energy changing for different RE-O bonds was anisotropic: the bonds with large energy degradation were almost parallel with $a b$ plane, leading to the increase of anisotropy in bonding strength between $a b$ plane and $c$ direction. Ridley et al. [86] used the same technique to investigate the anisotropic thermal expansion of $\mathrm{X} 2-(\mathrm{ScYDyErYb})_{2} \mathrm{SiO}_{5}$. They found that linear CTE generally followed the rule of mixture (ROM), while the $c$-axis CTE show larger differences. They attributed this deviation to the rigid $\mathrm{Si}-\mathrm{O}$ tetrahedron in the structure interacted less with incorporated elements. The thermal expansions of reported HEMs are summarized in Fig. 4.2. These preliminary researches have revealed the complexity of structure response of HECs to temperature due to their

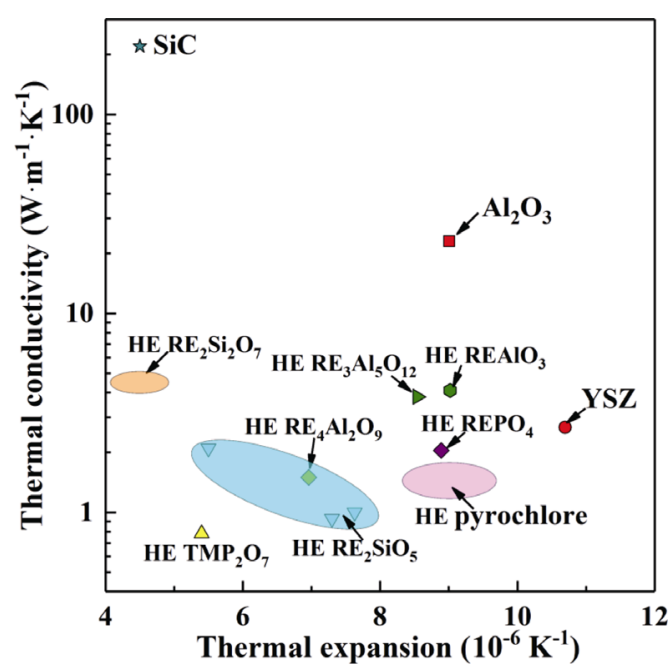

Fig. 4.2 Relationship of thermal conductivity and thermal expansion of some HEOs based on the reported values. 
complex composition, lattice, and bonding. However, they also demonstrate the possibility of tailoring the thermal expansion of HECs by composition design.

Composition design requires large-scale screening of different combinations of elements. Theoretical prediction is regarded as an efficient and feasible tool to achieve automatic and low-cost screening process. Calculating the thermal expansion is accessible by DFT and molecular dynamics (MD). Yang et al. [184] constructed SQS supercells with 64 atoms for (TaNbHfTiZr)C and (TaNbHfTiZr)N, and they used Debye-Grüneisen model to estimate the thermal expansion of these two HECs using the Helmholtz free energy calculated from DFT. The room temperature TEC they estimated was much smaller than the experiment data reported by Yan et al. [35]. Possible explanation is that the Helmholtz free energy $(F)$ was treated by the Debye-Grüneisen model, which discards the volume-dependence of $F$. Dai et al. [50,52] employed a deep leaning potential, which combined the accuracy of DFT and efficiency of MD, to calculate the properties of (TaNbHfTiZr)C and (TaNbHfTiZr) $\mathrm{B}_{2}$. The lattice parameter and thermal properties of high-entropy carbide agreed well with experiment, with the TEC slightly higher than experiments. While for high-entropy boride, the TECs along $a$ and $c$ directions at room temperature were estimated as 8.55 and $8.39 \times 10^{-6} \mathrm{~K}^{-1}$, respectively. Large expansion along $a$ direction is unusual since strong covalent $\mathrm{B}-\mathrm{B}$ bond net is parallel to the $a b$ plane. Considering the chemical complexity of high-entropy borides, the inaccurately fitted deep learning potential was believed to be responsible for the unexpectedly large thermal expansion along $a$ direction.

Unlike thermal conductivity, the thermal expansion of HECs is far from understood. The effect of different constituents on the linear and anisotropic TECs of HECs and methods to tune the thermal expansion to meet the requirement of their applications are still blurry, and theoretical methods for accurate prediction of TECs in HECs are still awaited.

\section{5 Oxidation and CMAS corrosion}

\subsubsection{Oxidation}

Ultrahigh temperature ceramics (UHTCs) are materials of choice for the nose tip and leading edges of hypersonic vehicles. However, easy oxidation under high temperature and oxygen-containing conditions is one of the obstacles for their applications. In order to adapt to the stringent demands of hypersonic vehicles, a new type of high-entropy UHTCs with better oxidation resistance has been developed.

Gild et al. [34] first developed a variety of high-entropy borides (HEBs), which exhibited much better oxidation resistance than the individual borides at $1000-1200{ }^{\circ} \mathrm{C}$ for $1 \mathrm{~h}$. Following this work, oxidation behaviors of high-entropy carbides $\left(\mathrm{Hf}_{0.2} \mathrm{Zr}_{0.2} \mathrm{Ta}_{0.2} \mathrm{Nb}_{0.2} \mathrm{Ti}_{0.2}\right) \mathrm{C}$ [185-188] and $\left(\mathrm{Hf}_{0.25} \mathrm{Zr}_{0.25} \mathrm{Ta}_{0.25} \mathrm{Nb}_{0.25}\right) \mathrm{C}[189,190]$ were investigated by several research groups. Similar to HEBs, all these high-entropy carbides exhibited better oxidation resistance than the individual transition-metal carbides. However, the oxidation mechanism of high-entropy carbides is debatable. Ye at al. $[185,186]$ pointed out that the oxidation of $\left(\mathrm{Hf}_{0.2} \mathrm{Zr}_{0.2} \mathrm{Ta}_{0.2} \mathrm{Nb}_{0.2} \mathrm{Ti}_{0.2}\right) \mathrm{C}$ was mainly controlled by the inward diffusion of oxidant based on the oxidation activation energy. In contrast, Wang et al. [187] observed the formation of Ti-depleted layer and proposed that outward diffusion of TiO was the controlling-step. This mechanism was supported by thermodynamic calculations indicating that $\mathrm{TiO}$ was easily formed with large vapor pressure of $\mathrm{TiO}$ during high-temperature oxidation and re-oxidation experiments showing that the weight gain curve during re-oxidation followed the original oxidation curve [187]. It is worth noting that the vapor pressure of $\mathrm{TiO}$ at high temperatures is even higher than that of $\mathrm{SiO}$, which is often considered as the diffusion species in traditional UHTC-SiC systems [191-193]. Therefore, the outward diffusion of TiO was also observed in the oxidation process of $\left(\mathrm{Hf}_{0.2} \mathrm{Zr}_{0.2} \mathrm{Ta}_{0.2} \mathrm{Nb}_{0.2} \mathrm{Ti}_{0.2}\right) \mathrm{C}-\mathrm{SiC}$ ceramics, even with the addition of $\mathrm{SiC}$ [188]. The removal of $\mathrm{TiC}$ from $\left(\mathrm{Hf}_{0.2} \mathrm{Zr}_{0.2} \mathrm{Ta}_{0.2} \mathrm{Nb}_{0.2} \mathrm{Ti}_{0.2}\right) \mathrm{C}$ to form $\left(\mathrm{Hf}_{0.25} \mathrm{Zr}_{0.25} \mathrm{Ta}_{0.25} \mathrm{Nb}_{0.25}\right) \mathrm{C}$ could avoid the formation of high vapor-pressure TiO during oxidation process [189]. A dense oxidation layer was observed and no depleted layer was found in the oxidized $\left(\mathrm{Hf}_{0.25} \mathrm{Zr}_{0.25} \mathrm{Ta}_{0.25} \mathrm{Nb}_{0.25}\right) \mathrm{C}$. In this case, the oxidation controlling step was transformed into oxidant inward diffusion. Wang et al. [190] also studied the oxidation of $\left(\mathrm{Hf}_{0.25} \mathrm{Zr}_{0.25} \mathrm{Ta}_{0.25} \mathrm{Nb}_{0.25}\right) \mathrm{C}$ and confirmed that the oxidation process was controlled by the diffusion of oxygen.

Regardless of whether the controlling process was species outward diffusion or oxidant inward diffusion, the formed oxide layers for $\left(\mathrm{Hf}_{0.2} \mathrm{Zr}_{0.2} \mathrm{Ta}_{0.2} \mathrm{Nb}_{0.2} \mathrm{Ti}_{0.2}\right) \mathrm{C}$ and $\left(\mathrm{Hf}_{0.25} \mathrm{Zr}_{0.25} \mathrm{Ta}_{0.25} \mathrm{Nb}_{0.25}\right) \mathrm{C}$ were not a single phase. 
Previous studies showed that $\mathrm{Hf} / \mathrm{Zr}$-rich oxide layer formed the outer layer followed by a $\mathrm{Ta} / \mathrm{Nb}$-rich oxide inner layer based on the similarity solution principle [186-191]. The formed sequential oxide layer structure during oxidation was mainly attributed to the selective oxidation among the multicomponent cations. As indicated by Backman et al. [194,195], the sequence of binding ability for the five transition metals for oxygen atoms was $\mathrm{Hf}>\mathrm{Zr}>\mathrm{Ti}>\mathrm{Ta}>\mathrm{Nb}$. Thus, the $\mathrm{Hf} / \mathrm{Zr}$-rich oxide would form first, followed by the $\mathrm{Ta} / \mathrm{Nb}$ oxide layer. Meanwhile, the metal-species would also diffuse outward into the formed oxide layer during oxidation even though the controlling process was the oxidant inward diffusion [189]. In the multicomponent oxide, the retarded diffusion of these metal-species might result in the slow thickening of the oxide layer, and thus greatly improve the oxidation resistance of the high-entropy carbides or borides.

It is interesting to note that the high-entropy nitride films of (AlCrTaTiZr)-Si $x_{x}-\mathrm{N},\left(\mathrm{Al}_{23.1} \mathrm{Cr}_{30.8} \mathrm{Nb}_{7.7} \mathrm{Si}_{7.7} \mathrm{Ti}_{30.7}\right) \mathrm{N}_{50}$, and $\left(\mathrm{Al}_{29.1} \mathrm{Cr}_{30.8} \mathrm{Nb}_{11.2} \mathrm{Si}_{7.7} \mathrm{Ti}_{21.2}\right) \mathrm{N}_{50}$ have both high hardness and good oxidation resistance [153-155]. These films are promising for applications as hard coatings for cutting tools.

\subsubsection{CMAS corrosion}

High-entropy thermal/environmental barrier coatings (T/EBCs) have been developed in recent years to meet the requirements for next generation turbines [23,37, 196,197]. These coatings demonstrated improved thermophysical $[23,37,196,197]$ and mechanical properties [196] as well as excellent high-temperature stability $[43,88]$. Thus, they can protect substrate materials (superalloys or ceramic matrix composites (CMCs)) from harsh thermal and environmental attacks.

Since the coatings for next generation turbines would work at temperatures higher than $1300{ }^{\circ} \mathrm{C}$, the attack from molten calcia-magnesia-aluminosilicate (CMAS) is of great concern. The interaction behaviors of high-entropy T/EBCs with CMAS are essential to qualify them as potential T/EBCs materials. For EBCs, Dong et al. [87] and Ren et al. [43] developed highentropy disilicate $\left(\left(\mathrm{Yb}_{0.2} \mathrm{Y}_{0.2} \mathrm{Lu}_{0.2} \mathrm{Sc}_{0.2} \mathrm{Gd}_{0.2}\right) \mathrm{Si}_{2} \mathrm{O}_{7}\right)$ and monosilicate $\left(\left(\mathrm{Y}_{1 / 4} \mathrm{Ho}_{1 / 4} \mathrm{Er}_{1 / 4} \mathrm{Yb}_{1 / 4}\right) \mathrm{Si}_{2} \mathrm{O}_{5}\right)$, respectively, which exhibited more desirable properties (thermophysical and corrosion resistance) than their single constituents. Synergistic effects of the different kinds of RE elements play a key role in the improvement of properties. Sun et al. [89] studied the CMAS interaction behavior with high-entropy disilicate $\left(\left(\mathrm{Er}_{0.25} \mathrm{Tm}_{0.25} \mathrm{Yb}_{0.25} \mathrm{Lu}_{0.25}\right)_{2} \mathrm{Si}_{2} \mathrm{O}_{7}\right)$ at $1500{ }^{\circ} \mathrm{C}$. It was demonstrated that the high-entropy disilicate still followed the reaction-precipitation mechanism that has been proved in those individual constituents. The high-entropy disilicate dissolved when it came in contact with molten CMAS and the $\mathrm{Ca}-\mathrm{Si}-\mathrm{RE}$ containing apatite precipitated when the elements reached saturation in the molten glass. It should be noted that, compared with the single constituents such as $\gamma-\mathrm{Y}_{2} \mathrm{Si}_{2} \mathrm{O}_{7}, \beta-\mathrm{Sc}_{2} \mathrm{Si}_{2} \mathrm{O}_{7}$, $\beta-\mathrm{Yb}_{2} \mathrm{Si}_{2} \mathrm{O}_{7}$, and $\beta-\mathrm{Lu}_{2} \mathrm{Si}_{2} \mathrm{O}_{7}$, the resistance of highentropy disilicate against molten CMAS was significantly improved. These improvements in high-entropy disilicate can be mainly attributed to the slower dissolution rate and enhanced grain boundary stability, which may originate from the sluggish diffusion effect and lattice distortion introduced by the high-entropy disilicate. Regarding the TBCs, Wright et al. [198] recently reported the CMAS resistance of high-entropy fluorites, which can be potentially employed as TBC materials due to their promising thermophysical and mechanical properties $[23,37,43,196]$. The equimolar high-entropy fluorite also presented reaction and precipitation behavior at all examined temperatures $\left(1200-1500{ }^{\circ} \mathrm{C}\right)$ similar to high-entropy disilicate. They further compared the CMAS corrosion behaviors among high-entropy fluorite $\left(\left(\mathrm{Hf}_{0.2} \mathrm{Zr}_{0.2} \mathrm{Ce}_{0.2} \mathrm{Y}_{0.2} \mathrm{Yb}_{0.2}\right) \mathrm{O}_{2-\delta}\right)$, medium-entropy fluorites $\quad\left(\left(\mathrm{Hf}_{0.314} \mathrm{Zr}_{0.314} \mathrm{Ce}_{0.314} \mathrm{Y}_{0.029} \mathrm{Yb}_{0.029}\right) \mathrm{O}_{2-\delta}\right.$, $\left.\left(\mathrm{Hf}_{0.284} \mathrm{Zr}_{0.284} \mathrm{Ce}_{0.284} \mathrm{Y}_{0.074} \mathrm{Yb}_{0.074}\right) \mathrm{O}_{2-\delta}\right)$, and 8YSZ. The medium-entropy fluorites presented more resistance to molten CMAS than 8YSZ, which was evident by the obvious grain boundary infiltration layer in 8YSZ. Moreover, the high-entropy fluorite showed the most significant CMAS resistance at tested temperatures. Notably, there was no grain boundary infiltration layer in the high-entropy fluorite, which was seen in all other samples. The authors concluded that high-entropy fluorites have the highest reactivity rate with molten CMAS to form a dense apatite phase, which was beneficial for arresting grain boundary infiltration.

These experimental results showed significant improvement in resistance against molten CMAS in high-entropy T/EBC materials. High-entropy T/EBC materials tend to react with molten CMAS to form dense apatite phase. Moreover, a sluggish diffusion effect in HEMs retarded the atomic diffusion and thereby reduced further corrosion by CMAS. The above results provide a new perspective for the design of $\mathrm{T} / \mathrm{EBC}$ materials with comprehensive properties by 
high-entropy compositionally complex route.

\section{6 Irradiation resistance}

Investigations on HEAs revealed that the unique combination of superior mechanical properties, corrosion resistance, irradiation tolerance made them promising for nuclear applications [199-202]. Motivated by the achievement in HEAs, the irradiation effects of high-entropy carbides were also investigated [169,203]. In contrast to $\mathrm{ZrC}$, which is characterized by structural swelling (i.e., lattice parameter expansion) after neutron, proton, and ion irradiation [204], after $120 \mathrm{keV}$ helium ion irradiation at $25^{\circ} \mathrm{C}$, the coalescence of helium bubbles was significantly suppressed in $\left(\mathrm{Hf}_{0.2} \mathrm{Zr}_{0.2} \mathrm{Ta}_{0.2} \mathrm{Nb}_{0.2} \mathrm{Ti}_{0.2}\right) \mathrm{C}$ [203]. Wang et al. [169] further investigated the irradiation damage of $\left(\mathrm{Zr}_{0.25} \mathrm{Ta}_{0.25} \mathrm{Nb}_{0.25} \mathrm{Ti}_{0.25}\right) \mathrm{C}$. Through irradiation of $3 \mathrm{MeV}$ $\mathrm{Zr}$ ions to $20 \mathrm{dpa}$ at 25,300 , and $500{ }^{\circ} \mathrm{C}$, the rock-salt structure was maintained without phase transformation or amorphous formation, indicating good phase stability of $\left(\mathrm{Zr}_{0.25} \mathrm{Ta}_{0.25} \mathrm{Nb}_{0.25} \mathrm{Ti}_{0.25}\right) \mathrm{C}$. About $\sim 0.2 \%$ lattice expansion was revealed through XRD analysis. The irradiation-induced microstructures were comprised of defect clusters with diameters of several nanometers, without void formation or radiation-induced segregation at grain boundaries. Nanoindentation tests showed irradiation-induced hardness increase, which was attributed to the high density dislocation loops and lattice strain. These results demonstrated that highentropy carbides exhibit excellent damage tolerance and are promising for applications in generation-IV reactors.

\section{7 Electronic and ionic conductivity}

Lattice distortion has widely been used to reduce the electrical contribution to the thermal conductivity, thus for highly conductive ceramics like borides and carbides, electron scattering can be exacerbated resulting in reduced electrical conductivity in high-entropy borides and carbides [167]. Although theoretical calculations indicate that metallic conductivity is preserved in $\left(\mathrm{Hf}_{0.2} \mathrm{Zr}_{0.2} \mathrm{Ta}_{0.2} \mathrm{Nb}_{0.2} \mathrm{Ti}_{0.2}\right) \mathrm{B}_{2}$ [57] and $\left(\mathrm{Cr}_{0.2} \mathrm{Mn}_{0.2} \mathrm{Fe}_{0.2} \mathrm{Co}_{0.2} \mathrm{Mo}_{0.2}\right) \mathrm{B}$ [96], the experimentally measured electrical conductivity of $\left(\mathrm{Cr}_{0.2} \mathrm{Mn}_{0.2} \mathrm{Fe}_{0.2} \mathrm{Co}_{0.2} \mathrm{Mo}_{0.2}\right) \mathrm{B}\left((0.49 \pm 0.04) \times 10^{6} \mathrm{~S} / \mathrm{m}\right)$ is much lower than that of $\mathrm{CrB}\left(0.3 \times 10^{7} \mathrm{~S} / \mathrm{m}\right), \mathrm{FeB}$ $\left(0.5 \times 10^{7} \mathrm{~S} / \mathrm{m}\right)$, and $\mathrm{ZrB}_{2}\left(1.0 \times 10^{7} \mathrm{~S} / \mathrm{m}\right)$ [96]. For insulating ceramics such as oxides, the multi-component strategy can narrow the band gap [60] and increase defect species, making them semiconducting or mixed conducting. From this angle, the high-entropy concept provides new avenues for new material design through band gap engineering.

One of the breakthroughs of HECs is the high $\left.\begin{array}{lllll}\text { Li-ion conductivity }\left(>\quad 10^{-3}\right. & \mathrm{S} \cdot \mathrm{cm}^{-1}\end{array}\right)$ [21]. $(\mathrm{MgCoNiCuZn})_{1-x-y} \mathrm{Ga}_{y} \mathrm{~A}_{x} \mathrm{O}(\mathrm{A}=\mathrm{Li}, \mathrm{Na}, \mathrm{K})$ with rock-salt structure were fabricated and their electonic and ionic conductivities were systematically investigated. To the best of our knowledge, this is the first research work on the conductivity of HECs. On one hand, the electronic conductivity $\left(\sigma_{\mathrm{e}}\right)$ was investigated by monitoring the current density of the materials which were employed by a $1 \mathrm{~V}$ potential step over 2 days with blocking electrodes. According to Eq. (4.6):

$$
\sigma_{\mathrm{e}}=e I /(S \Delta E)
$$

where $e$ is the material thickness, $S$ is the active surface, $\Delta E$ is the applied voltage, and $I$ is the residual current intensity measured after 2 days, the electronic conductivity of the material was defined as $2 \times 10^{-9}$ $\mathrm{S} \cdot \mathrm{cm}^{-1}$. Therefore, these materials were regarded as electronic insulators. On the other hand, the room temperature $\mathrm{Li}^{+}$conductivity of the compounds with $\mathrm{Li}$ $>20 \%$ was found to exceed the ionic conductivity of LiPON by two orders of magnitude. These new materials are superionic lithium-ion conductors and fast-ionic sodium-ion conductors, with $\mathrm{Li}^{+}$conductivity exceeding $10^{-3} \mathrm{~S} \cdot \mathrm{cm}^{-1}$ and $\mathrm{Na}^{+}$conductivity reaching $5 \times 10^{-6} \mathrm{~S} \cdot \mathrm{cm}^{-1}$ at room temperature. The extremely high ionic conductivity of $(\mathrm{MgCoNiCuZn})_{1-x-y} \mathrm{Ga}_{y} \mathrm{~A}_{x} \mathrm{O}$ $(\mathrm{A}=\mathrm{Li}, \mathrm{Na}, \mathrm{K})$ was ascribed to the formation of abundant oxygen vacancies through a charge compensation mechanism [205]. When a monovalent element (e.g., $\mathrm{Li}^{+}$or $\mathrm{Na}^{+}$) is introduced, the concentration or the ordering of the oxygen vacancies as well as the size of the divalent cations in the compound can be optimized. That is, the insertion of Li-ions into a rock-salt structure opens several diffusion pathways for Li-ions through the crystal lattice, giving rise to the increased conductivity.

\section{8 Dielectric properties}

In high-entropy ceramics, there are more than one sublattices in which at least one sublattice site is occupied by multi-elements. The sublattice, on the one hand, exhibits long-range periodicity with the distortion that influences the behaviors of electrons, dipoles and band structure. On the other hand, random 
distributed multi-elements results in compositional disorder that reduces short range order. The ample type of HECs provide more flexible ways to tailor the composition, defects, disorder/order, band structure, in which dielectric properties are easily tuned.

The colossal dielectric constant, which is one of the important breakthroughs of HECs, was reported by Bérandan et al. [20] in rock-salt structured HEOs. The dielectric constant (the relative permittivity) for $(\mathrm{Mg}, \mathrm{Co}, \mathrm{Ni}, \mathrm{Cu}, \mathrm{Zn})_{0.95} \mathrm{Li}_{0.05} \mathrm{O}$ measured at $440 \mathrm{~K}$ and 20 $\mathrm{Hz}$ with an LCR bridge method was close to $2 \times 10^{5}$. Large values of dielectric constant were obtained for ( $\mathrm{Mg}, \mathrm{Co}, \mathrm{Ni}, \mathrm{Cu}, \mathrm{Zn}) \mathrm{O}$ family irrespective of substitutions as long as the high-entropy oxide phase was formed. For instance, the dielectric constant for high-entropy ( $\mathrm{Mg}, \mathrm{Co}, \mathrm{Ni}, \mathrm{Cu}, \mathrm{Zn}) \mathrm{O}$ without any substitution was larger than 1000 while the dielectric $\operatorname{loss}(\tan \delta)$ was lower than 0.01 measured at $313 \mathrm{~K}$ and $\mathrm{MHz}$ range.

Zhou et al. [206] investigated the dielectric properties of high-entropy perovskite oxides $\mathrm{Ba}\left(\mathrm{Zr}_{0.2} \mathrm{Ti}_{0.2} \mathrm{Sn}_{0.2} \mathrm{Hf}_{0.2} \mathrm{Me}_{0.2}\right) \mathrm{O}_{3}\left(\mathrm{Me}=\mathrm{Nb}^{5+}, \mathrm{Ta}^{5+}\right)$ and found that the dielectric constant and dielectric loss slightly decreased with the increasing of frequency from 1 to $1000 \mathrm{kHz}$. In the temperature from 303 to $473 \mathrm{~K}$, the dielectric constant and dielectric loss possess excellent stability at fixed frequency. The dielectric constant is in a range from 90 to 113 for $\mathrm{Ba}\left(\mathrm{Zr}_{0.2} \mathrm{Ti}_{0.2} \mathrm{Sn}_{0.2} \mathrm{Hf}_{0.2} \mathrm{Ta}_{0.2}\right) \mathrm{O}_{3}$ and 120 to 140 for $\mathrm{Ba}\left(\mathrm{Zr}_{0.2} \mathrm{Ti}_{0.2} \mathrm{Sn}_{0.2} \mathrm{Hf}_{0.2} \mathrm{Nb}_{0.2}\right) \mathrm{O}_{3}$ in the frequency from 1 to $1000 \mathrm{kHz}$. Intriguingly, the dielectric loss $(\tan \delta)$ is lower than 0.002 . The relatively low permittivity was attributed to a minor concentration of titanium in the $\mathrm{B}$-site sub-lattice and small grain size.

The dielectric relaxation of $\left(\mathrm{Na}_{0.2} \mathrm{Bi}_{0.2} \mathrm{Ba}_{0.2} \mathrm{Sr}_{0.2} \mathrm{Ca}_{0.2}\right) \mathrm{TiO}_{3}$ was studied by $\mathrm{Pu}$ et al. [129]. The dielectric peak was broad and shifted toward higher temperature with increasing frequency. Meanwhile, the dielectric loss increases with increasing frequency, which is similar to those for the relaxation of other ferroelectrics with perovskite structure. The degree of relaxation is 1.72, being close to the ideal relaxation ferroelectrics. Du et al. [207] investigated the dielectric properties of high-entropy $\mathrm{Ba}\left(\mathrm{Ti}_{1 / 6} \mathrm{Sn}_{1 / 6} \mathrm{Zr}_{1 / 6} \mathrm{Hf}_{1 / 6} \mathrm{Nb}_{1 / 6} \mathrm{Ga}_{1 / 6}\right) \mathrm{O}_{3}$ and found that the dielectric constants are on the order of 40-80 up to $1 \mathrm{MHz}$ and the dielectric loss tangents are in the neighborhood of 0.15 . The results also revealed the dielectric relaxation behavior of high-entropy perovskite ceramics. Liu et al. [208] investigated dielectric and energy storage properties of flash-sintered high-entropy $\left(\mathrm{Bi}_{0.2} \mathrm{Na}_{0.2} \mathrm{~K}_{0.2} \mathrm{Ba}_{0.2} \mathrm{Ca}_{0.2}\right) \mathrm{TiO}_{3}$ ceramic. The dielectric characterization reveals the relaxor ferroelectric nature of $\left(\mathrm{Bi}_{0.2} \mathrm{Na}_{0.2} \mathrm{~K}_{0.2} \mathrm{Ba}_{0.2} \mathrm{Ca}_{0.2}\right) \mathrm{TiO}_{3}$. The discharge energy storage density and efficiency of the as-prepared high-entropy $\left(\mathrm{Bi}_{0.2} \mathrm{Na}_{0.2} \mathrm{~K}_{0.2} \mathrm{Ba}_{0.2} \mathrm{Ca}_{0.2}\right) \mathrm{TiO}_{3}$ ceramic are $0.684 \mathrm{~J} / \mathrm{cm}^{3}$ and $87.5 \%$ under the electric field of $129 \mathrm{kV} / \mathrm{cm}$, respectively. Besides high-entropy oxides, high-entropy metal nitride composed of $\mathrm{V}, \mathrm{Cr}$, $\mathrm{Nb}$, Mo, $\mathrm{Zr}$, and $\mathrm{N}$ was reported to exhibit characteristics of a supercapacitor with a specific capacitance of $78 \mathrm{~F} / \mathrm{g}$ achieved at a scan rate of $100 \mathrm{mV} / \mathrm{s}$ in $1 \mathrm{M} \mathrm{KOH} \mathrm{[122].}$

\section{9 Magnetic properties}

The soft magnetic properties of HEAs aiming to reach high saturation magnetization and low coercivity are widely investigated [209]. Generally speaking, HEAs are good soft magnetic materials due to low concentration of elements with the highest net magnetic moments, which can be operated under alternating current with lower frequency (usually below $\mathrm{MHz}$ ) due to the nature of conductivity without a band gap. However, HECs are usually semiconductors or insulators with a band gap and possess higher electric resistivity (usually $\Omega \cdot \mathrm{cm}$ ), which can be applied at the higher frequency (above MHz) under alternating current operation. Compared to HEAs, investigations on magnetic properties of HECs are still in their nascent beginning.

Mao et al. [210] found that $(\mathrm{CoCrFeMnNi})_{3} \mathrm{O}_{4}$ basically exhibited a ferromagnetic behavior and $M-H$ loops showed a typical magnetic curves at room temperature. The saturation magnetization and coercivity of $(\mathrm{CoCrFeMnNi})_{3} \mathrm{O}_{4}$ changed in the range of 4.85 $15.98 \mathrm{emu} / \mathrm{g}$ and 176.55-21.39 Oe, respectively, depending on the synthesis temperature.

Mao et al. [211] also investigated the magnetic properties of rock-salt structured $\mathrm{Co}_{0.2} \mathrm{Cu}_{0.2} \mathrm{Mg}_{0.2} \mathrm{Ni}_{0.2} \mathrm{Zn}_{0.2} \mathrm{O}$ and found that nanocrystalline $\mathrm{Co}_{0.2} \mathrm{Cu}_{0.2} \mathrm{Mg}_{0.2} \mathrm{Ni}_{0.2} \mathrm{Zn}_{0.2} \mathrm{O}$ powders exhibited long-range ordered antiferromagnetic behavior below the Néel temperature $\left(T_{\mathrm{N}}=106 \mathrm{~K}\right)$, which was ascribed to the extreme chemical disorder of $\mathrm{Co}_{0.2} \mathrm{Cu}_{0.2} \mathrm{Mg}_{0.2} \mathrm{Ni}_{0.2} \mathrm{Zn}_{0.2} \mathrm{O}$ and the significant amount of nonmagnetic ions, compared to the monoxides $\mathrm{CoO}$, $\mathrm{NiO}$, and $\mathrm{CuO}$. The existence of long-range magnetic ordering in rock-salt structured $\mathrm{Co}_{0.2} \mathrm{Cu}_{0.2} \mathrm{Mg}_{0.2} \mathrm{Ni}_{0.2} \mathrm{Zn}_{0.2} \mathrm{O}$ below $120 \mathrm{~K}$ was also confirmed by Jimenez-Segura et al. [212]. Other rock-salt structured HEOs with various chemical substitutions were found to host 
either an antiferromagnetic order or a spin glass state depending on the amount of magnetic ions. Long range antiferromagnetic ordering below $T_{\mathrm{N}}=113 \mathrm{~K}$ was confirmed by a cusp in DC magnetic susceptibility, magnetic peaks in neutron powder diffraction, and strong magnetic excitations in inelastic neutron scattering [213]. The magnetic properties of rock-salt structured $\mathrm{Co}_{0.2} \mathrm{Cu}_{0.2} \mathrm{Mg}_{0.2} \mathrm{Ni}_{0.2} \mathrm{Zn}_{0.2} \mathrm{O}$ were also investigated using theoretical methods involving first-principles calculations in combination with Monte Cartlo (MC) simulations [214]. It was found that the material possessed a long range antiferromagnetic ground state in consistent with the literature [211-213]. The antiferromagnetic ordering was suppressed by the presence of $\mathrm{Mg}$ and $\mathrm{Zn}$, and the material became paramagnetic when the concentration of nonmagnetic cations exceeded 84\%. Meisenheimer et al. [215] reported on the magnetic ordering, anisotropy, and ordering temperature in the anisotropy of permalloy/ $\left(\mathrm{Mg}_{0.25(1-x)} \mathrm{Co}_{x} \mathrm{Ni}_{0.25(1-x)} \mathrm{Cu}_{0.25(1-x)} \mathrm{Zn}_{0.25(1-x)} \mathrm{O}\right.$ heterostructures, in which exchange bias thin film heterostructures are composed of a ferromagnetic layer (Py, $3 \mathrm{~nm}$ ), an antiferromagnetic layer, and an entropy-stabilized oxides layer with $80 \mathrm{~nm}$. The disorder, exchange field and magnetic anisotropy could be tuned by changing the composition of the $\mathrm{Mg}_{0.25(1-x)} \mathrm{Co}_{x} \mathrm{Ni}_{0.25(1-x)} \mathrm{Cu}_{0.25(1-x)} \mathrm{Zn}_{0.25(1-x)} \mathrm{O}$. The exchange bias observed at low temperature could reach 10 times of thatobserved in a $\mathrm{CoO} / \mathrm{Py}$ control sample.

The magnetic properties of perovskite-type highentropy oxides with the general composition $\mathrm{Gd}_{0.2} \mathrm{La}_{0.2} \mathrm{Nd}_{0.2} \mathrm{Sm}_{0.2} \mathrm{Y}_{0.2} \mathrm{BO}_{3}$, in which $\mathrm{B}$ site was respectively $\mathrm{Co}, \mathrm{Cr}$, and $\mathrm{Fe}$, was investigated by Witte et al. [216]. The magnetic behavior of perovskite-type HEOs depended sensitively on the nature of the transition metals on the $\mathrm{B}$ site. The magnetic properties of different rare-earth (RE) ions on the A site and transition metal (TM) ions on the B-site were presented. Compounds with five intermixed $\mathrm{TM}$ elements on the $\mathrm{B}$ site and single RE elements on the A site as well as a compound with five different $\mathrm{RE}$ elements on the $\mathrm{A}$ site, namely $\mathrm{Gd}_{0.2} \mathrm{La}_{0.2} \mathrm{Nd}_{0.2} \mathrm{Sm}_{0.2} \mathrm{Y}_{0.2} \mathrm{Co}_{0.2} \mathrm{Cr}_{0.2} \mathrm{Fe}_{0.2} \mathrm{Mn}_{0.2} \mathrm{Ni}_{0.2} \mathrm{O}_{3}$, have been investigated [78]. It was observed that antiferromagnetic behavior in the single-phase $\mathrm{ABO}_{3}$ materials was dominant, combined with a small ferromagnetic contribution. A large degree of magnetic frustration was found due to the high degree of disorder and competing ferromagnetic and antiferromagnetic interactions. Vertical exchange bias of about $25 \%$ of the remnant magnetization was obtained due to nanoscale magnetic feature. $\left(\mathrm{Ba}_{0.5} \mathrm{Sr}_{0.5}\right)\left(\mathrm{Fe}_{2.4} \mathrm{Al}_{2.4} \mathrm{Mn}_{2.4} \mathrm{Ti}_{2.4} \mathrm{Ni}_{2.4}\right) \mathrm{O}_{19}$ with a magnetoplumbite structure was explored by Vinnik et al. [94], and a paramagnetic behavior near the room temperature was revealed.

\section{Prospective applications}

The new material design paradigm and countless composition and microstructure combinations have endowed HECs properties that cannot be achieved in traditional materials. The prospective applications of this nascent family of materials cover from structural to functional including ultrahigh temperature thermal protection and thermal insulation of hypersonic vehicles, thermal and environmental barrier coatings for engine components, irradiation resistant materials for nuclear energy, cutting tools, and wear resistant coatings, electromagnetic wave absorption and interference shielding, anodes for rechargeable batteries, catalysts for clean energy and environment, thermoelectrics, supercapacitors, etc., as shown in Fig. 5.1.

\section{1 Thermal protection and insulation}

HECs exhibit low thermal conductivity and excellent thermal stability and are promising candidates for thermal protection and insulation. Thermal conductivity arises from both electrical and phonon contributions. In electrical insulating materials, thermal conductivity at low temperature is mainly affected by the directional movement of phonons. Therefore, thermal conduction is mainly restricted by various phonon-scattering processes, including phonon-phonon scattering, grain boundary scattering, and defect scattering [217-219]. Due to the huge differences in atomic mass, ionic radius, and interatomic force between multiple elements in HECs, mass and strain fluctuations are induced, resulting in enhanced phonon scattering. Thus, the thermal conductivity of HECs is much lower than their constituting components. For example, the thermal conductivity of a high-entropy (Mo, Nb, Ta, Ti, W) $\mathrm{Si}_{2}$ $\left(6.9 \mathrm{~W} \cdot \mathrm{m}^{-1} \cdot \mathrm{K}^{-1}\right)$ is much lower than those of the individual constituent disilicides $\left(19.1-65.0 \mathrm{~W} \cdot \mathrm{m}^{-1} \cdot \mathrm{K}^{-1}\right)$ and the rule-of-mixture (RoM) average $\left(40.0 \mathrm{~W} \cdot \mathrm{m}^{-1} \cdot \mathrm{K}^{-1}\right)$ of the five disilicides [33]. Moreover, benefiting from the highly disordered interatomic forces, a class of HEOs $\left(\mathrm{Mg}_{x} \mathrm{Ni}_{x} \mathrm{Cu}_{x} \mathrm{Co}_{x} \mathrm{Zn}_{x} \mathrm{M}_{x} \mathrm{O}\right.$, where $x=0.167$, and 


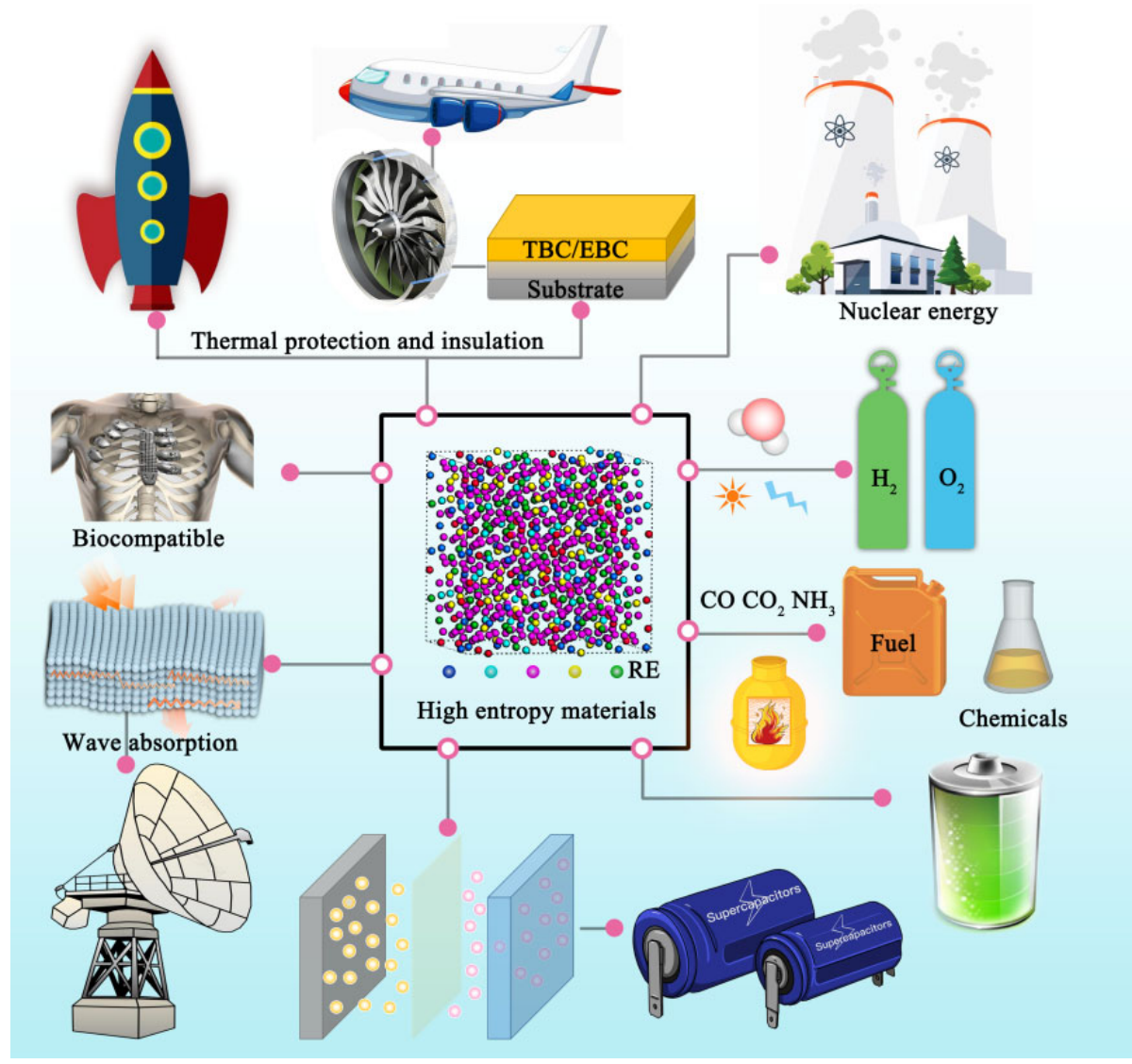

Fig. 5.1 Prospective applications of HECs covering from ultrahigh-temperature structural to energy and catalytic functional applications.

M representing for $\mathrm{Sc}, \mathrm{Sb}, \mathrm{Sn}, \mathrm{Cr}$, and $\mathrm{Ge}$, respectively) show the highest ratio of modulus to thermal conductivity [19].

Among HECs, high-entropy ultra-high temperature ceramics (HE UHTCs), especially highly porous HE UHTCs, have attracted much attention in the area of ultra-high temperature thermal protection and insulation, owing to their low thermal conductivity, good thermal stability, and low density $[22,35,40]$. Recently, a novel strategy towards making ultrahigh temperature ceramics thermal insulating was proposed as shown in Fig. 5.2 $[22,40]$. Through this novel strategy, highly porous high-entropy carbides and borides ceramics with low thermal conductivity were fabricated. For instance, the porous $\left(\mathrm{Zr}_{0.2} \mathrm{Hf}_{0.2} \mathrm{Ti}_{0.2} \mathrm{Nb}_{0.2} \mathrm{Ta}_{0.2}\right) \mathrm{C}$ with a porosity of $80.99 \%$ exhibits an ultralow thermal conductivity of $0.39 \mathrm{~W} \cdot \mathrm{m}^{-1} \cdot \mathrm{K}^{-1}$ and a low density of $1.79 \mathrm{~g} \cdot \mathrm{cm}^{-3}$ [22] while the dense $\left(\mathrm{Zr}_{0.2} \mathrm{Hf}_{0.2} \mathrm{Ti}_{0.2} \mathrm{Nb}_{0.2} \mathrm{Ta}_{0.2}\right) \mathrm{C}$ ceramic usually possesses a thermal conductivity of about $6.45 \mathrm{~W} \cdot \mathrm{m}^{-1} \cdot \mathrm{K}^{-1}$. Similarly, porous $\mathrm{HE}$ $\left(\mathrm{Zr}_{0.2} \mathrm{Hf}_{0.2} \mathrm{Ti}_{0.2} \mathrm{Nb}_{0.2} \mathrm{Ta}_{0.2}\right) \mathrm{B}_{2}$ with a porosity of $80 \%$ can also be used as thermal protection and insulation

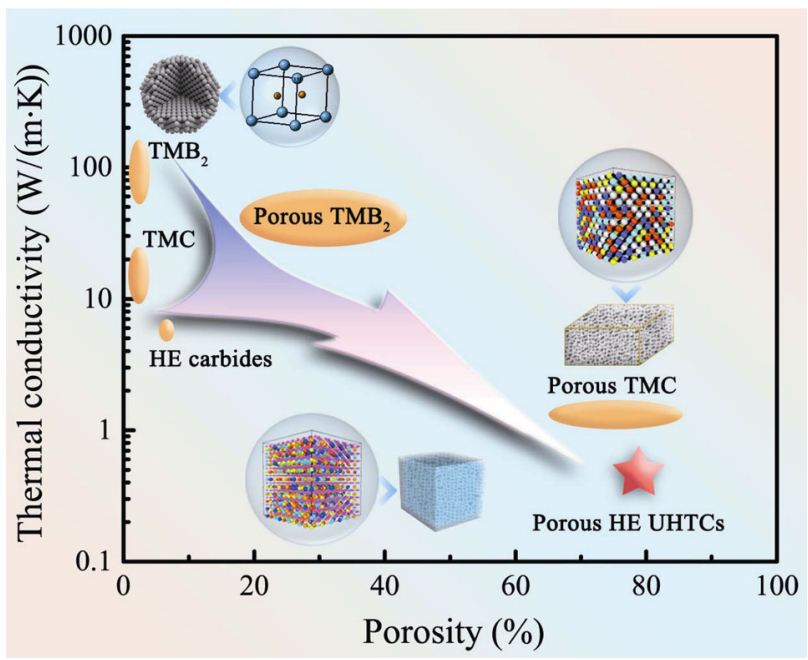

Fig. 5.2 Schematic illustration of the strategy towards making ultrahigh temperature ceramics thermal insulating $[22,40]$.

material for its high melting point, high strength (3.93 MPa), and ultralow thermal conductivity $\left(0.51 \mathrm{~W} \cdot \mathrm{m}^{-1} \cdot \mathrm{K}^{-1}\right)[40]$.

The low thermal conductivities of highly porous $\mathrm{HE}$ 
UHTCs can be attributed to their high porosity as well as the reduced thermal conductivity of high-entropy backbone materials, which can significantly reduce the solid thermal conduction. The porous high-entropy ceramics also show good dimensional and phase stability. The linear shrinkage curve of porous $\mathrm{HE}$ $\left(\mathrm{Zr}_{0.2} \mathrm{Hf}_{0.2} \mathrm{Ti}_{0.2} \mathrm{Nb}_{0.2} \mathrm{Ta}_{0.2}\right) \mathrm{C}$ during the second round heating process is shown in Fig. 5.3. It can be seen that there is little volume change during the second round heat treatment even up to $1850{ }^{\circ} \mathrm{C}$. No evidence of decomposition or phase transformation was observed in the XRD pattern. SEM images of as-prepared and heat treated porous $\left(\mathrm{Zr}_{0.2} \mathrm{Hf}_{0.2} \mathrm{Ti}_{0.2} \mathrm{Nb}_{0.2} \mathrm{Ta}_{0.2}\right) \mathrm{C}$ show rarely differences in grain size and microstructure, indicating that the porous $\mathrm{HE}\left(\mathrm{Zr}_{0.2} \mathrm{Hf}_{0.2} \mathrm{Ti}_{0.2} \mathrm{Nb}_{0.2} \mathrm{Ta}_{0.2}\right) \mathrm{C}$ is thermally stable at least up to $1850{ }^{\circ} \mathrm{C}$ in argon atmosphere which is promising for ultrahigh temperature thermal insulation applications.

Other than passive thermal protection and insulation, porous HECs are also promising for applications in active thermal protection. Transpiration cooling is an active and reusable thermal protection method, which has the potential to reduce heat loads on hypersonic vehicles with higher thermal protection efficiency [220-222]. The unique combination of low density,

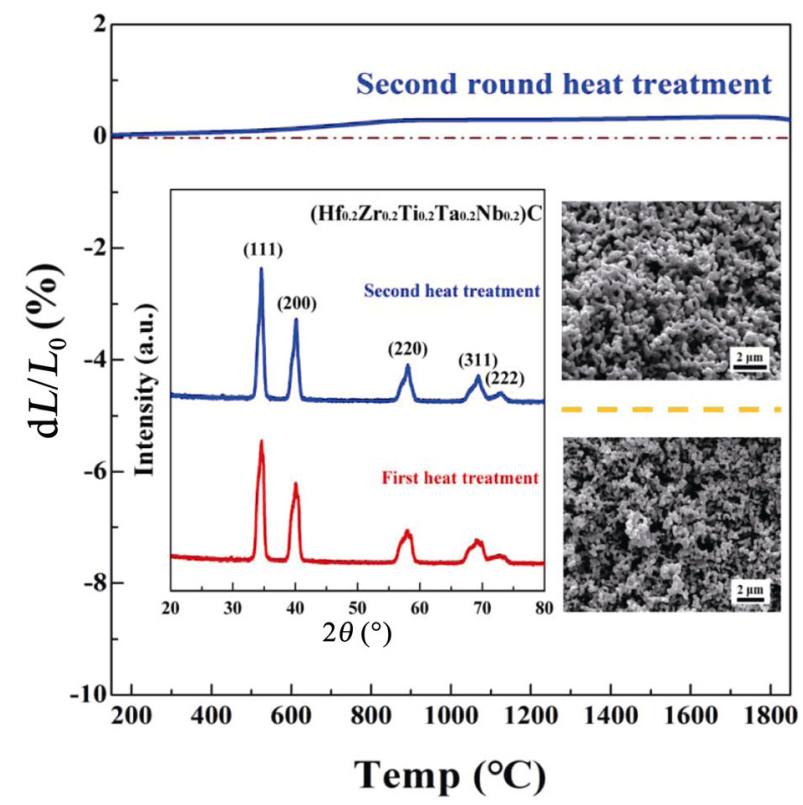

Fig. 5.3 Linear shrinkage curve of porous $\mathrm{HE}$ $\left(\mathrm{Zr}_{0.2} \mathrm{Hf}_{0.2} \mathrm{Ti}_{0.2} \mathrm{Nb}_{0.2} \mathrm{Ta}_{0.2}\right) \mathrm{C}$ during the second-round heat treatment, inset showing the XRD patterns and SEM images of as-prepared porous $\mathrm{HE}\left(\mathrm{Zr}_{0.2} \mathrm{Hf}_{0.2} \mathrm{Ti}_{0.2} \mathrm{Nb}_{0.2} \mathrm{Ta}_{0.2}\right) \mathrm{C}$ and the sample after second-round heat treatment at $1850{ }^{\circ} \mathrm{C}$. Reproduced with permission from Ref. [22], (C) Elsevier 2019. high porosity, and high permeability makes porous HE UHTCs potential for transpiration cooling applications. Recently, porous $\mathrm{HE} \quad\left(\mathrm{Y}_{0.2} \mathrm{Yb}_{0.2} \mathrm{Sm}_{0.2} \mathrm{Nd}_{0.2} \mathrm{Eu}_{0.2}\right) \mathrm{B}_{6}$ $\left(\mathrm{HEREB}_{6}\right)$ was synthesized by in-situ reaction/partial sintering method using $\mathrm{HE}\left(\mathrm{Y}_{0.2} \mathrm{Yb}_{0.2} \mathrm{Sm}_{0.2} \mathrm{Nd}_{0.2} \mathrm{Eu}_{0.2}\right) \mathrm{B}_{6}$ as the backbone material [98]. The permeability of porous $\mathrm{HE} \mathrm{REB}_{6}$ with a porosity of $70.64 \%$ and $64.35 \%$ are determined to be $2.73 \times 10^{-11} \mathrm{~m}^{2}$ and $2.65 \times 10^{-11} \mathrm{~m}^{2}$, respectively according to the Darcy equation [223]. A large number of interconnected pores with a large pore diameter of porous $\mathrm{HE}$ $\left(\mathrm{Y}_{0.2} \mathrm{Yb}_{0.2} \mathrm{Sm}_{0.2} \mathrm{Nd}_{0.2} \mathrm{Eu}_{0.2}\right) \mathrm{B}_{6}$ was shown in the XRT image in Fig. 3.3(b), corresponding to high permeability. Thus, porous $\mathrm{HE}\left(\mathrm{Y}_{0.2} \mathrm{Yb}_{0.2} \mathrm{Sm}_{0.2} \mathrm{Nd}_{0.2} \mathrm{Eu}_{0.2}\right) \mathrm{B}_{6}$ can be used in the field of active thermal protection.

\section{2 Thermal/environmental barrier coatings}

HECs exhibit superior properties such as high hardness, good water-vapor corrosion resistance, good thermal stability, low thermal conductivity, low grain growth rate, and tunable thermal expansion coefficient [23,37, 58,71,85,88-93] and are thus prospective as thermal/ environmental barrier coating materials. According to the strategy for engine materials [224], thermal/ environmental barrier coatings (T/EBCs) play pivotal roles in protecting superalloys, silicon-based composites, and non-silicon-based composites. Figure 5.4 shows the roadmap of engine materials and the schematic structures for $\mathrm{T} / \mathrm{EBC}$ s to protect superalloys, $\mathrm{SiC}_{\mathrm{f}} / \mathrm{SiC}$ composites and $\mathrm{Al}_{2} \mathrm{O}_{3 \mathrm{f}} / \mathrm{Al}_{2} \mathrm{O}_{3}$ composites. To meet the development of engine materials, a serious of highentropy ceramics including zirconates $[37,74,149,196]$, aluminates [23,90,91], silicates [43,87-89], phosphates [93], niobates, and tantalates [71] were designed and synthesized.

\subsubsection{TBCs for nickel-based superalloys}

Rare-earth zirconates have been proposed as potential candidate TBC materials for nickel-based alloys because of their relatively high TECs, low thermal conductivity, and good thermal stability. However, the relatively high thermal conductivity and poor sintering resistance are the main drawbacks that limit their practical application. Recently, high-entropy zirconates with cubic pyrochlore structures have been synthesized as candidates of TBC materials [37,74,145,196]. The high-entropy zirconates exhibit lower thermal conductivity than their components due to the enhanced scattering of phonons. Besides low thermal conductivity, matched 


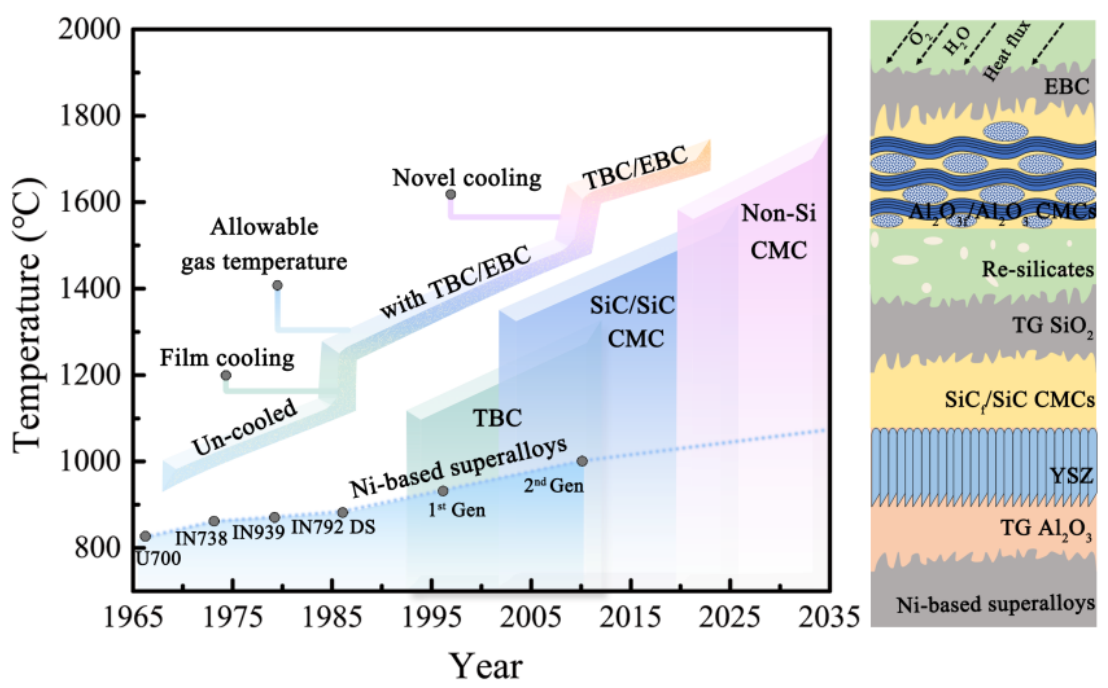

Fig. 5.4 Roadmap for the development of engine materials, and schematic structures for the corresponding T/EBCs to protect superalloys, $\mathrm{SiC}_{\mathrm{f}} / \mathrm{SiC}$, and $\mathrm{Al}_{2} \mathrm{O}_{3 \mathrm{f}} / \mathrm{Al}_{2} \mathrm{O}_{3}$ composites.

thermal expansion coefficient and a slow grain growth rate are also required for T/EBC materials. Since large lattice distortion hindered the atomic movement and effective diffusion of the atoms, $\mathrm{HE}$ $\left(\mathrm{La}_{0.2} \mathrm{Ce}_{0.2} \mathrm{Nd}_{0.2} \mathrm{Sm}_{0.2} \mathrm{Eu}_{0.2}\right)_{2} \mathrm{Zr}_{2} \mathrm{O}_{7}$ exhibits a much slower grain growth rate [37] such that it has prospective applications as a top layer of TBC.

To improve the thermal shock resistance, a doubleceramic-layer (DCL) [149] thermal barrier coating (TBC) with high-entropy rare-earth zirconate (HE-REZ) as the top layer and yttria-stabilized zirconia (YSZ) as the inner layer was designed. The DCL coating exhibited better thermal shock resistance than that of the single component $\mathrm{La}_{2} \mathrm{Zr}_{2} \mathrm{O}_{7}$ coating, which was attributed to the matched TEC and slower shrinkage rate owing to the sluggish diffusion effect of highentropy materials.

High entropy $\left(\mathrm{Y}_{0.2} \mathrm{Yb}_{0.2} \mathrm{Lu}_{0.2} \mathrm{Eu}_{0.2} \mathrm{Er}_{0.2}\right)_{3} \mathrm{Al}_{5} \mathrm{O}_{12}$ ceramic was also considered as a candidate thermal barrier material [90]. Close thermal expansion coefficient ((8.54 $0.29) \times 10^{-6} \mathrm{~K}^{-1}$ at $\left.673-1273 \mathrm{~K}\right)$ to $\mathrm{TG}-\mathrm{Al}_{2} \mathrm{O}_{3}$, low thermal conductivity $\left(3.81 \mathrm{~W} \cdot \mathrm{m}^{-1} \cdot \mathrm{K}^{-1}\right.$ at $\left.300 \mathrm{~K}\right)$, good phase stability, excellent chemical compatibility with TG $\mathrm{Al}_{2} \mathrm{O}_{3}$, and slow grain growth rate $\left(0.038 \mu \mathrm{m}^{2} / \mathrm{h}\right)$ endowed it a promising candidate for thermal barrier applications. A very recent work by Zhao et al. [71] revealed that high-entropy $\left(\mathrm{Y}_{1 / 3} \mathrm{Yb}_{1 / 3} \mathrm{Er}_{1 / 3}\right)_{3} \mathrm{TaO}_{7},\left(\mathrm{Y}_{1 / 3} \mathrm{Yb}_{1 / 3} \mathrm{Er}_{1 / 3}\right)_{3} \mathrm{NbO}_{7}$, and $\left(\mathrm{Sm}_{1 / 6} \mathrm{Eu}_{1 / 6} \mathrm{Y}_{1 / 6} \mathrm{Yb}_{1 / 6} \mathrm{Lu}_{1 / 6} \mathrm{Er}_{1 / 6}\right)_{3}\left(\mathrm{Nb}_{1 / 2} \mathrm{Ta}_{1 / 2}\right) \mathrm{O}_{7}$ exhibit high Vickers hardness (10.9-12.0 GPa), close thermal expansion coefficients to that of single-principalcomponent $\mathrm{RE}_{3} \mathrm{TaO}_{7}$ and $\mathrm{RE}_{3} \mathrm{NbO}_{7}(7.9-10.8) \times 10^{-6} \mathrm{~K}^{-1}$ at room temperature), good phase stability, and good chemical compatibility with $\mathrm{TG}-\mathrm{Al}_{2} \mathrm{O}_{3}$ and are suitable as candidate materials for TBC materials.

\subsubsection{EBC for $\mathrm{SiC}_{f} / \mathrm{SiC}$ composites}

Rare-earth aluminates such as $\mathrm{RE}_{4} \mathrm{Al}_{2} \mathrm{O}_{9}$ have been considered as T/EBC materials for silicon-based composite substrates [225]. The main restrictions for the practical application of rare-earth aluminates are phase transition at high temperature, relatively low thermal expansion coefficient, and high thermal conductivity. Recently, high-entropy $\left(\mathrm{Nd}_{0.2} \mathrm{Sm}_{0.2} \mathrm{Eu}_{0.2} \mathrm{Y}_{0.2} \mathrm{Yb}_{0.2}\right)_{4} \mathrm{Al}_{2} \mathrm{O}_{9}$ was designed and synthesized [91], which has a close thermal expansion coefficient $\left(6.96 \times 10^{-6} \mathrm{~K}^{-1}\right.$ at $300-1473 \mathrm{~K}$ ) to that of mullite, good phase stability, and low thermal conductivity $\left(1.50 \mathrm{~W} \cdot \mathrm{m}^{-1} \cdot \mathrm{K}^{-1}\right.$ at room temperature). The thermal expansion increased linearly with the increase of temperature, indicating that there was no abrupt volume change caused by phase transformations. Intriguingly, strong anisotropy in thermal expansion coefficients of $\mathrm{HE}\left(\mathrm{Nd}_{0.2} \mathrm{Sm}_{0.2} \mathrm{Eu}_{0.2} \mathrm{Y}_{0.2} \mathrm{Yb}_{0.2}\right)_{4} \mathrm{Al}_{2} \mathrm{O}_{9}$ was observed [91], which was attributed to different $\mathrm{RE}$ atoms arrangement density, i.e., the arrangement of rare earth atoms along the $a$ - and $b$-axis is much denser than that along the $c$-axis in the crystal structure of HE $\left(\mathrm{Nd}_{0.2} \mathrm{Sm}_{0.2} \mathrm{Eu}_{0.2} \mathrm{Y}_{0.2} \mathrm{Yb}_{0.2}\right)_{4} \mathrm{Al}_{2} \mathrm{O}_{9}$.

Besides high-entropy aluminates, the thermophysical and chemical properties of high-entropy silicates, such as $\mathrm{HE}\left(\mathrm{Yb}_{0.25} \mathrm{Y}_{0.25} \mathrm{Lu}_{0.25} \mathrm{Er}_{0.25}\right)_{2} \mathrm{SiO}_{5}$ [85], $\mathrm{HE}$ $\left(\mathrm{Yb}_{0.2} \mathrm{Y}_{0.2} \mathrm{Lu}_{0.2} \mathrm{Sc}_{0.2} \mathrm{Gd}_{0.2}\right)_{2} \mathrm{Si}_{2} \mathrm{O}_{7}$ [87], and $\mathrm{HE}$ $\left(\mathrm{Y}_{1 / 4} \mathrm{Ho}_{1 / 4} \mathrm{Er}_{1 / 4} \mathrm{Yb}_{1 / 4}\right)_{2} \mathrm{SiO}_{5}$ [43] were also investigated. 
According to these studies, high-entropy silicates displayed excellent phase stability from room temperature to $1300{ }^{\circ} \mathrm{C}$, matching CTE with silicon-based matrix composites, and good corrosion resistance in water-vapor environments, indicating their potential for applications as $\mathrm{T} / \mathrm{EBC}$ materials for silicon-based composites. Similar to $\mathrm{HE}\left(\mathrm{Nd}_{0.2} \mathrm{Sm}_{0.2} \mathrm{Eu}_{0.2} \mathrm{Y}_{0.2} \mathrm{Yb}_{0.2}\right)_{4} \mathrm{Al}_{2} \mathrm{O}_{9}$, HE $\left(\mathrm{Yb}_{0.25} \mathrm{Y}_{0.25} \mathrm{Lu}_{0.25} \mathrm{Er}_{0.25}\right)_{2} \mathrm{SiO}_{5}$ also shows a strong anisotropy in thermal expansion. The TECs in the $a, b$, and $c$ crystallographic directions are $(2.57 \pm 0.07) \times$ $10^{-6} \mathrm{~K}^{-1}, \quad(8.07 \pm 0.13) \times 10^{-6} \mathrm{~K}^{-1}$, and $(9.98 \pm 0.10) \times$ $10^{-6} \mathrm{~K}^{-1}$, respectively. The strong anisotropy in thermal expansion is favorable in minimizing the coating/substrate mismatch if the preferred orientation of $\mathrm{HE}\left(\mathrm{Yb}_{0.25} \mathrm{Y}_{0.25} \mathrm{Lu}_{0.25} \mathrm{Er}_{0.25}\right)_{2} \mathrm{SiO}_{5}$ is controlled on different substrates [85].

\subsubsection{EBC for $\mathrm{Al}_{2} \mathrm{O}_{3 \mathrm{f}} / \mathrm{Al}_{2} \mathrm{O}_{3}$ composites}

In general, the key requirements for selecting the EBC materials of $\mathrm{Al}_{2} \mathrm{O}_{3} \mathrm{f} / \mathrm{Al}_{2} \mathrm{O}_{3}$ composites include good phase stability and absence of decomposition and phase transformation from room temperature to the service temperature, close thermal expansion coefficient and good chemical compatibility with $\mathrm{Al}_{2} \mathrm{O}_{3}$, good durability to extreme environments such as high temperature heat flux and $\mathrm{H}_{2} \mathrm{O} / \mathrm{O}_{2}$ corrosion, and low thermal conductivity. Figure 5.5(a) compares the thermal conductivity and thermal expansion coefficient of recent designed high-entropy ceramics with other candidate $\mathrm{EBCs}$ for $\mathrm{Al}_{2} \mathrm{O}_{3}$.

$\mathrm{HE}\left(\mathrm{Y}_{0.2} \mathrm{Nd}_{0.2} \mathrm{Sm}_{0.2} \mathrm{Eu}_{0.2} \mathrm{Er}_{0.2}\right) \mathrm{AlO}_{3}$ possesses a high thermal expansion coefficient $\left(9.02 \times 10^{-6} \mathrm{~K}^{-1}\right)$ close to that of $\mathrm{Al}_{2} \mathrm{O}_{3} \quad\left(\sim 9.0 \times 10^{-6} \mathrm{~K}^{-1}\right)$, and simultaneous excellent water vapor corrosion resistance, which makes it a promising candidate $\mathrm{EBC}$ material to protect $\mathrm{Al}_{2} \mathrm{O}_{3 \mathrm{f}} / \mathrm{Al}_{2} \mathrm{O}_{3}$ composites from the corrosion of high-temperature water vapor in combustion environments [23]. Additionally, a dense high-entropy garnet reaction layer forms at the interface when $\mathrm{HE}$ $\left(\mathrm{Y}_{0.2} \mathrm{Nd}_{0.2} \mathrm{Sm}_{0.2} \mathrm{Eu}_{0.2} \mathrm{Er}_{0.2}\right) \mathrm{AlO}_{3}$ reacts with $\mathrm{Al}_{2} \mathrm{O}_{3}$ at $1500{ }^{\circ} \mathrm{C}$. The dense $\mathrm{HE}$ garnet reaction layer can separate the $\mathrm{HE}\left(\mathrm{Y}_{0.2} \mathrm{Nd}_{0.2} \mathrm{Sm}_{0.2} \mathrm{Eu}_{0.2} \mathrm{Er}_{0.2}\right) \mathrm{AlO}_{3}$ layer from the $\mathrm{Al}_{2} \mathrm{O}_{3}$ layer and prevents them from further interaction. Thus, analogous to the YSZ/TG $\mathrm{Al}_{2} \mathrm{O}_{3} /$ Ni-based super alloy TBC and the RE-silicates/ TG-SiO ${ }_{2} /\left(\mathrm{SiC}_{\mathrm{f}} / \mathrm{SiC}\right.$ composites $)$ EBC structures, a tri-layer EBC system $\mathrm{REAlO}_{3} / \mathrm{RE}_{3} \mathrm{Al}_{5} \mathrm{O}_{12} /\left(\mathrm{Al}_{2} \mathrm{O}_{3 \mathrm{f}} / \mathrm{Al}_{2} \mathrm{O}_{3}\right.$ $\mathrm{CMCs}$ ) was designed by Zhao et al. [23], as illustrated in Fig. 5.5(b) by using the reacting-formed garnet layer as a barrier for penetrating the water vapor from the top $\mathrm{HE} \mathrm{REAlO}_{3}$ layer.

High-entropy rare-earth phosphate monazite ceramic $\left(\mathrm{La}_{0.2} \mathrm{Ce}_{0.2} \mathrm{Nd}_{0.2} \mathrm{Sm}_{0.2} \mathrm{Eu}_{0.2}\right) \mathrm{PO}_{4}$ [93] exhibits good chemical compatibility with $\mathrm{Al}_{2} \mathrm{O}_{3}$, without reaction with $\mathrm{Al}_{2} \mathrm{O}_{3}$ at high temperatures as high as $1600{ }^{\circ} \mathrm{C}$ in air. Its thermal expansion coefficient is $8.9 \times 10^{-6} \mathrm{~K}^{-1}$ at 300 $1000{ }^{\circ} \mathrm{C}$ and is close to that of $\mathrm{Al}_{2} \mathrm{O}_{3}$. The thermal conductivity of $\mathrm{HE}\left(\mathrm{La}_{0.2} \mathrm{Ce}_{0.2} \mathrm{Nd}_{0.2} \mathrm{Sm}_{0.2} \mathrm{Eu}_{0.2}\right) \mathrm{PO}_{4}$ at room temperature is as low as $2.08 \mathrm{~W} \cdot \mathrm{m}^{-1} \cdot \mathrm{K}^{-1}$, which is about $42 \%$ lower than that of $\mathrm{LaPO}_{4}$. Good chemical compatibility, close TEC to $\mathrm{Al}_{2} \mathrm{O}_{3}$, and low thermal conductivity indicate that $\mathrm{HE}\left(\mathrm{La}_{0.2} \mathrm{Ce}_{0.2} \mathrm{Nd}_{0.2} \mathrm{Sm}_{0.2} \mathrm{Eu}_{0.2}\right) \mathrm{PO}_{4}$ is suitable as a candidate $\mathrm{EBC} / \mathrm{TBC}$ material or an interphase for $\mathrm{Al}_{2} \mathrm{O}_{3} / \mathrm{Al}_{2} \mathrm{O}_{3}$ composites [93].

In short, low thermal conductivity, tunable thermal expansion coefficient, slow grain growth rate, excellent phase stability, good resistance to corrosion, and compatibility with the substrate make high-entropy
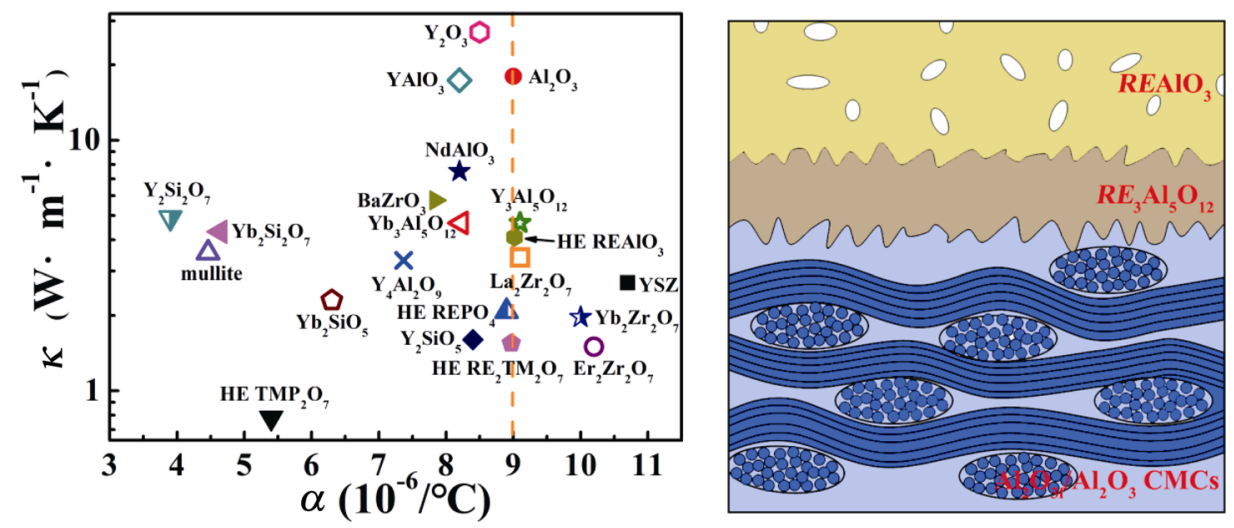

Fig. 5.5 (a) Comparison of thermal conductivity versus thermal expansion coefficient of recent designed high-entropy ceramics with other candidate $\mathrm{EBCs}$ for $\mathrm{Al}_{2} \mathrm{O}_{3}$; (b) schematic illustration of a tri-layer EBC system $\mathrm{REAlO}_{3} / \mathrm{RE}_{3} \mathrm{Al}_{5} \mathrm{O}_{12} /$ $\left(\mathrm{Al}_{2} \mathrm{O}_{3 \mathrm{f}} / \mathrm{Al}_{2} \mathrm{O}_{3} \mathrm{CMCs}\right.$ for $\mathrm{Al}_{2} \mathrm{O}_{3 \mathrm{f}} / \mathrm{Al}_{2} \mathrm{O}_{3}$ composites. Reproduced with permission from Ref. [23], (C) Elsevier 2020. 
ceramics promising candidates for T/EBC applications.

\section{3 Hard and wear resistant coatings}

Superhard materials find applications in cutting tools and drill bits for precision processing, hard materials' machining and wear resistant plates, rolls, etc., in harsh working environments [3]. As we have described in Section 3.2.3, the hardness of high-entropy nitride, carbide, and boride films are significantly enhanced so that they have important applications as hard and wear resistant coatings to extend the lifetime of cutting tools and wear parts. Cutting tools for dry cutting and high-speed cutting need longer lifetime, which can be improved by hard high-entropy coatings. High-entropy nitride films such as (AlCrTaTiZr) $-\mathrm{Si}_{x}-\mathrm{N}$, $\left(\mathrm{Al}_{23.1} \mathrm{Cr}_{30.8} \mathrm{Nb}_{7.7} \mathrm{Si}_{7.7} \mathrm{Ti}_{30.7}\right) \mathrm{N}_{50}$, and $\left(\mathrm{Al}_{29.1} \mathrm{Cr}_{30.8} \mathrm{Nb}_{11.2} \mathrm{Si}_{7.7} \mathrm{Ti}_{21.2}\right) \mathrm{N}_{50}$ films exhibit not only high hardness (over $34 \mathrm{GPa}$ ) but also good oxidation resistance. Cutting tools coated with these nitride films could have good performance and improved lifetime [152-155]. Cutting performance tests [3] demonstrated that high-entropy nitrides coated insert had superior oxidation and wear resistance over TiN and TiAlN coated inserts for high-speed dry cutting of 304 stainless steel work piece.

TiAlCrSiV/(TiAlCrSiV)N double-layer coatings [156] show high hardness and corrosion resistance and can be used as wear and corrosion resistant coatings. High-entropy carbides films such as (CuSiTiYZr)C have high hardness (over $29 \mathrm{GPa}$ ), low coefficient of friction $(\sim 0.15)$ and superior corrosion resistance [159] and can be used as wear resistant coatings working in harsh environment. High-entropy (TiZrHfVNbTa)C coatings [160] are superhard with low coefficient of frication and can be used as self-lubricating or wear resistant surface coatings. High-entropy $\left(\mathrm{Zr}_{0.23} \mathrm{Ti}_{0.20} \mathrm{Hf}_{0.19} \mathrm{~V}_{0.14} \mathrm{Ta}_{0.24}\right) \mathrm{B}_{2}$ with a hardness of 47 $\mathrm{GPa}$ can be used as superhard coatings of cutting tools as excavator buckets [163].

\section{4 Nuclear energy}

Due to the excellent solubility for minor actinide (MA: $\mathrm{Np}, \mathrm{Am}, \mathrm{Cm}$ ) elements in rock-salt structured transition metal carbides and nitrides [226], they can be used as inert matrix fuels (IMF) for transmuting transuranium elements for further use as fission fuel and producing clean wastes [227,228]. In addition, carbide and nitride ceramics can be used as structural materials for cladding and TRISO (tri-isotropic) in nuclear reactors by taking advantages of their favorable thermal and mechanical properties. For high-entropy transition metal carbides and nitrides, they keep the rock-salt structure with atomic scattering and lattice strain inside. The atomic scattering, lattice strain, and low heat dissipation may help improve the stability of lattice during irradiation [203] and the sluggish diffusion may improve the oxidation resistance under $1200{ }^{\circ} \mathrm{C}$ water vapor atmosphere [229]. The decreased thermal conductivity due to the enhanced phonon scattering [35], however, is a very critical concern for their application as cladding materials. As such, how to balance the irradiation resistance and the thermal conductivity would be an important issue for the development of high-entropy ceramics for possible application as core materials in nuclear reactors. Furthermore, materials with small values of neutron absorption cross-section are important for the application in fission reactors. The concern for high-entropy ceramics developed for fission reactors is the complicated atomic composition with different values of neutron absorption cross section.

Transition metal diboride has the potential to be used as plasma facing material for nuclear fusion reactors on the strength of its high melting point, high thermal conductivity, low sputtering yield, low hydrogen isotope retention, and excellent resistance to helium ions and neutron irradiation, etc. [230,231]. It can be expected that high-entropy boride ceramics would have good irradiation resistance. However, similar to the high-entropy carbide ceramics, the trade-off between the improved irradiation resistance and the decreased thermal conductivity would be a key issue for the researchers. Non-equimolar and medium-entropy composition design would be a possible approach.

On the other hand, immobilization of high-level radioactive waste (HLW) is important for the safe utilization of nuclear energy. The waste forms must withstand the self-radiation of HLW for long time and demonstrate good chemical durability, high thermal and mechanical stabilities and low leaching rate. Based on these criteria, ceramics are considered as good candidates. As HECs are characterized by sluggish diffusion and good irradiation resistance, they should be competitive in the application of immobilization for the HLW.

\section{5 Electromagnetic wave (EM) absorption and EM interference shielding}

The increasing electromagnetic hazards including 
electromagnetic interference and electromagnetic pollution, which were stemmed from massive usage of electromagnetic technology, has triggered widespread concerns. To cope with this challenge, electromagnetic interference shielding and electromagnetic wave absorbing materials with high performance are greatly needed.

It has come to light that materials with sufficiently large permittivity and permeability values will demonstrate a strong attenuation response to incident electromagnetic radiation as such composites made of conductive/magnetic components show enhanced microwave absorption properties [232]. However, the uniform dispersion of different nanometer sized phases and precise control of their compositions and interfaces pose challenges to the conductive/magnetic composites. Thus searching for single-phase materials with both high permittivity and permeability which allow the optimization of EMW absorbing in micrometer grain size through dielectric/magnetic loss coupling is appealing. The advent of HECs makes the design of new materials through dielectric/magnetic loss coupling possible. Besides, developing HECs is also an effective way to tailor the dielectric and magnetic losses at $\mathrm{GHz}$ frequency range by compositional design, thus realizing better impedance matching and microwave absorption performance.

Chen et al. [101] investigated the electromagnetic wave absorption properties of high-entropy $\mathrm{RE}_{3} \mathrm{Si}_{2} \mathrm{C}_{2} /$ $\mathrm{RE}_{2} \mathrm{O}_{3}(\mathrm{RE}=\mathrm{Tm}, \mathrm{Pr}, \mathrm{Gd}, \mathrm{Dy}, \mathrm{Tb}, \mathrm{Y})$ composites and found that strong EM absorption capability and wide efficient absorption bandwidth could be achieved for these HECs. Zhou et al. [233] investigated the EMW absorption properties of transition metal carbides TMCs $(T M=\mathrm{Ti}, \mathrm{Zr}, \mathrm{Hf}, \mathrm{Nb}$, and $\mathrm{Ta})$ and high-entropy $\left(\mathrm{Ti}_{0.2} \mathrm{Zr}_{0.2} \mathrm{Hf}_{0.2} \mathrm{Nb}_{0.2} \mathrm{Ta}_{0.2}\right)$ C. Intriguingly, they found that the electromagnetic parameters, i.e., complex permittivity and permeability are tunable by forming single-phase solid solution or high-entropy $\left(\mathrm{Ti}_{0.2} \mathrm{Zr}_{0.2} \mathrm{Hf}_{0.2} \mathrm{Nb}_{0.2} \mathrm{Ta}_{0.2}\right) \mathrm{C}$, which opens a new window to design single-phase high performance EMW absorbing materials by dielectric/magnetic loss coupling. Zhang et al. [99] designed five high-entropy rare earth hexaborides HE REB 6 including $\left(\mathrm{Ce}_{0.2} \mathrm{Y}_{0.2} \mathrm{Sm}_{0.2} \mathrm{Er}_{0.2} \mathrm{Yb}_{0.2}\right) \mathrm{B}_{6}$ $\left(\mathrm{HE} \quad \mathrm{REB}_{6}-1\right), \quad\left(\mathrm{Ce}_{0.2} \mathrm{Eu}_{0.2} \mathrm{Sm}_{0.2} \mathrm{Er}_{0.2} \mathrm{Yb}_{0.2}\right) \mathrm{B}_{6} \quad(\mathrm{HE}$ $\left.\mathrm{REB}_{6}-2\right),\left(\mathrm{Ce}_{0.2} \mathrm{Y}_{0.2} \mathrm{Eu}_{0.2} \mathrm{Er}_{0.2} \mathrm{Yb}_{0.2}\right) \mathrm{B}_{6}$ (HE $\left.\mathrm{REB}_{6}-3\right)$, $\left(\mathrm{Ce}_{0.2} \mathrm{Y}_{0.2} \mathrm{Sm}_{0.2} \mathrm{Eu}_{0.2} \mathrm{Yb}_{0.2}\right) \mathrm{B}_{6} \quad$ (HE $\left.\mathrm{REB}_{6}-4\right)$, and $\left(\mathrm{Nd}_{0.2} \mathrm{Y}_{0.2} \mathrm{Sm}_{0.2} \mathrm{Eu}_{0.2} \mathrm{Yb}_{0.2}\right) \mathrm{B}_{6}$ (HE $\left.\mathrm{REB}_{6}-5\right)$, and five $\mathrm{HE} \quad \mathrm{REB}_{6} / \mathrm{HE} \quad \mathrm{REBO}_{3}$ composites including
$\left(\mathrm{Ce}_{0.2} \mathrm{Y}_{0.2} \mathrm{Sm}_{0.2} \mathrm{Er}_{0.2} \mathrm{Yb}_{0.2}\right) \mathrm{B}_{6} /\left(\mathrm{Ce}_{0.2} \mathrm{Y}_{0.2} \mathrm{Sm}_{0.2} \mathrm{Er}_{0.2} \mathrm{Yb}_{0.2}\right) \mathrm{BO}_{3}$ ( $\left.\mathrm{HE} \quad \mathrm{REB}_{6} / \mathrm{HE}^{\mathrm{R}} \mathrm{REBO}_{3}-1\right), \quad\left(\mathrm{Ce}_{0.2} \mathrm{Eu}_{0.2} \mathrm{Sm}_{0.2} \mathrm{Er}_{0.2} \mathrm{Yb}_{0.2}\right) \mathrm{B}_{6} /$ $\left(\mathrm{Ce}_{0.2} \mathrm{Eu}_{0.2} \mathrm{Sm}_{0.2} \mathrm{Er}_{0.2} \mathrm{Yb}_{0.2}\right) \mathrm{BO}_{3}\left(\mathrm{HE} \mathrm{REB}{ }_{6} / \mathrm{HE} \mathrm{REBO}_{3}-2\right)$, $\left(\mathrm{Ce}_{0.2} \mathrm{Y}_{0.2} \mathrm{Eu}_{0.2} \mathrm{Er}_{0.2} \mathrm{Yb}_{0.2}\right) \mathrm{B}_{6} /\left(\mathrm{Ce}_{0.2} \mathrm{Y}_{0.2} \mathrm{Eu}_{0.2} \mathrm{Er}_{0.2} \mathrm{Yb}_{0.2}\right) \mathrm{BO}_{3}$ (HE REB 6 /HE REBO $\left.\mathrm{H}_{3}-3\right),\left(\mathrm{Ce}_{0.2} \mathrm{Y}_{0.2} \mathrm{Sm}_{0.2} \mathrm{Eu}_{0.2} \mathrm{Yb}_{0.2}\right) \mathrm{B}_{6} /$ $\left(\mathrm{Ce}_{0.2} \mathrm{Y}_{0.2} \mathrm{Sm}_{0.2} \mathrm{Eu}_{0.2} \mathrm{Yb}_{0.2}\right) \mathrm{BO}_{3}\left(\mathrm{HE} \mathrm{REB}_{6} / \mathrm{HE} \mathrm{REBO}_{3}-4\right)$, and $\left(\mathrm{Nd}_{0.2} \mathrm{Y}_{0.2} \mathrm{Sm}_{0.2} \mathrm{Eu}_{0.2} \mathrm{Yb}_{0.2}\right) \mathrm{B}_{6}\left(\mathrm{Nd}_{0.2} \mathrm{Y}_{0.2} \mathrm{Sm}_{0.2} \mathrm{Eu}_{0.2} \mathrm{Yb}_{0.2}\right) \mathrm{BO}_{3}$ (HE REB 6 /HE $\left.\mathrm{REBO}_{3}-5\right)$ with dielectric and magnetic losses coupling. These powders were fabricated through a facial one-step boron carbide reduction method. $\left(\mathrm{Ce}_{0.2} \mathrm{Y}_{0.2} \mathrm{Sm}_{0.2} \mathrm{Er}_{0.2} \mathrm{Yb}_{0.2}\right) \mathrm{B}_{6}$ powders with the average particle size of $1.86 \mu \mathrm{m}$ were found to possess the best EM wave absorption properties among the $\mathrm{HE} \mathrm{REB}_{6} \mathrm{~s}$. The $R L_{\text {min }}$ value of $\left(\mathrm{Ce}_{0.2} \mathrm{Y}_{0.2} \mathrm{Sm}_{0.2} \mathrm{Er}_{0.2} \mathrm{Yb}_{0.2}\right) \mathrm{B}_{6}$ reached $-33.4 \mathrm{~dB}$ at $11.5 \mathrm{GHz}$ with the thickness of $2 \mathrm{~mm}$; meanwhile, the optimized effective absorption bandwidth $\left(E_{\mathrm{AB}}\right)$ reached $3.9 \mathrm{GHz}$ from 13.6 to $17.5 \mathrm{GHz}$ with the thickness of $1.5 \mathrm{~mm}$.

Moreover, enhanced electromagnetic wave absorption performances were achieved in high-entropy rare earth hexaboride/tetraboride $\left(\mathrm{HE} \mathrm{REB} 6 / \mathrm{HE} \mathrm{REB}_{4}\right)$ composite powders [234]. As shown in Figs. 5.6(a) and 5.6(b), the optimal minimum reflection loss $\left(R L_{\min }\right)$ and effective absorption bandwidth $\left(E_{\mathrm{AB}}\right)$ of $\left(\mathrm{Y}_{0.2} \mathrm{Nd}_{0.2} \mathrm{Sm}_{0.2} \mathrm{Eu}_{0.2} \mathrm{Er}_{0.2}\right) \mathrm{B}_{6}$ $\left(\mathrm{Y}_{0.2} \mathrm{Nd}_{0.2} \mathrm{Sm}_{0.2} \mathrm{Eu}_{0.2} \mathrm{Er}_{0.2}\right) \mathrm{B}_{4}\left(\mathrm{HE} \mathrm{REB}_{6} / \mathrm{HE} \mathrm{REB}_{4}-1\right)$ and $\left(\mathrm{Y}_{0.2} \mathrm{Nd}_{0.2} \mathrm{Sm}_{0.2} \mathrm{Er}_{0.2} \mathrm{Yb}_{0.2}\right) \mathrm{B}_{6} /\left(\mathrm{Y}_{0.2} \mathrm{Nd}_{0.2} \mathrm{Sm}_{0.2} \mathrm{Er}_{0.2} \mathrm{Yb}_{0.2}\right) \mathrm{B}_{4}$ (HE REB 6 / $\mathrm{HE} \mathrm{REB}_{4}-2$ ) are $-53.3 \mathrm{~dB}$ (at $1.7 \mathrm{~mm}$ ), $4.2 \mathrm{GHz}$ (at $1.5 \mathrm{~mm}$ ), and $-43.5 \mathrm{~dB}(1.3 \mathrm{~mm}), 4.2 \mathrm{GHz}$ $(1.5 \mathrm{~mm})$, respectively. Through combining a second phase of high-entropy rare-earth tetraborides (HE $\mathrm{REB}_{4}$ ) with good electrical conductivity and magnetism, the dielectric loss capability was enhanced without sacrificing magnetic loss ability. As a result, HE $\mathrm{REB}_{6} / \mathrm{HE} \mathrm{REB}_{4}-1$ and $\mathrm{HE} \mathrm{REB}_{6} / \mathrm{HE} \mathrm{REB}_{4}-2$ possess thin thickness, wide effective bandwidth, and strong absorbing capability in Fig. 5.6(c), which indicates good EM wave absorption performance.

HECs also find applications for EMI shielding, especially under oxidation, corrosion, abrasion, and high temperature circumstances. Zhang et al. [96] designed a high-entropy monoboride $\left(\mathrm{Cr}_{0.2} \mathrm{Mn}_{0.2} \mathrm{Fe}_{0.2} \mathrm{Co}_{0.2} \mathrm{Mo}_{0.2}\right) \mathrm{B}$ and found that the combination of good phase stability, high electrical conductivity and unique mechanical properties rendered it possible as an EMI shielding material. Bulk $\mathrm{HE}\left(\mathrm{Cr}_{0.2} \mathrm{Mn}_{0.2} \mathrm{Fe}_{0.2} \mathrm{Co}_{0.2} \mathrm{Mo}_{0.2}\right) \mathrm{B}$ with $3.0 \mathrm{~mm}$ thickness exhibit good EMI shielding performance, which surpasses $20 \mathrm{~dB}$ (99\% shielding) in the K-band. The EMI shielding mechanism $\left(\mathrm{Cr}_{0.2} \mathrm{Mn}_{0.2} \mathrm{Fe}_{0.2} \mathrm{Co}_{0.2} \mathrm{Mo}_{0.2}\right) \mathrm{B}$ is reflection-dominated 
(a)

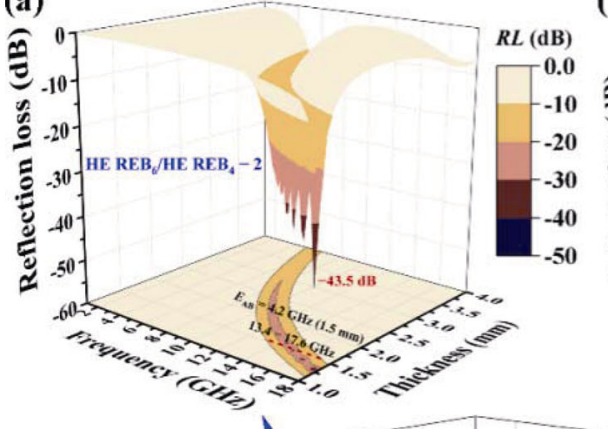

(b)

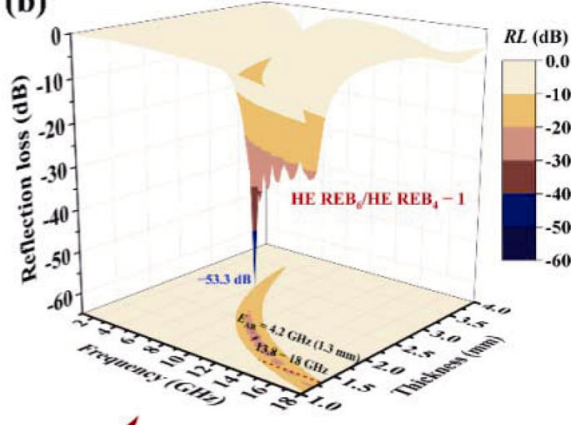

\section{(c)}

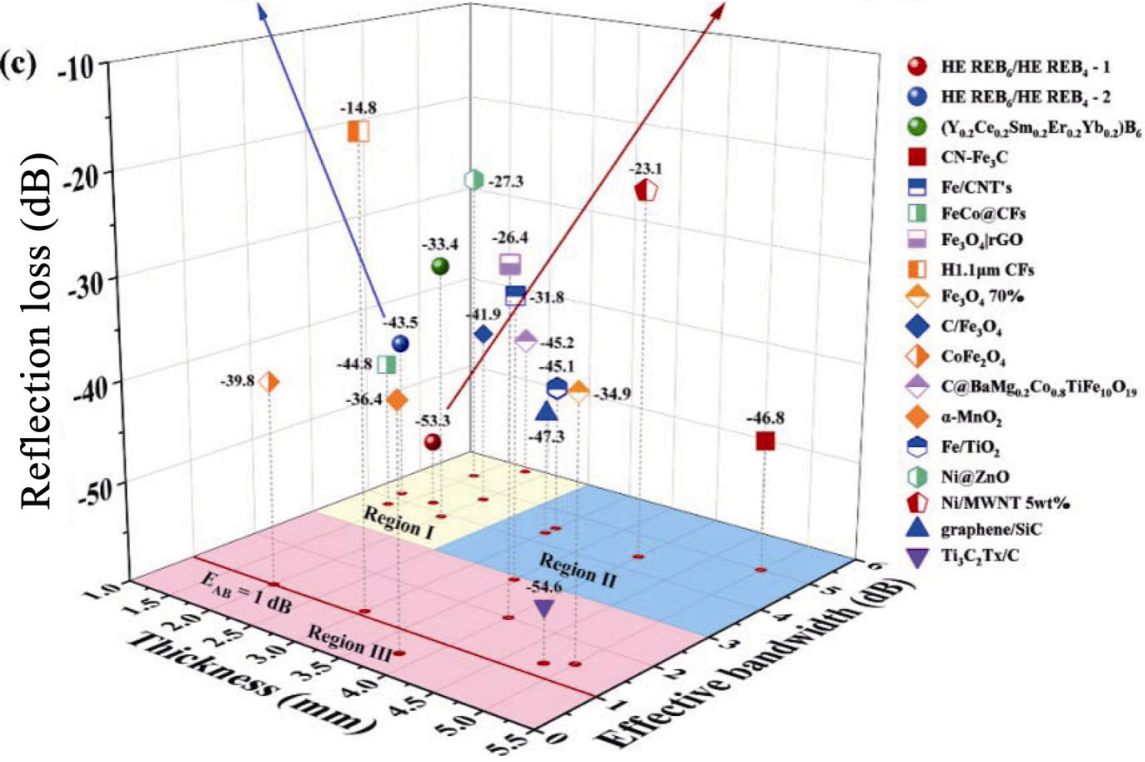

Fig. 5.6 3D representations of reflection loss $(R L)$ values of (a) $\mathrm{HE} \mathrm{REB}_{6} / \mathrm{HE}^{\mathrm{REB}} \mathrm{RE}_{4}-2$ and (b) $\mathrm{HE}_{\mathrm{REB}} / \mathrm{HE} \mathrm{REB}_{4}-1$. (c) Comparisons of EM wave absorption properties including reflection loss, thickness, and effective bandwidth of $\mathrm{HE} \mathrm{REB}_{6} / \mathrm{HE}$ $\mathrm{REB}_{4}-1$ and $\mathrm{HE} \mathrm{REB}_{6} / \mathrm{HE} \mathrm{REB}_{4}-2$ with current EM wave absorbing materials in a $3 \mathrm{D}$ plot. Reproduced with permission from Ref. [234], (C) Elsevier 2021.

due to its high electrical conductivity.

\section{6 Rechargeable (Li and non-Li ion) batteries}

The superionic conductivity observed in rock-salt structured ( $\mathrm{MgCoNiCuZn}) \mathrm{O}$ stimulated investigations on the use of HECs in Li-ion batteries [66,235,236]. As an anode material, (MgCoNiCuZn)O delivers a high capacity retention and good cycling stability. The high cycling stability is due to the ability to preserve the rock-salt structure throughout the entire redox process because of the entropy stabilization. Further introducing $\mathrm{Li}$ and $\mathrm{F}$ element to $(\mathrm{MgCoNiCuZn}) \mathrm{O}$, it can be utilized as a cathode material [237]. Element $\mathrm{F}$ in $\mathrm{Li}_{x}(\mathrm{MgCoNiCuZn}) \mathrm{OF}_{x}$ can play a role in suppressing the oxygen loss during charging and discharging, which can increase the cycling stability of the material. Similar to $(\mathrm{MgCoNiCuZn}) \mathrm{O}, \mathrm{Li}_{x}\left(\mathrm{MgCoNiCuZn} \mathrm{OF}_{x}\right.$ also shows a rock-salt structure, where $\mathrm{Li}$ and $\mathrm{F}$ distribute randomly on the cation and anion sublattice, respectively. $\mathrm{Li}_{x}(\mathrm{MgCoNiCuZn}) \mathrm{OF}_{x}$ had a working potential of $3.4 \mathrm{~V}$ versus $\mathrm{Li}^{+} / \mathrm{Li}$, exceeding that of (MgCoNiCuZn)O, i.e., $1.0 \mathrm{~V}$. The $\mathrm{Li}_{x}(\mathrm{MgCoNiCuZn}) \mathrm{OF}_{x}$ also shows a high cycling stability with a stable columbic efficiency due to the entropy stabilization by reducing the performance degradation aroused from the oxygen release.

In addition to the rock-salt structured HECs, HECs in other systems have also been used in Li-ion batteries, such as spinel and perovskite. Wang et al. [238] fabricated spinel-structured $(\mathrm{FeCoNiCrMn})_{3} \mathrm{O}_{4}$ through a high-temperature solid-state reaction method and applied it as anode for lithium-ion batteries. The $(\mathrm{FeCoNiCrMn})_{3} \mathrm{O}_{4}$ calcined at $900{ }^{\circ} \mathrm{C}$ exerted a high capacity (discharge/charge, 1034/680 $\mathrm{mAh} \cdot \mathrm{g}^{-1}$ ) and good rate capability $\left(182 \mathrm{mAh} \cdot \mathrm{g}^{-1}\right.$ at $\left.2 \mathrm{~A} \cdot \mathrm{g}^{-1}\right)$ with a commercial mass loading. The multiple metal elements 
with mixed valence states and different cation radius in $(\mathrm{FeCoNiCrMn})_{3} \mathrm{O}_{4}$ resulted in optimized electron configurations, smooth ion diffusion paths, and abundant active storage sites, which leads to its excellent electrochemical performance. Recently, a class of high-entropy perovskite oxide (HEPO) $\left[(\mathrm{Bi}, \mathrm{Na})_{1 / 5}(\mathrm{La}, \mathrm{Li})_{1 / 5}(\mathrm{Ce}, \mathrm{K})_{1 / 5} \mathrm{Ca}_{1 / 5} \mathrm{Sr}_{1 / 5}\right] \mathrm{TiO}_{3}$ synthesized by a conventional solid-state method has been explored as anode material for lithium-ion batteries [239]. An outstanding reversible capacity of $120.4 \mathrm{mAh} \cdot \mathrm{g}^{-1}$ and superior delivering retention of $100 \%$ can be obtained at $1000 \mathrm{~mA} \cdot \mathrm{g}^{-1}$ after 300 cycles. Such an outstanding cycling stability can be ascribed to the entropystabilized structure. Overall, the HEC concept could pave the way to develop advanced anode, cathode, and electrolyte materials, which indicates the possibility of fabricating HEC-based $\mathrm{Li}$ and non-Li ion batteries.

\section{7 Catalysts and water splitting}

Catalysis is one of the most important and intricate processes used in the chemical industry. Finding novel catalysts with high activity and selectivity, good stability, long lifetime, as well as low cost, is the continuous pursuit of scientific researchers. In the hunt of catalysts, many problems are encountered, such as the high cost of precious metal catalytic materials, the light absorption and lifetime of semiconductor photocatalytic materials, the poisoning of catalytic active sites, etc. Nowadays, the development of high-entropy metals and ceramics seems to provide a good remedy. With the broken of solid solution limit, various atoms with distinct atomic sizes occupy the lattice sites and form simple solid solutions, resulting in a non-equilibrium state where atoms possess high potential energy. Thus, HEMs are much more active, and the catalysis process is thermodynamically easier to proceed because less energy is needed to activate the reaction (lower than the activation energy barrier $\Delta E$ ). From dynamics perspective, activity and selectivity can be enhanced by special chemical composition, severe lattice distortion which provides more active sites and intermediates, and sluggish diffusion that can contribute to high stability. Moreover, the cost can of course be controlled by element design, as shown in Fig. 5.7. In this part, HEA/HECs are reviewed according to their usage in specific catalytic reactions, such as ammonia and carbon monoxide oxidation, oxygen and hydrogen evolution, ammonia decomposition, water splitting, and dye degradation.

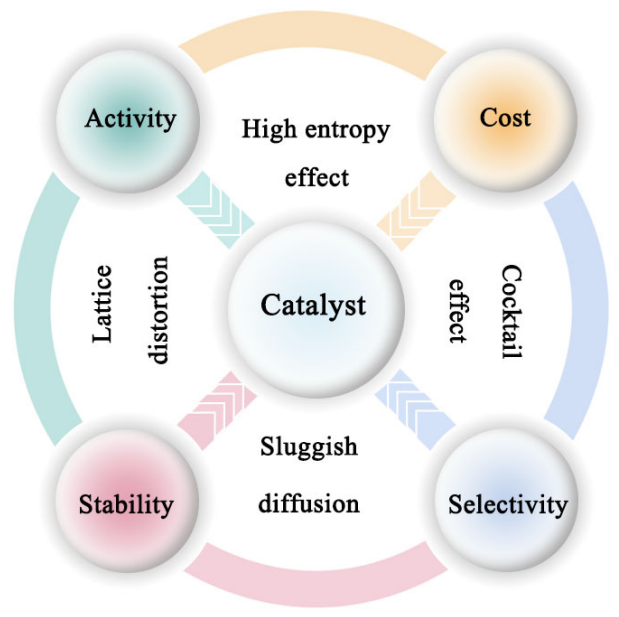

Fig. 5.7 Schematic diagram of high entropy effect on catalysis.

\subsubsection{Water splitting}

Photo/electrocatalytic water splitting to produce hydrogen and oxygen is a promising way to produce clean energy in the future. The essential idea of electrocatalysis is relatively simple, i.e., two-electrode systems are employed and the cathode part involves hydrogen evolution reaction (HER) or oxygen reduction reaction (ORR) while the anode part proceeds with oxygen evolution reaction (OER) or oxidation of some chemical fuels. For example, in an alkaline solution, electrochemical oxygen evolution is of a 4-step process, which can be generally written as

$$
\begin{aligned}
\mathrm{M}^{*}+\mathrm{OH}^{-} & \rightarrow \mathrm{MOH}^{*}+\mathrm{e}^{-} \\
\mathrm{MOH}^{*}+\mathrm{OH}^{-} & \rightarrow \mathrm{MO}^{*}+\mathrm{H}_{2} \mathrm{O}+\mathrm{e}^{-} \\
\mathrm{MO}^{*}+\mathrm{OH}^{-} & \rightarrow \mathrm{MOOH}^{*}+\mathrm{e}^{-} \\
\mathrm{MOOH}^{*}+\mathrm{OH}^{-} & \rightarrow \mathrm{M}^{*}+\mathrm{H}_{2} \mathrm{O}+\mathrm{O}_{2} \uparrow+\mathrm{e}^{-}
\end{aligned}
$$

where $*$ indicates the active sites for absorbing discharging species, which is $\mathrm{OH}^{-}$in this case while $\mathrm{M}$ represents the metallic elements, such as $\mathrm{Fe}, \mathrm{Co}, \mathrm{Ni}, \mathrm{Cr}$, and $\mathrm{Nb}$.

The main bottleneck of OER is sluggish kinetics due to the high over potential in the four-electron process. Highly dispersed active sites, large active surface area, severe lattice distortion, superb long-term durability, and fast dynamics of HEMs make them excellent OER catalysts. Ding et al. [240] fabricated a high-entropy intermetallic-oxide core-shell nanostructure by using a eutectic HEA $\mathrm{FeCoNiCrNb} \mathrm{N}_{0.5}$ as a template. They found that the bulk porous intermetallic-oxide nanostructure shows outstanding OER activity with the 
smallest Tafel slope $\left(27.7 \mathrm{mV} \cdot \mathrm{dec}^{-1}\right)$ reported so far, a much lower overpotential (0.288 V@10 $\left.\mathrm{mA} \cdot \mathrm{cm}^{-2}\right)$, and excellent durability for $30 \mathrm{~h}$ (Figs. 5.8(a) and 5.8(b)). They proposed and verified that the diversity of the valence states of the oxides/hydroxides in HEO layers provides tremendous intermediates $\left(\mathrm{MOH}^{*}\right.$, $\mathrm{MO}^{*}$, and $\mathrm{MOOH}^{*}$ ) and hence active sites, which can easily bypass the kinetic barriers. Moreover, the design of intermetallic-oxide core-shell nanostructure in HEMs increases the active surface area and enhances the OER performance.

Aside from HEOs, spinel structured $\left(\mathrm{Co}_{0.2} \mathrm{Mn}_{0.2} \mathrm{Ni}_{0.2} \mathrm{Fe}_{0.2} \mathrm{Zn}_{0.2}\right) \mathrm{Fe}_{2} \mathrm{O}_{4}$ and perovskite fluorides (HEPFs) $\mathrm{K}_{0.8} \mathrm{Na}_{0.2}(\mathrm{MgMnFeCoNi}) \mathrm{F}_{3}$ were prepared and acted as OER catalyst for $\mathrm{O}_{2}$ evolution [241,242], outperforming the commercial materials $\mathrm{IrO}_{2}$ and the typical perovskite oxide $\mathrm{Ba}_{0.5} \mathrm{Sr}_{0.5} \mathrm{Co}_{0.8} \mathrm{Fe}_{0.2} \mathrm{O}_{3-d}$. The researchers found that the disordered occupation of multivalent cations generated severe lattice distortion and thereby facilitated the formation of structurally stable, high-density oxygen vacancies on the exposed surface, and low overpotential which provided numerous catalytic sites on the surface and enhanced the OER performance.

For hydrogen evolution, developing non-precious catalysts as Pt substitutes for electrochemical hydrogen evolution reaction (HER) with superior stability in acidic electrolyte is of critical importance. The elementary diversity and unique structure of HEAs helps to design catalytic materials with non or less precious metal input and superior stability. Combining the catalytic property of $\mathrm{Co}, \mathrm{Fe}, \mathrm{Ni}$, and the corrosion-resistant ability of $\mathrm{Cr}$ and $\mathrm{Al}, \mathrm{CoCrFeNiAl}$ HEA electrocatalyst was designed and prepared by mechanical alloying and SPS [243]. The abundant metal hydroxide/oxide groups formed after electrochemical activation on HEA and large electrochemical surface area (ECSA) benefiting from highly dispersed active sites and severe lattice distortion characters of HEMs, enabled the CoCrFeNiAl outstanding HER activity in $0.5 \mathrm{M} \mathrm{H}_{2} \mathrm{SO}_{4}$ solution with an overpotential of $73 \mathrm{mV}$ at the current density of $10 \mathrm{~mA} \cdot \mathrm{cm}^{-2}$ and a Tafel slope of $39.7 \mathrm{mV} \cdot \mathrm{dec}^{-1}$. Also, taking advantage of the stability of HEA, CoCrFeNiAl achieved improved performance after 4000 cycles.

Two-step thermochemical water splitting method is also used to generate hydrogen; the key is to reduce the reaction temperature. $(\mathrm{MgCoNiFe}) \mathrm{O}_{x}(x \approx 1.2)$ has been investigated to perform two-step thermochemical water splitting [244]. The $\mathrm{H}_{2}$ yields of $(\mathrm{MgCoNiFe}) \mathrm{O}_{x}$ is $1.4 \pm 0.5 \mathrm{~mL} \cdot \mathrm{H}_{2} \cdot \mathrm{g}^{-1}$ at $1100{ }^{\circ} \mathrm{C}$, whereas ceria and spinel ferrites require $>1300{ }^{\circ} \mathrm{C}$ to yield appreciable $\mathrm{H}_{2}$ (Figs. 5.8(c) and 5.8(d)). Moreover, almost no performance degradation of $(\mathrm{MgCoNiFe}) \mathrm{O}_{x}$ was found over 10 cycles, indicating that high mixing entropy prevents phase separation. The authors proposed that reducing particle size, adding redox-active species Fe and high melting point elements in HEOs is of great importance.

For photocatalysis, the limitation is the light absorption range and photo generated carrier lifetime. In HEMs, the energy band can be tailored by $\mathrm{HE}$ effects, leading to desirable light absorption. Moreover, the fast dynamic and lattice distortion can help separating photo generated carriers, thus enhancing the photocatalytic efficiency. However, currently there is no relevant research reported, which is one of the future directions.

\subsubsection{Oxidation}

The catalytic oxidation of methane, ammonia, and carbon monoxide compared with traditional flame combustion is capable of stabilizing complete oxidation of fuel at low temperatures, while simultaneously reducing emissions (for example, $\mathrm{NO}_{x}$ ). The search for high conversion rate, low cost, and good stability of catalytic materials has always been a hot research field. A research group led by $\mathrm{Hu}$ at the University of Maryland has designed a series of HEAs with five or more elements and investigated their possibility as the catalyst. For ammonia oxidation, HEA nanoparticles (PtPdRhRuCe) were prepared by a novel two-step carbon thermal shock (CTS) process [127]. The results show that $100 \%$ conversion of ammonia and $>99 \%$ product selectivity have been reached by PtPdRhRuCe nanoparticles with no performance decay over $\sim 30$ hours of continuous operation at $700{ }^{\circ} \mathrm{C}$ when using less precious metal and under lower reaction activation temperatures, as shown in Figs. 5.8(e) and 5.8(f), owing to the highly homogeneous and none phase separation or elemental segregation nature of HEMs. The ten-element HEAs they designed also showed excellent performance in the process of methanol catalytic oxidation [128]. Besides, (MgCoNiCuZn)O was used for $\mathrm{CO}$ oxidation in a fixed-bed reactor at different temperatures [63]. The entropy stabilized ( $\mathrm{MgCoNiCuZn)O} \mathrm{can} \mathrm{help} \mathrm{disperse} \mathrm{the} \mathrm{active} \mathrm{sites} \mathrm{and}$ improve thermal stability $\left(900{ }^{\circ} \mathrm{C}\right)$, resulting in complete 

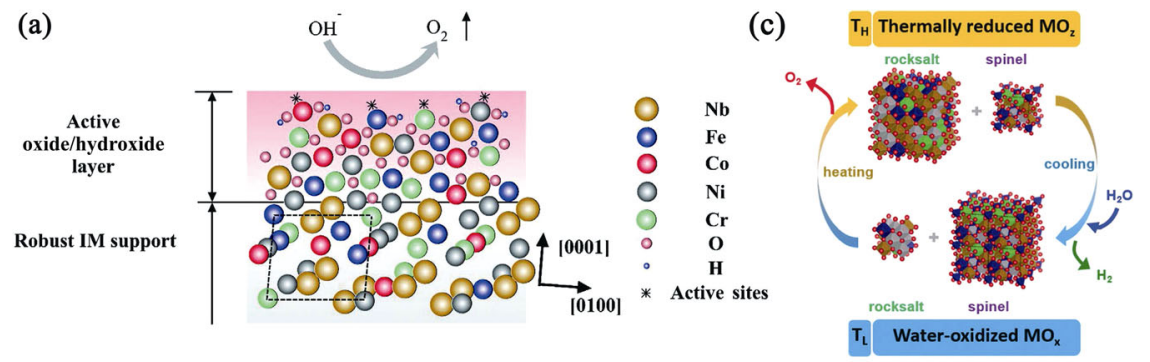

(b)

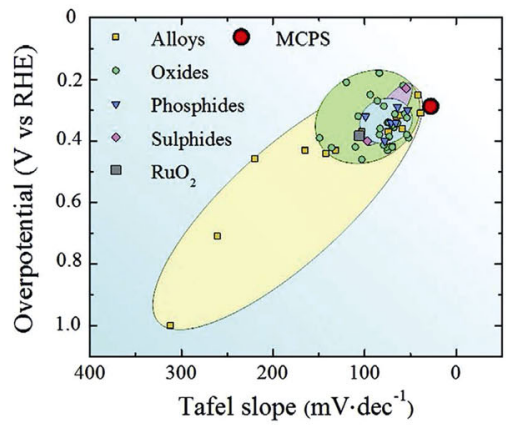

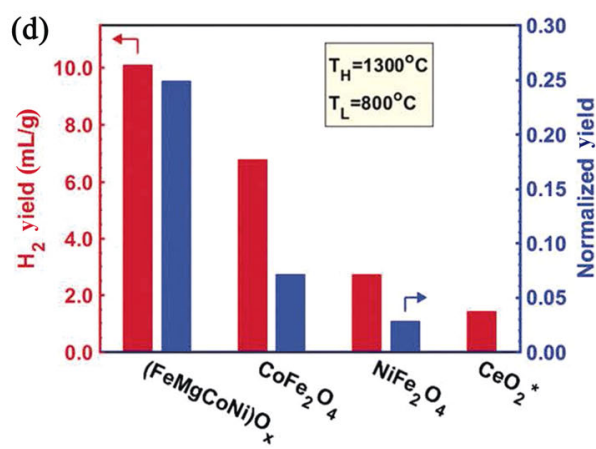

Fig. 5.8 Catalysts and water splitting performances of high-entropy materials. (a) Illustration of OER mechanisms of porous intermetallic supported multicomponent oxide film hierarchy. (b) Comparison of the performance of high-entropy intermetallicoxide core-shell nanostructure with previously reported OER electrocatalysts in terms of Tafel slope and overpotential at 10 $\mathrm{mA} \cdot \mathrm{cm}^{-2}$. (c) Schematic of two-step thermochemical water splitting using ( $\left.\mathrm{MgCoNiFe}\right) \mathrm{O}_{x}$. (d) $\mathrm{H}_{2}$ yield from long cycles of ( $\mathrm{MgCoNiFe}) \mathrm{O}_{x}$ compared with $\mathrm{CoFe}_{2} \mathrm{O}_{4}, \mathrm{NiFe}_{2} \mathrm{O}_{4}$, and $\mathrm{CeO}_{2}$. Reproduced with permission from Ref. [240] for (a, b), (C) WILEY-VCH Verlag GmbH \& Co. KGaA 2020; Ref. [244] for (c, d), C RSC 2018.

conversion of $\mathrm{CO}$ achieved at $305^{\circ} \mathrm{C}$. Thus, highly homogeneous, phase stability, high temperature stability, randomly active site distribution, and low coat make HEMs promising candidates for catalytic oxidation, accompanied by the need for more in-depth mechanism exploration.

\subsubsection{Decomposition}

The degradation of pollution is of practical significance from the perspective of environmental protection and water-saving. Lv et al. [245] found that the AlCoCrTiZn powder shows excellent performance with dye degraded in $10 \mathrm{~min}$. They proposed that the severe lattice distortion makes atoms possess high potential energy and are thus much more active than those in conventional alloys, leading to a low activation energy barrier, i.e., $30 \mathrm{~kJ} / \mathrm{mol}$. Moreover, selecting highly active elements can boost the catalytic properties. Large specific areas and abundant surface active sites of HEMs play an important role in the excellent dye decomposition behavior. For ammonia decomposition, Xie et al. [246] synthesized a serial of $\mathrm{CoMoFeNiCu}$ catalysts with robust control over the $\mathrm{Co} / \mathrm{Mo}$ atomic ratio. They demonstrated that the formation of HEAs can break the miscibility limitation in bimetallic $\mathrm{Co}-\mathrm{Mo}$ alloys and present good catalytic activity with the improvement factors exceeding 20 times as compared to precious metal $\mathrm{Ru}$, and even more so versus conventional Co-Mo catalysts. This study proposed that well-mixed surface-active sites on the HEA catalysts, tailored surface absorption properties, controllable * $\mathrm{NH}_{x}$ binding strength, and phase stability of HEMs are the reasons for the excellent catalytic performance.

\section{8 Thermoelectrics}

In view of thermoelectricity, higher efficiency of directconversional heat and electricity energy is invariably being hunted by researchers. The efficiency is dominated by the dimensionless figure of merit, i.e., the $z T$ value of materials, which is expressed as

$$
z T=\frac{\sigma S^{2}}{\kappa_{\mathrm{L}}+\kappa_{\mathrm{e}}} T
$$

where $\sigma$ is the electrical conductivity, $S$ is the Seebeck coefficient, $T$ is the absolute temperature, and $\kappa_{\mathrm{L}}$ and $\kappa_{\mathrm{e}}$ are lattice-induced and electron-induced thermal conductivity, respectively. High $\sigma S^{2}$ (i.e., power factor, PF) and low $\kappa=\kappa_{\mathrm{L}}+\kappa_{\mathrm{e}}$ are the key factors for improving $z T$, but unfortunately, carrier-concentration-associated coupling of $\sigma, S$, and $\kappa_{\mathrm{e}}$ leads to difficulty of regulating every 
single parameter independently. $\kappa_{\mathrm{L}}$, which is induced by lattice vibration and quantified as phonon, is a relatively independent parameter and focused on as the main tactic for enhancing $z T$. However, scattering phonon generally declines transfer of conductive carrier and deteriorates the electronic transport properties, and thus high $\sigma S^{2}$ and low $\kappa$ are difficult to be satisfied simultaneously.

Recently, enhancing chaos intentionally, aka high configurational entropy (HCE) engineering [24-26,209, $247,248]$, is emerging as a new route to increase $z T$ in thermoelectric (TE) community. Compared with ordinary TE semiconductors, which have minor amount of element or doping dosage, at least 5 constituents with $5 \%-35 \%$ proportion should be included in high configurational TE materials for high $\Delta S$. HCE strategy exhibits nice pertinence to penetrate the stubborn problem of TE: tightly coupling correlation of $S, \sigma$, and $\kappa$. Thus, this section will sum up the validity of high-entropy engineering in improving TE behavior and put forward the prospect of HCE materials in the future.

Liu et al. [44] developed a predictive model of entropy-indicator for discovering possible multicomponent TE materials. Several combinations of materials, such as $(\mathrm{Cu} / \mathrm{Ag})(\mathrm{In} / \mathrm{Ga}) \mathrm{Te}_{2^{-}}, \mathrm{Cu}_{2}(\mathrm{~S} / \mathrm{Se} / \mathrm{Te})-$, and $(\mathrm{Mn} /$ $\mathrm{Ge} / \mathrm{Sn} / \mathrm{Pb}) \mathrm{Te}-$ based materials, were successfully predicted and experimentally evaluated. Continuous enhancement of configurational entropy, which is touched off by increased solute constituent, causes drastic phonon scattering, so that $\kappa_{\mathrm{L}}$ is depressed to amorphous limit. Furthermore, increased configurational entropy induces higher and more obvious structural symmetry of crystals in intrinsically low symmetrical materials; such behavior increases the electronic density of state (DOS) and effective mass, as it increases the Seebeck coefficient. The reinforced Seebeck coefficient of $\mathrm{Cu}_{2}(\mathrm{~S} / \mathrm{Se} / \mathrm{Te})$ (from $20-40$ to $70-130 \mu \mathrm{V} / \mathrm{K}$ at room temperature) illustrates the connection of entropy-increasing and DOS-increasing. Besides, crystal-symmetry-induced reduction of phase transition temperature is observed in middle and low-entropy system. Another highentropy-oriented model was illustrated by Zhang et al. [111], and traced down a high-entropy sulfide TE ceramic of $\mathrm{Cu}_{5} \mathrm{SnMgGeZnS}_{9}$. The single-phase was synthesized and showed clear metallic behavior with high carrier concentration, which caused poor Seebeck coefficient. By introducing extra $\mathrm{Sn}$, the carrier concentration was reduced and Fermi level was dropped down, and thus $\mathrm{PF}$ was $800 \mathrm{~mW} /\left(\mathrm{m} \cdot \mathrm{K}^{2}\right)$ at $773 \mathrm{~K}$, which is comparable with other CuS-based TE materials. Also, low thermal conductivity of $\sim 1.03 \mathrm{~W} /(\mathrm{m} \cdot \mathrm{K})$ was achieved at $773 \mathrm{~K}$ due to intrinsically weak bonding of copper and sulfur, ultimately $z T$ of 0.58 was approached at $773 \mathrm{~K}$. Effect of high-entropy seems negligible in CuS-based TE materials owing to essentially low thermal conductivity, especially in pure phase materials.

Roychowdhury et al. [249] synthesized a highentropy selenide $(\mathrm{GeSe})_{0.5}\left(\mathrm{AgBiSe}_{2}\right)_{0.5}$. The introduction of AgBiSe portion transferred GeSe from p-type to n-type and increased the carrier concentration to $3.29 \times$ $10^{18} \mathrm{~cm}^{-3}$, which in one order of magnitude larger than that of pristine GeSe $\left(1.2 \times 10^{17} \mathrm{~cm}^{-3}\right)$, but the PF of $380 \mathrm{~mW} /\left(\mathrm{m} \cdot \mathrm{K}^{2}\right)$ still has space to be improved. Attributing to drastic scattering of phonons in highentropy system, the $z T$ of 0.45 was obtained at $677 \mathrm{~K}$.

Hu et al. [250] employed the multi-principal-element alloying (MPEA) with all-scale phonon-scattering to track higher $z T$ of SnTe-based TE material. MPEA is a lower configuration alloy with less component element, unequal molar compositions but the mix entropy is sufficiently high to acquire the core effects of HEMs $[247,250]$. Firstly, pristine SnTe co-alloyed with Sn-Ge-Te-Mn subtly modified by MPEA, such tactic made the Seebeck coefficient and carrier concentration increased concurrently, which was attributed to the better band convergence and higher level of solid solution doping, respectively. Hence $z T$ value of 1.07 was achieved in $\left(\mathrm{Sn}_{0.7} \mathrm{Ge}_{0.2} \mathrm{~Pb}_{0.1}\right)_{0.9} \mathrm{Mn}_{0.11} \mathrm{Te}$, being much higher than that of pristine $\operatorname{SnTe}(z T=0.38)$ at 900 K. Subsequently, all-scale phonon scattering was adopted for reducing thermal conductivity comprehensively by tuning the content of Mn. Benefiting from high-entropy effect, higher content of $\mathrm{Mn}$ in this matrix was occurred, which yields hierarchical precipitated phases as phonon scattering sources. Atomic-scale point defect and several micro-scale precipitated phases, i.e., GeTe, MnTe, and Ge, respectively, suppress shortwave and long-wave phonons, while local combination of line defect, strain clusters, and dislocation arrays contributing to hinder short-wave, and middle-wave phonons. At $900 \mathrm{~K}$, the strong phonon rampart restrains the $\kappa_{\mathrm{L}}$ to $0.32 \mathrm{~W} \cdot \mathrm{m}^{-1} \cdot \mathrm{K}^{-1}$ (total $\kappa=\sim 1.1 \mathrm{~W} \cdot \mathrm{m}^{-1} \cdot \mathrm{K}^{-1}$ ) and higher $z T$ of 1.27 was achieved in $\left(\mathrm{Sn}_{0.7} \mathrm{Ge}_{0.2} \mathrm{~Pb}_{0.1}\right)_{0.75} \mathrm{Mn}_{0.275} \mathrm{Te}$. It is worth mentioning that the tangly line defect and strain clusters are firstly discovered in high-entropy TE materials, which is referential for future development. Finally, content of 
Sn was finely tuned to improve over-high carrier concentration for more satisfied PF, eventually the optimized $z T$ of 1.42 was obtained in $\mathrm{Sn}_{0.555} \mathrm{Ge}_{0.15} \mathrm{~Pb}_{0.075} \mathrm{Mn}_{0.275} \mathrm{Te}$ at $900 \mathrm{~K}$.

Luo et al. [251] synthesized high-entropy SnSe-based materials to search for higher $z T$ values. $\mathrm{AgSbSe}_{2}$ was adopted to introduce cation disorder for restricting $\kappa$ and inducing special multi-peak electronic valence band. And then additional Te atom was led in for extra cation and anion, as well as formation of compact dislocation arrays. Such scenario caused amorphous glass-like $\kappa_{\mathrm{L}}$ of $\sim 0.32 \mathrm{~W} \cdot \mathrm{m}^{-1} \cdot \mathrm{K}^{-1}$. Simultaneously, convergence of band was promoted in the highest entropy sample $\left(\mathrm{AgSnSbSe}_{1.5} \mathrm{Te}_{1.5}\right)$, which represented the effect in enhancing electric behavior by entropy production. A peak $z T$ of 1.14 was achieved at $723 \mathrm{~K}$ and the average $z T$ of $\sim 1$ was comparable with other SnSe-based materials. Similarly, Tang et al. [252] intensified atomic disordering to restrain $\kappa_{\mathrm{L}}$ of SnTebased materials and combined MnTe for increasing the amount of transporting valence band to tune electrical performance. For $\mathrm{Sn}_{1 / 3} \mathrm{~Pb}_{1 / 3} \mathrm{Ge}_{1 / 3} \mathrm{Te}$, monotonously decreasing of $\kappa_{\mathrm{L}}$ (as low as $0.6 \mathrm{~W} \cdot \mathrm{m}^{-1} \cdot \mathrm{K}^{-1}$ ) with the increasing of the disorder parameter $\Gamma_{\text {total }}$, which expressed the increased entropy restrained phonon transfer, was observed. Additional introduction of suitable MnTe caused the rise of DOS near Fermi level, which indicated a maximized degeneracy of effective valence band due to the maximum of effective mass, hence ameliorating the transport properties. Besides, $\mathrm{Mn}$ ion reinforced point scattering for short-wave phonons, further reducing $\kappa_{\mathrm{L}}$, and finally, $z T$ of $\sim 1.8$ was approached at $850 \mathrm{~K}$.

From the route of enhancing transport properties, carrier behavior could be manipulated by artful doping. Qiu et al. [253] reduced phase transition temperature of GeTe-based material by employing a multi-doping method. Just like other HEMs, hierarchical-scale phonon scattering let $\kappa_{\mathrm{L}}$ go down to $0.4 \mathrm{~W} \cdot \mathrm{m}^{-1} \cdot \mathrm{K}^{-1}$ and markedly improved $z T$ from 0.03 for pristine GeTe to 0.5 for $\mathrm{Ge}_{0.84} \mathrm{In}_{0.010} \mathrm{~Pb}_{0.1} \mathrm{Sb}_{0.05} \mathrm{Te}_{0.997} \mathrm{I}_{0.003}$ at $\mathrm{RT}$ (the latter also showed 2.1 of $z T$ at $800 \mathrm{~K}$ ). Tang et al. [254] depicted another path of entropy engineering to manipulate TE behavior, wherein $\mathrm{Li}$ and $\mathrm{Mn}$ dual-doping were actualized in $\mathrm{BiCuSeO}$ system. The introduction of light $\mathrm{Li}$ increased carrier mobility dramatically via reduced carrier scattering (as high as $\left.7.39 \mathrm{~cm}^{2} /(\mathrm{V} \cdot \mathrm{s})\right)$ for enhancing $\sigma$, while different low-spin states of $\mathrm{Mn}^{2+}$ and $\mathrm{Mn}^{4+}$ ions rise the spin entropy, making improvement of Seebeck coefficient, which exhibited a novel pathway to rise system entropy. Nano-precipitated phases of $\mathrm{MnO}$ and point defect from dual-doping make up the multi-scale phonon scattering sources and suppress $\kappa_{\mathrm{L}}$ to $0.51 \mathrm{~W} \cdot \mathrm{m}^{-1} \cdot \mathrm{K}^{-1}$, resulting in a $z T$ of 0.9 at $873 \mathrm{~K}$ in $\mathrm{Bi}_{0.9} \mathrm{Li}_{0.1} \mathrm{Cu}_{0.9} \mathrm{Mn}_{0.1} \mathrm{SeO}$.

In summary, recent works unambiguously demonstrated the routes of enhancing the figure of merit, $z T=\frac{\sigma S^{2}}{\kappa_{\mathrm{L}}+\kappa_{\mathrm{e}}} T:$ multi-element component drives shortrange disorder, restrains transmission of heat-phonon due to grain and mass field fluctuation and hierarchical scattering, effectively decreasing $\kappa_{\mathrm{L}}$, while shaping band convergence and increasing band effective mass to increase crystal structure symmetry for improving transport properties, liberating the freedom of regulating $\sigma, S$, and $\kappa_{\mathrm{e}}$ to some extent.

In the case of regulating thermal conductivity, phonon scattering is augmented cogently, and the main reasons could be concluded as: (1) dense point defects are contained in multicomponent matrix, which induces fierce lattice distortion; (2) drastic fluctuation of mass and strain occurs due to coupling difference between solvent and solute atoms; (3) sluggish diffusion of atom conduces to hierarchical low-dimensional morphology, which contributes to all-scale phonon scattering. Such increasing $\Delta S$ strategy decreases $\kappa_{\mathrm{L}}$ forcefully and suppresses it to the limitation of amorphous, which depicts a mouthwatering tactic in enhancing energy converting efficiency. In the case of regulating transport properties, multi-atom doping expands solubility and tends to form high-symmetry crystal structure, which causes band convergence and larger band effective mass for adjusting transport properties. Besides, special element doping induces artful reinforcement of $\mathrm{PF}$, such as increased carrier mobility by light-element doping and enhanced Seebeck coefficient by spin-entropy. However, while effectively inhibiting the heat-carrier phonons, severely disordered atom distribution also affects carrier mobility, which results in unsatisfied PF for high $z T$ value. Thus, the degradation of carrier mobility should be compensated by excellent heat-barrier capacity and other electrical transport properties, which is still a need for exploring.

Figure 5.9 concludes the temperature-dependent $z T$ values of materials discussed in this section, illustrating that the ranking of properties is based on the matrix materials. It also implies that the enhancement of high 


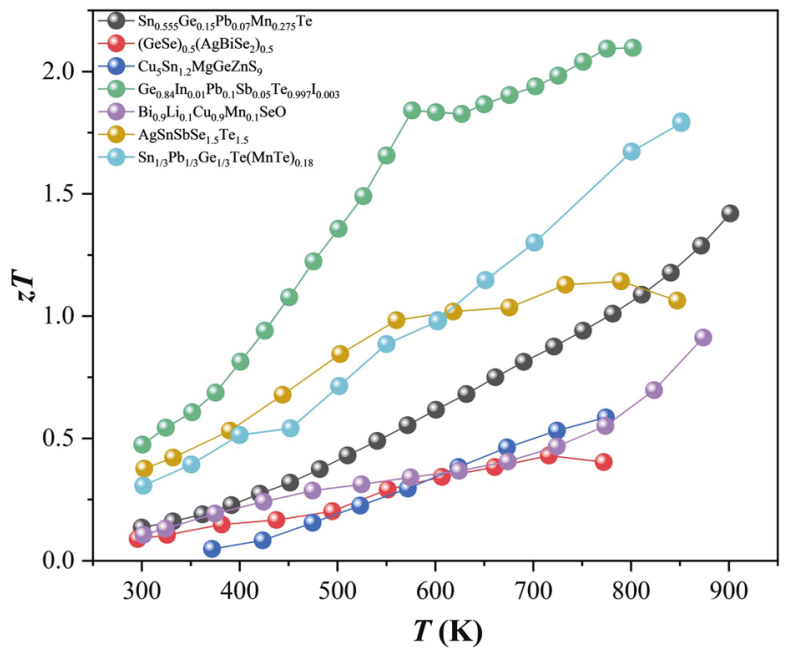

Fig. 5.9 Temperature-dependent $z T$ values of materials discussed in this section.

entropy is finite. Hence, despite high configurational entropy engineering directs the pathway of a new generation TE materials, such next generation TE material exhibits vast space for further improving its TE properties. Firstly, high-entropy produces insufficient benefit in those materials with intrinsically low $\kappa_{\mathrm{L}}$ or high symmetry $[44,250]$. As a conventional 3-dimensional system, it should be generalized to lower-dimension directions for further breakthrough since the striking effect of low-dimensionality was attested in thermoelectricity [255]. Profiting from the relatively mature film/coating layer application of HEMs [25], it is a promising direction to start corresponding TE researches from the two-dimensional TE films, aiming for a more enhanced effect in combination of high entropy and low-dimensional confinement effect. Also, the concept of high entropy could be expanded from homogeneous distribution of microscopic phases to low-dimensional morphology of hierarchical phases, i.e., the nanoscale inclusion and precipitation, which compose the potential barrier/well for further regulation of carrier and phonon. Besides, the entire mechanism of high-entropy effect in thermoelectricity is still not clear; more relevant theories are urgently needed. At last, what kind of practical application can make the best use of such a material with other excellent properties in addition to TE property, is a meaningful question.

\section{9 Supercapacitors}

Supercapacitors, the largest electric double-layer capacitors in mass production in the world, are electric double-layer capacitors. According to the choice of electrodes, supercapacitors mainly include carbon-based supercapacitors, metal oxide supercapacitors, and polymer supercapacitors. Among them, carbon-based supercapacitors are now the most widely used. Their performance depends to a large extent on the properties of carbon materials, surface area, particle size distribution, electrical conductivity, electrochemical stability, and other properties of the electrode materials. By introducing HEMs into carbon-based electrode materials, it is possible to increase the active sites and active surface area, and improve electrochemical stability, thereby obtaining higher capacity and current density. FeNiCoMnMg HEA-NPs modified super aligned electrospun carbon nanofibers were prepared and characterized [256]. Taking advantage of the stable charge/discharge rate provided by HEA-NPs, the samples exhibited a high capacitance of $203 \mathrm{~F} \cdot \mathrm{g}^{-1}$, a specific energy density of $21.7 \mathrm{Wh} \cdot \mathrm{kg}^{-1}$, and good stability after 2000 cycles, as shown in Fig. 5.10. Other than HEAs, high-entropy nitride (CrMoNbVZr)N was synthesized using a mechanochemical soft urea approach and investigated for use in supercapacitor applications [122]. (CrMoNbVZr)N exhibited specific capacitances of $78 \mathrm{~F} \cdot \mathrm{g}^{-1}$, owing to the high surface area and unique chemical properties of HEMs. These findings give hints for the HEA, HECs, and related compounds as promising candidates for energy storage applications.

\section{10 Microeletronics}

With the miniaturization of microelectronics, novel materials are needed to prevent the formation of $\mathrm{Cu}_{3} \mathrm{Si}$ at the interface between copper and silicon which increases resistance and reduces the efficiency of the devices. High-entropy nitrides are particularly promising as diffusion barriers for microelectronic devices. The severe lattice distortion and high packing density of HE nitrides caused by distinct atom radius will lead to sluggish diffusion and provide an ideal solution for preventing microelectronic devices' interdiffusion. Currently, most high-entropy nitrides, like amorphous (AlMoNbSiTaTiZr)N [257], nanocrystalline (AlCrTaTiZr)N [258], and (CrHfTiVZr)N thin film [259] have been reported; even if the thickness of HE nitride film was very thin, only about $10 \mathrm{~nm}$, they show good barrier performance. The performance of amorphous (AlMoNbSiTaTiZr)N film was evaluated by constructing a $\mathrm{Cu} /(\mathrm{AlMoNbSiTaTiZr}) \mathrm{N} / \mathrm{Si}$ test structure, as shown in Fig. 5.11, and annealed at the 


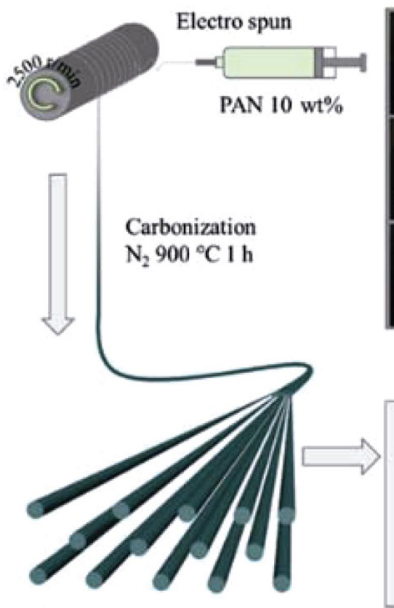

Oriented carbon nanofiber

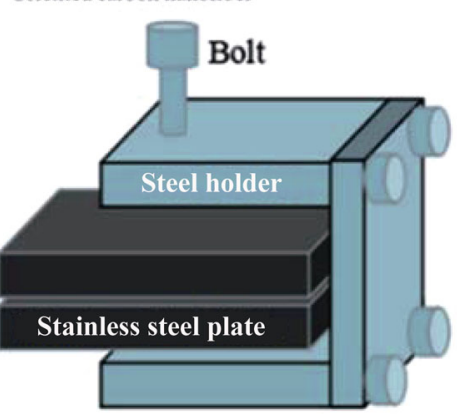

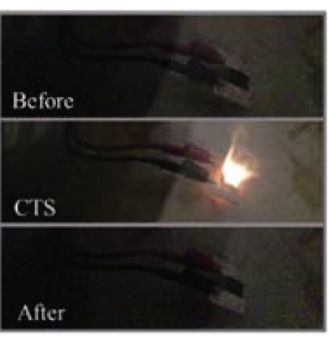
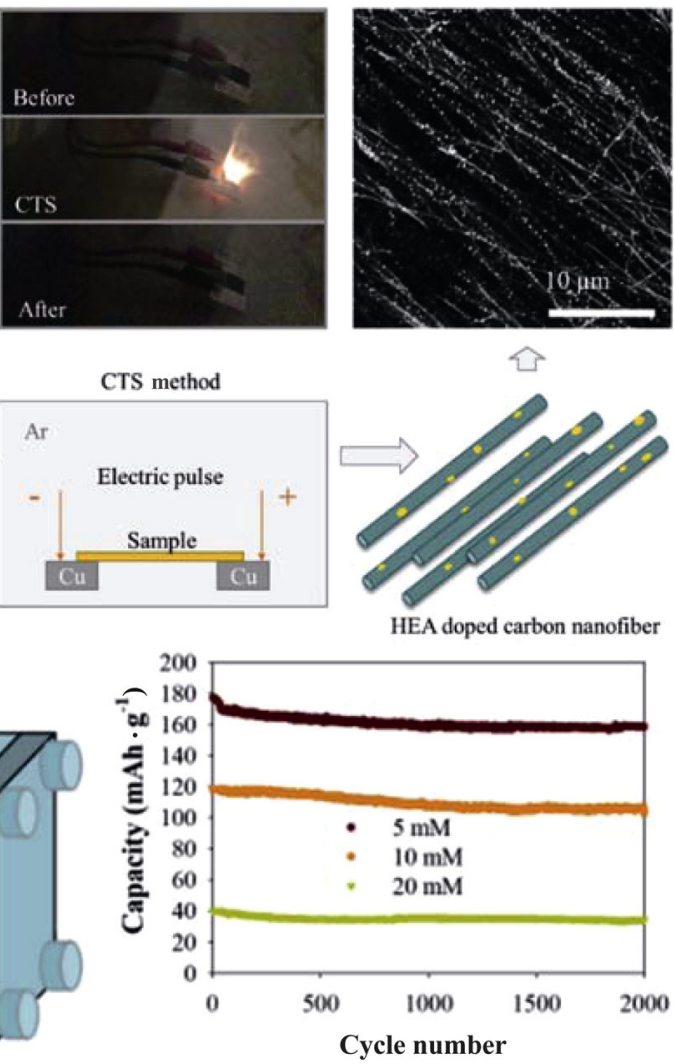

Fig. 5.10 Synthesis of HEA-NPs/ACNFs film and electrochemical characterization. Reproduced with permission from Ref. [256], (C) Elsevier B.V. 2020.
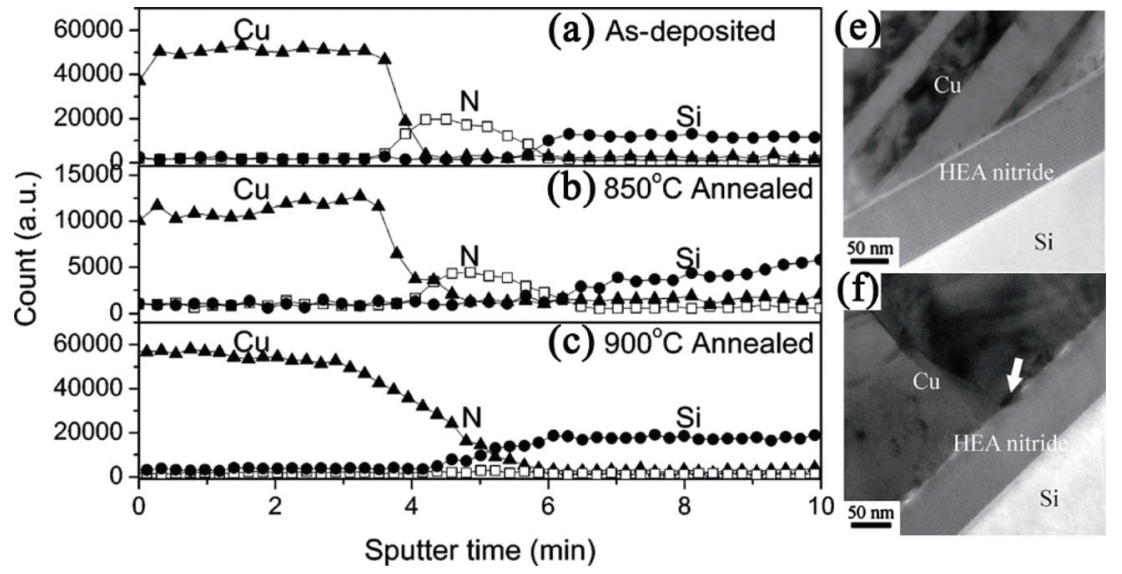

Fig. 5.11 Characterization of $\mathrm{Cu} / \mathrm{MHEAN} / \mathrm{Si}$ structure. AES depth profiles of (a) as-deposited, (b) $850{ }^{\circ} \mathrm{C}$-annealed, (c) $900{ }^{\circ} \mathrm{C}$-annealed. Transmission electron micrographs of $\mathrm{Cu} / \mathrm{MHEAN} / \mathrm{Si}$ (e) after $800{ }^{\circ} \mathrm{C}$ annealing and (f) after $850{ }^{\circ} \mathrm{C}$ annealing. Reproduced with permission from Ref. [257], (C) AIP Publishing 2008.

temperature range from 750 to $900{ }^{\circ} \mathrm{C}$ for $30 \mathrm{~min}$. The results show that the amorphous structure of the as-deposited high-entropy nitride still remained and the current nitride can prevent the reaction between $\mathrm{Cu}$ and $\mathrm{Si}$ around $800{ }^{\circ} \mathrm{C}$ before its failure at $900{ }^{\circ} \mathrm{C}$; even small copper diffusion occurred to a distance of $10 \mathrm{~nm}$, as shown in Fig. 5.11(f). The high thermal stability of the amorphous structure was proposed to originate from the multielement effect first. This multielement mixture led to severe lattice distortion and reduced diffusion kinetics. Secondly, due to the size differences between the various kinds of atoms, a higher atomic packing density was expected, thereby less free volume making diffusion more difficult. 


\section{11 Biocompatible coatings}

Various materials have been explored for biomedical applications, e.g., orthopedy, dentistry, ophthalmology, pharmaceutical drugs, biopharmaceuticals, etc. At present, only 316L stainless steels, titanium, and cobaltchromium alloys are considered as suitable biomaterials for dental and orthopedic implants. However, their biocompatibility, wear, and corrosion resistance are relatively low. As usual, good biocompatible coating must have the following characters: low elastic modulus, high chemical stability, good wear-corrosion resistance low friction coefficient, biological compatibility, and good adhesion to the substrate. For HECs, especially high-entropy carbides and nitrides, solution strengthening and lattice distortion can significantly increase their strength, hardness, and other mechanical properties; sluggish diffusion effects endow them good wearcorrosion resistance and high chemical stability, which makes them promising as coating materials for biomedical implants. $\mathrm{HE} \mathrm{CaMgZnSrYb}$ amorphous alloy [260] can withstand four weeks of animal tests, and new bone tissue formed around the femur, indicating that the $\mathrm{HE} \mathrm{CaMgZnSrYb}$ can promote the proliferation and differentiation of rat osteoblasts, and accelerate the healing of bone tissue. Braic et al. [261] investigated the biomedical properties of $\mathrm{HE}$ (TiZrNbHfTa)N and (TiZrNbHfTa)C coatings. They reported that the $\mathrm{HE}$ carbide coating exhibited wear resistance and excellent biocompatibility when tested in simulated body fluids. Cell-viability tests proved that the osteoblast cells were adherent to the (TiZrNbHfTa)N and (TiZrNbHfTa)C coatings, and a very high ratio of live cells (in green) was observed on their surfaces after $72 \mathrm{~h}$ of incubation time, as shown in Fig. 5.12. Si-containing coatings can further improve cell attachment and viability, with (HfNbSiTiZr)C being the most biocompatible material until now [262].

\section{Future directions}

\section{1 Demand driven materials' design}

Knowledge based materials' design has long been the objective of material research, especially after the announcement of Materials Genome Initiative (MGI) in 2011, which challenges the traditional "try and error" research schema towards a new paradigm that accelerate the discovery, design, and deployment of materials by synergistically combining experiment, theory, and computation in a tightly integrated, high-throughput manner [263]. Due to the increase of computational capability, the high-throughput and machine learning (ML) assisted approaches are playing increasing roles in the design of materials.

Since the advent of HEMs, including HEAs and HECs, efforts have been carried out to design new HEMs to meet the needs in different domains, e.g., energy, transportation, national defense, and aerospace, etc. The distinct multi-principal elements of HEMs in comparison with traditional materials make people believe that new physics and properties can be discovered in HEMs, e.g., overcoming the strengthductility trade-off [11], colossal dielectric constant [20], lithium superionic conductivity [21], and amorphouslike thermal conductivity [19]. It is not only the high-entropy single phase state but also the mediumentropy state or multi-phase state can provide intriguing properties. Therefore, the development of HEMs is on its way to compositionally complex materials [26,264-267].

For the demand driven design of HEMs, two fundamental aspects need to be addressed, as shown in Fig. 6.1. One is predicting the formation ability of HEMs with respect to composition and processing; while the other is exploring the "composition-structureproperty" relations, and developing property prediction
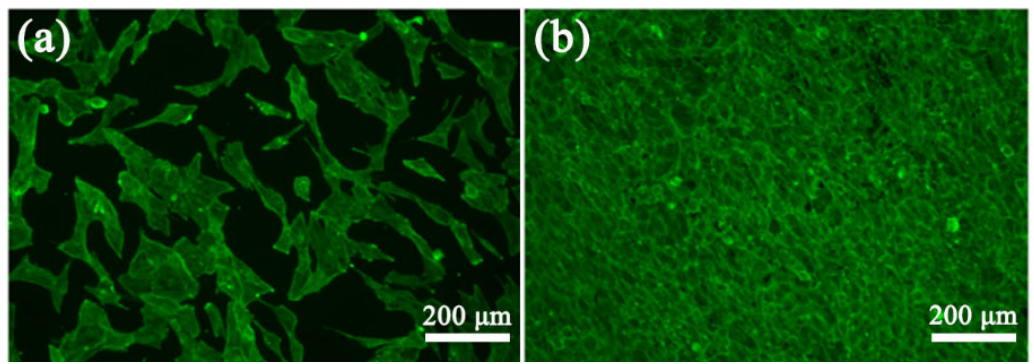

Fig. 5.12 Immunofluorescence images of cells seeded on samples: Ti6Al4V sample at $24 \mathrm{~h}$ (a), (TiZrNbHfTa)C sample at $72 \mathrm{~h}$ (b). Reproduced with permission from Ref. [261], (C) Elsevier Ltd. 2012. 


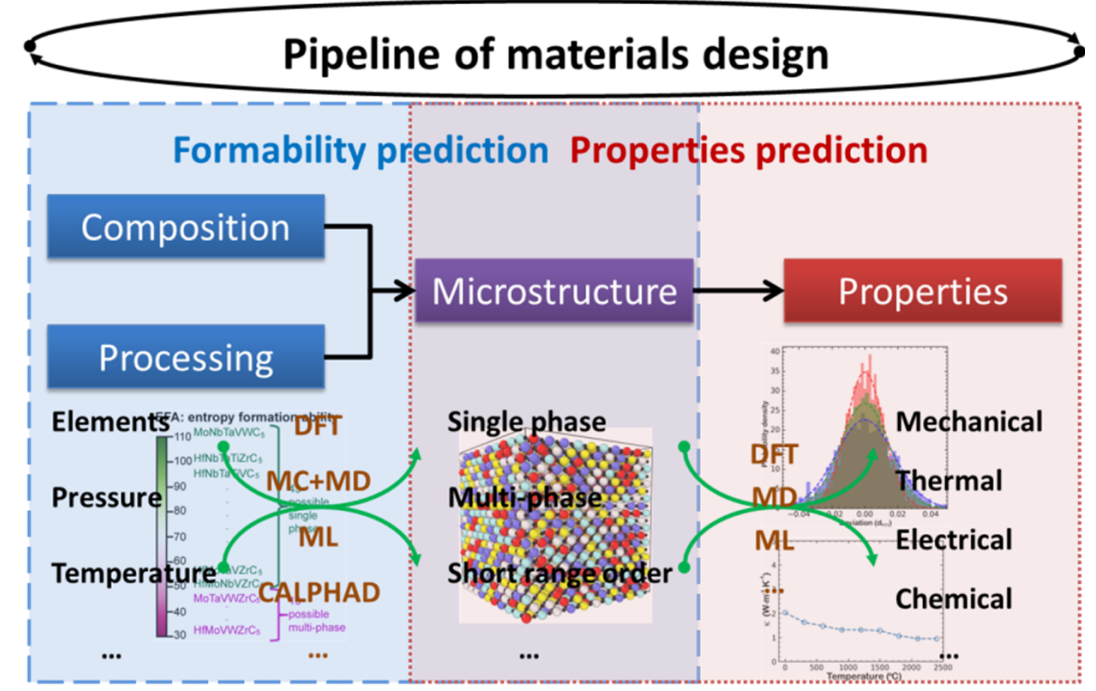

Fig. 6.1 Pipeline of material design. DFT stands for density functional theory, MC stands for Monte Carlo, MD stands for molecular dynamics, ML stands for machine learning, and CALPHAD stands for calculation of phase diagram.

models. Computational modeling can employ density functional theory (DFT) based method, molecular dynamic (MD) simulations, Monte Carlo (MC) simulations, calculation of phase diagrams (CALPHAD), surrogate models from machine learning, simplified models based on physical assumptions, or other methods.

\section{2 Property prediction}

\subsubsection{Stability prediction}

Very few theoretical investigations have been carried out to predict the formation ability of HECs or to evaluate the order-disorder transformation of HECs. Anand et al. [49] employed generic algorithm and MD simulations with traditional force fields to study order-disorder transformation of HECs in $\mathrm{Mg}-\mathrm{Co}-\mathrm{Ni}-$ $\mathrm{Cu}-\mathrm{Zn}-\mathrm{O}$ oxides, which explains well experimental results reported by Rost et al. [29]. A descriptor called entropy forming ability (EFA), which is based on variance of configurational dependent energies, was proposed by Sarker et al. [64] to predict the formation ability of high-entropy carbides. Kaufmann et al. [267] trained a random forest model (a type of ML model) to predict EFA of HE carbides, and checked the generality of the model with correctly predicted and synthesized Cr-containing HE carbides. Similar idea was also adopted by Pitike at al. [106], who approximated configurational energies of HECs only by considering pairwise interactions, and analyzed the formation ability of rock-salt oxides by considering both the mean and the variance of configurational dependent energies. Similar descriptors as those of Sarker et al. [64] and Pitike et al. [106] in combination with redox mechanism were also adopted by Lun et al. [67] to predict the formation ability of high-entropy battery cathodes. Zhang et al. [111] developed a data-driven model to choose elements that may exhibit high possibility to form high-entropy sulfides. In comparison to HECs, more studies on predicting the formation ability have been done in HEAs [166, 268-273]. These works provide guidelines to develop predictive models for HECs, for example, approximating configurational energies by only considering pairwise interactions. Though such simplification loses some accuracy, it greatly reduces the computational consumption that needs to explore the vast combination space of elements, which enables people to fast scanning on large compositional space.

\subsubsection{Properties prediction}

Theoretical investigations on HECs are in their infant stage, and only limited papers have been published [19,48,50-53,57,183,184,274,275]. Among HECs, $\mathrm{Mg}-\mathrm{Co}-\mathrm{Ni}-\mathrm{Cu}-\mathrm{Zn}-\mathrm{O}$ HEOs family is the most theoretically studied. Rák et al. [48,53] evaluated the charge compensation mechanism in three $\mathrm{Mg}-\mathrm{Co}-\mathrm{Ni}-$ $\mathrm{Cu}-\mathrm{Zn}-\mathrm{X}-\mathrm{O}$ oxides and Jahn-Teller distortions related to $\mathrm{Cu}$ cations in $\left(\mathrm{Mg}_{0.2} \mathrm{Co}_{0.2} \mathrm{Ni}_{0.2} \mathrm{Cu}_{0.2} \mathrm{Zn}_{0.2}\right) \mathrm{O}$ by DFT calculations with special quasi-random structures (SQS) to model the random occupation of cations. Their results are highly consistent with experimental measurements $[29,46,47]$, which provides atomic scale understanding 
of $\mathrm{Mg}-\mathrm{Co}-\mathrm{Ni}-\mathrm{Cu}-\mathrm{Zn}-\mathrm{O}$ oxides. Braun et al. [19] examined the amorphous-like thermal conductivities of $\mathrm{Mg}-\mathrm{Co}-\mathrm{Ni}-\mathrm{Cu}-\mathrm{Zn}-\mathrm{X}-\mathrm{O}$ family oxides with virtual crystal approximation (VCA) and MD simulations, which reveals the importance of charge non-uniformity (more strictly, chemical bonding distortion or atomic force disorder) in reducing the thermal conductivity to an extra-low regime. Their findings were further confirmed by Lim et al. [183], who checked the effects of mass and atomic force disorder on thermal conductivity in $\mathrm{Mg}-\mathrm{Co}-\mathrm{Ni}-\mathrm{Cu}-\mathrm{Zn}-\mathrm{X}-\mathrm{O}$ oxides by MD simulations. Chen et al. [274] revealed that substitutions of $\mathrm{Li}$ or $\mathrm{Mn}$ into $\left(\mathrm{Mg}_{0.2} \mathrm{Co}_{0.2} \mathrm{Ni}_{0.2} \mathrm{Cu}_{0.2} \mathrm{Zn}_{0.2}\right) \mathrm{O}$ will reduce the compressibility due to the weaker ionic bonding by MD relaxations. In comparison to HEAs, charge compensation between cations, anions, and vacancies and chemical environment selectivity introduce more freedom of local distortions for HECs, which may offer higher probability to discover intriguing physics and properties.

The other set of HECs that has been studied theoretically is high-entropy UHTCs, e.g., carbides and diborides [50-52,57,104,275]. With SQS and DFT calculations, the electronic structures and mechanical properties of $\left(\mathrm{Ta}_{0.2} \mathrm{Nb}_{0.2} \mathrm{Hf}_{0.2} \mathrm{Ti}_{0.2} \mathrm{Zr}_{0.2}\right) \mathrm{C}$ and $\left(\mathrm{Hf}_{0.2} \mathrm{Zr}_{0.2} \mathrm{Ta}_{0.2} \mathrm{M}_{0.2} \mathrm{Ti}_{0.2}\right) \mathrm{B}_{2}(\mathrm{M}=\mathrm{Nb}, \mathrm{Mo}, \mathrm{Cr})$ were studied by Wang et al. [57] and Yang et al. [275], respectively. However, the real compositions in their calculations deviate from the proposed mole ratio of cations due to the limited supercell sizes, even though the deviation may not cause significant changes in the properties. In modeling HEMs, the most fundamental complexity faced with is the chemical complexity due to their multi-principal elements in nature. A sufficient large supercell is necessary to characterize the random occupation state of different elements, which is usually beyond the computational limit of DFT based method. By introducing machine learning potentials to bridge DFT calculations and MD simulations, Dai et al. $[50,52]$ predicted lattice distortions and temperature dependent elastic and thermal properties of $\left(\mathrm{Ti}_{0.2} \mathrm{Zr}_{0.2} \mathrm{Hf}_{0.2} \mathrm{Nb}_{0.2} \mathrm{Ta}_{0.2}\right) \mathrm{C}$ and $\left(\mathrm{Ti}_{0.2} \mathrm{Zr}_{0.2} \mathrm{Hf}_{0.2} \mathrm{Nb}_{0.2} \mathrm{Ta}_{0.2}\right) \mathrm{B}_{2}$, where the room temperature results agree well with experimental measurements. This new paradigm enables high accurate and high efficient atomistic simulations in systems with high chemical and structural complexities, e.g., HEMs, surface or interfaces. It is hopeful that deep insight into HECs will come forth in near further with such powerful methods.
Up to now, most theoretical investigations focus on DFT calculations and MD simulations, and empirical property prediction models derived based on physical assumptions or trained from data with machine learning methods have rarely been proposed for HECs. Though DFT calculations and MD simulations can provide in depth understanding of "compositionstructure-property" relations of HECs, empirical models are still essential for property tailoring and material design due to their ability of fast scanning on large compositional and structural space. In principle, the fast scanning ability is quite important because of the huge compositional space of HEMs.

\section{3 Innovative and green processing}

Up to now, methods used to make HECs are limited, which will hinder the practical applications and further development of this new family of materials. Currently, the most widely used methods for preparing bulk HECs are SPS and HP, and it is challenging to scale up the sample size for testing and practical applications. Due to limited sample size, hardness, Young's modulus, and thermal conductivity are frequently reported. However, only very limited data are available on room and elevated temperature strength and fracture toughness of HECs [170]. Besides improving the SPS and HP processes, densification methods like pressureless sintering and reactive sintering are useful to scale up the sample size. As we have mentioned in Section 3, pressureless sintering has successfully been used to fabricate transparent $\left(\mathrm{Lu}_{0.2} \mathrm{Y}_{0.395} \mathrm{Gd}_{0.2} \mathrm{Yb}_{0.2} \mathrm{Tm}_{0.005}\right)_{2} \mathrm{O}_{3}$ [110] and reactive sintering has been used to prepare bulk $(\mathrm{Ca}, \mathrm{Sr}, \mathrm{Ba}) \mathrm{ZrO}_{3}$ [45], suggesting that these methods are applicable to other systems. Especially, most current ceramic processing techniques comprise powder processing, milling, forming, and sintering; integrating these steps into a forming-reactive sintering process is energy-saving and more efforts need to be devoted in this direction.

Aside from dense bulk, porous and fibrous HECs play pivotal roles in ultrahigh-temperature thermal protection and thermal insulation. Highly porous high-entropy $\quad\left(\mathrm{Zr}_{0.2} \mathrm{Hf}_{0.2} \mathrm{Ti}_{0.2} \mathrm{Nb}_{0.2} \mathrm{Ta}_{0.2}\right) \mathrm{C} \quad$ [22], $\left(\mathrm{Zr}_{0.2} \mathrm{Hf}_{0.2} \mathrm{Ti}_{0.2} \mathrm{Nb}_{0.2} \mathrm{Ta}_{0.2}\right) \mathrm{B}_{2}$ [40], and $\left(\mathrm{Y}_{0.2} \mathrm{Yb}_{0.2} \mathrm{Sm}_{0.2} \mathrm{Nd}_{0.2} \mathrm{Eu}_{0.2}\right) \mathrm{B}_{6}$ [98] have already been prepared by the in situ reaction/partial sintering process. Since the process uses carbothermal, borothermal, or boro/carbothermal reduction released gases to produce porous highentropy carbide and boride ceramics, it has the 
advantages of low-cost starting materials, low synthesizing temperatures, and no need of pore forming agents and sintering additives, and partial sintering can be completed immediately after synthesis. It is expected that this process can be applied to prepare other porous HECs. Up to now, there have been no reports concerning the fabrication of HECs fibers. Since HECs exhibit good high-temperature strength [170,171], excellent creep resistance [172], good thermal/environmental stability, and low thermal conductivity $[23,37,71,85,88-93]$, it is expected that HECs fibers will have better high-temperature strength, good stability, and low thermal conductivity. In light of this, more efforts should be devoted to this direction. For example, electrospinning of HECs precursor followed by calcining is an efficient and simple way to fabricate fibrous HECs for thermal insulating application [276]. In addition, template method which is usually employed to prepare polymer and ceramic nanowires with various microstructure also has the potential for HE nanowires, and owns the advantages of highly structure controllable, high yield, and less energy input.

Flash sintering, which is characterized by low furnace temperature and ultrafast synthesis, has been used to fabricate HECs powders and dense HECs bulk [123-126]. In addition, solid-state reaction and densification can be integrated into one cycle so that it is an energy-saving process. It is expected that this process can be used in other systems during the hunt for new HECs. Besides flash sintering, other field assisted process such as microwave sintering is also promising as a fast and green processing method since the electromagnetic properties of HECs are tunable, which allows the rapid synthesis and densification of HECs.

For HECs powders, which can be used as initial material for fabrication of bulk HECs or as electromagnetic wave absorbing materials, photocatalysts, battery materials, etc., wet chemical methods are highly recommended due to the fact that multi-components can be homogeneously mixed at the molecular level and synthesis reaction can be conducted at low temperatures. Although wet chemical methods have been used to synthesize high-entropy oxides [31,60, 87,115,119], carbides [121], and nitrides [122], more efforts need to be devoted especially for the synthesis of nanometer-sized HECs powders. Thus, in addition to hydrothermal, co-precipitation, sol-gel, and other methods, we propose that microemulsion method with the advantage of low-cost and controllable size, electrolysis for high purity nanoparticles, reaction ball milling, high-temperature combustion method with high efficiency, and rotating-electrodeposition [277] may also be used to prepare HEMs.

In above content, we have proposed existing and possible methods for preparing HE particles and bulks. However, microstructure, surface modification, and interface construction that of great importance for reaching high performance are barely reported. Fabricating HEMs with various micro-nanostructure, like core-shell and York-shell nanoparticles, hollow fibers, and aligned wires is one of the future directions. Core-shell HEA particles, composed of coarse-grained (CG) core and ultrafine-grained (UFG) shell, have been prepared via a controlled mechanical milling and subsequent SPS process [278]. The adjustable core-shell ratio has great influence on the mechanical properties. Besides physical methods, in order to realize the structural design, one can also learn from the aforementioned wet chemical methods. For example, HEA oxides@ HEA core-shell nanoparticles were synthesized by a facile and rapid electrochemical process and show enhanced OER activities [279]. Thus, microstructure design based on HEMs can promote the development of mechanics, electrochemistry, energy, catalysis, and other fields, which needs more investment and efforts.

From the preparation of functional unit like particles and films to microstructure design, then the next steps will come to the manufacture of devices for microelectronic, catalysis, energy power, drug, or gene delivery, etc. The FePt alloy nanopropeller device has been prepared by electron beam evaporation on silica and titanium layers. This nanopropeller could be accurately steered toward specific cells, where transfection and gene delivery are achieved, indicating broad application prospects in the biomedical field, and it is also very instructive for HEM biodevices [280]. Direct writing technology can precisely manipulate a single micro-nanowire, of course high-entropy fibers, and prepare highly ordered inorganic micro-nanowires on a rigid substrate and a flexible substrate efficiently which is a convenient method to make optoelectronic devices [281]. The spin-coated HE precursor combined with subsequent heat treatment can produce multilayer film devices, such as SOFC. Although it is not easy, the preparation of devices is inevitable for further performance improvement and application development. 


\section{4 Novel characterization methods}

The fascinating properties of HECs are dictated by their microstructures and compositional elements. The large structural and compositional complexity of HECs provide great possibility for engineering their properties; however, design and preparation of HECs with desired properties still hinge on the clearly understanding of the composition-structure-property relationships at microscale and nanoscale. In this part, we focus on the advanced methods for the characterization of the phase composition, elemental distribution, lattice distortion, and valence state of the elements in HECs.

\subsubsection{Phase composition and elemental distribution}

As is known, an ideal HEC should exhibit a long-range ordered and periodic lattice structure but with compositional disorder. Therefore, single phase composition and homogeneous elemental distribution are two main structural features of HECs, which are commonly characterized by X-ray diffraction (XRD) and energy dispersive X-ray spectroscopy (EDS) equipped in scanning electron microscope (SEM), respectively. Another widely used method to verify the single-phase composition of HECs is through analyzing the selected-area electron diffraction (SAED) pattern obtained in transmission electron microscopy (TEM) or the fast Fourier transformations (FFTs) of highresolution TEM (HRTEM) image. Jin et al. [122] used HRTEM image and its corresponding FFTs to show the single-phase structure and nanocrystalline grains of a high-entropy metal nitride ceramic. By using similar methods, Sarkar et al. [31] illustrated the perfect crystalline and single orthorhombic perovskite structure of $\left(\mathrm{Gd}_{0.2} \mathrm{La}_{0.2} \mathrm{Nd}_{0.2} \mathrm{Sm}_{0.2} \mathrm{Y}_{0.2}\right)\left(\mathrm{Co}_{0.2} \mathrm{Cr}_{0.2} \mathrm{Fe}_{0.2} \mathrm{Mn}_{0.2} \mathrm{Ni}_{0.2}\right) \mathrm{O}_{3}$.

Compared to SEM-EDS, scanning TEM (STEM) is one of the state-of-the-art techniques to probe into the elemental distribution of HEMs at atomic scale. Through analyzing the contrast in the atomicresolution high angle annular dark field (HAADF) image obtained in STEM, Sarkar et al. [31] showed the homogeneity of the elemental distribution at nanoscale in a high-entropy perovskite oxide. For comparison, STEM-EDS is a more thorough method to character the elemental distribution of HEMs. For example, Rost et al. [29] used STEM-EDS mapping to show the atomic-scale distribution of the $\mathrm{Mg}, \mathrm{Co}, \mathrm{Ni}, \mathrm{Cu}, \mathrm{Zn}$ in $\left(\mathrm{Mg}_{0.2} \mathrm{Ni}_{0.2} \mathrm{Co}_{0.2} \mathrm{Cu}_{0.2} \mathrm{Zn}_{0.2}\right) \mathrm{O}$ thin film (Fig. 6.2(a)), revealing the chemical and structural homogeneity of
$\left(\mathrm{Mg}_{0.2} \mathrm{Ni}_{0.2} \mathrm{Co}_{0.2} \mathrm{Cu}_{0.2} \mathrm{Zn}_{0.2}\right) \mathrm{O}$. Ding et al. [39] also used this method to investigate the atomic-scale elemental distribution in a CrFeCoNiPd alloy (Fig. 6.2(b)), combined with correlated analysis, they found the existence of short-range ordering nanoscale clusters and revealed their important role in improving the yield strength, strain hardening, and tensile ductility.

Electron energy loss spectrometry (EELS) is also a robust method to characterize the elemental distribution in HECs. Sharma et al. [117] illustrated the atomicscale homogeneous distribution of $\mathrm{Cr}, \mathrm{Mn}, \mathrm{Fe}, \mathrm{Co}, \mathrm{Ni}$ in $\mathrm{B}$-site position of a single crystal perovskite $\mathrm{La}\left(\mathrm{Cr}_{0.2} \mathrm{Mn}_{0.2} \mathrm{Fe}_{0.2} \mathrm{Co}_{0.2} \mathrm{Ni}_{0.2}\right) \mathrm{O}_{3}$ thin film by using STEM-EELS. Besides, EELS is a complementary technique to EDS in the determination of low atomic number elements which are difficult to detect by conventional EDS method in HECs. Therefore, it can be used to detect the anion elements (such as B and C) or low atomic number cation elements (such as $\mathrm{Li}$ ) in HECs.

Atom probe tomography (APT) is a method to characterize the elemental distribution of materials at atomic scale in three-dimension (3D). By using APT, Chellali et al. [282] confirmed the homogeneity of elemental distribution in $3 \mathrm{D}$ at atomic scale in three different HECs, including rocksalt $\left(\mathrm{Co}_{0.2} \mathrm{Cu}_{0.2} \mathrm{Mg}_{0.2} \mathrm{Ni}_{0.2} \mathrm{Zn}_{0.2}\right) \mathrm{O}$, fluorite $\left(\mathrm{Ce}_{0.2} \mathrm{La}_{0.2} \mathrm{Pr}_{0.2} \mathrm{Sm}_{0.2} \mathrm{Y}_{0.2}\right) \mathrm{O}_{2-\delta}$, and perovskite $\left(\mathrm{Gd}_{0.2} \mathrm{La}_{0.2} \mathrm{Nd}_{0.2} \mathrm{Sm}_{0.2} \mathrm{Y}_{0.2}\right)\left(\mathrm{Co}_{0.2} \mathrm{Cr}_{0.2} \mathrm{Fe}_{0.2} \mathrm{Mn}_{0.2} \mathrm{Ni}_{0.2}\right) \mathrm{O}_{3}$ (Fig. 6.2(c)).

\subsubsection{Lattice distortion}

Besides phase composition and elemental distribution, lattice distortion is also an important atomic scale structural characteristic of HECs. As one of the four main characteristics of HEMs, lattice distortion is of great significance for the low thermal conductivity, enhanced mechanical properties, and high temperature stability of HECs. Through tuning the lattice distortion, the physical properties such as band gap and magnetic properties of HEC could also be tuned.

Currently, the lattice distortion of HECs is usually illustrated by analyzing the extended X-ray absorption fine structure (EXAFS). By using this method, Rost et al. [46] illustrated the existence of severe distortion around the $\mathrm{Cu}-\mathrm{O}$ polyhedra in $\mathrm{Mg}_{0.2} \mathrm{Ni}_{0.2} \mathrm{Co}_{0.2} \mathrm{Cu}_{0.2} \mathrm{Zn}_{0.2} \mathrm{O}$. After related density functional theory (DFT) calculations, they showed that the lattice distortion in $\mathrm{Mg}_{0.2} \mathrm{Ni}_{0.2} \mathrm{Co}_{0.2} \mathrm{Cu}_{0.2} \mathrm{Zn}_{0.2} \mathrm{O}$ results from the disorder in the oxygen sublattice. Braun et al. [19] used the similar 


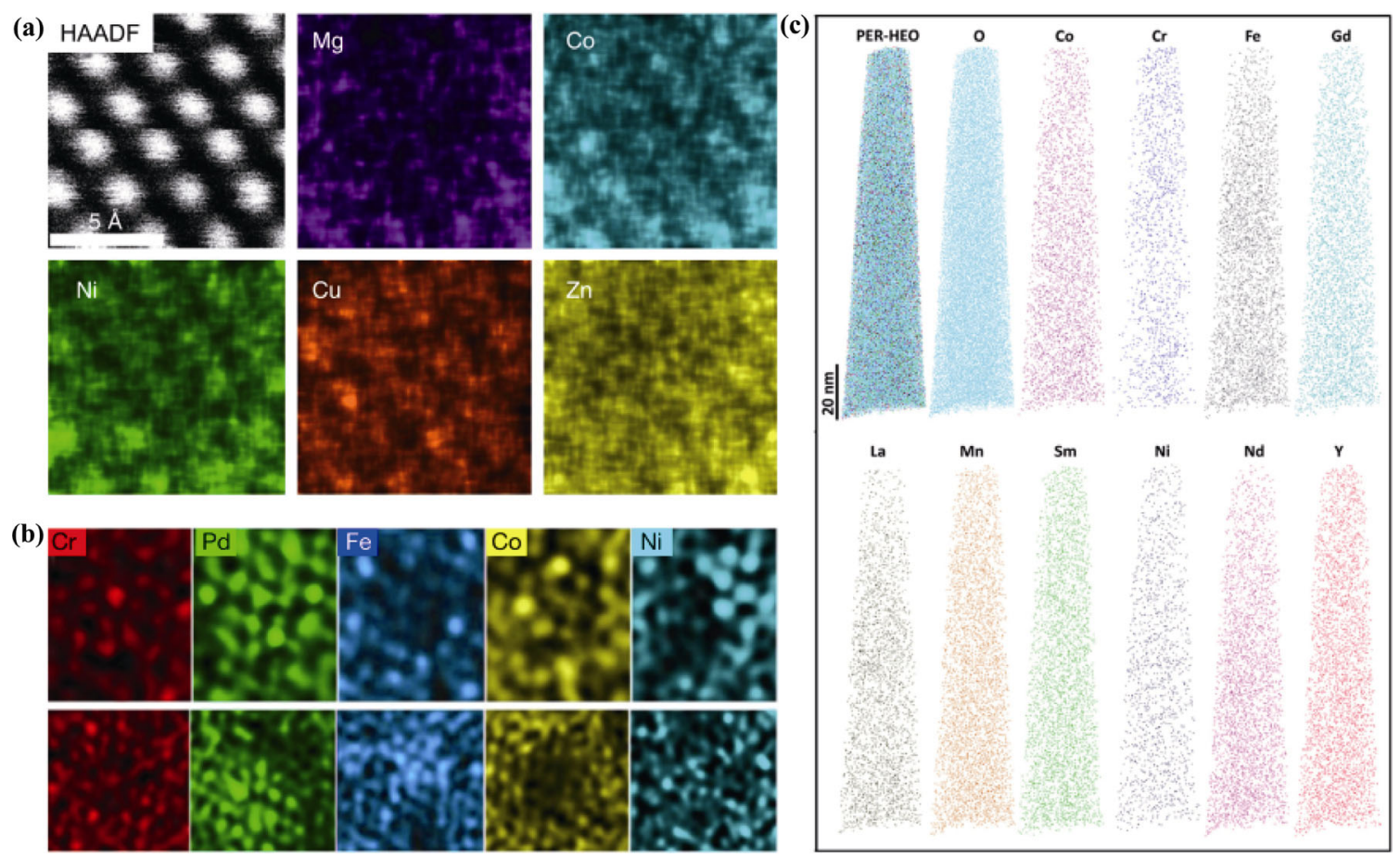

Fig. 6.2 Methods for the characterization of the elemental distribution of elements in HECs at atomic scale. (a) HAADF image of $\left(\mathrm{Mg}_{0.2} \mathrm{Ni}_{0.2} \mathrm{Co}_{0.2} \mathrm{Cu}_{0.2} \mathrm{Zn}_{0.2}\right) \mathrm{O}$ thin film, and the corresponding EDS maps for individual cation elements. (b) Local concentration distribution of each elements in $\mathrm{CrFeCoNiPd}$ alloy. (c) APT results showing homogeneous distribution of individual element in $\left(\mathrm{Gd}_{0.2} \mathrm{La}_{0.2} \mathrm{Nd}_{0.2} \mathrm{Sm}_{0.2} \mathrm{Y}_{0.2}\right)\left(\mathrm{Co}_{0.2} \mathrm{Cr}_{0.2} \mathrm{Fe}_{0.2} \mathrm{Mn}_{0.2} \mathrm{Ni}_{0.2}\right) \mathrm{O}_{3}$ in three dimensions. Reproduced with permission from Ref. [29] for (a), (C) The Authors 2015; Ref. [39] for (b), (C) Springer Nature 2019; Ref. [282] for (c), (C Elsevier 2019.

method to show a large strain induced strong oxygen sublattice distortion in a class of six-cation HEOs (Figs. 6.3(a) and 6.3(b)).

Pair distribution function (PDF) is another indirect method to character the lattice distortion in HECs. By analyzing PDF result, Cheng et al. [283] found the slight deviation of bond angles from the ideal values in a fluorite $\left(\mathrm{Ce}_{0.2} \mathrm{La}_{0.2} \mathrm{Pr}_{0.2} \mathrm{Sm}_{0.2} \mathrm{Y}_{0.2}\right) \mathrm{O}_{2-\delta}$, showing the existence of lattice distortion in this HEO (Figs. 6.3(c) and $6.3(\mathrm{~d})$ ). They then used a combination of in situ synchrotron radiation X-ray diffraction, Raman spectroscopy, and ultraviolet-visible absorption spectroscopy to illustrate a pressure-induced reversible tuning of lattice distortion and band gap, showing interesting tunable properties of $\left(\mathrm{Ce}_{0.2} \mathrm{La}_{0.2} \mathrm{Pr}_{0.2} \mathrm{Sm}_{0.2} \mathrm{Y}_{0.2}\right) \mathrm{O}_{2-\delta}$ by applying different pressure.

Besides the above-mentioned indirect methods, annular bright field (ABF) imaging in aberrationcorrected STEM provides a direct way to observe the lattice distortion in real-space but is rarely applied in the investigation of the lattice distortion of HECs. By using STEM-ABF, both heavy and light atoms can be imaged at the same time. Therefore, the combination of HAADF and ABF techniques is appropriate to visualize the lattice distortion in oxides. For example, Aso et al. [284] observed the oxygen octahedra distorting at the interface between $\mathrm{SrRuO}_{3}$ and $\mathrm{GdScO}_{3}$ at atomic level, underlying the important role of lattice distortion in the connection between $\mathrm{SrRuO}_{3}$ and $\mathrm{GdScO}_{3}$ heterointerface.

With the development of state-of-the-art TEM techniques, such as aberration-corrected STEM (AC-STEM), high-speed pixellated electron detector, and monochromated EELS, the direct observation of more detailed structural characteristics of materials is becoming reality. For example, Gao et al. [285] directly observed the local charge density distribution at the $\mathrm{SrTiO}_{3} / \mathrm{BiFeO}_{3}$ interface with sub-ångström resolution by using AC-STEM equipped with an angle-resolved pixelated fast-electron detector, which presents a new way to character the local bonding in heterogeneous materials. More recently, Yan et al. [286] reported a direct way to image local phonon spectral density near a single (111) stacking faults in cubic $\mathrm{SiC}$ by using atomic resolution and angle-resolved EELS.

Such attractive STEM techniques could also be further applied in the investigation of structural characteristics of HECs. The direct observation of lattice 


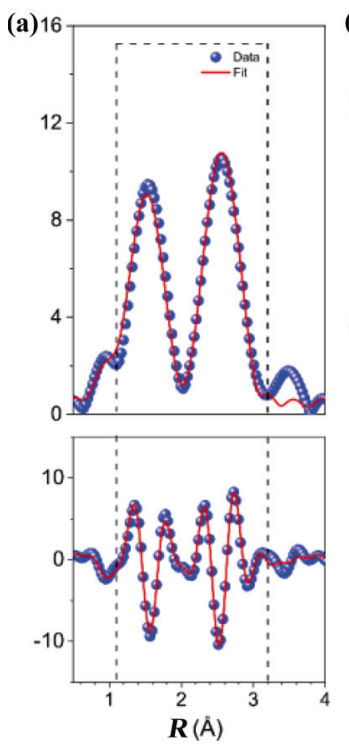

(e)

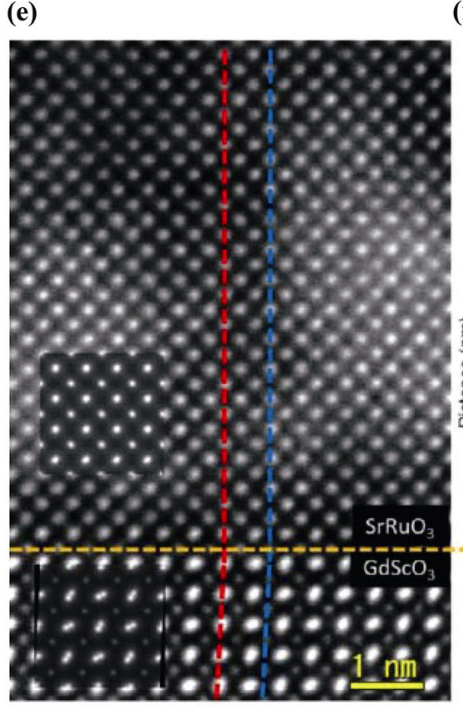

(b)
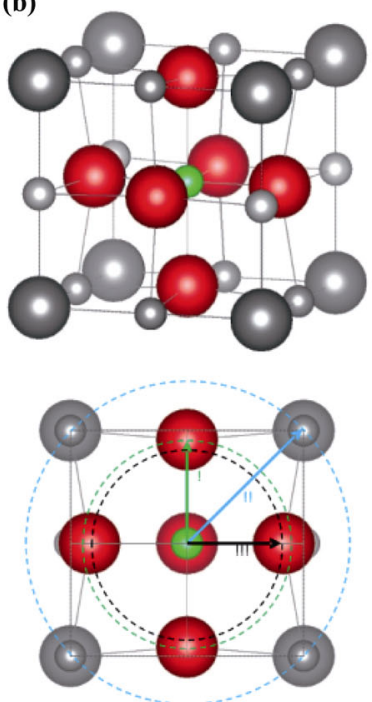

(c)

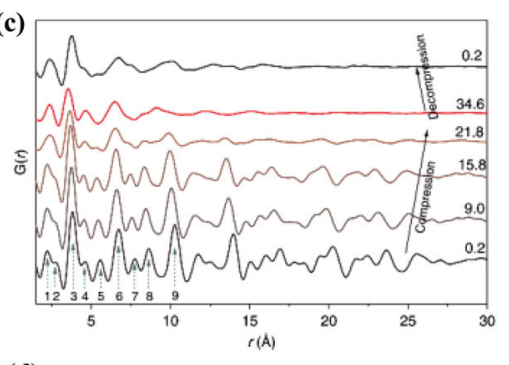

(d)

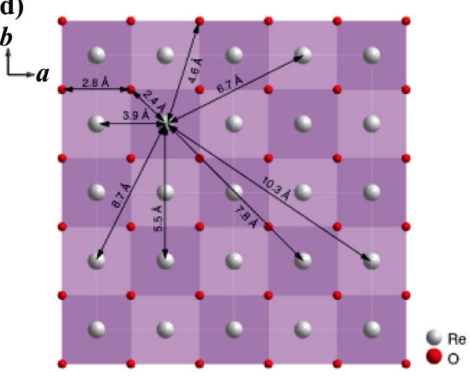

(f) B-site HAADF intensity (a.u.)

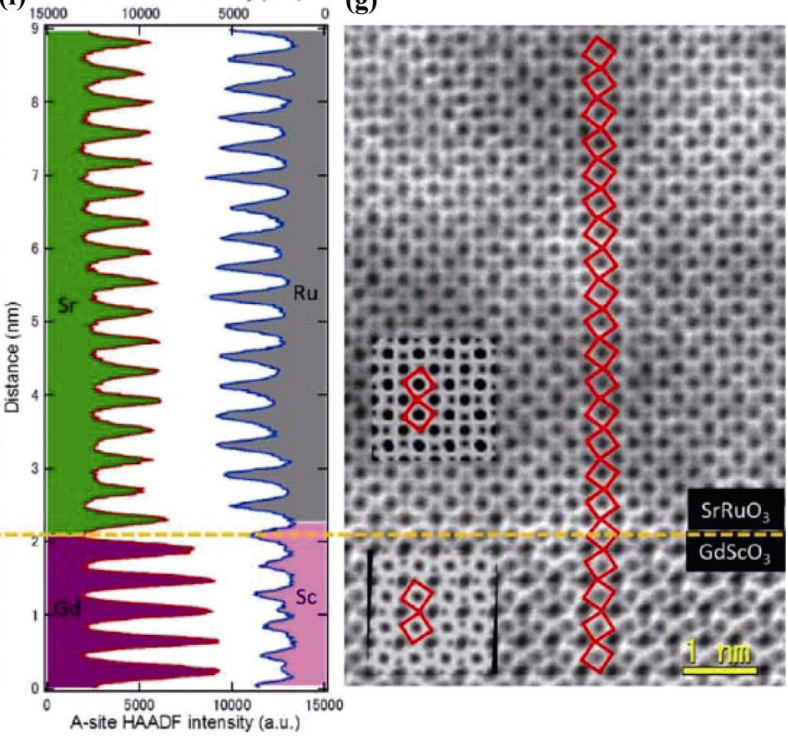

Fig. 6.3 Methods for the characterization of lattice distortion of HECs. (a) EXAFS data and models about cobalt for $\mathrm{Mg}_{x} \mathrm{Ni}_{x} \mathrm{Cu}_{x} \mathrm{Co}_{x} \mathrm{Zn}_{x} \mathrm{Cr}_{x} \mathrm{O}(x=0.167)$. (b) Modified local structure of $\mathrm{Mg}_{x} \mathrm{Ni}_{x} \mathrm{Cu}_{x} \mathrm{Co}_{x} \mathrm{Zn}_{x} \mathrm{Cr}_{x} \mathrm{O}(x=0.167)$ from the EXAFS result in (a). (c) PDF of the $\left(\mathrm{Ce}_{0.2} \mathrm{La}_{0.2} \mathrm{Pr}_{0.2} \mathrm{Sm}_{0.2} \mathrm{Y}_{0.2}\right) \mathrm{O}_{2-\delta}$ during loading and releasing at room temperature. (d) The structure model for the cubic structure of $\left(\mathrm{Ce}_{0.2} \mathrm{La}_{0.2} \mathrm{Pr}_{0.2} \mathrm{Sm}_{0.2} \mathrm{Y}_{0.2}\right) \mathrm{O}_{2-\delta}$ that is used for the study of structural evolution in (c). (e-g) Atomic-scale structural characterization of $\mathrm{SrRuO}_{3} / \mathrm{GdSmO}_{3}$ heterostructure by high-resolution HAADF- and ABF-STEM techniques. Reproduced with permission from Ref. [19] for (a, b), (C) WILEY - VCH Verlag GmbH \& Co. KGaA, Weinheim 2018; Ref. [283] for (c, d), (C) The Author(s) 2019; Ref. [284] for (e-g), (C) The Authors 2013.

distortion, charge distribution, and local phonon spectral density in HECs would provide new perspectives to understand the composition-structure-property relationships at the atomic scale.

\section{5 Tuning properties for prospective applications}

In Section 5, we have introduced prospective applications of HECs covered from ultrahigh-temperature thermal protection and thermal insulation to catalysts, batteries, and electromagnetic wave absorption. In fact, balanced properties are often required for many applications such that methods for tuning properties through multiphase compositions and microstructure control are awaited.

To demonstrate the importance of multiphase design, two examples are given here. In the first example [179], dual-phase ultrahigh-temperature ceramics consisting of a hexagonal high-entropy boride (HEB) phase and a 
cubic high-entropy carbide (HEC) phase were fabricated through SPS. Both the density and hardness are found to be higher than the single phase samples, indicating better properties than the single phase solid solutions. In the second example [234], high entropy hexaborides/tetraborides $\left(\mathrm{HE} \mathrm{REB}_{6} / \mathrm{HE} \mathrm{REB}_{4}\right)$ composites with synergistic dielectric and magnetic losses were designed and successfully synthesized through a one-step boron carbide reduction method. $\left(\mathrm{Y}_{0.2} \mathrm{Nd}_{0.2} \mathrm{Sm}_{0.2} \mathrm{Eu}_{0.2} \mathrm{Er}_{0.2}\right) \mathrm{B}_{6} /\left(\mathrm{Y}_{0.2} \mathrm{Nd}_{0.2} \mathrm{Sm}_{0.2} \mathrm{Eu}_{0.2} \mathrm{Er}_{0.2}\right) \mathrm{B}_{4}$ (HE REB $\left.6 / \mathrm{HE} \mathrm{REB}_{4}-1\right)$ and $\left(\mathrm{Y}_{0.2} \mathrm{Nd}_{0.2} \mathrm{Sm}_{0.2} \mathrm{Er}_{0.2} \mathrm{Yb}_{0.2}\right) \mathrm{B}_{6} /$ $\left(\mathrm{Y}_{0.2} \mathrm{Nd}_{0.2} \mathrm{Sm}_{0.2} \mathrm{Er}_{0.2} \mathrm{Yb}_{0.2}\right) \mathrm{B}_{4}\left(\mathrm{HE} \quad \mathrm{REB}_{6} / \mathrm{HE} \quad \mathrm{REB}_{4}-2\right)$ exhibit excellent EM wave absorption properties. The optimal minimum reflection loss $\left(R L_{\min }\right)$ and effective absorption bandwidth $\left(E_{\mathrm{AB}}\right)$ of $\mathrm{HE} \mathrm{REB}_{6} / \mathrm{HE} \mathrm{REB}_{4}-1$ and $\mathrm{HE} \mathrm{REB} 6 / \mathrm{HE} \mathrm{REB}_{4}-2$ are $-53.3 \mathrm{~dB}$ (at $1.7 \mathrm{~mm}$ ), $4.2 \mathrm{GHz}$ (at $1.5 \mathrm{~mm}$ ) and $-43.5 \mathrm{~dB}(1.3 \mathrm{~mm}), 4.2 \mathrm{GHz}$ (1.5 mm), respectively. The authors found that combination of conducting $\mathrm{HE} \mathrm{REB}_{4}$ with magnetism into $\mathrm{HE} \mathrm{REB}_{6}$ as a second phase enhances dielectric and magnetic losses, which lead to enhanced EM wave absorption performance [234]. These results imply that multiphase compositional design is important for tuning the properties of HECs.

For structural applications, low fracture toughness and damage tolerance are the main limitations that must be overcome. Although the available data are very limited, recent work by Sun et al. [176] indicates that high-entropy bixbyite-structured oxides $\mathrm{RE}_{2} \mathrm{O}_{3}$ $(\mathrm{RE}=\mathrm{Sm}, \mathrm{Eu}, \mathrm{Er}, \mathrm{Lu}, \mathrm{Y}$, and $\mathrm{Yb})$ are more brittle than the single component $\mathrm{Y}_{2} \mathrm{O}_{3}$, which needs further attention in the development of HECs. Actually, considering the enhanced hardness and strength instead of fracture toughness, high-entropy carbide (HfZrTiTaNb)C is also brittle albeit its strength can be maintained up to $1800{ }^{\circ} \mathrm{C}$ [170]. Thus improving the fracture toughness is the bottleneck that needs to make a breakthrough.

Thermal shock resistance is also a concern for high-temperature applications. Qiu et al. [45] revealed that $(\mathrm{Ca}, \mathrm{Sr}, \mathrm{Ba}) \mathrm{ZrO}_{3}$ solid solution possesses good corrosion resistance to $\mathrm{TiNi}$ alloy melt and is promising for application as a novel crucible material for the vacuum melting of titanium alloys. However, the observed glass-like low thermal conductivity may lead to exacerbated thermal shock resistance, which needs to pay attention. And more works are needed to balance the properties.

As EBC materials for CMCs, decomposition of rare earth disilicate into monosilicate during air plasma spray and mismatch of thermal expansion coefficient are the main reasons for the cracking of the coatings [287]. High-entropy rare earth silicates have been proven to have good thermal stability without phase transformation $[88,89]$; however, if decomposition can be restricted during air plasma spray needs to be tested. On the other hand, the tunable thermal expansion coefficient has been recognized as one of the main characteristics of HECs [167]. However, strong anisotropy in high-entropy rare earth monoslicate may induce cracking in coating; thus more efforts need to be devoted to either reduce the anisotropy in thermal expansion coefficient or develop a novel method to precisely control the preferred orientation of the rare earth silicate coatings [85].

Generally, the resistance of high-temperature oxidation depends on the formation of dense and protective scales like $\mathrm{Al}_{2} \mathrm{O}_{3}$ and $\mathrm{SiO}_{2}$ [288,289]. However, the presence of multicomponents in HECs may lead to the formation of ternary or quaternary compounds instead of protective scales during high-temperature oxidation from the view point of thermodynamic analysis. In addition, preferential oxidation could result in possible destabilization of the solid solutions or formation of other competing phases [194,195,290]. To tackle this problem, careful composition design needs to be conducted to ensure good oxidation resistance of HECs. One good example is that high-entropy nitride films containing $\mathrm{Al}, \mathrm{Si}$, and $\mathrm{Cr}$ have both high hardness and strength, and the effect of these elements on the oxidation resistance of carbides and borides need to be investigated, which is expected as an important direction for developing oxidation resistant HECs for high and ultrahigh temperature applications.

We must acknowledge that searching for appropriate compositions is an arduous task using the traditional "try and error" research schema because the composition space is huge. Although many properties are unexpected and unpredictable as a result of cocktail effect, a combination of theoretical prediction and experiments is highly recommended.

\section{Conclusions}

In summary, this article has reviewed recent progress on HECs. We have summarized the structural characteristics, the current explored material systems, 
and theoretical approaches for stability and property predictions, followed by processing methods for powders, dense and porous bulks, thin films, and coatings. Then the structural and functional properties and HECs have been reviewed and prospective applications are proposed. Finally, challenges and future directions are emphasized from aspects of theoretical prediction, micro and nanoscale structure characterization, processing and properties tuning for applications. Distinct from metals, the diversity of crystal structure and electronic structure of ceramics allows properties tuning through both band gap engineering and phonon engineering using the HEMs design paradigm. As such, aside from enhanced hardness, strength, and low thermal conductivity that have been observed in HEAs, the new compositional design paradigm has brought new phenomena that have not been observed in HEAs, such as colossal dielectric constant, super ionic conductivity, strong anisotropic thermal expansion coefficient, etc. The fascinating properties of HECs make them promising for applications as ultrahigh-temperature thermal protection and insulating materials, thermal barrier and environmental barrier coatings for superalloys and CMCs, precise and high speed cutting tool materials and wear resistant parts in harsh environments, irradiation resistant materials for nuclear reactors, electromagnetic wave absorption and electromagnetic interference shielding materials, anode materials for $\mathrm{Li}$ and non-Li batteries, catalytic materials for clean energy and environment, thermoelectric materials, supercapacity materials, molten salt resistant crucibles, etc. However, due to the small sample size, the data on fracture toughness, room and high temperature strength, fatigue and creep resistance are very limited. To scale up the sample size, novel and energy saving singlecycle processing routs like reactive pressureless sintering, field assisted sintering and novel forming methods should be developed. In addition, new single phase and multiphase HECs need to be explored. And more efforts should be devoted to fundamental understanding, theoretical prediction, and database establishment.

\section{Author contributions}

This article is a result of group effort. Huimin Xiang wrote Sections 2.1, 2.2, 2.3, 2.4, 4.1, 4.3, and 4.4; Yan Xing wrote Sections 3.2.3, 5.7, 5.9, 5.10, 5.11, and 6.3, and she also designed and plotted Figs. 3.1, 3.2(a), 5.1, 5.2, 5.4, and 5.7; Fu-zhi Dai wrote Sections 6.1 and 6.2; Hongjie Wang wrote Sections 5.1 and 5.2; Lei Su wrote Section 6.4; Lei Miao wrote Section 5.8; Guojun Zhang wrote Sections 4.6 and 5.4; Yiguang Wang wrote Section 4.5; Xiwei Qi wrote Sections 4.8 and 4.9; Lei Yao wrote Sections 4.7 and 5.6; Yanchun Zhou designed the whole structure of the paper and wrote the Abstract, Sections 1, 3.1, 3.2.1, 3.2.2, 4.2, 5.3, 5.5, 6.4, and 7, and he also rewrote and reorganized the whole paper and made the final check.

\section{Acknowledgements}

The authors would like to thank Dr. Na Ni from Shanghai Jiao Tong University, Dr. Luchao Sun, and Dr. Xiaohui Wang from Institute of Metal Research, Chinese Academy of Sciences, for their helpful discussions. Financial supports from the National Natural Science Foundation of China under Grant Nos. 51972089, 51672064, and U1435206 are also acknowledged.

\section{References}

[1] Ye YF, Wang Q, Lu J, et al. High-entropy alloy: Challenges and prospects. Mater Today 2016, 19: 349362.

[2] Cantor B, Chang ITH, Knight P, et al. Microstructural development in equiatomic multicomponent alloys. Mat Sci Eng A 2004, 375-377: 213-218.

[3] Yeh J-W, Lin S-J. Breakthrough applications highentroy materials. J Mater Res 2018, 33: 3129-3137.

[4] Zhang Y, Zuo TT, Tang Z, et al. Microstructure and properties of high-entropy alloys. Prog Mater Sci 2014, 61: 1-93.

[5] Miracle DB, Senkov ON. A critical review of high entropy alloys and related concepts. Acta Mater 2017, 122: 448-511.

[6] Cantor B. High-entropy alloys. In: Encyclopedia of Materials: Science and Technology. Buschow KHJ, Cahn RW, Flemings MC, et al. Eds. Amsterdam: Elsevier, 2001.

[7] Yeh JW. Recent progress in high-entropy alloys. Ann Chim Sci Mat 2006, 31: 633-648.

[8] Ranganathan S. Alloyed pleasures: Multimetallic cocktails. Curr Sci 2003, 8: 1404-1406.

[9] Zhou YJ, Zhang Y, Wang YL, et al. Solid solution alloys of $\mathrm{AlCoCrFeNiTi}_{x}$ with excellent room-temperature mechanical properties. Appl Phys Lett 2007, 90: 181904.

[10] Senkov ON, Wilks GB, Scott JM, et al. Mechanical properties of $\mathrm{Nb}_{25} \mathrm{Mo}_{25} \mathrm{Ta}_{25} \mathrm{~W}_{25}$ and $\mathrm{V}_{20} \mathrm{Nb}_{20} \mathrm{Mo}_{20} \mathrm{Ta}_{20} \mathrm{~W}_{20}$ refractory high entropy alloys. Intermetallics 2011, 19: 
698-706.

[11] Li Z, Pradeep KG, Deng Y, et al. Metastable highentropy dual-phase alloys overcome the strengthductility trade-off. Nature 2016, 534: 227-230.

[12] Zaddach AJ, Niu C, Koch CC, et al. Mechanical properties and stacking fault energies of $\mathrm{NiFeCrCoMn}$ high-entropy alloy. JOM 2013, 65: 1780-1789.

[13] Chuang MH, Tsai MH, Wang WR, et al. Microstructure and wear behavior of $\mathrm{Al}_{x} \mathrm{Co}_{1.5} \mathrm{CrFeNi}_{1.5} \mathrm{Ti}_{y}$ high-entropy alloys. Acta Mater 2011, 59: 6308-6317.

[14] Perrin A, Sorescu M, Burton MT, et al. The role of compositional tuning of the distributed exchange on magnetocaloric properties of high-entropy alloys. JOM 2017, 69: 2125-2129.

[15] Koželj P, Vrtnik S, Jelen A, et al. Discovery of a superconducting high-entropy alloy. Phys Rev Lett 2014, 113: 107001.

[16] Kao YF, Chen SK, Sheu JH, et al. Hydrogen storage properties of multi-principal-component $\mathrm{CoFeMnTi}_{x} \mathrm{~V}_{y} \mathrm{Zr}_{z}$ alloys. Int J Hydrog Energy 2010, 35: 9046-9059.

[17] Lei ZF, Liu XJ, Wang H, et al. Development of advanced materials via entropy engineering. Scripta Mater 2019, 165: 164-169.

[18] Sharma AS, Yadav S, Biswas K, et al. High-entropy alloys and metallic nanocomposites: Processing challenges, microstructure development and property enhancement. Mat Sci Eng R 2018, 131: 1-42.

[19] Braun JL, Rost CM, Lim M, et al. Charge-induced disorder controls the thermal conductivity of entropystabilized oxides. Adv Mater 2018, 30: 1805004.

[20] Bérardan D, Franger S, Dragoe D, et al. Colossal dielectric constant in high entropy oxides. Status Solidi RRL 2016, 10: 328-333.

[21] Bérardan D, Franger S, Meena AK, et al. Room temperature lithium superionic conductivity in high entropy oxides. J Mater Chem A 2016, 4: 9536-9541.

[22] Chen H, Xiang HM, Dai FZ, et al. High porosity and low thermal conductivity high entropy $\left(\mathrm{Zr}_{0.2} \mathrm{Hf}_{0.2} \mathrm{Ti}_{0.2} \mathrm{Nb}_{0.2} \mathrm{Ta}_{0.2}\right)$ C. J Mater Sci Technol 2019, 35: $1700-1705$.

[23] Zhao ZF, Chen H, Xiang HM, et al. High-entropy $\left(\mathrm{Y}_{0.2} \mathrm{Nd}_{0.2} \mathrm{Sm}_{0.2} \mathrm{Eu}_{0.2} \mathrm{Er}_{0.2}\right) \mathrm{AlO}_{3}$ : $\quad$ A promising thermal/environmental barrier material for oxide/oxide composites. J Mater Sci Technol 2020, 47: 45-51.

[24] Zhang RZ, Reece MJ. Review of high entropy ceramics: Design, synthesis, structure and properties. $J$ Mater Chem A 2019, 7: 22148-22162.

[25] Oses C, Toher C, Curtarolo S. High-entropy ceramics. Nat Rev Mater 2020, 5: 295-309.

[26] Wright AJ, Luo J. A step forward from high-entropy ceramics to compositionally complex ceramics: A new perspective. J Mater Sci 2020, 55: 9812-9827.

[27] Guo S, Ng C, Lu J, et al. Effect of valence electron concentration on stability of fcc or bcc phase in high entropy alloys. $J$ Appl Phys 2011, 109: 103505.

[28] Ye YF, Liu CT, Yang Y. A geometric model for intrinsic residual strain and phase stability in high entropy alloys.
Acta Mater 2015, 94: 152-161.

[29] Rost CM, Sachet E, Borman T, et al. Entropy-stabilized oxides. Nat Commun 2015, 6: 8485.

[30] Djenadic R, Sarkar A, Clemens O, et al. Multicomponent equiatomic rare earth oxides. Mater Res Lett 2017, 5: 102-109.

[31] Sarkar A, Djenadic R, Wang D, et al. Rare earth and transition metal based entropy stabilised perovskite type oxides. J Eur Ceram Soc 2018, 38: 2318-2327.

[32] Dąbrowa J, Stygar M, Mikuła A, et al. Synthesis and microstructure of the $(\mathrm{Co}, \mathrm{Cr}, \mathrm{Fe}, \mathrm{Mn}, \mathrm{Ni})_{3} \mathrm{O}_{4}$ high entropy oxide characterized by spinel structure. Mater Lett 2018, 216: 32-36.

[33] Qin Y, Liu JX, Li F, et al. A high entropy silicide by reactive spark plasma sintering. $J A d v$ Ceram 2019, 8: 148-152.

[34] Gild J, Zhang Y, Harrington T, et al. High-entropy metal diborides: A new class of high-entropy materials and a new type of ultrahigh temperature ceramics. Sci Rep 2016, 6: 37946.

[35] Yan XL, Constantin L, Lu YF, et al. $\left(\mathrm{Hf}_{0.2} \mathrm{Zr}_{0.2} \mathrm{Ta}_{0.2} \mathrm{Nb}_{0.2} \mathrm{Ti}_{0.2}\right) \mathrm{C}$ high-entropy ceramics with low thermal conductivity. $J$ Am Ceram Soc 2018, 101: 4486-4491.

[36] Ren K, Wang QK, Shao G, et al. Multicomponent high-entropy zirconates with comprehensive properties for advanced thermal barrier coating. Scripta Mater 2020, 178: 382-386.

[37] Zhao ZF, Xiang HM, Dai FZ, et al. $\left(\mathrm{La}_{0.2} \mathrm{Ce}_{0.2} \mathrm{Nd}_{0.2} \mathrm{Sm}_{0.2} \mathrm{Eu}_{0.2}\right)_{2} \mathrm{Zr}_{2} \mathrm{O}_{7}$ : A novel high-entropy ceramic with low thermal conductivity and sluggish grain growth rate. J Mater Sci Technol 2019, 35: 2647-2651.

[38] Gild J, Samiee M, Braun JL, et al. High-entropy fluorite oxides. J Eur Ceram Soc 2018, 38: 3578-3584.

[39] Ding Q, Zhang Y, Chen X, et al. Tuning element distribution, structure and properties by composition in high-entropy alloys. Nature 2019, 574: 223-227.

[40] Chen H, Xiang HM, Dai FZ, et al. Porous high entropy $\left(\mathrm{Zr}_{0.2} \mathrm{Hf}_{0.2} \mathrm{Ti}_{0.2} \mathrm{Nb}_{0.2} \mathrm{Ta}_{0.2}\right) \mathrm{B}_{2}$ : A novel strategy towards making ultrahigh temperature ceramics thermal insulating. J Mater Sci Technol 2019, 35: 2404-2408.

[41] Ye BL, Wen TQ, Nguyen MC, et al. First-principles study, fabrication and characterization of $\left(\mathrm{Zr}_{0.25} \mathrm{Nb}_{0.25} \mathrm{Ti}_{0.25} \mathrm{~V}_{0.25}\right) \mathrm{C}$ high-entropy ceramics. Acta Mater 2019, 170: 15-23.

[42] Harrington TJ, Gild J, Sarker P, et al. Phase stability and mechanical properties of novel high entropy transition metal carbides. Acta Mater 2019, 166: 271-280.

[43] Ren XM, Tian ZL, Zhang J, et al. Equiatomic quaternary $\quad\left(\mathrm{Y}_{1 / 4} \mathrm{Ho}_{1 / 4} \mathrm{Er}_{1 / 4} \mathrm{Yb}_{1 / 4}\right)_{2} \mathrm{SiO}_{5}$ silicate: A perspective multifunctional thermal and environmental barrier coating material. Scripta Mater 2019, 168: $47-50$

[44] Liu RH, Chen HY, Zhao KP, et al. Entropy as a genelike performance indicator promoting thermoelectric materials. Adv Mater 2017, 29: 1702712. 
[45] Qiu SH, Li ML, Shao G, et al. (Ca, Sr, Ba)ZrO $\mathrm{Zr}_{3}$ : A promising entropy-stabilized ceramic for titanium alloys smelting. J Mater Sci Technol 2021, 65: 82-88.

[46] Rost CM, Rak Z, Brenner DW, et al. Local structure of the $\mathrm{Mg}_{x} \mathrm{Ni}_{x} \mathrm{Co}_{x} \mathrm{Cu}_{x} \mathrm{Zn}_{x} \mathrm{O}(x=0.2)$ entropy-stabilized oxide: An EXAFS study. J Am Ceram Soc 2017, 100: 27322738.

[47] Berardan D, Meena AK, Franger S, et al. Controlled Jahn-Teller distortion in ( $\mathrm{MgCoNiCuZn}) \mathrm{O}$-based high entropy oxides. J Alloys Compd 2017, 704: 693-700.

[48] Rák Z, Maria JP, Brenner DW. Evidence for Jahn-Teller compression in the $(\mathrm{Mg}, \mathrm{Co}, \mathrm{Ni}, \mathrm{Cu}, \mathrm{Zn}) \mathrm{O}$ entropystabilized oxide: A DFT study. Mater Lett 2018, 217: 300-303.

[49] Anand G, Wynn AP, Handley CM, et al. Phase stability and distortion in high-entropy oxides. Acta Mater 2018, 146: $119-125$.

[50] Dai FZ, Wen B, Sun YJ, et al. Theoretical prediction on thermal and mechanical properties of high entropy $\left(\mathrm{Zr}_{0.2} \mathrm{Hf}_{0.2} \mathrm{Ti}_{0.2} \mathrm{Nb}_{0.2} \mathrm{Ta}_{0.2}\right) \mathrm{C}$ by deep learning potential. $J$ Mater Sci Technol 2020, 43: 168-174.

[51] Ye B, Wen T, Huang K, et al. First-principles study, fabrication, and characterization of $\left(\mathrm{Hf}_{0.2} \mathrm{Zr}_{0.2} \mathrm{Ta}_{0.2} \mathrm{Nb}_{0.2} \mathrm{Ti}_{0.2}\right) \mathrm{C}$ high-entropy ceramic. J Am Ceram Soc 2019, 102: 4344-4352.

[52] Dai FZ, Sun YJ, Wen B, et al. Temperature dependent thermal and elastic properties of high entropy $\left(\mathrm{Ti}_{0.2} \mathrm{Zr}_{0.2} \mathrm{Hf}_{0.2} \mathrm{Nb}_{0.2} \mathrm{Ta}_{0.2}\right) \mathrm{B}_{2}$ : Molecular dynamics simulation by deep learning potential. J Mater Sci Technol 2021, 72: $8-15$.

[53] Rák Z, Rost CM, Lim M, et al. Charge compensation and electrostatic transferability in three entropystabilized oxides: Results from density functional theory calculations. J Appl Phys 2016, 120: 095105.

[54] Zunger A, Wei S, Ferreira LG, et al. Special quasirandom structures. Phys Rev Lett 1990, 65: 353356.

[55] Wei SH, Ferreira LG, Bernard JE, et al. Electronic properties of random alloys: Special quasirandom structures. Phys Rev B 1990, 42: 9622-9649.

[56] Jiang S, Shao L, Fan TW, et al. Elastic and thermodynamic properties of high entropy carbide (HfTaZrTi)C and (HfTaZrNb)C from ab initio investigation. Ceram Int 2020, 46: 15104-15112.

[57] Wang YP, Gan GY, Wang W, et al. Ab initio prediction of mechanical and electronic properties of ultrahigh temperature high-entropy ceramics $\left(\mathrm{Hf}_{0.2} \mathrm{Zr}_{0.2} \mathrm{Ta}_{0.2} \mathrm{M} 0.2 \mathrm{Ti}_{0.2}\right) \mathrm{B}_{2}$ $(\mathrm{M}=\mathrm{Nb}, \mathrm{Mo}, \mathrm{Cr})$. Phys Status Solidi B 2018, 255: 1800011.

[58] Liu YC, Jia DC, Zhou Y, et al. $\mathrm{Zn}_{0.1} \mathrm{Ca}_{0.1} \mathrm{Sr}_{0.4} \mathrm{Ba}_{0.4} \mathrm{ZrO}_{3}$ : A non-equimolar multicomponent perovskite ceramic with low thermal conductivity. J Eur Ceram Soc 2020, 40: 6272-6277.

[59] Gao MC, Yeh JW, Liaw PK, et al. High-Entropy Alloys. Cham, Switzerland: Springer International Publishing, 2016.

[60] Sarkar A, Loho C, Velasco L, et al. Multicomponent equiatomic rare earth oxides with a narrow band gap and associated praseodymium multivalency. Dalton Trans 2017, 46: 12167-12176.

[61] Sarkar A, Eggert B, Velasco L, et al. Role of intermediate $4 \mathrm{f}$ states in tuning the band structure of high entropy oxides. APL Mater 2020, 8: 051111.

[62] Sarkar A, Breitung B, Hahn H. High entropy oxides: The role of entropy, enthalpy and synergy. Scripta Mater 2020, 187: 43-48.

[63] Chen H, Fu J, Zhang PF, et al. Entropy-stabilized metal oxide solid solutions as $\mathrm{CO}$ oxidation catalysts with high-temperature stability. J Mater Chem A 2018, 6: 11129-11133.

[64] Sarkar A, Velasco L, Wang D, et al. High entropy oxides for reversible energy storage. Nat Commun 2018, 9: 3400 .

[65] Mao AQ, Xiang HZ, Zhang ZG, et al. Solution combustion synthesis and magnetic property of rock-salt $\left(\mathrm{Co}_{0.2} \mathrm{Cu}_{0.2} \mathrm{Mg}_{0.2} \mathrm{Ni}_{0.2} \mathrm{Zn}_{0.2}\right) \mathrm{O}$ high-entropy oxide nanocrystalline powder. J Magn Magn Mater 2019, 484: 245-252.

[66] Wang QS, Sarkar A, Li ZY, et al. High entropy oxides as anode material for Li-ion battery applications: A practical approach. Electrochem Commun 2019, 100: 121-125.

[67] Lun Z, Ouyang B, Kwon DH, et al. Cation-disordered rocksalt-type high-entropy cathodes for $\mathrm{Li}$-ion batteries. Nat Mater 2021, 20: 214-221.

[68] Chen KP, Pei XT, Tang L, et al. A five-component entropy-stabilized fluorite oxide. J Eur Ceram Soc 2018, 38: 4161-4164.

[69] Dąbrowa J, Szymczak M, Zajusz M, et al. Stabilizing fluorite structure in ceria-based high-entropy oxides: Influence of Mo addition on crystal structure and transport properties. J Eur Ceram Soc 2020, 40: 5870-5881.

[70] Chen XQ, Wu YQ. High-entropy transparent fluoride laser ceramics. J Am Ceram Soc 2020, 103: 750-756.

[71] Zhao ZF, Chen H, Xiang HM, et al. High entropy defective fluorite structured rare-earth niobates and tantalates for thermal barrier applications. $J A d v$ Ceram 2020, 9: 303-311.

[72] Teng Z, Zhu LN, Tan YQ, et al. Synthesis and structures of high-entropy pyrochlore oxides. J Eur Ceram Soc 2020, 40: 1639-1643.

[73] Wright AJ, Wang QY, Ko ST, et al. Size disorder as a descriptor for predicting reduced thermal conductivity in medium- and high-entropy pyrochlore oxides. Scripta Mater 2020, 181: 76-81.

[74] Li F, Zhou L, Liu JX, et al. High-entropy pyrochlores with low thermal conductivity for thermal barrier coating materials. J Adv Ceram 2019, 8: 576-582.

[75] Zhang KB, Li WW, Zeng JJ, et al. Preparation of $\left(\mathrm{La}_{0.2} \mathrm{Nd}_{0.2} \mathrm{Sm}_{0.2} \mathrm{Gd}_{0.2} \mathrm{Yb}_{0.2}\right)_{2} \mathrm{Zr}_{2} \mathrm{O}_{7}$ high-entropy transparent ceramic using combustion synthesized nanopowder. $J$ Alloys Compd 2020, 817: 153328.

[76] Jiang $\mathrm{SC}, \mathrm{Hu} \mathrm{T}$, Gild $\mathrm{J}$, et al. A new class of 
high-entropy perovskite oxides. Scripta Mater 2018, 142: 116-120.

[77] Zhou SY, Pu YP, Zhang QW, et al. Microstructure and dielectric properties of high entropy $\mathrm{Ba}\left(\mathrm{Zr}_{0.2} \mathrm{Ti}_{0.2} \mathrm{Sn}_{0.2} \mathrm{Hf}_{0.2} \mathrm{Me}_{0.2}\right) \mathrm{O}_{3}$ perovskite oxides. Ceram Int 2020, 46: 7430-7437.

[78] Witte R, Sarkar A, Kruk R, et al. High-entropy oxides: An emerging prospect for magnetic rare-earth transition metal perovskites. Phys Rev Mater 2019, 3: 034406.

[79] Sharma Y, Musico BL, Gao X, et al. Single-crystal high entropy perovskite oxide epitaxial films. Phys Rev Mater 2018, 2: 060404.

[80] Dąbrowa J, Stygar M, Mikuła A, et al. Synthesis and microstructure of the $\left(\mathrm{Co}, \mathrm{Cr}, \mathrm{Fe}, \mathrm{Mn}, \mathrm{Ni}_{3} \mathrm{O}_{4}\right.$ high entropy oxide characterized by spinel structure. Mater Lett 2018, 216: 32-36.

[81] Grzesik Z, Smoła G, Miszczak M, et al. Defect structure and transport properties of $(\mathrm{Co}, \mathrm{Cr}, \mathrm{Fe}, \mathrm{Mn}, \mathrm{Ni})_{3} \mathrm{O}_{4}$ spinel-structured high entropy oxide. $J$ Eur Ceram Soc 2020, 40: 835-839.

[82] Mao AQ, Xiang HZ, Zhang ZG, et al. A new class of spinel high-entropy oxides with controllable magnetic properties. J Magn Magn Mater 2020, 497: 165884.

[83] Parida T, Karati A, Guruvidyathri K, et al. Novel rare-earth and transition metal-based entropy stabilized oxides with spinel structure. Scripta Mater 2020, 178: 513-517.

[84] Lewin E. Multi-component and high-entropy nitride coatings-A promising field in need of a novel approach. J Appl Phys 2020, 127: 160901.

[85] Chen H, Xiang HM, Dai FZ, et al. High entropy $\left(\mathrm{Yb}_{0.25} \mathrm{Y}_{0.25} \mathrm{Lu}_{0.25} \mathrm{Er}_{0.25}\right)_{2} \mathrm{SiO}_{5}$ with strong anisotropy in thermal expansion. J Mater Sci Technol 2020, 36: 134-139.

[86] Ridley M, Gaskins J, Hopkins P, et al. Tailoring thermal properties of multi-component rare earth monosilicates. Acta Mater 2020, 195: 698-707.

[87] Dong Y, Ren K, Lu YH, et al. High-entropy environmental barrier coating for the ceramic matrix composites. J Eur Ceram Soc 2019, 39: 2574-2579.

[88] Sun LC, Luo YX, Ren XM, et al. A multicomponent $\gamma$-type $\left(\mathrm{Gd}_{1 / 6} \mathrm{~Tb}_{1 / 6} \mathrm{Dy}_{1 / 6} \mathrm{Tm}_{1 / 6} \mathrm{Yb}_{1 / 6} \mathrm{Lu}_{1 / 6}\right)_{2} \mathrm{Si}_{2} \mathrm{O}_{7}$ disilicate with outstanding thermal stability. Mater Res Lett 2020, 8: $424-430$.

[89] Sun LC, Luo YX, Tian ZL, et al. High temperature corrosion of $\left(\mathrm{Er}_{0.25} \mathrm{Tm}_{0.25} \mathrm{Yb}_{0.25} \mathrm{Lu}_{0.25}\right)_{2} \mathrm{Si}_{2} \mathrm{O}_{7}$ environmental barrier coating material subjected to water vapor and molten calcium-magnesium-aluminosilicate (CMAS). Corros Sci 2020, 175: 108881.

[90] Chen H, Zhao ZF, Xiang HM, et al. High entropy $\left(\mathrm{Y}_{0.2} \mathrm{Yb}_{0.2} \mathrm{Lu}_{0.2} \mathrm{Eu}_{0.2} \mathrm{Er}_{0.2}\right)_{3} \mathrm{Al}_{5} \mathrm{O}_{12}$ : A novel high temperature stable thermal barrier material. J Mater Sci Technol 2020, 48: 57-62.

[91] Zhao ZF, Xiang HM, Chen $\mathrm{H}$, et al. High-entropy $\left(\mathrm{Nd}_{0.2} \mathrm{Sm}_{0.2} \mathrm{Eu}_{0.2} \mathrm{Y}_{0.2} \mathrm{Yb}_{0.2}\right)_{4} \mathrm{Al}_{2} \mathrm{O}_{9}$ with good high temperature stability, low thermal conductivity, and anisotropic thermal expansivity. $J$ Adv Ceram 2020, 9:
595-605.

[92] Zhao ZF, Xiang HM, Dai FZ, et al. (TiZrHf) $\mathrm{P}_{2} \mathrm{O}_{7}$ : An equimolar multicomponent or high entropy ceramic with good thermal stability and low thermal conductivity. $J$ Mater Sci Technol 2019, 35: 2227-2231.

[93] Zhao ZF, Chen $\mathrm{H}$, Xiang $\mathrm{HM}$, et al. $\left(\mathrm{La}_{0.2} \mathrm{Ce}_{0.2} \mathrm{Nd}_{0.2} \mathrm{Sm}_{0.2} \mathrm{Eu}_{0.2}\right) \mathrm{PO}_{4}: \quad \mathrm{A}$ high-entropy rare-earth phosphate monazite ceramic with low thermal conductivity and good compatibility with $\mathrm{Al}_{2} \mathrm{O}_{3} . J$ Mater Sci Technol 2019, 35: 2892-2896.

[94] Vinnik DA, Trofimov EA, Zhivulin VE, et al. High-entropy oxide phases with magnetoplumbite structure. Ceram Int 2019, 45: 12942-12948.

[95] Zhao PB, Zhu JP, Zhang YL, et al. A novel high-entropy monoboride $\left(\mathrm{Mo}_{0.2} \mathrm{Ta}_{0.2} \mathrm{Ni}_{0.2} \mathrm{Cr}_{0.2} \mathrm{~W}_{0.2}\right) \mathrm{B}$ with superhardness and low thermal conductivity. Ceram Int 2020, 46: 26626-26631.

[96] Zhang HM, Zhao B, Dai FZ, et al. $\left(\mathrm{Cr}_{0.2} \mathrm{Mn}_{0.2} \mathrm{Fe}_{0.2} \mathrm{Co}_{0.2} \mathrm{Mo}_{0.2}\right) \mathrm{B}$ : A novel high-entropy monoboride with good electromagnetic interference shielding performance in K-band. J Mater Sci Technol 2021, 77: 58-65.

[97] Qin MD, Yan QZ, Wang HR, et al. High-entropy monoborides: Towards superhard materials. Scripta Mater 2020, 189: 101-105.

[98] Chen H, Zhao ZF, Xiang HM, et al. Effect of reaction routes on the porosity and permeability of porous high entropy $\left(\mathrm{Y}_{0.2} \mathrm{Yb}_{0.2} \mathrm{Sm}_{0.2} \mathrm{Nd}_{0.2} \mathrm{Eu}_{0.2}\right) \mathrm{B}_{6}$ for transpiration cooling. J Mater Sci Technol 2020, 38: 80-85.

[99] Zhang WM, Zhao B, Xiang HM, et al. One-step synthesis and electromagnetic absorption properties of high entropy rare earth hexaborides $\left(\mathrm{HE} \mathrm{REB}_{6}\right)$ and high entropy rare earth hexaborides/borates $\left(\mathrm{HE} \mathrm{REB}_{6} / \mathrm{HE}\right.$ $\mathrm{REBO}_{3}$ ) composite powders. J Adv Ceram 2021, 10: 62-77.

[100] Qin MD, Yan QZ, Wang HR, et al. High-entropy rare earth tetraborides. J Eur Ceram Soc 2021, 41: 2968-2973.

[101] Chen H, Zhao B, Zhao ZF, et al. Achieving strong microwave absorption capability and wide absorption bandwidth through a combination of high entropy rare earth silicide carbides/rare earth oxides. J Mater Sci Technol 2020, 47: 216-222.

[102] Gild J, Braun J, Kaufmann K, et al. A high-entropy silicide: $\left(\mathrm{Mo}_{0.2} \mathrm{Nb}_{0.2} \mathrm{Ta}_{0.2} \mathrm{Ti}_{0.2} \mathrm{~W}_{0.2}\right) \mathrm{Si}_{2} . \quad J$ Materiomics 2019, 5: 337-343.

[103] Wright AJ, Wang QY, Huang CY, et al. From high-entropy ceramics to compositionally-complex ceramics: A case study of fluorite oxides. J Eur Ceram Soc 2020, 40: 2120-2129.

[104] Sarker P, Harrington T, Toher C, et al. High-entropy high-hardness metal carbides discovered by entropy descriptors. Nat Commun 2018, 9: 4980.

[105] Curtarolo S, Setyawan W, Hart GLW, et al. AFLOW: An automatic framework for high-throughput materials discovery. Comput Mater Sci 2012, 58: 218-226.

[106] Pitike KC, Santosh KC, Eisenbach M, et al. Predicting 
the phase stability of multicomponent high-entropy compounds. Chem Mater 2020, 32: 7507-7515.

[107] Saunders N, Miodownik AP. CALPHAD: Calculation of Phase Diagrams - A Comprehensive Guide. Amsterdam: Elsevier, 1998.

[108] Zhong Y, Sabarou H, Yan XT, et al. Exploration of high entropy ceramics (HECs) with computational thermodynamics - A case study with $\mathrm{LaMnO}_{3 \pm \delta}$. Mater Des 2019, 182: 108060.

[109] Castle E, Csanádi T, Grasso S, et al. Processing and properties of high-entropy ultra-high temperature carbides. Sci Rep 2018, 8: 8609.

[110] Zhang GR, Milisavljevic I, Zych E, et al. High-entropy sesquioxide $\mathrm{X}_{2} \mathrm{O}_{3}$ upconversion transparent ceramics. Scripta Mater 2020, 186: 19-23.

[111] Zhang RZ, Gucci F, Zhu HY, et al. Data-driven design of ecofriendly thermoelectric high-entropy sulfides. Inorg Chem 2018, 57: 13027-13033.

[112] Lei ZF, Liu XJ, Li R, et al. Ultrastable metal oxide nanotube arrays achieved by entropy-stabilization engineering. Scripta Mater 2018, 146: 340-343.

[113] Zhang JR, Zhang XY, Li Y, et al. High-entropy oxides $10 \mathrm{La}_{2} \mathrm{O}_{3}-20 \mathrm{TiO}_{2}-10 \mathrm{Nb}_{2} \mathrm{O}_{5}-20 \mathrm{WO}_{3}-20 \mathrm{ZrO}_{2}$ amorphous spheres prepared by containerless solidification. Mater Lett 2019, 244: 167-170.

[114] Guo YC, Li JQ. Preparation of high-entropy (ReTiZrYAl)O glasses by aerodynamic levitation and performance study. In: Proceedings of the 21st National Annual Conference on High Technology Ceramics, 2020: $15-10$.

[115] Okejiri F, Zhang ZH, Liu JX, et al. Room-temperature synthesis of high-entropy perovskite oxide nanoparticle catalysts through ultrasonication-based method. ChemSusChem 2020, 13: 111-115.

[116] Wang KW, Ma BS, Li T, et al. Fabrication of high-entropy perovskite oxide by reactive flash sintering. Ceram Int 2020, 46: 18358-18361.

[117] Sharma Y, Zheng Q, Mazza AR, et al. Magnetic anisotropy in single-crystal high-entropy perovskite oxide $\mathrm{La}\left(\mathrm{Cr}_{0.2} \mathrm{Mn}_{0.2} \mathrm{Fe}_{0.2} \mathrm{Co}_{0.2} \mathrm{Ni}_{0.2}\right) \mathrm{O}_{3}$ films. Phys Rev Materials 2020, 4: 014404.

[118] Tallarita G, Licheri R, Garroni S, et al. Novel processing route for the fabrication of bulk high-entropy metal diborides. Scripta Mater 2019, 158: 100-104.

[119] Sarkar A, Djenadic R, Usharani NJ, et al. Nanocrystalline multicomponent entropy stabilised transition metal oxides. J Eur Ceram Soc 2017, 37: 747-754.

[120] Djenadic R, Botros M, Benel C, et al. Nebulized spray pyrolysis of Al-doped $\mathrm{Li}_{7} \mathrm{La}_{3} \mathrm{Zr}_{2} \mathrm{O}_{12}$ solid electrolyte for battery applications. Solid State Ionics 2014, 263: 49-56.

[121] Du B, Liu HH, Chu YH. Fabrication and characterization of polymer-derived high-entropy carbide ceramic powders. J Am Ceram Soc 2020, 103: 4063-4068.

[122] Jin T, Sang XH, Unocic RR, et al. Mechanochemical- assisted synthesis of high-entropy metal nitride via a soft urea strategy. Adv Mater 2018, 30: 1707512.

[123] Jesus LM, Silva RS, M'Peko JC. Ultrafast synthesis and sintering of materials in a single running experiment approach by using electric fields. $J$ Adv Ceram 2019, 8: 265-277.

[124] Liu DG, Peng XY, Liu JL, et al. Ultrafast synthesis of entropy-stabilized oxide at room temperature. $J$ Eur Ceram Soc 2020, 40: 2504-2508.

[125] Yoon B, Avila V, Raj R, et al. Reactive flash sintering of the entropy-stabilized oxide $\mathrm{Mg}_{0.2} \mathrm{Ni}_{0.2} \mathrm{Co}_{0.2} \mathrm{Cu}_{0.2} \mathrm{Zn}_{0.2} \mathrm{O}$. Scripta Mater 2020, 181: 48-52.

[126] Wang KW, Ma BS, Li T, et al. Fabrication of high-entropy perovskite oxide by reactive flash sintering. Ceram Int 2020, 46: 18358-18361.

[127] Yao Y, Huang Z, Xie P, et al. Carbothermal shock synthesis of high-entropy-alloy nanoparticles. Science 2018, 359: 1489-1494.

[128] Li TY, Yao YG, Huang ZN, et al. Denary oxide nanoparticles as highly stable catalysts for methane combustion. Nat Catal 2021, 4: 62-70.

[129] Pu YP, Zhang QW, Li R, et al. Dielectric properties and electrocaloric effect of high-entropy $\left(\mathrm{Na}_{0.2} \mathrm{Bi}_{0.2} \mathrm{Ba}_{0.2} \mathrm{Sr}_{0.2} \mathrm{Ca}_{0.2}\right) \mathrm{TiO}_{3}$ ceramic. Appl Phys Lett 2019, 115: 223901.

[130] Moskovskikh DO, Vorotilo S, Sedegov AS, et al. High-entropy (HfTaTiNbZr)C and (HfTaTiNbMo)C carbides fabricated through reactive high-energy ball milling and spark plasma sintering. Ceram Int 2020, 46 19008-19014.

[131] Guan JY, Li DX, Yang ZH, et al. Synthesis and thermal stability of novel high-entropy metal boron carbonitride ceramic powders. Ceram Int 2020, 46: 26581-26589.

[132] Ning SS, Wen TQ, Ye BL, et al. Low-temperature molten salt synthesis of high-entropy carbide nanopowders. J Am Ceram Soc 2020, 103: 2244-2251.

[133] Feng L, Fahrenholtz WG, Hilmas GE, et al. Synthesis of single-phase high-entropy carbide powders. Scripta Mater 2019, 162: 90-93.

[134] Liu D, Wen TQ, Ye BL, et al. Synthesis of superfine high-entropy metal diboride powders. Scripta Mater 2019, 167: 110-114.

[135] Zhang Y, Jiang ZB, Sun SK, et al. Microstructure and mechanical properties of high-entropy borides derived from boro/carbothermal reduction. J Eur Ceram Soc 2019, 39: 3920-3924.

[136] Feng L, Fahrenholtz WG, Hilmas GE. Low-temperature sintering of single-phase, high-entropy carbide ceramics. $J$ Am Ceram Soc 2019, 102: 7217-7224.

[137] Zhang Y, Sun SK, Zhang W, et al. Improved densification and hardness of high-entropy diboride ceramics from fine powders synthesized via borothermal reduction process. Ceram Int 2020, 46: 14299-14303.

[138] Zhou YC, Xiang HM, Feng ZH, et al. General trends in electronic structure, stability, chemical bonding and mechanical properties of ultrahigh temperature ceramics $\mathrm{TMB}_{2}(\mathrm{TM}=$ transition metal). $J$ Mater Sci Technol 2015, 31: 285-294. 
[139] Zhang Y, Guo WM, Jiang ZB, et al. Dense high-entropy boride ceramics with ultra-high hardness. Scripta Mater 2019, 164: 135-139.

[140] Gu JF, Zou J, Sun SK, et al. Dense and pure high-entropy metal diboride ceramics sintered from self-synthesized powders via boro/carbothermal reduction approach. Sci China Mater 2019, 62: 1898-1909.

[141] Feng L, Fahrenholtz WG, Hilmas GE. Processing of dense high-entropy boride ceramics. J Eur Ceram Soc 2020, 40: 3815-3823.

[142] Monteverde F, Saraga F, Gaboardi M. Compositional disorder and sintering of entropy stabilized (Hf, $\mathrm{Nb}, \mathrm{Ta}$, Ti, Zr)B ${ }_{2}$ solid solution powders. J Eur Ceram Soc 2020, 40: 3807-3814.

[143] Castle E, Csanádi T, Grasso S, et al. Processing and properties of high-entropy ultra-high temperature carbides. Sci Rep 2018, 8: 8609.

[144] Zhang H, Hedman D, Feng P, et al. A high-entropy $\mathrm{B}_{4}\left(\mathrm{HfMo}_{2} \mathrm{TaTi}\right) \mathrm{C}$ and $\mathrm{SiC}$ ceramic composite. Dalton Trans 2019, 48: 5161-5167.

[145] Mao HR, Guo RF, Cao Y, et al. Ultrafast densification of high-entropy oxide $\left(\mathrm{La}_{0.2} \mathrm{Nd}_{0.2} \mathrm{Sm}_{0.2} \mathrm{Eu}_{0.2} \mathrm{Gd}_{0.2}\right)_{2} \mathrm{Zr}_{2} \mathrm{O}_{7}$ by reactive flash sintering. J Eur Ceram Soc 2021, 41: 2855-2860.

[146] Chen H, Xiang HM, Dai FZ, et al. Low thermal conductivity and high porosity $\mathrm{ZrC}$ and $\mathrm{HfC}$ ceramics prepared by in situ reduction reaction/partial sintering method for ultrahigh temperature applications. J Mater Sci Technol 2019, 35: 2778-2784.

[147] Chen H, Xiang HM, Dai FZ, et al. High strength and high porosity $\mathrm{YB}_{2} \mathrm{C}_{2}$ ceramics prepared by a new high temperature reaction/ partial sintering process. J Mater Sci Technol 2019, 35: 2883-2891.

[148] Guo QQ, Xiang HM, Sun X, et al. Preparation of porous $\mathrm{YB}_{4}$ ceramics using a combination of in situ borothermal reaction and high temperature partial sintering. J Eur Ceram Soc 2015, 35: 3411-3418.

[149] Zhou L, Li F, Liu JX, et al. High-entropy thermal barrier coating of rare-earth zirconate: A case study on $\left(\mathrm{La}_{0.2} \mathrm{Nd}_{0.2} \mathrm{Sm}_{0.2} \mathrm{Eu}_{0.2} \mathrm{Gd}_{0.2}\right)_{2} \mathrm{Zr}_{2} \mathrm{O}_{7} \quad$ prepared by atmospheric plasma spraying. J Eur Ceram Soc 2020, 40: $5731-5739$.

[150] Chen TK, Shun TT, Yeh JW, et al. Nanostructured nitride films of multi-element high-entropy alloys by reactive DC sputtering. Surf Coat Technol 2004, 188-189: 193-200.

[151] Chen TK, Shun TT, Yeh JW, et al. Nanostructured nitride films of multi-element high-entropy alloys by reactive DC sputtering. Surf Coat Technol 2004, 188-189: 193-200.

[152] Lai $\mathrm{CH}$, Cheng $\mathrm{KH}$, Lin SJ, et al. Mechanical and tribological properties of multi-element (AlCrTaTiZr)N coatings. Surf Coat Technol 2008, 202: 3732-3738.

[153] Lai CH, Lin SJ, Yeh JW, et al. Preparation and characterization of AlCrTaTiZr multi-element nitride coatings. Surf Coat Technol 2006, 201: 3275-3280.

[154] Cheng KH, Tsai CW, Lin SJ, et al. Effects of silicon content on the structure and mechanical properties of (AlCrTaTiZr) $-\mathrm{Si}_{x}-\mathrm{N}$ coatings by reactive $\mathrm{RF}$ magnetron sputtering. J Phys D: Appl Phys 2011, 44: 205405.

[155] Hsieh MH, Tsai MH, Shen WJ, et al. Structure and properties of two Al-Cr-Nb-Si-Ti high-entropy nitride coatings. Surf Coat Technol 2013, 221: 118-123.

[156] Lin CH, Duh JG. Corrosion behavior of (Ti-Al-Cr-Si-V) ${ }_{x} \mathrm{~N}_{y}$ coatings on mild steels derived from RF magnetron sputtering. Surf Coat Technol 2008, 203: 558-561.

[157] Lin CH, Duh JG, Yeh JW. Multi-component nitride coatings derived from Ti-Al-Cr-Si-V target in RF magnetron sputter. Surf Coat Technol 2007, 201: 6304-6308.

[158] Braic M, Balaceanu M, Vladescu A, et al. Deposition and characterization of multi-principal-element (CuSiTiYZr)C coatings. Appl Surf Sci 2013, 284: 671-678.

[159] Jhong YS, Huang CW, Lin SJ. Effects of $\mathrm{CH}_{4}$ flow ratio on the structure and properties of reactively sputtered (CrNbSiTiZr) $\mathrm{C}_{x}$ coatings. Mater Chem Phys 2018, 210: 348-352.

[160] Chen TK, Wong MS. Structure and properties of reactively-sputtered $\mathrm{Al}_{x} \mathrm{CoCrCuFeNi}$ oxide films. Thin Solid Films 2007, 516: 141-146.

[161] Huang YS, Chen L, Lui HW, et al. Microstructure, hardness, resistivity and thermal stability of sputtered oxide films of $\mathrm{AlCoCrCu}_{0.5} \mathrm{NiFe}$ high-entropy alloy. Mat Sci Eng A 2007, 457: 77-83.

[162] Gorban' VF, Andreyev AA, Kartmazov GN, et al. Production and mechanical properties of high-entropic carbide based on the TiZrHfVNbTa multicomponent alloy. J Superhard Mater 2017, 39: 166-171.

[163] Malinovskis P, Fritze S, Riekehr L, et al. Synthesis and characterization of multicomponent (CrNbTaTiW)C films for increased hardness and corrosion resistance. Mater Des 2018, 149: 51-62.

[164] Mayrhofer PH, Kirnbauer A, Ertelthaler P, et al. High-entropy ceramic thin films; A case study on transition metal diborides. Scripta Mater 2018, 149: 93-97.

[165] Biesuz M, Spiridigliozzi L, Dell'Agli G, et al. Synthesis and sintering of $(\mathrm{Mg}, \mathrm{Co}, \mathrm{Ni}, \mathrm{Cu}, \mathrm{Zn}) \mathrm{O}$ entropystabilized oxides obtained by wet chemical methods. $J$ Mater Sci 2018, 53: 8074-8085.

[166] Toda-Caraballo I, Rivera-Díaz-del-castillo PEJ. Modelling solid solution hardening in high entropy alloys. Acta Mater 2015, 85: 14-23.

[167] Haché MJR, Cheng CJ, Zou Y. Nanostructured highentropy materials. J Mater Res 2020, 35: 1051-1075.

[168] Csanádi T, Castle E, Reece MJ, et al. Strength enhancement and slip behaviour of high-entropy carbide grains during micro-compression. Sci Rep 2019, 9: 10200

[169] Wang F, Yan XL, Wang TY, et al. Irradiation damage in $\left(\mathrm{Zr}_{0.25} \mathrm{Ta}_{0.25} \mathrm{Nb}_{0.25} \mathrm{Ti}_{0.25}\right) \mathrm{C}$ high-entropy carbide ceramics. Acta Mater 2020, 195: 739-749.

[170] Feng L, Chen WT, Fahrenholtz WG, et al. Strength of 
single-phase high-entropy carbide ceramics up to $2300{ }^{\circ} \mathrm{C}$. J Am Ceram Soc 2021, 104: 419-427.

[171] Demirskyi D, Borodianska H, Suzuki TS, et al. High-temperature flexural strength performance of ternary high-entropy carbide consolidated via spark plasma sintering of $\mathrm{TaC}, \mathrm{ZrC}$ and $\mathrm{NbC}$. Scripta Mater 2019, 164: 12-16.

[172] Han XX, Girman V, Sedlak R, et al. Improved creep resistance of high entropy transition metal carbides. $J$ Eur Ceram Soc 2020, 40: 2709-2715.

[173] Qiao JW, Ma SG, Huang EW, et al. Microstructural characteristics and mechanical behaviors of $\mathrm{AlCoCrFeNi}$ high-entropy alloys at ambient and cryogenic temperatures. Mater Sci Forum 2011, 688: 419-425.

[174] Boccaccini AR. Machinability and brittleness of glassceramics. J Mater Process Technol 1997, 65: 302-304.

[175] Bao YW, Hu CF, Zhou YC. Damage tolerance of nanolayer grained ceramics and quantitative estimation. Mater Sci Technol 2006, 22: 227-230.

[176] Sun YN, Xiang HM, Dai FZ, et al. Preparation and properties of CMAS resistant bixbyite structured high-entropy oxides $\mathrm{RE}_{2} \mathrm{O}_{3}(\mathrm{RE}=\mathrm{Sm}, \mathrm{Eu}, \mathrm{Er}, \mathrm{Lu}, \mathrm{Y}$, and $\mathrm{Yb}$ ): Promising environmental barrier coating materials for $\mathrm{Al}_{2} \mathrm{O}_{3 \mathrm{f}} / \mathrm{Al}_{2} \mathrm{O}_{3}$ composites. $J$ Adv Ceram 2021, https://doi.org/10.1007/s40145-021-0461-6.

[177] Gild J, Wright A, Quiambao-Tomko K, et al. Thermal conductivity and hardness of three single-phase highntropy metal diborides fabricated by borocarbothermal reduction and spark plasma sintering. Ceram Int 2020, 46: 6906-6913.

[178] Zhu JT, Meng X, Xu J, et al. Ultra-low thermal conductivity and enhanced mechanical properties of high-entropy rare earth niobates $\left(\mathrm{RE}_{3} \mathrm{NbO}_{7}, \mathrm{RE}=\mathrm{Dy}, \mathrm{Y}\right.$, Ho, Er, Yb). J Eur Ceram Soc 2021, 41: 1052-1057.

[179] Qin MD, Gild J, Hu CZ, et al. Dual-phase high-entropy ultra-high temperature ceramics. J Eur Ceram Soc 2020, 40: $5037-5050$.

[180] Wen TQ, Ye BL, Nguyen MC, et al. Thermophysical and mechanical properties of novel high-entropy metal nitride-carbides. J Am Ceram Soc 2020, 103: 64756489.

[181] Zhao ZF, Chen $\mathrm{H}$, Xiang $\mathrm{HM}$, et al. $\left(\mathrm{Y}_{0.25} \mathrm{Yb}_{0.25} \mathrm{Er}_{0.25} \mathrm{Lu}_{0.25}\right)_{2}\left(\mathrm{Zr}_{0.5} \mathrm{Hf}_{0.5}\right)_{2} \mathrm{O}_{7}:$ A defective fluorite structured high entropy ceramic with low thermal conductivity and close thermal expansion coefficient to $\mathrm{Al}_{2} \mathrm{O}_{3}$. J Mater Sci Technol 2020, 39: 167-172.

[182] Rost CM, Borman T, Hossain MD, et al. Electron and phonon thermal conductivity in high entropy carbides with variable carbon content. Acta Mater 2020, 196: 231-239.

[183] Lim M, Rak Z, Braun JL, et al. Influence of mass and charge disorder on the phonon thermal conductivity of entropy stabilized oxides determined by molecular dynamics simulations. J Appl Phys 2019, 125: 055105.

[184] Yang Y, Ma L, Gan GY, et al. Investigation of thermodynamic properties of high entropy (TaNbHfTiZr)C and (TaNbHfTiZr)N. J Alloys Compd 2019, 788: 1076-1083.

[185] Ye BL, Wen TQ, Liu D, et al. Oxidation behavior of $\left(\mathrm{Hf}_{0.2} \mathrm{Zr}_{0.2} \mathrm{Ta}_{0.2} \mathrm{Nb}_{0.2} \mathrm{Ti}_{0.2}\right) \mathrm{C}$ high-entropy ceramics at 1073-1473 K in air. Corros Sci 2019, 153: 327-332.

[186] Ye BL, Wen TQ, Chu YH. High-temperature oxidation behavior of $\left(\mathrm{Hf}_{0.2} \mathrm{Zr}_{0.2} \mathrm{Ta}_{0.2} \mathrm{Nb}_{0.2} \mathrm{Ti}_{0.2}\right) \mathrm{C}$ high-entropy ceramics in air. J Am Ceram Soc 2020, 103: 500-507.

[187] Wang HX, Han X, Liu W, et al. Oxidation behavior of high-entropy carbide $\left(\mathrm{Hf}_{0.2} \mathrm{Ta}_{0.2} \mathrm{Zr}_{0.2} \mathrm{Ti}_{0.2} \mathrm{Nb}_{0.2}\right) \mathrm{C}$ at 1400-1600 ${ }^{\circ} \mathrm{C}$. Ceram Int 2021, 47: 10848-10854.

[188] Wang HX, Cao YJ, Liu W, et al. Oxidation behavior of $\left(\mathrm{Hf}_{0.2} \mathrm{Ta}_{0.2} \mathrm{Zr}_{0.2} \mathrm{Ti}_{0.2} \mathrm{Nb}_{0.2}\right) \mathrm{C}-x \mathrm{SiC}$ ceramics at high temperature. Ceram Int 2020, 46: 11160-11168.

[189] Wang HX, Wang SY, Cao YJ, et al. Oxidation behaviors of $\left(\mathrm{Hf}_{0.25} \mathrm{Zr}_{0.25} \mathrm{Ta}_{0.25} \mathrm{Nb}_{0.25}\right) \mathrm{C}$ and $\left(\mathrm{Hf}_{0.25} \mathrm{Zr}_{0.25} \mathrm{Ta}_{0.25} \mathrm{Nb}_{0.25}\right) \mathrm{C}-\mathrm{SiC}$ at 1300-1500 ${ }^{\circ} \mathrm{C}$. J Mater Sci Technol 2021, 60: 147155.

[190] Wang YC, Zhang RZ, Zhang BH, et al. The role of multi-elements and interlayer on the oxidation behaviour of (Hf-Ta-Zr-Nb)C high entropy ceramics. Corros Sci 2020, 176: 109019.

[191] Wang YG, Ma BS, Li LL, et al. Oxidation behavior of $\mathrm{ZrB}_{2}-\mathrm{SiC}-\mathrm{TaC}$ ceramics. J Am Ceram Soc 2012, 95: 374-378.

[192] Li N, Hu P, Zhang XH, et al. Effects of oxygen partial pressure and atomic oxygen on the microstructure of oxide scale of $\mathrm{ZrB}_{2}$-SiC composites at $1500{ }^{\circ} \mathrm{C}$. Corros Sci 2013, 73: 44-53.

[193] He JB, Wang YG, Luo L, et al. Oxidation behaviour of $\mathrm{ZrB}_{2}-\mathrm{SiC}(\mathrm{Al} / \mathrm{Y})$ ceramics at $1700{ }^{\circ} \mathrm{C} . J$ Eur Ceram Soc 2016, 36: 3769-3774.

[194] Backman L, Gild J, Luo J, et al. Part I: Theoretical predictions of preferential oxidation in refractory high entropy materials. Acta Mater 2020, 197: 20-27.

[195] Backman L, Gild J, Luo J, et al. Part II: Experimental verification of computationally predicted preferential oxidation of refractory high entropy ultra-high temperature ceramics. Acta Mater 2020, 197: 81-90.

[196] Ren K, Wang QK, Shao G, et al. Multicomponent high-entropy zirconates with comprehensive properties for advanced thermal barrier coating. Scripta Mater 2020, 178: 382-386.

[197] Turcer LR, Sengupta A, Padture NP. Low thermal conductivity in high-entropy rare-earth pyrosilicate solid-solutions for thermal environmental barrier coatings. Scripta Mater 2021, 191: 40-45.

[198] Wright AJ, Huang CY, Walock MJ, et al. Sand corrosion, thermal expansion, and ablation of medium- and high-entropy compositionally complex fluorite oxides. $J$ Am Ceram Soc 2021, 104: 448-462.

[199] Granberg F, Nordlund K, Ullah MW, et al. Mechanism of radiation damage reduction in equiatomic multicomponent single phase alloys. Phys Rev Lett 2016, 116: 135504.

[200] El-Atwani O, Li N, Li M, et al. Outstanding radiation 
resistance of tungsten-based high-entropy alloys. Sci $A d v$ 2019, 5: eaav2002.

[201] Lin YP, Yang TF, Lang L, et al. Enhanced radiation tolerance of the Ni-Co-Cr-Fe high-entropy alloy as revealed from primary damage. Acta Mater 2020, 196: 133-143.

[202] Kareer A, Waite JC, Li B, et al. Low activation, refractory, high entropy alloys for nuclear applications. $J$ Nucl Mater 2019, 526: 151744.

[203] Wang F, Yan X, Shao L, et al. Irradiation damage behavior in novel high-entropy carbide ceramics. Transactions Am Nucl Soc 2019, 120: 327.

[204] Gosset D, Dollé M, Simeone D, et al. Structural evolution of zirconium carbide under ion irradiation. $J$ Nucl Mater 2008, 373: 123-129.

[205] Osenciat N, Bérardan D, Dragoe D, et al. Charge compensation mechanisms in Li-substituted high-entropy oxides and influence on $\mathrm{Li}$ superionic conductivity. $J$ Am Ceram Soc 2019, 102: 6156-6162.

[206] Zhou SY, Pu YP, Zhang QW, et al. Microstructure and dielectric properties of high entropy $\mathrm{Ba}\left(\mathrm{Zr}_{0.2} \mathrm{Ti}_{0.2} \mathrm{Sn}_{0.2} \mathrm{Hf}_{0.2} \mathrm{Me}_{0.2}\right) \mathrm{O}_{3}$ perovskite oxides. Ceram Int 2020, 46: 7430-7437.

[207] Du Q, Yan JH, Zhang XY, et al. Phase evolution and dielectric properties of $\mathrm{Ba}\left(\mathrm{Ti}_{1 / 6} \mathrm{Sn}_{1 / 6} \mathrm{Zr}_{1 / 6} \mathrm{Hf}_{1 / 6} \mathrm{Nb}_{1 / 6} \mathrm{Ga}_{1 / 6}\right) \mathrm{O}_{3}$ high-entropy perovskite ceramics. $J$ Mater Sci: Mater Electron 2020, 31: 7760-7765.

[208] Liu J, Ren K, Ma CY, et al. Dielectric and energy storage properties of flash-sintered high-entropy $\left(\mathrm{Bi}_{0.2} \mathrm{Na}_{0.2} \mathrm{~K}_{0.2} \mathrm{Ba}_{0.2} \mathrm{Ca}_{0.2}\right) \mathrm{TiO}_{3}$ ceramic. Ceram Int 2020, 46: 20576-20581.

[209] Gao MC, Miracle DB, Maurice D, et al. High-entropy functional materials. J Mater Res 2018, 33: 3138-3155.

[210] Mao AQ, Quan F, Xiang HZ, et al. Facile synthesis and ferrimagnetic property of spinel $(\mathrm{CoCrFeMnNi})_{3} \mathrm{O}_{4}$ high-entropy oxide nanocrystalline powder. $J$ Mol Struct 2019, 1194: 11-18.

[211] Mao AQ, Xiang HZ, Zhang ZG, et al. Solution combustion synthesis and magnetic property of rock-salt $\left(\mathrm{Co}_{0.2} \mathrm{Cu}_{0.2} \mathrm{Mg}_{0.2} \mathrm{Ni}_{0.2} \mathrm{Zn}_{0.2}\right) \mathrm{O}$ high-entropy oxide nanocrystalline powder. J Magn Magn Mater 2019, 484: 245-252.

[212] Jimenez-Segura MP, Takayama T, Bérardan D, et al. Long-range magnetic ordering in rocksalt-type highentropy oxides. Appl Phys Lett 2019, 114: 122401.

[213] Zhang JJ, Yan JQ, Calder S, et al. Long-range antiferromagnetic order in a rocksalt high entropy oxide. Chem Mater 2019, 31: 3705-3711.

[214] Rák Z, Brenner DW. Exchange interactions and long-range magnetic order in the $(\mathrm{Mg}, \mathrm{Co}, \mathrm{Cu}, \mathrm{Ni}, \mathrm{Zn}) \mathrm{O}$ entropy-stabilized oxide: A theoretical investigation. $J$ Appl Phys 2020, 127: 185108.

[215] Meisenheimer PB, Kratofil TJ, Heron JT. Giant enhancement of exchange coupling in entropy-stabilized oxide heterostructures. Sci Rep 2017, 7: 13344.

[216] Witte R, Sarkar A, Velasco L, et al. Magnetic properties of rare-earth and transition metal based perovskite type high entropy oxides. J Appl Phys 2020, 127: 185109.

[217] Regner KT, Sellan DP, Su Z, et al. Broadband phonon mean free path contributions to thermal conductivity measured using frequency domain thermoreflectance. Nat Commun 2013, 4: 1640.

[218] Savvides N, Goldsmid HJ. Boundary scattering of phonons in fine-grained hot-pressed Ge-Si alloys. I. The dependence of lattice thermal conductivity on grain size and porosity. J Phys C: Solid State Phys 1980, 13: 4657-4670.

[219] Guo L, Guo HB, Peng $\mathrm{H}$, et al. Thermophysical properties of $\mathrm{Yb}_{2} \mathrm{O}_{3}$ doped $\mathrm{Gd}_{2} \mathrm{Zr}_{2} \mathrm{O}_{7}$ and thermal cycling durability of $\left(\mathrm{Gd}_{0.9} \mathrm{Yb}_{0.1}\right)_{2} \mathrm{Zr}_{2} \mathrm{O}_{7} / \mathrm{YSZ}$ thermal barrier coatings. J Eur Ceram Soc 2014, 34: 1255-1263.

[220] Van Foreest A, Sippel M, Gülhan A, et al. Transpiration cooling using liquid water. $J$ Thermophys Heat Transf 2009, 23: 693-702.

[221] Zhang B, Huang HM, Lu XL, et al. Experimental investigation on transpiration cooling for porous ceramic with liquid water. Acta Astronaut 2020, 167: $117-121$

[222] Zhang B, Huang HM, Huang J, et al. An experimental investigation on performance of transpiration cooling with liquid water through $\mathrm{C} / \mathrm{SiC}$ porous ceramic. Appl Therm Eng 2020, 178: 115526.

[223] Despois JF, Mortensen A. Permeability of open-pore microcellular materials. Acta Mater 2005, 53: 13811388.

[224] Richards BT, Wadley HNG. Plasma spray deposition of tri-layer environmental barrier coatings. J Eur Ceram Soc 2014, 34: 3069-3083.

[225] Xiang HM, Feng ZH, Li ZP, et al. Crystal structure, mechanical and thermal properties of $\mathrm{Yb}_{4} \mathrm{Al}_{2} \mathrm{O}_{9}$ : A combination of experimental and theoretical investigations. J Eur Ceram Soc 2017, 37: 2491-2499.

[226] Lee YW, Kim HS, Kim SH, et al. Preparation of simulated inert matrix fuel with different powders by dry milling method. J Nucl Mater 1999, 274: 7-14.

[227] Katoh Y, Vasudevamurthy G, Nozawa T, et al. Properties of zirconium carbide for nuclear fuel applications. $J$ Nucl Mater 2013, 441: 718-742.

[228] Wheeler K, Peralta P, Parra M, et al. Effect of sintering conditions on the microstructure and mechanical properties of $\mathrm{ZrN}$ as a surrogate for actinide nitride fuels. J Nucl Mater 2007, 366: 306-316.

[229] Tan YQ, Chen C, Li SG, et al. Oxidation behaviours of high-entropy transition metal carbides in $1200{ }^{\circ} \mathrm{C}$ water vapor. J Alloys Compd 2020, 816: 152523.

[230] Bao WC, Robertson S, Zhao JW, et al. Structural integrity and damage of $\mathrm{ZrB}_{2}$ ceramics after $4 \mathrm{MeV} \mathrm{Au}$ ions irradiation. J Mater Sci Technol 2021, 72: 223-230.

[231] Duffy DM. Modeling plasma facing materials for fusion power. Mater Today 2009, 12: 38-44.

[232] Green M, Chen XB. Recent progress of nanomaterials for microwave absorption. J Materiomics 2019, 5: 503-541.

[233] Zhou YC, Zhao B, Chen H, et al. Electromagnetic wave 
absorbing properties of TMCs $(\mathrm{TM}=\mathrm{Ti}, \mathrm{Zr}, \mathrm{Hf}, \mathrm{Nb}$ and Ta) and high entropy $\left(\mathrm{Ti}_{0.2} \mathrm{Zr}_{0.2} \mathrm{Hf}_{0.2} \mathrm{Nb}_{0.2} \mathrm{Ta}_{0.2}\right) \mathrm{C} . \quad J$ Mater Sci Technol 2021, 74: 105-118.

[234] Zhang WM, Zhao B, Ni N, et al. High entropy rare earth hexaborides/tetraborides $\left(\mathrm{HE} \mathrm{REB}_{6} / \mathrm{HE} \mathrm{REB}_{4}\right.$ ) composite powders with enhanced electromagnetic wave absorption performance. J Mater Sci Technol 2021, 87: 155-166.

[235] Zheng YN, Yi YK, Fan MH, et al. A high-entropy metal oxide as chemical anchor of polysulfide for lithiumsulfur batteries. Energy Storage Mater 2019, 23: 678683.

[236] Qiu N, Chen H, Yang ZM, et al. A high entropy oxide $\left(\mathrm{Mg}_{0.2} \mathrm{Co}_{0.2} \mathrm{Ni}_{0.2} \mathrm{Cu}_{0.2} \mathrm{Zn}_{0.2} \mathrm{O}\right)$ with superior lithium storage performance. J Alloys Compd 2019, 777: 767-774.

[237] Wang QS, Sarkar A, Wang D, et al. Multi-anionic and -cationic compounds: New high entropy materials for advanced Li-ion batteries. Energy Environ Sci 2019, 12: 2433-2442.

[238] Wang D, Jiang SD, Duan CQ, et al. Spinel-structured high entropy oxide ( $\mathrm{FeCoNiCrMn})_{3} \mathrm{O}_{4}$ as anode towards superior lithium storage performance. $J$ Alloys Compd 2020, 844: 156158.

[239] Yan JH, Wang D, Zhang XY, et al. A high-entropy perovskite titanate lithium-ion battery anode. $J$ Mater Sci 2020, 55: 6942-6951.

[240] Ding ZY, Bian JJ, Shuang S, et al. High entropy intermetallic-oxide core-shell nanostructure as superb oxygen evolution reaction catalyst. Adv Sustain Syst 2020, 4: 1900105.

[241] Zhang Y, Lu T, Ye YK, et al. Stabilizing oxygen vacancy in entropy-engineered $\mathrm{CoFe}_{2} \mathrm{O}_{4}$-type catalysts for Co-prosperity of efficiency and stability in an oxygen evolution reaction. ACS Appl Mater Interfaces 2020, 12: 32548-32555.

[242] Wang T, Chen H, Yang ZZ, et al. High-entropy perovskite fluorides: A new platform for oxygen evolution catalysis. J Am Chem Soc 2020, 142: 4550-4554.

[243] Ma PY, Zhao MM, Zhang L, et al. Self-supported high-entropy alloy electrocatalyst for highly efficient $\mathrm{H}_{2}$ evolution in acid condition. $J$ Materiomics 2020, 6: 736-742.

[244] Zhai S, Rojas J, Ahlborg N, et al. The use of poly-cation oxides to lower the temperature of two-step thermochemical water splitting. Energy Environ Sci 2018, 11: 2172-2178.

[245] Lv ZY, Liu XJ, Jia B, et al. Development of a novel high-entropy alloy with eminent efficiency of degrading azo dye solutions. Sci Rep 2016, 6: 34213.

[246] Xie PF, Yao YG, Huang ZN, et al. Highly efficient decomposition of ammonia using high-entropy alloy catalysts. Nat Commun 2019, 10: 4011.

[247] Wei PC, Liao CN, Wu HJ, et al. Thermodynamic routes to ultralow thermal conductivity and high thermoelectric performance. Adv Mater 2020, 32: 1906457.

[248] Musicó BL, Gilbert D, Ward TZ, et al. The emergent field of high entropy oxides: Design, prospects, challenges, and opportunities for tailoring material properties. APL Mater 2020, 8: 040912.

[249] Roychowdhury S, Ghosh T, Arora R, et al. Stabilizing n-type cubic GeSe by entropy-driven alloying of $\mathrm{AgBiSe}_{2}$ : Ultralow thermal conductivity and promising thermoelectric performance. Angew Chem Int Ed 2018, 57: 15167-15171.

[250] $\mathrm{Hu} \mathrm{LP}$, Zhang Y, Wu HJ, et al. Entropy engineering of SnTe: Multi-principal-element alloying leading to ultralow lattice thermal conductivity and state-of-the-art thermoelectric performance. Adv Energy Mater 2018, 8: 1802116.

[251] Luo YB, Hao SQ, Cai ST, et al. High thermoelectric performance in the new cubic semiconductor $\mathrm{AgSnSbSe}_{3}$ by high-entropy engineering. $J \mathrm{Am}$ Chem Soc 2020, 142: 15187-15198.

[252] Tang J, Yao Z, Wu Y, et al. Atomic disordering advances thermoelectric group IV telluride alloys with a multiband transport. Mater Today Phys 2020, 15 100247.

[253] Qiu YT, Jin Y, Wang DY, et al. Realizing high thermoelectric performance in GeTe through decreasing the phase transition temperature via entropy engineering. J Mater Chem A 2019, 7: 26393-26401.

[254] Tang J, Xu R, Zhang J, et al. Light element doping and introducing spin entropy: An effective strategy for enhancement of thermoelectric properties in $\mathrm{BiCuSeO}$. ACS Appl Mater Interfaces 2019, 11: 15543-15551.

[255] Dresselhaus M, Chen G, Tang M, et al. New directions for low-dimensional thermoelectric materials. $A d v$ Mater 2007, 19: 1043-1053.

[256] Xu X, Du YK, Wang CH, et al. High-entropy alloy nanoparticles on aligned electronspun carbon nanofibers for supercapacitors. J Alloys Compd 2020, 822: 153642.

[257] Tsai MH, Wang CW, Lai CH, et al. Thermally stable amorphous (AlMoNbSiTaTiVZr) ${ }_{50} \mathrm{~N}_{50}$ nitride film as diffusion barrier in copper metallization. Appl Phys Lett 2018, 92: 052109.

[258] Chang SY, Chen MK, Chen DS. Multiprincipal-element AlCrTaTiZr-nitride nanocomposite film of extremely high thermal stability as diffusion barrier for $\mathrm{Cu}$ metallization. J Electrochem Soc 2009, 156: G37-G42.

[259] Liang SC, Tsai DC, Chang ZC, et al. Thermally stable TiVCrZrHf nitride films as diffusion barriers in copper metallization. Electrochem Solid-State Lett 2012, 15: H5.

[260] Li HF, Xie XH, Zhao K, et al. In vitro and in vivo studies on biodegradable $\mathrm{CaMgZnSrYb}$ high-entropy bulk metallic glass. Acta Biomater 2013, 9: 8561-8573.

[261] Braic V, Balaceanu M, Braic M, et al. Characterization of multi-principal-element (TiZrNbHfTa)N and (TiZrNbHfTa)C coatings for biomedical applications. $J$ Mech Behav Biomed Mater 2012, 10: 197-205.

[262] Vladescu A, Titorencu I, Dekhtyar Y, et al. In vitro biocompatibility of $\mathrm{Si}$ alloyed multi-principal element carbide coatings. PLoS One 2016, 11: e0161151.

[263] Materials Genome Initiative. Available at https://www. gi.ov/. 
[264] Zhang WR, Liaw PK, Zhang Y. Science and technology in high-entropy alloys. Sci China Mater 2018, 61: 2-22.

[265] Chang XJ, Zeng MQ, Liu KL, et al. Phase engineering of high-entropy alloys. Adv Mater 2020, 32: 1907226.

[266] Zhang R, Zhao S, Ding J, et al. Short-range order and its impact on the CrCoNi medium-entropy alloy. Nature 2020, 581: 283-287.

[267] Kaufmann K, Maryanovsky D, Mellor WM, et al. Discovery of high-entropy ceramics via machine learning. npj Comput Mater 2020, 6: 42.

[268] Troparevsky MC, Morris JR, Kent PR, et al. Criteria for predicting the formation of single-phase high-entropy alloys. Phys Rev X 2015, 5: 011041.

[269] King DJM, Middleburgh SC, McGregor AG, et al. Predicting the formation and stability of single phase high-entropy alloys. Acta Mater 2016, 104: 172-179.

[270] Ikeda Y, Grabowski B, Körmann F. Ab initio phase stabilities and mechanical properties of multicomponent alloys: A comprehensive review for high entropy alloys and compositionally complex alloys. Mater Charact 2019, 147: 464-511.

[271] Qi J, Cheung AM, Joseph Poon S. High entropy alloys mined from binary phase diagrams. Sci Rep 2019, 9: 15501.

[272] Zhou ZQ, Zhou YJ, He QF, et al. Machine learning guided appraisal and exploration of phase design for high entropy alloys. npj Comput Mater 2019, 5: 128.

[273] Zhang Y, Wen C, Wang CX, et al. Phase prediction in high entropy alloys with a rational selection of materials descriptors and machine learning models. Acta Mater 2020, 185: 528-539.

[274] Chen J, Liu WX, Liu JX, et al. Stability and compressibility of cation-doped high-entropy oxide $\mathrm{MgCoNiCuZnO}_{5}$. J Phys Chem C 2019, 123: 1773517744.

[275] Yang Y, Wang W, Gan GY, et al. Structural, mechanical and electronic properties of (TaNbHfTiZr)C high entropy carbide under pressure: Ab initio investigation. Phys B: Condens Matter 2018, 550: 163-170.

[276] Xing Y, Cheng J, Wu J, et al. Direct electrospinned $\mathrm{La}_{2} \mathrm{O}_{3}$ nanowires decorated with metal particles: Novel $1 \mathrm{D}$ adsorbents for rapid removal of dyes in wastewater. J Mater Sci Technol 2020, 45: 84-91.

[277] Huang Y, Yang C, Lang JL, et al. Metal nanoparticle harvesting by continuous rotating electrodeposition and separation. Matter 2020, 3: 1294-1307.

[278] Li GD, Liu MW, Lyu SY, et al. Simultaneously enhanced strength and strain hardening capacity in FeMnCoCr high-entropy alloy via harmonic structure design. Scripta Mater 2021, 191: 196-201.

[279] Dai WJ, Lu T, Pan Y. Novel and promising electrocatalyst for oxygen evolution reaction based on MnFeCoNi high entropy alloy. J Power Sources 2019,
430: 104-111.

[280] Kadiri VM, Bussi C, Holle AW, et al. Biocompatible magnetic micro- and nanodevices: Fabrication of FePt nanopropellers and cell transfection. Adv Mater 2020, 32: 2001114.

[281] Chen S, Lou Z, Chen D, et al. Printable $\mathrm{Zn}_{2} \mathrm{GeO}_{4}$ microwires based flexible photodetectors with tunable photoresponses. Adv Mater Technol 2018, 3: 1800050.

[282] Chellali MR, Sarkar A, Nandam SH, et al. On the homogeneity of high entropy oxides: An investigation at the atomic scale. Scripta Mater 2019, 166: 58-63.

[283] Cheng BY, Lou HB, Sarkar A, et al. Pressure-induced tuning of lattice distortion in a high-entropy oxide. Commun Chem 2019, 2: 114.

[284] Aso R, Kan D, Shimakawa Y, et al. Atomic level observation of octahedral distortions at the perovskite oxide heterointerface. Sci Rep 2013, 3: 2214.

[285] Gao W, Addiego C, Wang $\mathrm{H}$, et al. Real-space charge-density imaging with sub-ångström resolution by four-dimensional electron microscopy. Nature 2019, $\mathbf{5 7 5}$ : 480-484.

[286] Yan XX, Liu CY, Gadre CA, et al. Single-defect phonons imaged by electron microscopy. Nature 2021, 589: $65-69$.

[287] Richards BT, Young KA, de Francqueville F, et al. Response of ytterbium disilicate-silicon environmental barrier coatings to thermal cycling in water vapor. Acta Mater 2016, 106: 1-14.

[288] Wang XH, Zhou YC. Oxidation behavior of $\mathrm{Ti}_{3} \mathrm{AlC}_{2}$ at 1000-1400 ${ }^{\circ} \mathrm{C}$ in air. Corros Sci 2003, 45: 891-907.

[289] Sun Z, Zhou Y, Li M. High temperature oxidation behavior of $\mathrm{Ti}_{3} \mathrm{SiC}_{2}$-based material in air. Acta Mater 2001, 49: 4347-4353.

[290] Backman L, Opila EJ. Thermodynamic assessment of the group IV, V and VI oxides for the design of oxidation resistant multi-principal component materials. J Eur Ceram Soc 2019, 39: 1796-1802.

Open Access This article is licensed under a Creative Commons Attribution 4.0 International License, which permits use, sharing, adaptation, distribution and reproduction in any medium or format, as long as you give appropriate credit to the original author(s) and the source, provide a link to the Creative Commons licence, and indicate if changes were made.

The images or other third party material in this article are included in the article's Creative Commons licence, unless indicated otherwise in a credit line to the material. If material is not included in the article's Creative Commons licence and your intended use is not permitted by statutory regulation or exceeds the permitted use, you will need to obtain permission directly from the copyright holder.

To view a copy of this licence, visit http://creativecommons.org/licenses/by/4.0/. 